\title{
ZOOTAXA
}

1565

\section{Ostracoda (Myodocopa) from Anchialine Caves and Ocean Blue Holes}

LOUIS S. KORNICKER, THOMAS M. ILIFFE

$\&$ ELIZABETH HARRISON-NELSON

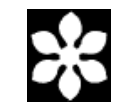

Magnolia Press

Auckland, New Zealand 
Louis S. Kornicker, Thomas M. Iliffe \& Elizabeth Harrison-Nelson

Ostracoda (Myodocopa) from Anchialine Caves and Ocean Blue Holes

(Zootaxa 1565)

151 pp.; $30 \mathrm{~cm}$.

31 August 2007

ISBN 978-1-86977-153-9 (paperback)

ISBN 978-1-86977-154-6 (Online edition)

FIRST PUBLISHED IN 2007 BY

Magnolia Press

P.O. Box 41-383

Auckland 1346

New Zealand

e-mail: zootaxa@mapress.com

http://www.mapress.com/zootaxa/

(C) 2007 Magnolia Press

All rights reserved.

No part of this publication may be reproduced, stored, transmitted or disseminated, in any form, or by any means, without prior written permission from the publisher, to whom all requests to reproduce copyright material should be directed in writing.

This authorization does not extend to any other kind of copying, by any means, in any form, and for any purpose other than private research use.

ISSN 1175-5326 (Print edition)

ISSN 1175-5334 (Online edition) 


\title{
Ostracoda (Myodocopa) from Anchialine Caves and Ocean Blue Holes
}

\author{
LOUIS S. KORNICKER ${ }^{1}$, THOMAS M. ILIFFE ${ }^{2} \&$ ELIZABETH HARRISON-NELSON $^{1}$ \\ ${ }^{\prime}$ Department of Invertebrate Zoology, National Museum of Natural History, Smithsonian Institution, Washington, D.C. 20560-0163, \\ U.S.A.E-mail: kornickl@si.edu; nelsone@si.ed \\ 2Department of Marine Biology, Texas A\&M University at Galveston, PO Box 1675 (MARB), Galveston TX 77553-1675, U.S.A. \\ E-mail: iliffet@tamug.edu
}

\section{Table of contents}

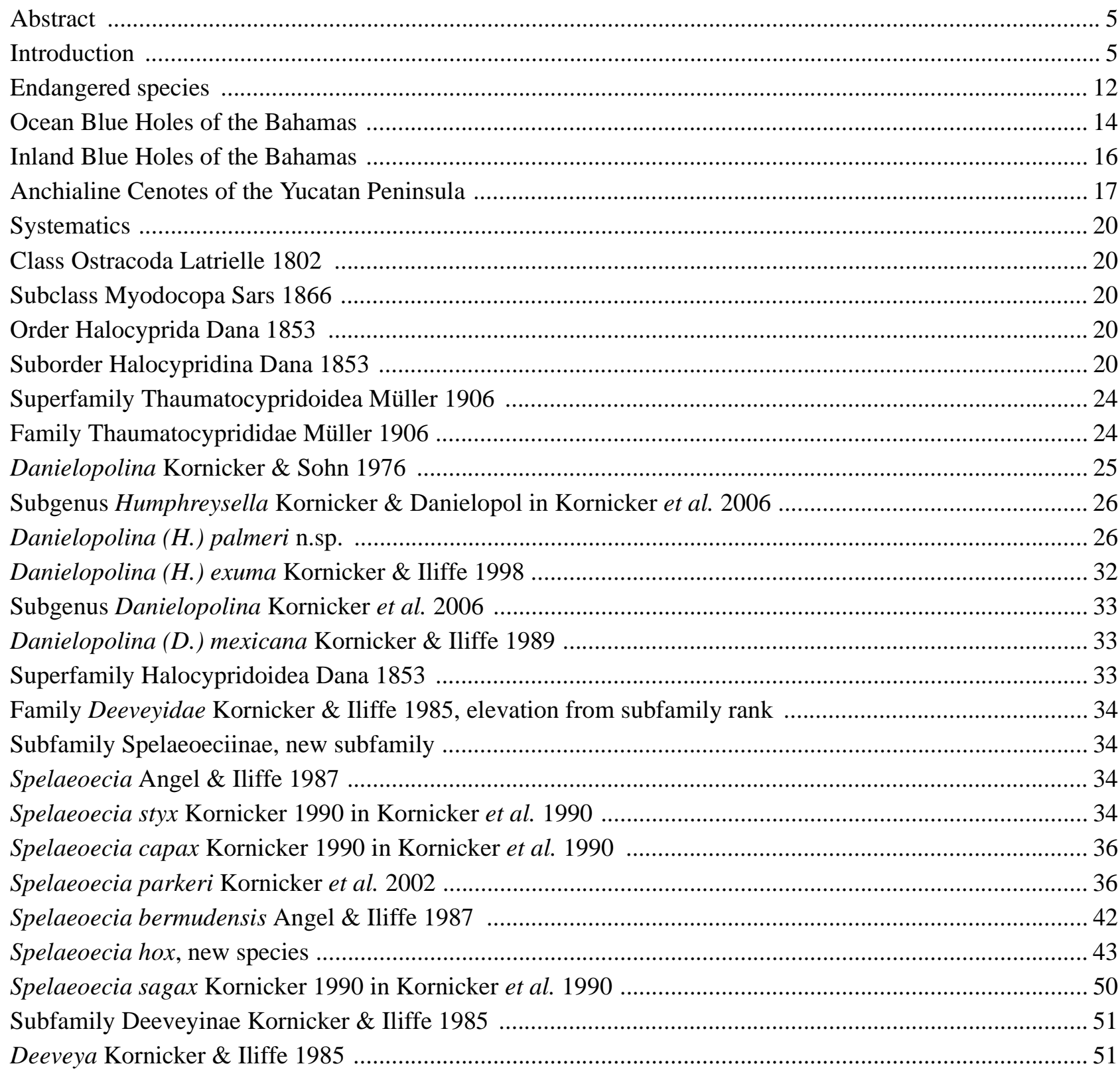


Deeveya spiralis Kornicker \& Iliffe 1985

Deeveya styrax Kornicker 1990 in Kornicker et al. 1990 ............................................................................... 56

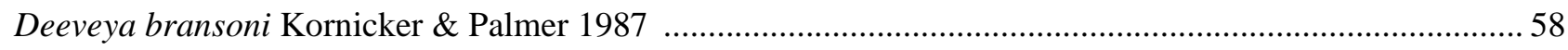

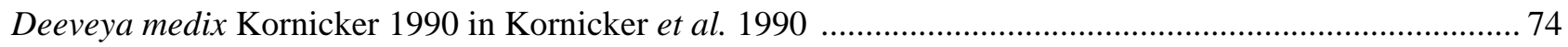

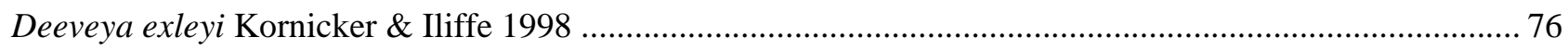

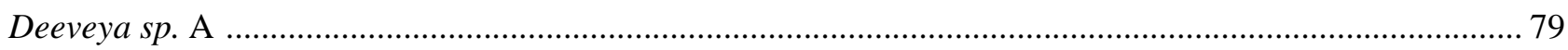

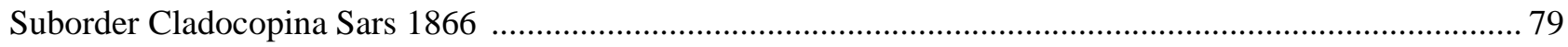

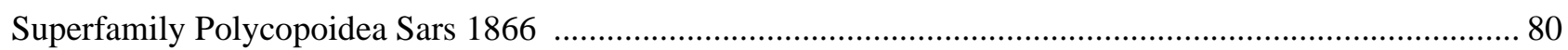

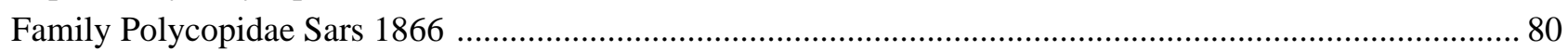

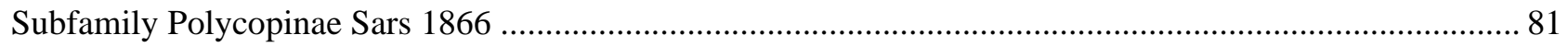

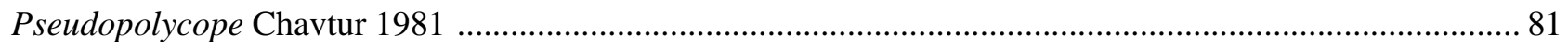

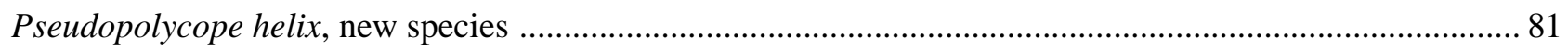

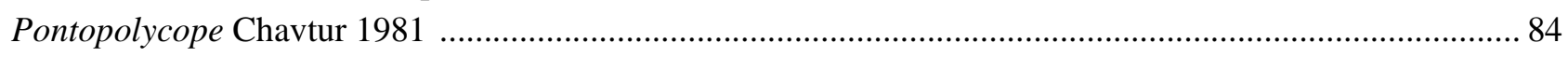

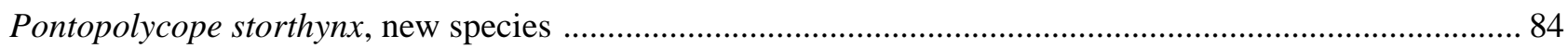

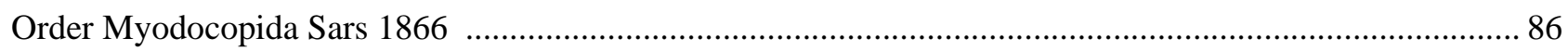

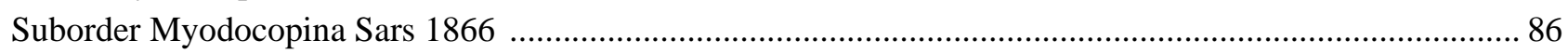

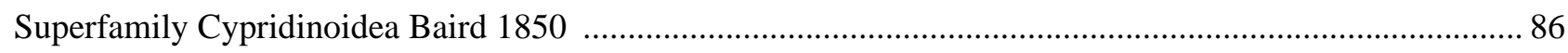

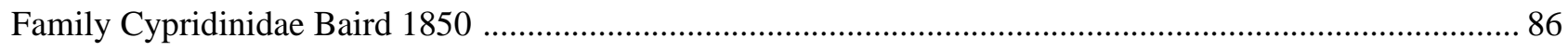

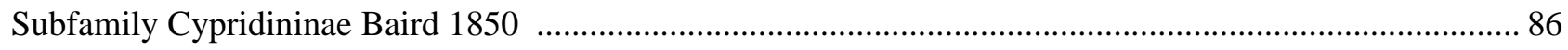

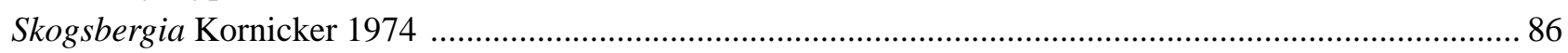

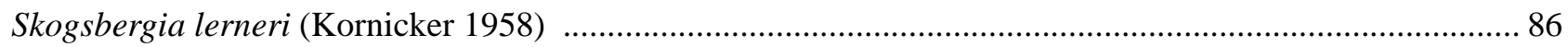

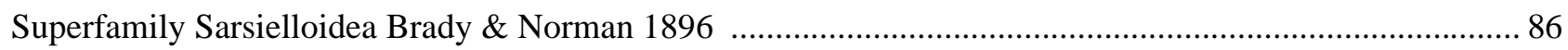

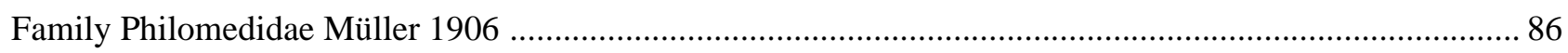

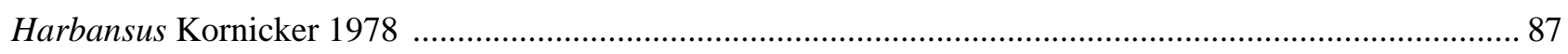

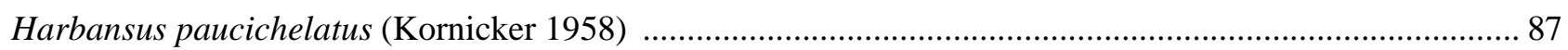

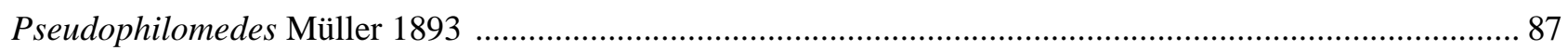

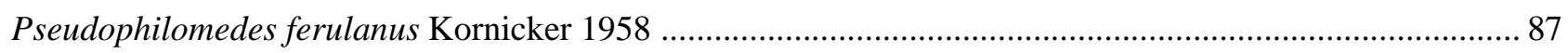

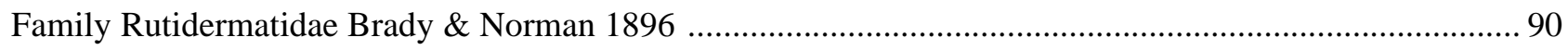

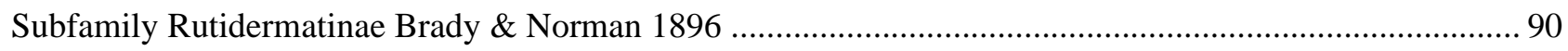

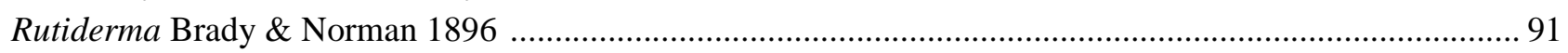

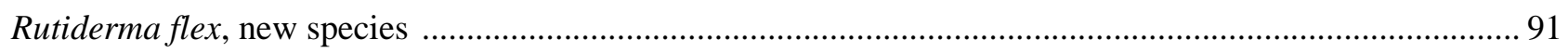

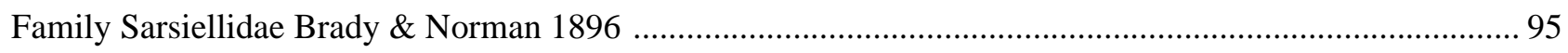

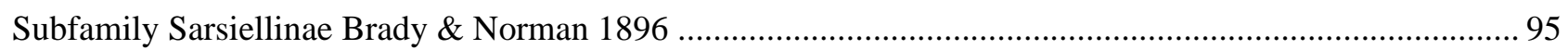

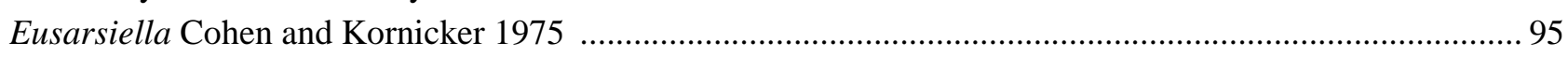

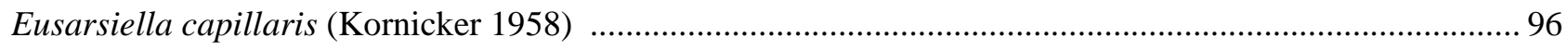

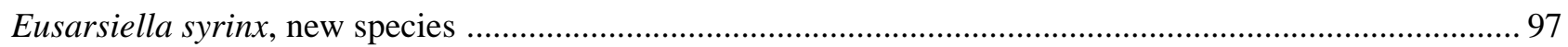

Eusarsiella paniculata Kornicker 1986 .................................................................................................. 118

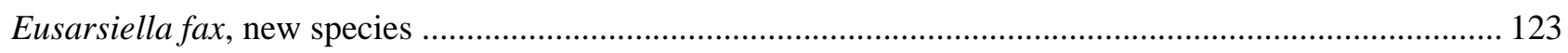

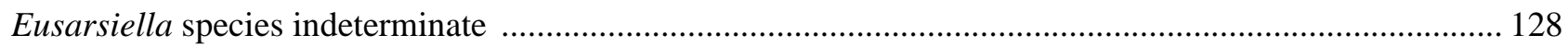

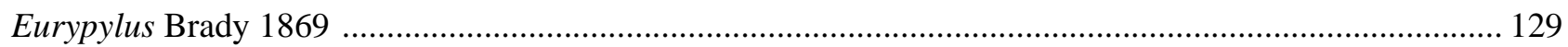

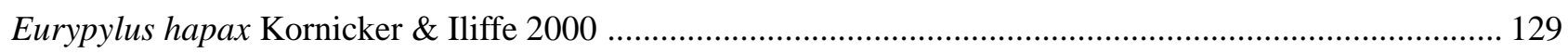

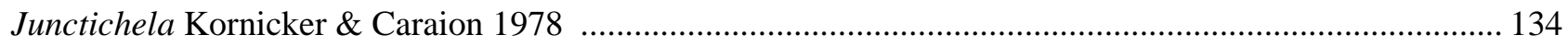

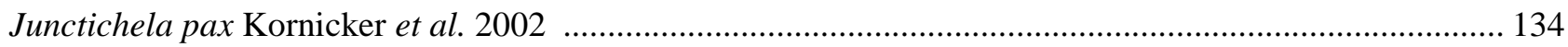

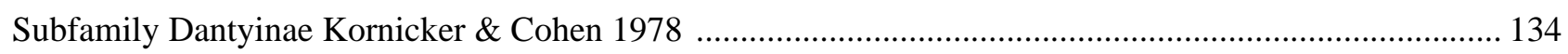

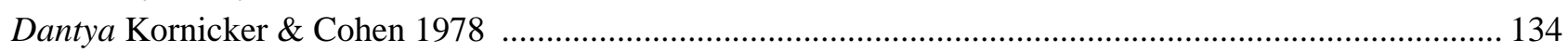

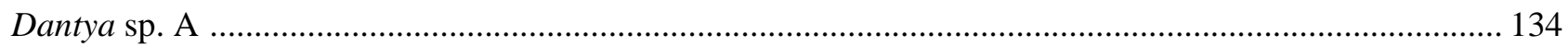

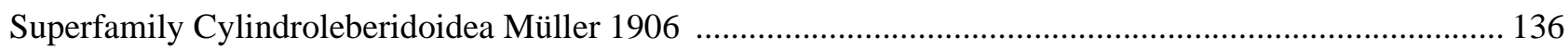




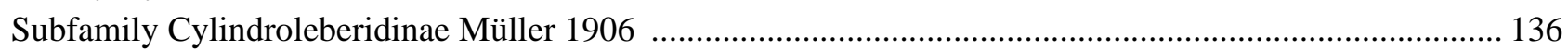

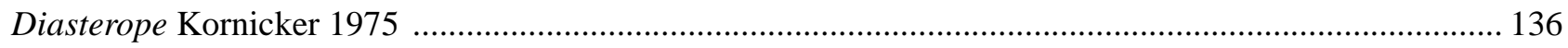

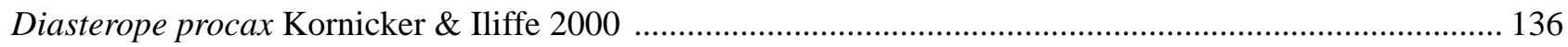

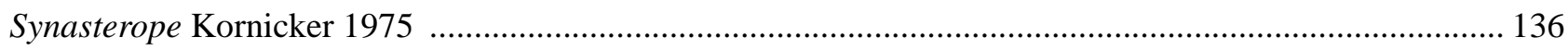

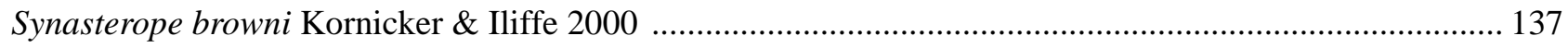

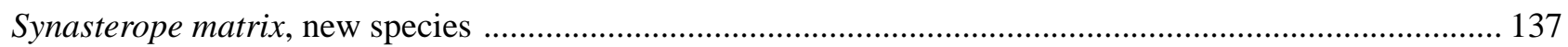

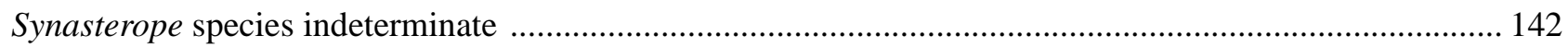

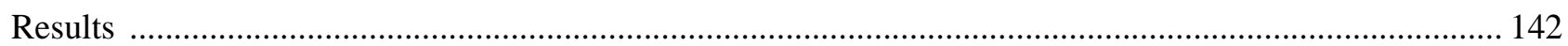

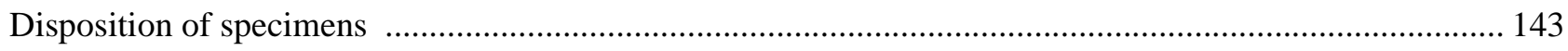

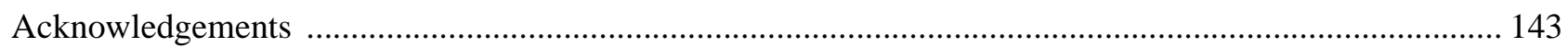

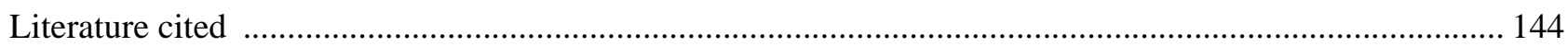

Appendix — Station data with specimens collected (in chronological order by location) ............................ 148

\begin{abstract}
Eleven stygobitic myodocopid ostracodes (two new-Danielopolina palmeri and Spelaeoecia hox) in the Order Halocyprida are reported from anchialine waters in 11 inland blue holes in Bahamas. One stygobitic halocyprid ostracode is reported from two localities in Bermuda, and one from a cave in Mexico. A new subfamily, Spelaeoeciinae, is proposed to contain the genus Spelaeoecia, and the subfamily Deeveyinae is elevated to family status. Two new species of cladocopid ostracode (Pseudopolycope helix and Pontopolycope storthynx), are described from a cave in Mexico and an oceanic blue hole in the Bahamas.

Nine species of myodocopid ostracodes (four new-Rutiderma flex, Eusarsiella syrinx, Eusarsiella fax, and Synasterope matrix) in the Suborder Myodocopina and one species in the Suborder Halocypridina are reported from ocean blue holes in the Bahamas. This is the first report of a halocyprid living in both an inland and ocean blue hole in the Bahamas. The sarsiellid genus Dantya Kornicker \& Cohen 1978 is reported for the first time in the Bahamas, but the single juvenile specimen is left in open nomenclature as Dantya sp. A. The development of Deeveya bransoni and Eusarsiella syrinx is described in detail.

With the exception of one species of Danielopolina from deep waters of the South Atlantic, all other species of Danielopolina, Spelaeoecia and Deeveya have been previously found only in inland, anchialine caves. The discovery of Deeveya inhabiting deeper, hydrologically-isolated waters in ocean blue holes, which are otherwise comparable to classical anchialine environments, has raised questions concerning the geographic limits to the anchialine habitat and its supposed reliance on terrestrial inputs.
\end{abstract}

Key words: Halocyprida, Myodocopida, Ostracoda, anchialine caves, blue holes, Bahamas, Mexico, Bermuda

\title{
Introduction
}

The term anchialine was coined by Holthuis (1973: 3) to designate "pools with no surface connection with the sea, containing salt or brackish water, which fluctuates with the tides". During the Bermuda Marine Cave Symposium October 1984 the definition was modified as follows:

Anchialine habitats consist of bodies of haline water, usually with a restricted exposure to open air, always with more or less extensive subterranean connections to the sea, and showing noticeable marine as well as terrestrial influences (Stock et al. 1986: 91).

Caves opening beneath sea level and entirely filled with seawater were termed "submarine caves" and were not considered anchialine since they lack a terrestrial influence.

Until recently, the distinction between anchialine and submarine caves appeared valid based on significant hydrological and biological differences. Typically, anchialine caves are well stratified with a surface layer of 
fresh or brackish water separated from underlying fully marine waters by a well defined halocline (Iliffe 2000: 61-63). Deeper, marine water in anchialine caves contains little particulate matter and is exceptionally transparent. Due to the cave's remote and indirect connections with the sea, such water appears to have a long residence time within the cave. Water currents range from negligible to low velocity. The fauna of anchialine caves is characterized by cave-adapted stygobitic (exclusively found in aquatic subterranean habitats) taxa. Anchialine species are most commonly found swimming slowly in the cave water column, while the rock walls and ceilings of the cave are for the most part barren of visible life forms. Stable carbon and nitrogen isotope studies have identified three sources of organic matter supporting 2 to 2.5 levels in the anchialine cave food web from the Yucatan Peninsula: 1) forest soil above the cave, 2) freshwater algae in cave entrance pools, and 3) chemoautotrophic bacteria (Pohlman et al. 1997, 2000).

Conversely, submarine caves are typically characterized by the presence of powerful tidal currents which reverse direction at the change of the tide (Warner \& Moore 1984: 34-41; Trott \& Warner 1986: 13). Water in submarine caves consists of open ocean water which is alternately sucked in and flushed out as tidal currents reverse. Residence times are thus on the order of a single to a few tidal cycles. The fauna of submarine caves is mostly made up of encrusting or benthic organisms. They are either well attached to the substrate or only are active when the tides goes slack as it changes direction. Most are filter feeders (e.g. sponges, hydroids, etc.) or scavengers (e.g. shrimp, amphipods, etc.) of the organic detritus carried in from the sea by the current. Few show any noticeable stygomorphic adaptations, and most are also found outside of caves.

Water filled caves in the Bahamas are commonly referred to as "blue holes" due to the predominant color of the water in them, especially when viewed from the air (Palmer 1997: 55). They include both anchialine (called inland blue holes) and submarine (known as ocean blue holes) caves. Within the last several years, cave divers using diver propulsion vehicles (or scooters), closed circuit rebreathers and special mixed gas technology (Prosser \& Gray, 1998; Bozanic 2002; Wienke 2002) have penetrated farther and deeper into these caves reaching horizontal penetrations of more than $1,500 \mathrm{~m}$ and depths in excess of $130 \mathrm{~m}$. In the deep interior of ocean blue holes, they have discovered habitats and organisms comparable to those previously known only from anchialine caves.

The presence of hydrologically isolated water bodies and stygobitic fauna in the deep interior of open ocean submarine caves significantly broadens the ecological range of the anchialine habitat and calls into question the assumption that terrestrial inputs are a necessary feature. Anchialine habitats, including caves with purely marine waters but inhabited by troglomorphic species (Sket 2004), extend from coastal areas of islands and other land masses across shallow-water platforms and shelves. The vertical depth limits of this habitat are as yet unknown but likely extend for well over $100 \mathrm{~m}$. At present, physiological and technological limitations of human divers restrict our knowledge of the anchialine environment.

Considering the $100 \mathrm{~m}$ plus vertical extent of glacial and post-glacial sea level fluctuations during the Pleistocene, nearly all present inland and ocean blue holes would have been dry and air filled for many tens of thousands of years. Long periods of lowered sea level are documented in submerged caves by the presence of stalactites and stalagmites that can only form in air by dripping water. These have been observed in both inland and ocean blue holes to depths in excess of $60 \mathrm{~m}$. During glacial epochs, the present-day shallow banks of the Bahamas would have been dry land and only the deepest submarine caves would have been anchialine.

Many anchialine taxa including the halocyprids are relict, long term survivors of ancient lineages, which have inhabited caves for hundreds of thousands, if not millions of years. For example, great age is implied by the biogeographic distribution of the anchialine fauna of Western Australia including the remipede Lasionectes Yager \& Schram 1986, the thermosbaenacean Halosbaena Stock 1976, the ostracode Danielopolina and the misophrioid copepod Speleophria Boxshall \& Iliffe 1986 that are otherwise known primarily from caves on opposite sides of the Atlantic (Humphreys 2004). This highly anomalous distribution, coupled with the poor long distance dispersal of stygobites and the tectonic history of Earth, suggests that these species may have initially colonized caves along the margins of the Tethys Sea prior to the breakup of Pangea some 180 
million years B.P. and were subsequently dispersed by plate tectonics. Remipedes, with fossil relatives from the Carboniferous, are considered to be among the most primitive of living crustaceans (Martin \& Davis 2001); their highly segmented bodies resemble the polychaete worms from which crustaceans are thought to have evolved. The platycopioid copepod Antrisocopia prehensilis Fosshagen 1985 in Fosshagen \& Iliffe 1985 from Bermuda caves agrees in many ways with the theoretical ancestral copepod (Fosshagen \& Iliffe 1985). Erebonectes nesioticu Fosshagen 1985 in Fosshagen \& Iliffe 1985, also from Bermuda caves, is considered one of the most primitive calanoids due to its first antennae with 27 segments (the highest number recorded), essentially unmodified mouthparts, and primitive legs (Fosshagen \& Iliffe 1985). The presence of numerous primitive and apparently ancient taxa in anchialine caves attests to the great age and long term stability of this habitat. Thus, anchialine caves act as preserving centers for relict taxa, known from nowhere else on Earth.

Paradoxically, many of the caves that are today inhabited by anchialine fauna are geologically quite young. The Monte Corona lava cave on Lanzarote in the Canary Islands is only 2,000 to 3,000 years old, yet is inhabited by a rich anchialine fauna including the remipede Speleonectes, four genera of misophrioid copepods (Dimisophria Boxshall \& Iliffe 1987, Expansophria Boxshall \& Iliffe 1987, Palpophria Boxshall \& Iliffe 1987 and Speleophriopsis Jaume \& Boxshall 1996), the thermosbaenacean Halosbaena Stock 1976 and two species of the halocyprid ostracod Danielopolina (Iliffe et al. 2000). Likewise, the limestone caves in Bermuda are relatively young. The limestone capping this mid-ocean volcanic seamount is no more than one to two million years old, but its caves are inhabited by a diverse group of anchialine taxa. The presence of primitive, relict species in such geologically recent caves suggests that the fauna was originally living in older and probably deeper habitats that allowed for migration into new caves as they formed.

Three halocyprid genera, Danielopolina, Deeveya and Spelaeoecia, are known primarily or exclusively from anchialine caves. They have a highly disjunct distribution, suggestive of a Tethyan origin (Fig. 6). Danielopolina is the most widely distributed with species on opposite sides of both the Atlantic and Pacific. Spelaeoecia is limited to Bermuda and the Caribbean (Bahamas, Cuba, Yucatan and Jamaica), while Deeveya occurs only within the Bahamas. The Caribbean and especially the Bahamas appear to be the center of biodiversity for these taxa. Twenty-seven out of the 31 known species of stygobitic halocyprids are found in the Caribbean and Bermuda. Nineteen species of halocyprids inhabit Bahamian caves. These observations are consistent with other anchialine taxa including remipedes (Yager and Humphreys 1996: 184), epacteriscid calanoid copepods (Fosshagen et al. 2001: 314-315), etc. Even within the Bahamas, these halocyprid genera are widely dispersed. Deeveya and Spelaeoecia are represented from caves on the Great Bahama Bank, Little Bahama Bank and San Salvador, although Danielopolina, which has the greatest worldwide distribution, is known at present only within the Bahamas on the Great Bahama Bank (Fig. 8). Deeveya medix inhabits caves on both the Great Bahama and Little Bahama Bank, separated by a deep water channel. Deeveya bransoni and Spelaeoecia styx occur in Andros and the Exumas, on opposite sides of the Great Bahama Bank and more than $150 \mathrm{~km}$ apart. Similar disjunct species distributions within the Bahamas also occur for several calanoid copepods from the family Epacteriscidae (Auden Fosshagen, pers. comm. 2003). Oven Rock Cave in the Exumas contains the world's greatest diversity of halocyprid species, including three species of Danielopolina, two species of Spelaeoecia and one species of Deeveya. Such anomalous distributions suggest that the anchialine habitat is far more extensive than has previously been thought.

The distribution of myodocopid species in the open ocean, ocean blue holes, and inland blue holes in the Bahamas is listed in Table 1. The total number of myodocopid species reported from the Bahamas is 62. Species in the suborder Halocypridina collected in each inland and ocean blue hole are listed in Table 2, and species in the suborder Myodocopina collected in each ocean blue hole are listed in Table 3. No species of Myodocopina were collected in inland blue holes, while only one species of Halocypridina (Deeveya bransoni) was collected in two ocean blue holes. 
TABLE 1. Comparison of Myodocopa in the Bahamas $(\mathrm{OO}=$ Open Ocean, $\mathrm{OBH}=$ Ocean Blue Holes, $\mathrm{IBH}=\mathrm{Inland}$ Blue Holes, $+=$ species present, - = species absent.

\begin{tabular}{|c|c|c|c|}
\hline Taxa & $\mathrm{OO}$ & OBH & IBH \\
\hline \multicolumn{4}{|l|}{ Order HALOCYPRIDA } \\
\hline \multicolumn{4}{|l|}{ Suborder HALOCYPRIDINA } \\
\hline \multicolumn{4}{|l|}{ Family HALOCYPRIDAE } \\
\hline Deeveya bransoni & - & + & + \\
\hline Deeveya exleyi & - & - & + \\
\hline Deeveya hirpex & - & - & + \\
\hline Deeveya jillae & - & - & + \\
\hline Deeveya medix & - & - & + \\
\hline Deeveya spiralis & - & - & + \\
\hline Deeveya sp. A & - & - & + \\
\hline Deeveya styrax & - & - & + \\
\hline Spelaeoecia barri & - & - & + \\
\hline Spelaeoecia capax & - & - & + \\
\hline Spelaeoecia hox & - & - & + \\
\hline Spelaeoecia parkeri & - & - & + \\
\hline Spelaeoecia sagax & - & - & + \\
\hline Spelaeoecia styx & - & - & + \\
\hline \multicolumn{4}{|c|}{ Family THAUMATOCYPRIDIDAE } \\
\hline Danielopolina bahamensis & - & - & + \\
\hline Danielopolina exuma & - & - & + \\
\hline Danielopolina kakuki & - & - & + \\
\hline Danielopolina palmeri & - & - & + \\
\hline Danielopolina sp. A & - & - & + \\
\hline \multicolumn{4}{|l|}{ Suborder CLADOCOPINA } \\
\hline \multicolumn{4}{|l|}{ Family POLYCOPIDAE } \\
\hline Polycope bahamensis & + & - & - \\
\hline Pontopolycope storthynx & - & + & - \\
\hline Pseudopolycope helix & - & + & - \\
\hline \multicolumn{4}{|l|}{ Order MYODOCOPIDA } \\
\hline \multicolumn{4}{|l|}{ Suborder MYODOCOPINA } \\
\hline \multicolumn{4}{|l|}{ Family CYPRIDINIDAE } \\
\hline Jimmorinia gamma & + & - & - \\
\hline Jimmorinia gunneri & + & - & - \\
\hline Skogsbergia lerneri & + & + & - \\
\hline Vargula exuma & + & - & - \\
\hline \multicolumn{4}{|l|}{ Family PHILOMEDIDAE } \\
\hline Harbansus paucichelatus & + & + & - \\
\hline Pseudophilomedes ferulanus & + & + & - \\
\hline Zeugophilomedes multichelatus & + & - & - \\
\hline \multicolumn{4}{|l|}{ Family RUTIDERMATIDAE } \\
\hline Alternochelata polychelata & + & - & - \\
\hline
\end{tabular}


TABLE 1. (continued)

\begin{tabular}{|c|c|c|c|}
\hline Taxa & $\mathrm{OO}$ & $\mathrm{OBH}$ & IBH \\
\hline Rutiderma cohenae & + & - & - \\
\hline Rutiderma darbyi & + & + & - \\
\hline Rutiderma dinochelatum & + & - & - \\
\hline Rutiderma flex & - & + & - \\
\hline Rutiderma schroederi & + & - & - \\
\hline \multicolumn{4}{|l|}{ Family SARSIELLIDAE } \\
\hline Chelicopia arostrata & + & - & - \\
\hline Dantya sp. A & - & + & - \\
\hline Eurypylus eageri & + & - & - \\
\hline Eurypylus hapax & + & + & - \\
\hline Eusarsiella athrix & + & - & - \\
\hline Eusarsiella capillaris & + & - & - \\
\hline Eusarsiella costata & + & - & - \\
\hline Eusarsiella fax & - & + & - \\
\hline Eusarsiella gigacantha & + & - & - \\
\hline Eusarsiella merx & - & + & - \\
\hline Eusarsiella paniculata & - & + & - \\
\hline Eusarsiella punctata & + & - & - \\
\hline Eusarsiella ryanae & + & + & - \\
\hline Eusarsiella syrinx & + & + & - \\
\hline Eusarsiella truncana & + & - & - \\
\hline Eusarsiella uncus & + & - & - \\
\hline Eusarsiella warneri & - & + & - \\
\hline Eusarsiella species X & + & - & - \\
\hline Junctichela pax & - & + & - \\
\hline \multicolumn{4}{|c|}{ Family CYLINDROLEBERIDIDAE } \\
\hline Actinoseta chelisparsa & + & + & - \\
\hline Amboleberis americana & + & + & - \\
\hline Asteropella monambon & + & + & - \\
\hline Diasterope procax & + & - & - \\
\hline Parasterope extrachelata & + & - & - \\
\hline Parasterope muelleri & + & - & - \\
\hline Synasterope browni & + & + & - \\
\hline Synasterope matrix & - & + & - \\
\hline Synasterope setisparsa & + & - & - \\
\hline Total no. species & 34 & 22 & 19 \\
\hline
\end{tabular}


TABLE 2. Bahamian distribution of anchialine ostracodes in the suborder Halocypridina. ${ }^{*}=$ localities from which ostracodes are reported herein, but not all species in list may be in present collections.)

San Salvador Island

Dixon Hill Lighthouse Cave

Spelaeoecia barri Kornicker in Kornicker \& Barr 1997

Deeveya sp. (Kornicker \& Barr 1997)

Little Bahama Bank

Abaco Island

Dan's Cave*

Deeveya styrax Kornicker 1990 in Kornicker et al. 1990

Deeveya hirpex Kornicker 1990 in Kornicker et al. 1990

Grand Bahama Island

Mermaid's Lair*

Spelaeoecia parkeri Kornicker et al. 2002

Spelaeoecia hox, herein

Sweeting's Cay

Sagittarius Blue Hole*

Deeveya styrax Kornicker 1990 in Kornicker et al. 1990

Deeveya medix Kornicker 1990 in Kornicker et al. 1990

Spelaeoecia sagax Kornicker 1990 in Kornicker et al. 1990

Lucy's Cave*

Spelaeoecia parkeri Kornicker et al. 2002

Virgo Blue Hole*

Deeveya medix Kornicker 1990 in Kornicker et al. 1990

Spelaeoecia sagax Kornicker 1990 in Kornicker et al. 1990

Great Bahama Bank

Eleuthra Island

Hatchet Bay Cave

Danielopolina bahamensis Kornicker \& Iliffe 1989a.

Deeveya jillae Kornicker \& Iliffe 1989a.

Long Island

Alfonso Dean Blue Hole.

Spelaeoecia capax Kornicker 1990 in Kornicker et al. 1990

Exuma Cays

Lee Stocking Island, Norman's Pond Cay

Norman's Pond Cave*

Danielopolina exuma Kornicker \& Iliffe 1998

Spelaeoecia capax Kornicker 1990 in Kornicker et al. 1990

Great Guana Cay

Spelaeoecia styx Kornicker 1990 in Kornicker et al. 1990

Oven Rock Cave*

Danielopolina exuma Kornicker \& Iliffe 1998

Danielopolina kakuki Kornicker \& Iliffe 2000

Danielopolina sp. A (Kornicker \& Iliffe 1998)

Spelaeoecia capax Kornicker 1990 in Kornicker et al. 1990

Spelaeoecia styx Kornicker 1990 in Kornicker et al. 1990

Deeveya exleyi Kornicker \& Iliffe 1998

Great Exuma Island

Basil Minn's Blue Hole*

Danielopolina exuma Kornicker \& Iliffe 1998

Deeveya medix Kornicker 1990 in Kornicker et al. 1990

continued 
Andros Island

North Andros Island

Guardian Blue Hole*

Deeveya sp. A, herein

Conch Sound Blue Hole* (ocean blue hole)

Deeveya bransoni Kornicker \& Palmer 1987

South Andros Island

Evelyn Green's Blue Hole

Deeveya bransoni Kornicker \& Palmer 1987

Stargate Blue Hole

Deeveya bransoni Kornicker \& Palmer 1987

Eldorado Cave

Spelaeoecia styx Kornicker 1990 in Kornicker et al. 1990

Sanctuary Blue Hole*

Danielopolina palmeri, herein

Deeveya bransoni Kornicker \& Palmer 1987

Spelaeoecia styx Kornicker 1990 in Kornicker et al. 1990

Double Drop Blue Hole* (ocean blue hole)

Deeveya bransoni Kornicker \& Palmer 1987

Turks and Caicos Islands, Providenciales Island

The Hole

Deeveya spiralis Kornicker \& Iliffe 1985

TABLE 3. Distribution in ocean blue holes in the Great Bahama Bank of ostracodes in the suborder Myodocopina. (* $=$ localities from which ostracodes are reported herein, but not all species in list may be from present collections.)

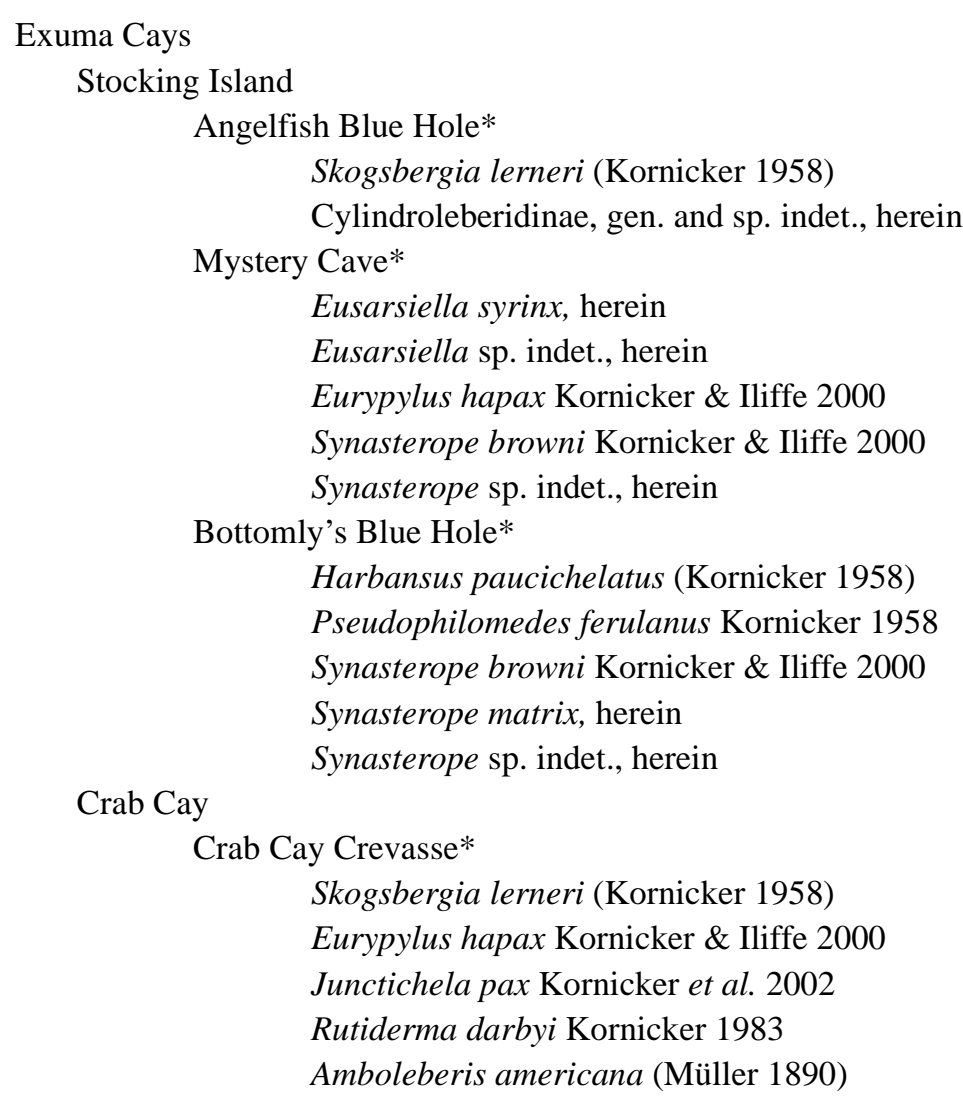

continued 
Sugar Cay

Sugar Cay Blue Hole (from Kornicker et al. 2002:96)

Harbansus paucichelatus (Kornicker 1958)

Eusarsiella merx Kornicker et al. 2002

Eusarsiella spp. indet.

Great Exuma Island

Master Harbor Cave (from Kornicker et al. 2002:96)

Skogsbergia lerneri (Kornicker 1958)

Cylindroleberidinae gen. and sp. indet., herein

The Subway*

Harbansus paucichelatus (Kornicker 1958)

Eusarsiella sp. indet., herein

South Andros Island

Four Shark Cave*

Skogsbergia lerneri (Kornicker 1958)

Dantya species A, herein

Eusarsiella ryanae Kornicker \& Iliffe 2000

Eusarsiella sp. indet., herein

Synasterope browni Kornicker \& Iliffe 2000

South Bight \#2 Blue Hole*

Eusarsiella sp. indet., herein

Double Drop Blue Hole*

Skogsbergia lerneri (Kornicker 1958)

Synasterope sp. indet., herein

Andros Island

Vortex Hole, Middle Bight*

Skogsbergia lerneri (Kornicker 1958)

Conch Sound Blue Hole*

Harbansus paucichelatus (Kornicker 1958)

Eusarsiella paniculata Kornicker 1986

Eusarsiella fax, herein

Eusarsiella sp. indet., herein

Rutiderma flex, herein

Rat Cay Blue Hole (from Kornicker et al. 2002:96)

Skogsbergia lerneri (Kornicker 1958)

Eusarsiella warneri Kornicker et al. 2002

Amboleberis americana (Müller 1890)

Actinoseta chelisparsa Kornicker 1958

Asteropella monambon (Kornicker 1958)

\section{Endangered species}

Unfortunately, many of these unique and fascinating animals are threatened with extinction due to the actions of man. In Bermuda alone, 25 species of cave animals are internationally recognized as "critically endangered" (IUCN 2006). This is the highest level of threat and roughly equates to a $50 \%$ chance of the species going extinct within the next decade if nothing is done. All too frequently, anchialine cave animals can be considered endangered since 1) they have very limited distributions, commonly being known only from a single cave, and 2) environmental conditions in these caves are often deteriorating through the effects of water pollution or cave destruction. 
Threats to caves include sewage and waste disposal, deep well injection, quarrying and construction activities and diver and other human disturbances (Iliffe 1979). As an example, the small oceanic island of Bermuda is the third most densely populated country in the world and has the largest number of private cesspits per capita. Disposal of sewage and other waste water into cesspits or by pumping down boreholes is contaminating the ground and cave water with nitrates, detergents, toxic metals and pharmaceuticals; depleting the very limited amounts of dissolved oxygen in cave water; and generating toxic levels of hydrogen sulfide (Iliffe et al. 1984). Some ocean caves such as the Blue Holes of the Bahamas have strong tidal currents sweeping through them for very considerable distances. In one such cave, plastic bottles and other trash have been observed littering the floor of the cave nearly a mile back into virgin passage. Far too many caves and sinkholes are viewed as preferred locations for the dumping of garbage and other waste products.

Another serious environmental problem concerns the destruction of caves by limestone quarries or construction activities. At least half a dozen or more caves have been totally destroyed by Bermuda limestone quarries which produced crushed aggregate for construction purposes. Untold other caves have been lost to enormous limestone mines in the Yucatan Peninsula. Many caves have been filled and built over by golf courses, hotels and housing developments in Bermuda. Recently, a series of luxury town homes were built directly on top of the largest cave lake in Bermuda.

Sometimes seemingly innocent activities can threaten caves and cave animals. Along the Caribbean coast of the Yucatan Peninsula, many open water cenote pools are inhabited by several species of freshwater fish. One of these fish, Astyanax mexicanus (De Filippi 1853), has learned to follow divers into caves, moving in front of the dive team and voraciously darting in to devour any crustaceans that chance to stray into the beam of a dive light. Considering the many hundreds to thousands of cave divers who use these systems each year, it is not surprising that the caves most heavily visited by tourist divers are now essentially devoid of life.

Even the gas exhaled by divers may have untold and unknown effects on cave animals. Since anchialine cave waters typically contain extremely low levels of dissolved oxygen in the micrograms per liter range, the oxygen in exhaust bubbles from open circuit scuba divers could have profound effects on the cave ecosystem (Humphreys et al. 1999). Several anchialine caves in Western Australia with unique fauna are currently off limits to open circuit divers and may only be visited by those using closed circuit rebreathers.

Some anchialine caves in Bermuda, the Canary Islands and Mallorca have been developed into commercial tourist attractions. Unfortunately, many of the tourists visiting these sites have viewed the deep clear water cave pools as natural wishing wells in which to throw a coin or two. Copper coins tend to rapidly deteriorate and dissolve in salt water, producing high levels of toxic copper ions in the cave waters. In one such cave in Lanzarote, an endemic, cave-adapted galatheid crab, Munidopsis polymorpha Koelbel 1892, is showing a marked decline in abundance over the last ten years or more, possibly in response to high levels of copper in the cave water.

Our knowledge of the biology and ecology of anchialine caves is still in its infancy. Possibly hundreds to thousand of new anchialine taxa await discovery. In the Yucatan Peninsula, more than 5,000 caves have been catalogued, but only about $1-2 \%$ of these have been surveyed biologically. A similar situation exists in the Bahamas and in numerous other locations around the world where many hundreds of caves remain unexplored. Furthermore, almost nothing is known about the nutritional requirements, life history, reproduction, behavior, physiology, dispersal abilities, etc. of most anchialine species. Considering the unprecedented number of new higher taxa already discovered in anchialine caves, their highly anomalous distribution, and their affinities to deep sea fauna, new hypotheses on the evolution and dispersal of life in the oceans are likely to be forthcoming. However, if these potentially endangered habitats and the unique animals within them are to survive, it is critical that we all strive to promote an awareness and appreciation of their worth among the general public and especially government officials and resource managers. To this end, we have created a website on this subject at www.cavebiology.com (Iliffe 2007). 
Populations of stygobitic taxa including ostracodes are generally quite low in most caves, and it is not uncommon to collect only a single specimen one time and at other times to find none. Due to limited availability of organic nutrients, coupled with low levels of dissolved oxygen, anchialine stygobite population sizes are severely restricted. Because of the low probability of observing individuals at any given time or place, it is difficult to assess the survival of threatened species, even in face of declining environmental quality of the habitat due to groundwater pollution or other factors. Certainly complete destruction of caves, as occurs during large scale quarrying of limestone or collapsing of caves to stabilize conditions for construction projects, and severe pollution of caves causing widespread anoxia and subsequent hydrogen sulfide accumulation will almost certainly extinguish all higher life forms within that cave. The middle ground, where environmental quality of ground and cave water is declining due to pollution or the effects of climate change but has yet to reach critical extremes, is harder to evaluate but nonetheless still extremely worrisome. Justifiably, many anchialine stygobites can be considered as endangered, and Spelaeoecia bermudensis from Bermuda caves is on the IUCN Red List of endangered and threatened species (IUCN, 2006).

\section{Ocean Blue Holes of the Bahamas}

In this section, noteworthy discoveries of anchialine ostracodes from marine caves (ocean blue holes) in the Bahamas (Fig. 1) and water quality data which help to explain their presence are discussed. Conch Sound Blue Hole is an ocean blue hole located at the northeast corner of Andros Island (see map in Palmer 1997:4851). The entrance consists of a submerged depression about $20 \mathrm{~m}$ from the coastline in a shallow bay. Strong tidal currents flow through the cave, so it can only be explored at the change of the tide when the inflow slows, goes slack and then reverses direction. The main passage extends to the south, out under the bay and away from land. It has been explored for more that 1,500 $\mathrm{m}$ at a maximum depth of $36 \mathrm{~m}$ (Brian Kakuk, pers. comm. 2002). At his limits of penetration into the cave, Kakuk discovered a dome room with a depth of $20 \mathrm{~m}$. Here, he has collected remipedes, thermosbaenaceans, the blind cave fish Lucifuga spelaeotes Cohen \& Robins, 1970, and the halocyprid ostracode Deeveya bransoni, previously known only from inland anchialine caves on South Andros.

Similar faunas, previously regarded as strictly anchialine, have been found from the deeper waters of ocean blue holes off the southern end of Andros Island. Halocyprid ostracodes reported on here have been collected from depths below $60 \mathrm{~m}$ in Double Drop Blue Hole (Fig. 2). This cave has a small entrance in a back reef area at $10 \mathrm{~m}$ depth. A narrow fissure angles steeply down before opening onto a $15 \mathrm{~m}$ wide chasm at $50 \mathrm{~m}$ depth. The bottom drops away to a boulder filled rift as the fissure passage continues. A Hydrolab Water Quality analyzer was used to obtain a water column profile of salinity, temperature, $\mathrm{pH}$ and dissolved oxygen as a function of depth. From the entrance to $60 \mathrm{~m}$ depth, all measured parameters were uniform and stable, indicating a well mixed water column consisting of open ocean sea water. At $60 \mathrm{~m}$ depth, an abrupt and well defined transition zone was encountered, as indicated by an increase in salinity (by 0.8 ppt) and decreases in temperature (by $3^{\circ} \mathrm{C}$ ), $\mathrm{pH}$ (by $0.5 \mathrm{pH}$ units) and dissolved oxygen (by $4 \mathrm{mg} / \mathrm{l}$ ) with increasing water depth. The direction of these changes and the chemistry of the water below the transition zone are consistent with what is found with increasing depth in inland (anchialine) blue holes. The anchialine ostracode Deeveya bransoni was collected from below this transition zone in Double Drop Blue Hole. 


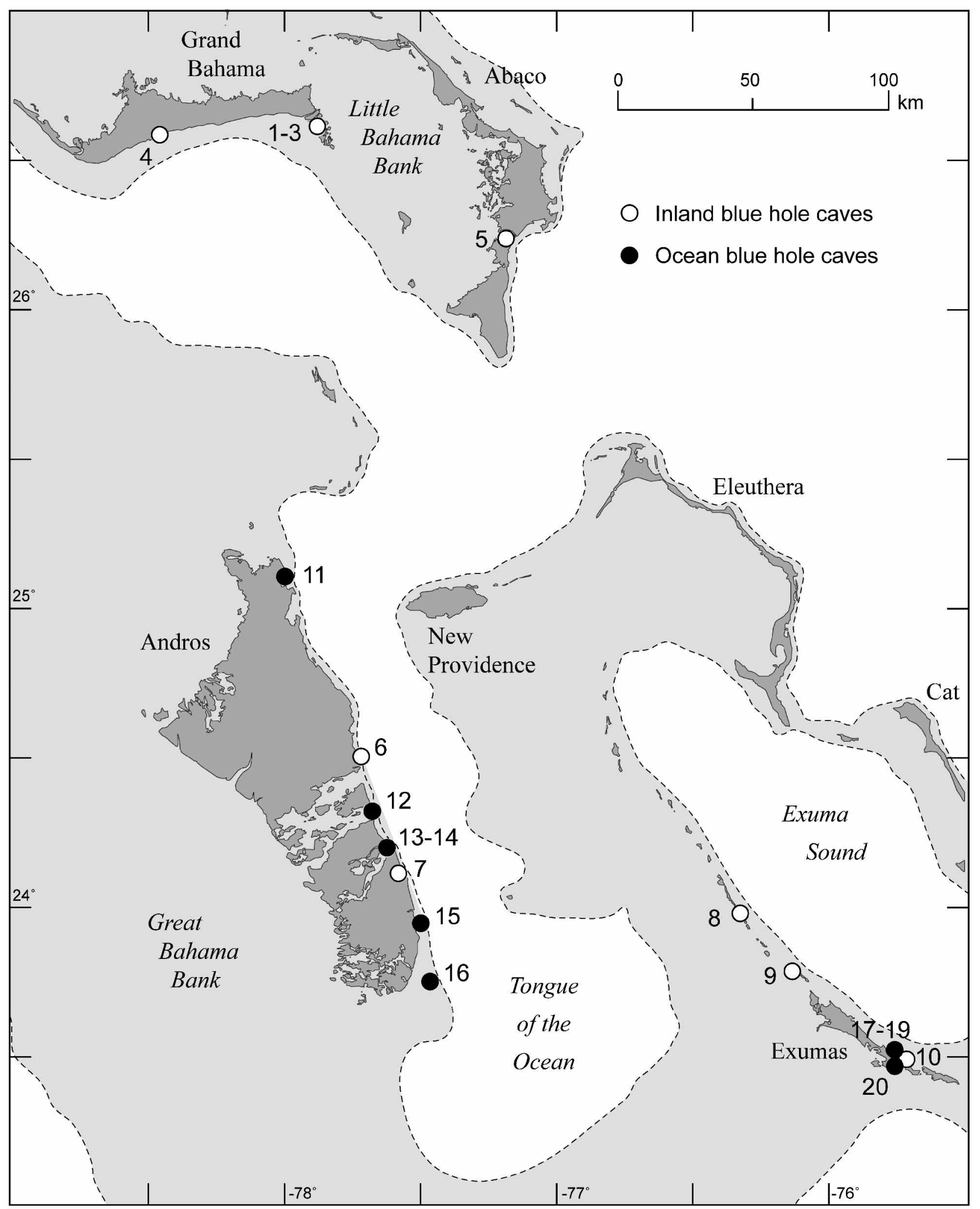

FIGURE 1. Locations of inland anchialine and ocean blue holes in the Bahamas. Inland blue hole caves (open circles O) include: 1. Sagittarius Blue Hole, 2. Virgo Blue Hole, 3. Lucy's Cave, 4. Mermaid's Lair, 5. Dan's Cave, 6. Guardian Blue Hole, 7. Sanctuary Blue Hole, 8. Oven Rock Cave, 9. Norman's Pond Cave, 10. Basil Minn's Blue Hole. Ocean blue hole caves (closed circles - -) include: 11. Conch Sound Blue Hole, 12. Vortex Blue Hole, 13. Exley's Boiling Hole, 14. South Bight \#2 Blue Hole, 15. Double Drop Blue Hole, 16. Four Shark Cave, 17. Angelfish Blue Hole, 18. Mystery Cave, 19. Crab Cay Crevasse, 20. The Subway. Map from Online Map Creation at: http://www.aquarius.ifm.geomar.de 
A comparable water column profile was obtained in another South Andros ocean blue hole known as Four Shark Cave (fig. 5 in Kornicker et al. 2002:8). The cave entrance is in a coral rimmed depression about $10 \mathrm{~m}$ deep. The cave immediately opens onto a $20 \mathrm{~m}$ wide and up to $50 \mathrm{~m}$ high cavern $20 \mathrm{~m}$ wide and up to $50 \mathrm{~m}$ high. A Hydrolab profile was taken from a dome in the ceiling of this room to the floor at $56 \mathrm{~m}$ depth (fig. 6 in Kornicker et al. 2002:9). Although no sharp transition zone was found, salinity increased, while temperature, $\mathrm{pH}$ and dissolved oxygen decreased with depth.

Other ocean blue holes sampled as part of this study include four caves in the Exuma Cays (Angelfish Blue Hole, Crab Cay Crevasse, Mystery Cave and The Subway) and three, in addition to Conch Sound and Double Drop Blue Holes, on or near Andros Island (Exley's Boiling Hole, South Bight \#2 Blue Hole and Vortex Blue Hole). Several of these caves have been described in previous publications: Angelfish Blue Hole (Kornicker \& Iliffe 2000:12), Crab Cay Crevasse (Kornicker \& Iliffe 2000:12) and Mystery Cave (Kornicker $\&$ Iliffe 2000:10). The Subway is an extensive, $56 \mathrm{~m}$ deep, ocean cave located just off the shore on the southwest side of Great Exuma Island. Exley's Boiling Hole in the South Bight bisecting Andros Island was at one time (1977) the world's longest (331 m) and deepest (103 m) explored submarine cave (Palmer 1997: 43; map in Exley 1994:101). Nearby South Bight \#2 Blue Hole has two passages extending in opposite directions at 40 $m$ depth from the bottom of a submerged entrance pit (Palmer 1997: 34-35). Vortex Blue Hole, located off Gibson Cay in the Middle Bight of Andros Island, is another deep, fracture guided cave that parallels the submarine vertical escarpment that separates Andros Island from the Tongue of the Ocean. Waters in this section of the cave should be even more isolated from exchange with the open sea where water quality and residence times may be comparable to inland anchialine caves. Indeed, in the deep interior of the cave, exploratory cave divers have observed but not collected possible stygobitic crustaceans within the water column (Dan Malone, pers. comm. 1998). However, due the isolated location, deep water depths and small size of connecting passageways in this cave, few biological collections have been made and only ostracodes typical of marine caves have been found to date.

\section{Inland Blue Holes of the Bahamas}

Inland, anchialine caves from the Bahamas included here (Fig. 1) are four caves on Grand Bahama Island or adjacent Sweeting's Cay (Lucy's Cave, Mermaid's Lair, Sagittarius Blue Hole and Virgo Blue Hole), one from Abaco (Dan's Cave), two from Andros (Guardian Blue Hole and Sanctuary Blue Hole) and three from the Exuma Cays (Basil Minn's Blue Hole, Norman's Pond Cave and Oven Rock Cave). Sagittarius and Virgo Blue Holes (see map in Palmer 1985: 88) are part of the Zodiac Caverns, a complex system of caves and lakes hydrologically linking the north and south shores of Sweeting's Cay. Nearby Lucy's Cave (see map in Palmer 1985: 89) is likewise entered from an inland pond and is extremely well decorated with submerged speleothems. Mermaid's Lair is part of the Lucayan Caverns on Grand Bahama (see map in Kornicker et al. 2002: 4). Dan's Cave in the pine forest of central Abaco is a very extensive cave containing a rich fauna including remipedes, thermosbaenaceans, shrimp and cirolanid isopods (Kornicker et al. 1990:2). Guardian Blue Hole on North Andros Island is a fracture guided cave, $673 \mathrm{~m}$ long and $133 \mathrm{~m}$ deep (Fig. 3). Sanctuary Blue Hole on South Andros Island is another deep, fracture guided, rift cave (see map in Palmer 1997:139). The three Exuma caves are exceptionally rich habitats for stygobitic fauna, including a new family of stenopodid shrimp (Alvarez et al. 2006), eight new genera of epacteriscid copepods (Fosshagen et al. 2001, Fosshagen \& Iliffe 2004), a new genus of cirolanid isopod (Botosaneanu \& Iliffe 2003), a new genus of ridgewayiid copepod (Fosshagen \& Iliffe 2003) and three new species of remipedes (Koenemann et al. 2003). Descriptions of these caves may be found in the following publications: Norman's Pond Cave (see map in Kornicker \& Iliffe 1998:4), Oven Rock Cave (see map in Kornicker \& Iliffe 1998:5) and Basil Minn's Cave (Koenemann et al. 2003:247). 


\section{Anchialine Cenotes of the Yucatan Peninsula}

Inland, anchialine cenotes from Yucatan containing ostracodes reported on in this paper (Fig. 4) include Temple of Doom Cenote (Cenote Esqueleto) on the mainland of the Peninsula and Cenote Aerolito on the island of Cozumel. Temple of Doom Cenote is an extensive cave system located just north of Tulum, Quintana Roo, on the north side of highway to Coba. The entrance is a collapse sinkhole with a $4 \mathrm{~m}$ undercut, vertical drop to a large pool. Submerged passages extend to the north and south of the entrance with general orientation being perpendicular to the Caribbean coastline. Cenote Aerolito, situated $240 \mathrm{~m}$ inland on Cozumel, has a mapped length of $6.1 \mathrm{~km}$ (Mejía et al. 2006).

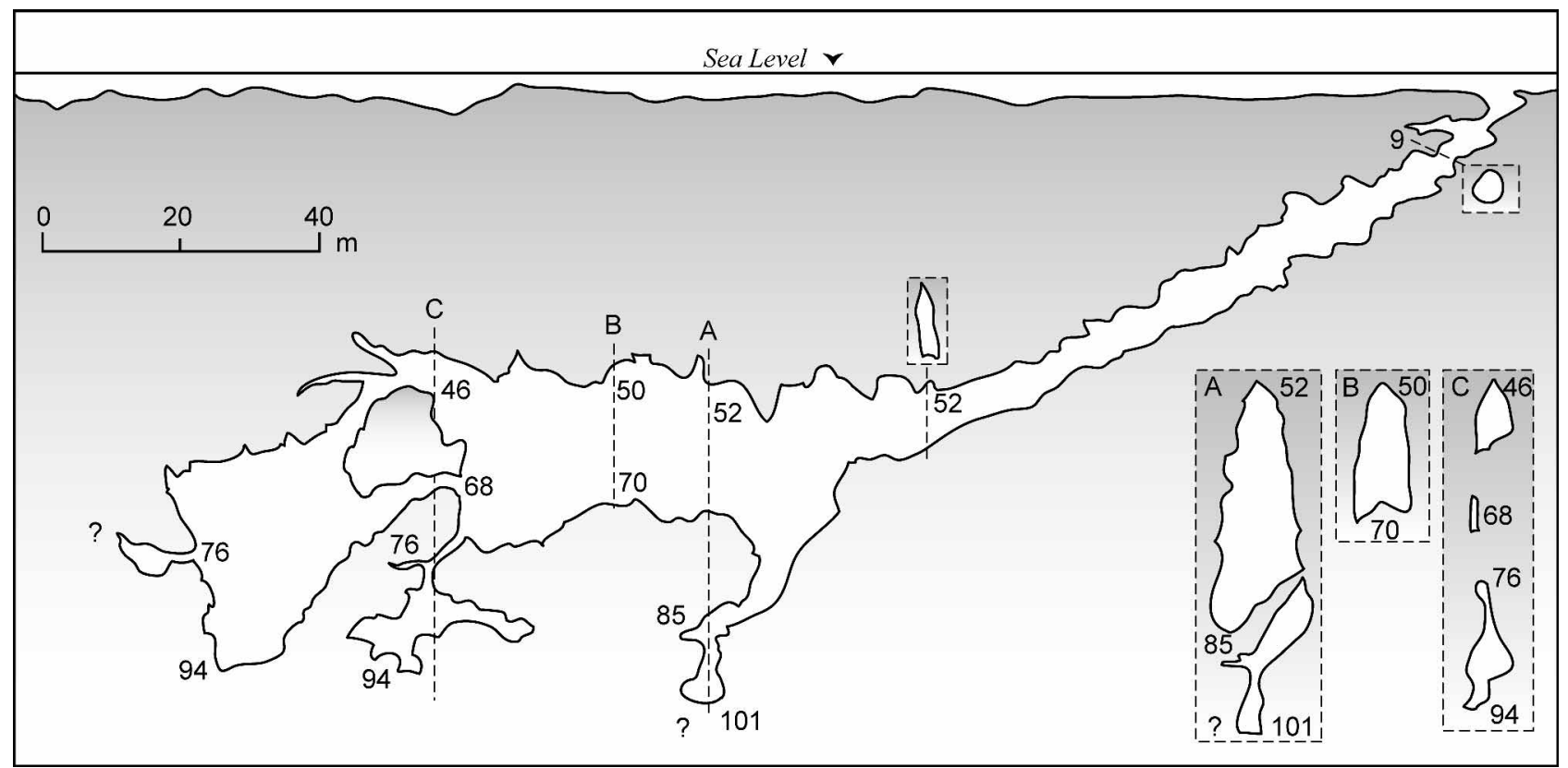

FIGURE 2. Profile view of Double Drop Blue Hole, Kemps Bay, Andros Island, Bahamas. Dashed lines indicate locations of cross sectional views. Map after Bowen, 1999:28.

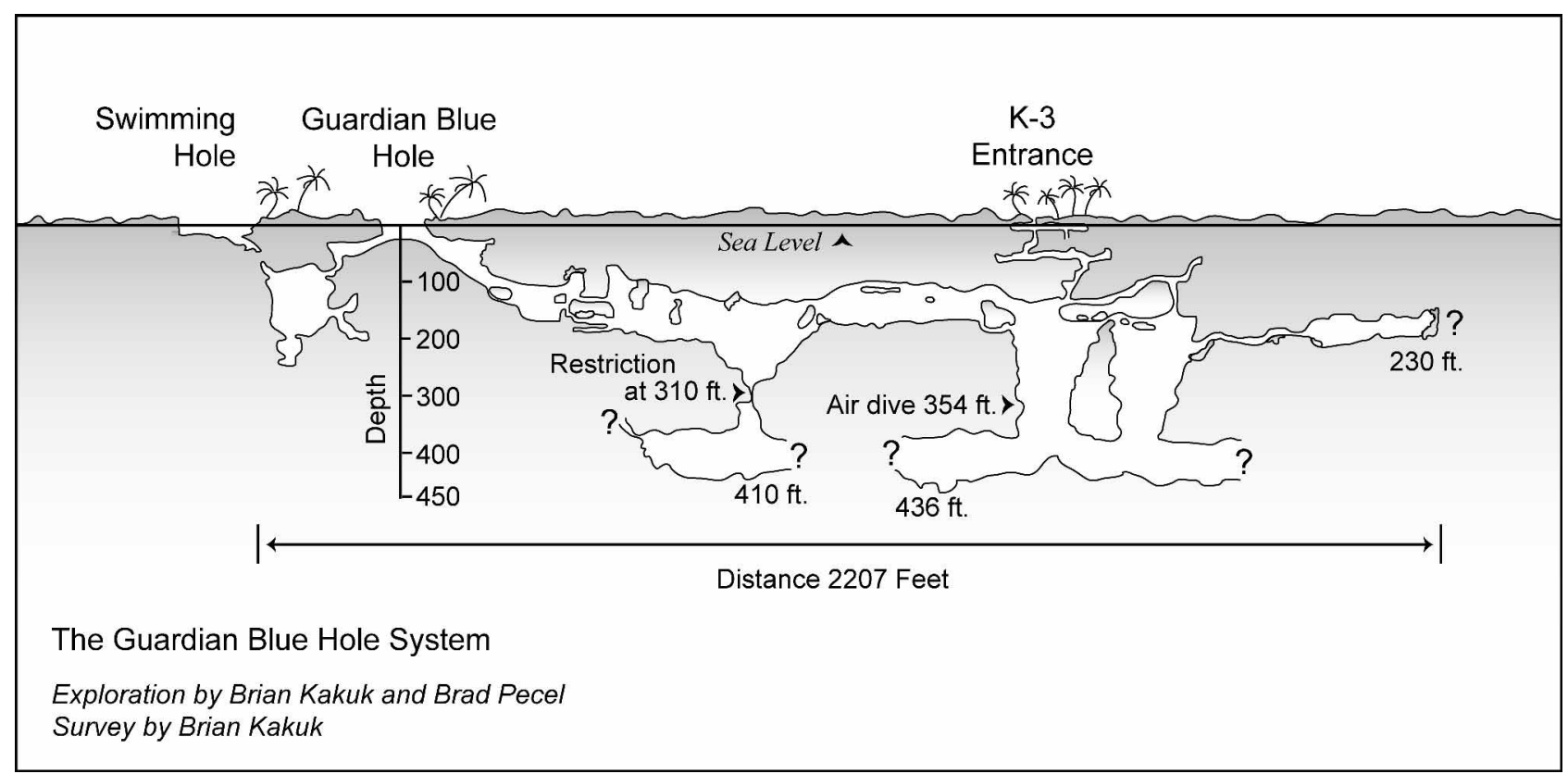

FIGURE 3. Profile map of Guardian Blue Hole System, North Andros Island, Bahamas. Exploration by Brian Kakuk and Brad Pecel; survey and map by Brian Kakuk. 


\section{Anchialine Caves of Bermuda}

Inland, anchialine habitats in Bermuda (Fig. 5) discussed here include Wonderland Cave and a saltwater well at the Bermuda Aquarium. Wonderland Cave, described in Bowman \& Iliffe (1983), is currently operated as a popular tourist attraction under the new name of Fantasy Cave. The $30 \mathrm{~m}$ deep well on the grounds of the Bermuda Aquarium at Flatts is pumped to supply salt water for exhibit tanks. Animals were observed and collected from the pump's filtration system.

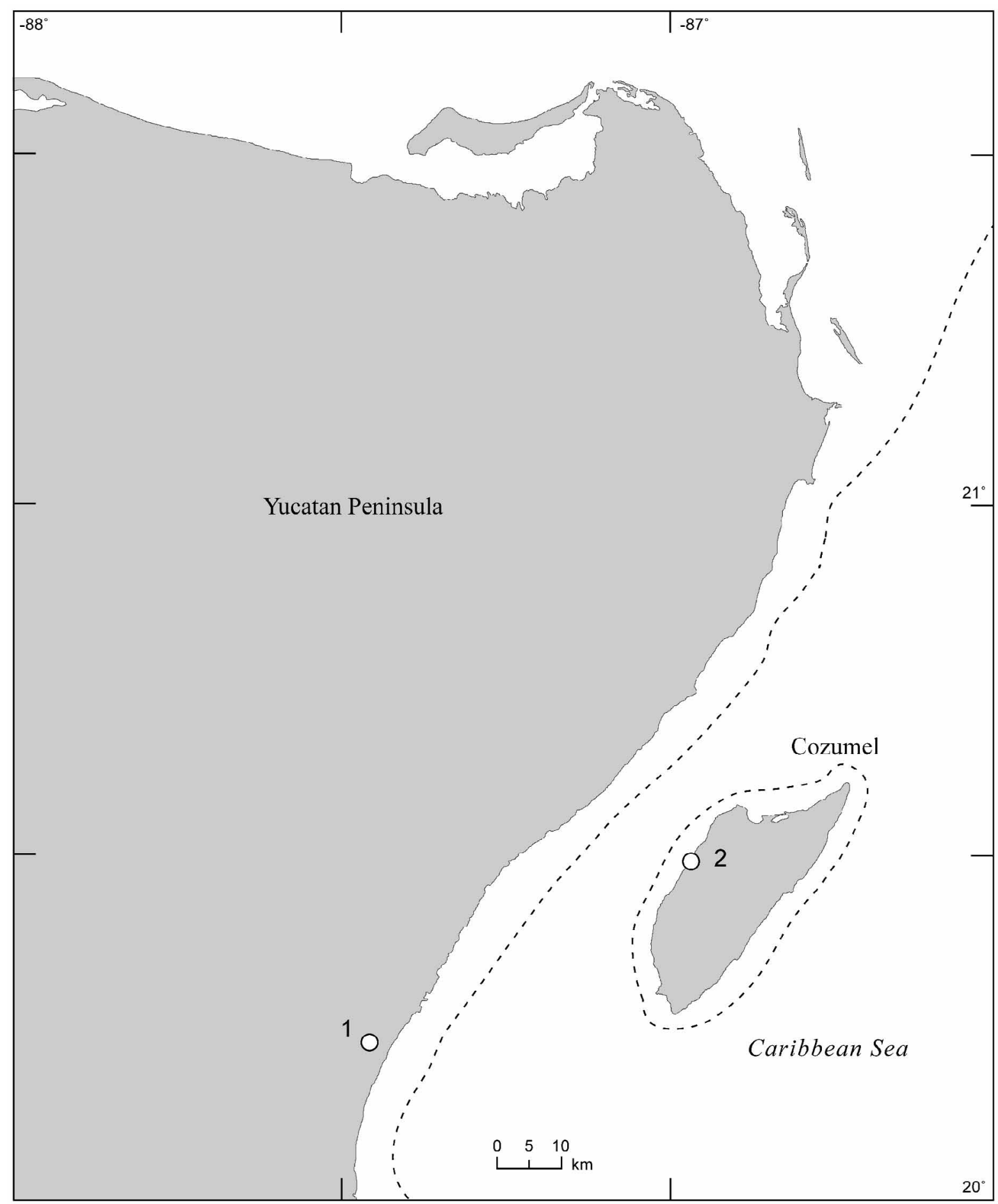

FIGURE 4. Locations of inland anchialine cenotes in the Yucatan Peninsula, Mexico. Cenotes open circles - O) include: 1. Temple of Doom Cenote, 2. Cenote Aerolito. Map from Online Map Creation at: http://www.aquarius.ifm.geomar.de 


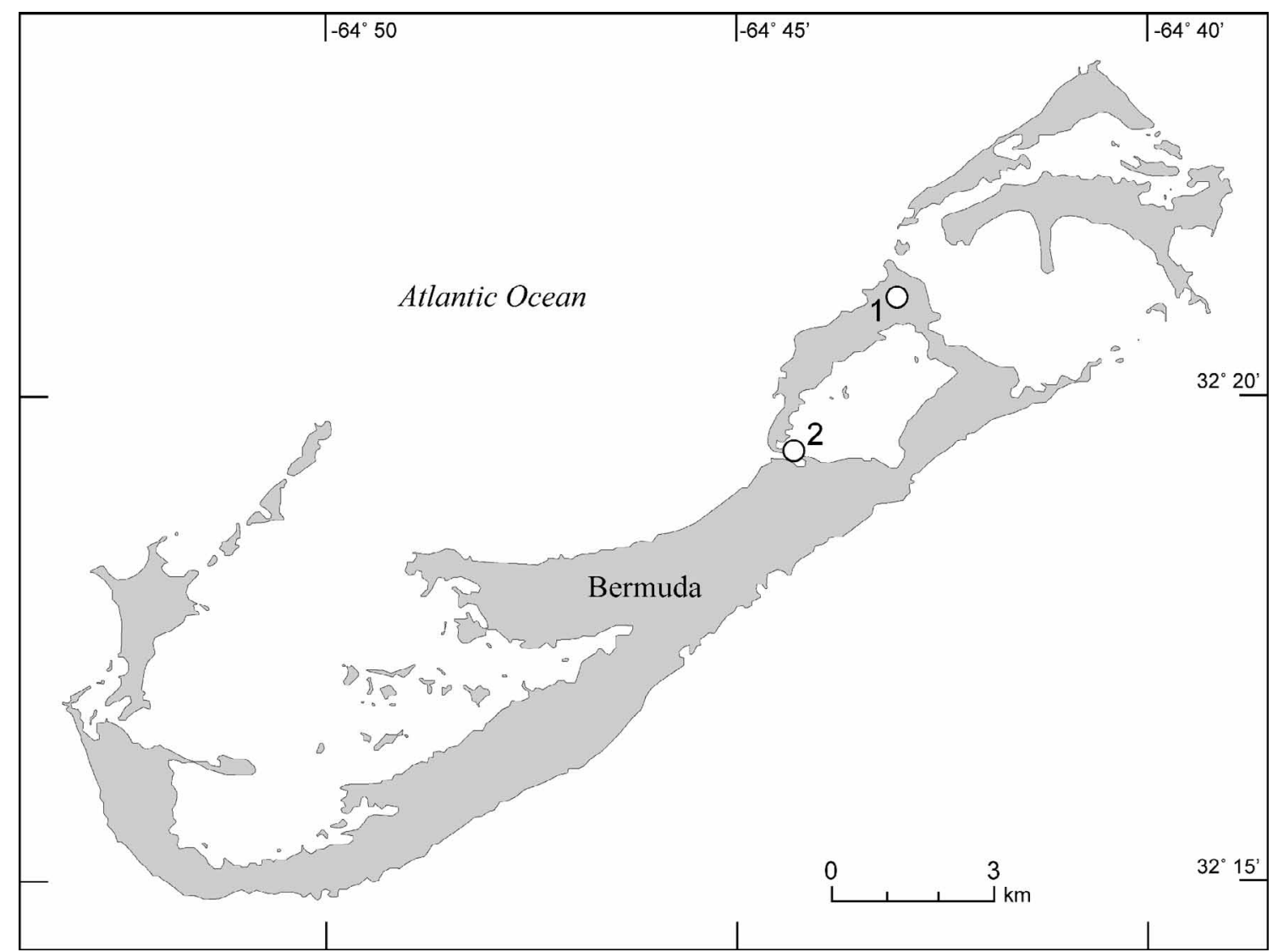

FIGURE 5. Locations of inland anchialine habitats in Bermuda. Sites (open circles - O) include: 1. Wonderland Cave, 2. Bermuda Aquarium well. Map from Online Map Creation at: http://www.aquarius.ifm.geomar.de

The following abbreviations are used in the illustrations and legends:

$\begin{array}{llll}\text { am } & \text { adductor muscle } & \text { lft } & \text { left } \\ \text { an } & \text { anus } & 1 l & \text { lower lip } \\ \text { av } & \text { anterior view } & 1 \mathrm{v} & \text { lateral view } \\ \text { bas } & \text { basale } & \text { me } & \text { medial eye } \\ \text { BO } & \text { Bellonci Organ } & \text { mo } & \text { mouth } \\ \text { co } & \text { copulatory organ } & \text { mnd } & \text { mandible } \\ \text { cx } & \text { coxa } & \text { mv } & \text { medial view } \\ \text { dv } & \text { dorsal view } & \text { mx } & \text { maxilla } \\ \text { end } & \text { endopod } & \text { nabs } & \text { not all bristles shown } \\ \text { epi } & \text { epipod } & \text { ov } & \text { outside view } \\ \text { esop } & \text { esophagus } & \text { precx } & \text { precoxa } \\ \text { ex } & \text { exopod } & \text { prot } & \text { protopod } \\ \text { fu } & \text { furca } & \text { rt } & \text { right } \\ \text { gen } & \text { genitalia } & \text { scl } & \text { sclerite } \\ \text { gl } & \text { gland } & \text { ul } & \text { upper lip } \\ \text { ht } & \text { heart } & \text { up } & \text { unpaired process } \\ \text { im } & \text { inner margin of infold } & \text { vv } & \text { ventral view } \\ \text { iv } & \text { inside view } & \text { Y-scl } & \text { Y-sclerite } \\ \text { le } & \text { lateral eye } & & \end{array}$




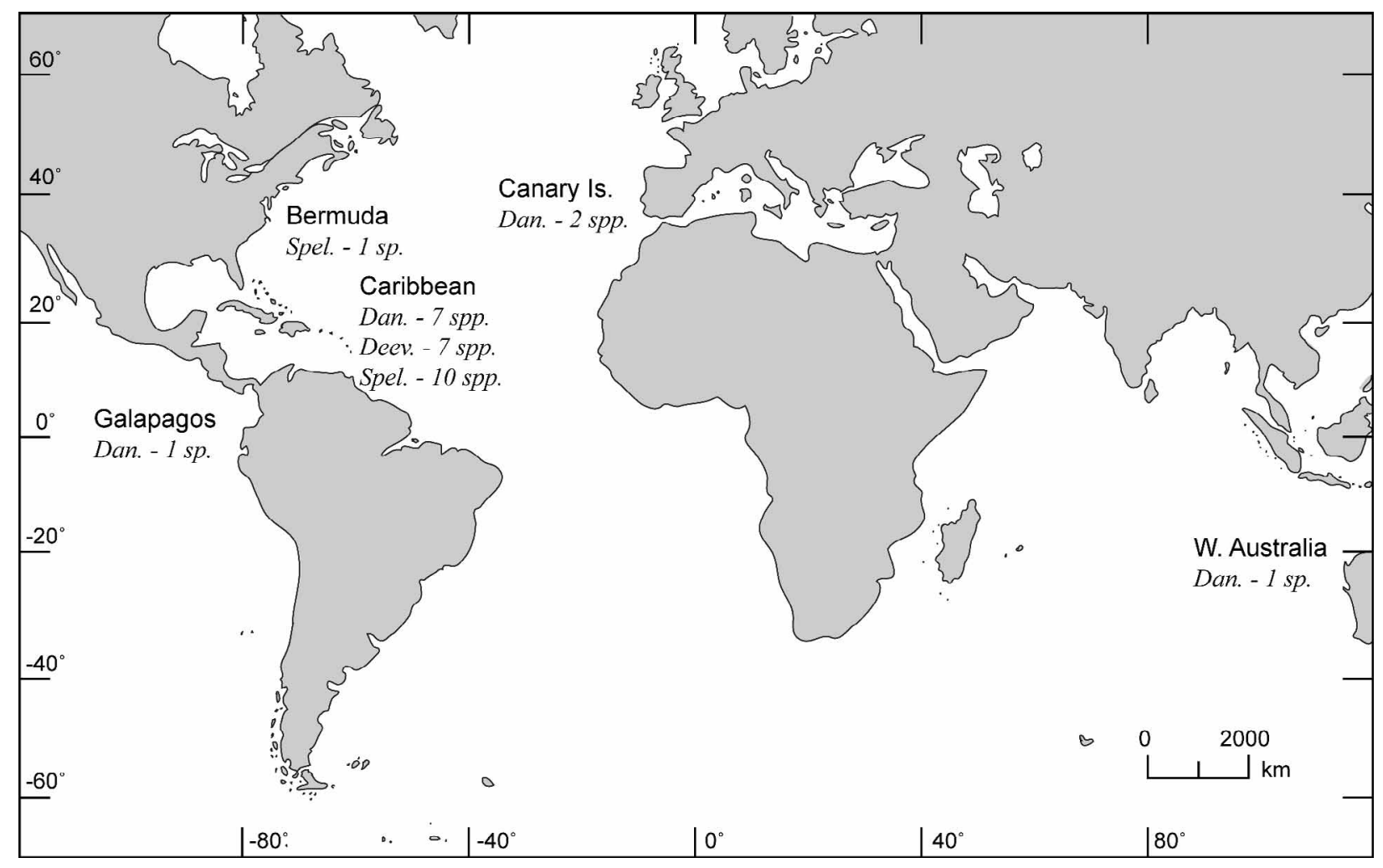

FIGURE 6. Worldwide distribution of stygobitic halocyprid ostracode species from the genera Danielopolina (Dan.), Deeveya (Deev.) and Spelaeoecia (Spel.). Map from Online Map Creation at: http://www.aquarius.ifm.geomar.de

In the figures Arabic numbers indicate limbs 1-7, as well as individual segments of each limb (the location of the numeral indicating whether a limb or segment is indicated); the number 5 is also used to designate the sensory bristle of the fifth segment of the first antenna. Roman numerals indicate the endites. Arrows indicate the anterior. All measurements are in millimeters unless otherwise noted. Letters used to identify bristles are explained in Skogsberg (1920: 187-188).

\section{Systematics}

\section{Class Ostracoda Latrielle 1802}

\section{Subclass Myodocopa Sars 1866}

Kornicker \& Sohn (1976: 4, fig. 2), on the basis of a cladistic analysis of several main characters, concluded that the subclass Myodocopa contained two orders, Myodocopida and Halocyprida, and that the latter contained two suborders, Cladocopina and Halocypridina. That classification is followed herein.

\section{Order Halocyprida Dana 1853}

\section{Suborder Halocypridina Dana 1853}

Composition and distribution. The suborder includes the superfamilies Halocypridoidea Dana, 1853, and Thaumatocypridoidea Müller, 1906. Both superfamilies are represented in the collections reported upon herein. The distribution of anchialine ostracodes in the suborder Halocypridina in inland and ocean blue holes in the Bahamas is shown in Tables 1 and 2. 
Discussion of identification. The following six morphological characters are useful in identifying the taxa and also may reflect relationships among the taxa (Table 5). A new subfamily, Spelaeoeciinae, is proposed herein, and that subfamily and the subfamily Deeveyinae are placed in the elevated family Deeveyidae in the superfamily Halocypridoidea. The genus Spelaeoecia was formerly placed in the subfamily Deeveyinae.

1. Members of the Thaumatocypridoidea and members of the Deeveyidae, a family in the Halocypridoidea, have two separated rami on the adult male copulatory organ: a broad anterior ramus and a narrower posterior ramus. The male copulatory organs of the adult males of taxa in the Halocypridoidea other than the Deeveyidae have the narrow posterior ramus inserted inside the broad anterior ramus. The A-1 males of all Halocypridoidea have separated rami. The inserted type is interpreted to be the apomorphic character state. The presence of two separate rami in the copulatory organ of all known extant members of the Thaumatocypridoidea, which have fossil members in the Permian, may support that conclusion (Fig. 9).

2. The sixth limbs of the Thaumatocypridoidea and members of the genera Deeveya and Spelaeoecia in the family Deeveyidae in the Halocypridoidea have an exopod represented by a lobe bearing bristles. The lobe is absent on members of the Halocyprididae. The lobe is interpreted herein to be the plesiomorphic character state, and the absence of a lobe the apomorphic character state.

3. The exopod lobe of the sixth limb bears different numbers of bristles: Thaumatocypris one bristle plus one spine, Danielopolina two bristles, Thaumatoconcha three bristles, Deeveya four bristles, Spelaeoecia five bristles. The Halocyprididae do not have a lobe but do have several bristles that could be interpreted to represent an exopod (Kornicker 2003); these have not been considered in Table 5. The number of exopod bristles for each genus is listed in Table 5, but whether the sequence reflects relationships is not known.

4. The carapaces of the Thaumatocypridoidea are without an incisure. In the Halocypridoidea, the carapaces of members of the genus Deeveya in the Deeveyidae have an incisure represented, at most, by a very slight anterior concavity. The carapaces of members of the genus Spelaeoecia, also in the Deeveyidae, and most species of the Halocyprididae have a well defined incisure. A well-defined incisure is interpreted herein as the apomorphic character state (Fig. 9).

5. The carapaces of the Thaumatocypridoidea are without the marginal glandular openings present in the carapaces of members of the Halocypridoidea. The presence of marginal glandular openings is tentatively interpreted herein as the apomorphic character state, mainly because they do not appear to be present in fossil carapaces.

6. The basis of the mandible of all known species of Deeveya and two species of Spelaeoecia, both members of the Deeveyidae, has two entwined lateral bristles (Fig. 28c, g). The corresponding bristles are not entwined on other known members of the Halocypridoidea. The entwined form is interpreted herein to be the apomorphic character state. 


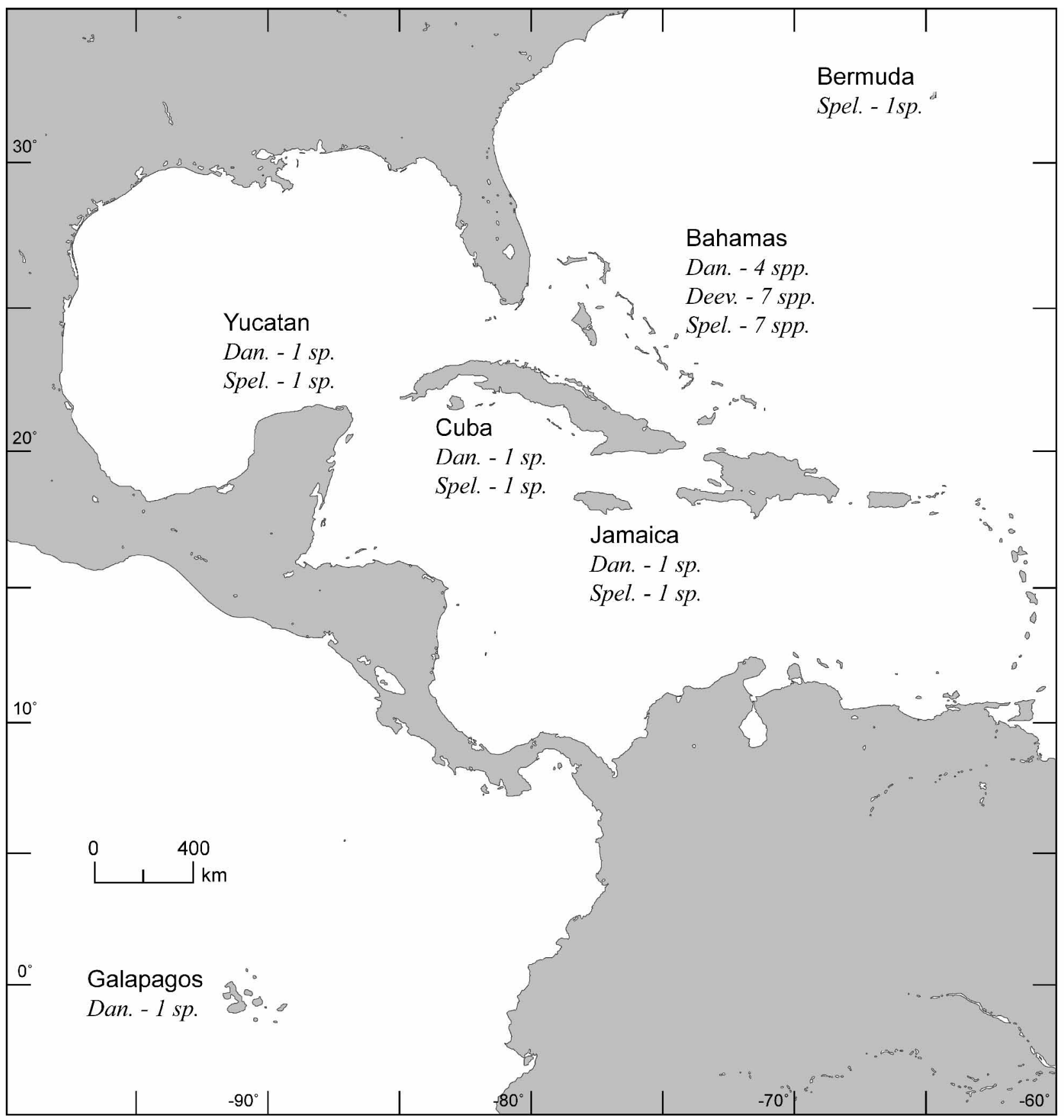

FIGURE 7. Distribution of stygobitic halocyprid ostracode species from the genera Danielopolina (Dan.), Deeveya (Deev.) and Spelaeoecia (Spel.) within the Caribbean. Map from Online Map Creation at: http://www.aquarius.ifm.geomar.de

Discussion of mandible. The basis of mandibles of adults and late instars of known species of Deeveya and also two species of Spelaeoecia has two entwined bristles (Table 6; Fig. 28c, g) (Kornicker \& Iliffe 1998: figs. $7 \mathrm{e}, 13 \mathrm{c}, \mathrm{d})$. Although the data are few on early instars, both bristles are absent on the A-5 instar, only one of the bristles is present on the A-4 and A-3 instars, and both bristles are present in later stages (Table 6). In species of Deeveya the bristles cross two or three times on the A-2 instar and five times on the A-1 instar and on both the adult female and male (Table 6; Fig. 28g). The two bristles cross each other twice on an A-1 instar as well as on an adult male and female of $S$. cubensis, and cross each other five times on an adult female $S$. capax and only three times on an adult male. The absence of entwined bristles on thaumatocyprids suggests that the entwining of the bristles in Deeveya represents a synapomorphic character state. The entwining in the 
two species of Spelaeoecia is tentatively interpreted as convergence. The function, if any, of the entwined bristles is unknown. Of possible significance is that in the entwined state the bristles are shorter than if they were not entwined. In an enquiry among a few crustacean specialists (Decapoda, Isopoda, Copepoda), none could recall having observed species with entwined bristles.

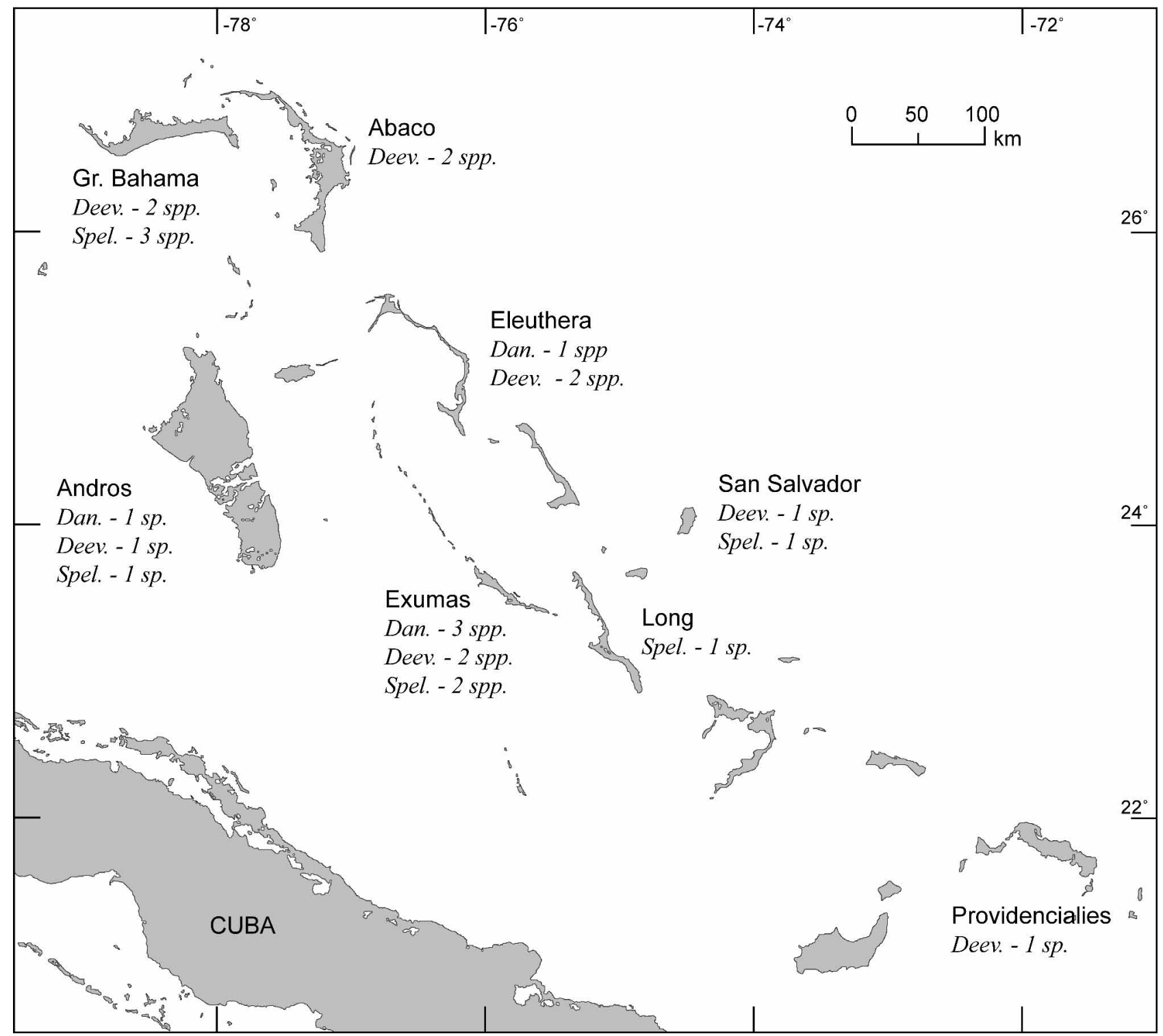

FIGURE 8. Distribution of stygobitic halocyprid ostracode species from the genera Danielopolina (Dan.), Deeveya (Deev.) and Spelaeoecia (Spel.) within the Bahamas. Map from Online Map Creation at: http://www.aquarius.ifm.geomar.de 
TABLE 4. Approximate diameter of eggs within the ovaries of Spelaeoecia bermudensis (listed in order of increasing diameter), and percentage increase in diameter of consecutive eggs. Dashed lines separate hypothetical clutches (each clutch includes consecutive eggs differing in diameter by less than $15 \%$ ).

\begin{tabular}{|c|c|c|c|}
\hline \multirow{2}{*}{$\begin{array}{l}\text { USNM } 1021397 \\
\text { Diameter }(\mu)\end{array}$} & \multirow[b]{2}{*}{ Increase $(\%)$} & \multicolumn{2}{|c|}{ USNM 1021396} \\
\hline & & Diameter. $(\mu)$ & Increase $(\%)$ \\
\hline 28 & - & 25 & - \\
\hline 29 & 4 & 27 & 8 \\
\hline 31 & 7 & 27 & 0 \\
\hline---- & & 28 & 4 \\
\hline 51 & 65 & --------------- & \\
\hline 56 & 10 & 33 & 18 \\
\hline 115 & 105 & 41 & 24 \\
\hline & & 45 & 10 \\
\hline 151 & 31 & 47 & 4 \\
\hline ---- & & 52 & 11 \\
\hline 170 & 13 & --------------- & \\
\hline \multirow[t]{3}{*}{220} & 29 & 66 & 27 \\
\hline & & 118 & 79 \\
\hline & & 169 & 43 \\
\hline
\end{tabular}

TABLE 5. Distribution of selected morphological characters in the superfamilies Thaumatocypridoidea and Halocypridoidea. $(-=$ plesiomorphic,$+=$ apomorphic $)$

\begin{tabular}{|c|c|c|c|c|c|c|}
\hline \multirow[t]{4}{*}{ Character* } & \multirow{2}{*}{\multicolumn{3}{|c|}{$\begin{array}{l}\text { Thaumatocypridoidea } \\
\text { Thaumatocyprididae }\end{array}$}} & \multicolumn{3}{|c|}{ Halocypridoidea } \\
\hline & & & & \multicolumn{2}{|c|}{ Deeveyidae } & \multirow{3}{*}{$\begin{array}{l}\text { Halocyprididae } \\
\text { Planktonic halocyprids }\end{array}$} \\
\hline & \multirow[b]{2}{*}{ Thaumatocypris } & \multirow[b]{2}{*}{ Danielopolina } & \multirow[b]{2}{*}{ Thaumatoconcha } & Deeveyinae & Spelaeoeciinae & \\
\hline & & & & Deeveya & Spelaeoecia & \\
\hline 1 & - & - & - & - & - & + \\
\hline 2 & - & - & - & - & - & + \\
\hline 3 & 1 & 2 & 3 & 4 & 5 & $?$ \\
\hline 4 & - & - & - & - & + & -+ \\
\hline 5 & - & - & - & - & + & + \\
\hline 6 & - & - & - & + & -+ & - \\
\hline
\end{tabular}

*The six morphological characters are discussed in "Discussion of Identification" (p. 21 herein)

\section{Superfamily Thaumatocypridoidea Müller 1906}

Composition. This superfamily includes only the family Thaumatocyprididae Müller 1906

\section{Family Thaumatocyprididae Müller 1906}

Composition. This family includes two genera known only from the Permian (Thaumatomma Kornicker \& 
Sohn 1976) and Mesozoic (Pokornyopsis Kozur 1974) and three known from the Holocene: Thaumatocypris Müller 1906; Thaumatoconcha Kornicker \& Sohn 1976; and Danielopolina Kornicker \& Sohn 1976.

Distribution. Worldwide (Fig. 6).

Discussion. When Kornicker \& Sohn (1976) proposed the two genera Thaumatoconcha and Danielopolina, the former was known from eight species, the latter from two species, and Thaumatocypris, the third genus in the family, from one species. At present Thaumatoconcha includes 10 species, Danielopolina 12 species, and Thaumatocypris two species. Most of the characters used by Kornicker \& Sohn $(1976: 24,93)$ to distinguish the three genera no longer hold. A distinguishing character that persists is a difference in the number of bristles on the exopod of the sixth limb: Thaumatoconcha with three long bristles, Danielopolina with two long bristles, and Thaumatocypris with one long bristle and one short spine.

TABLE 6. Number of bristles on the mandibular basis of seven species of Deeveya and two species of Spelaeoecia, with numbers of crossings of the two entwined bristles (in parentheses). (nd = no data.)

\begin{tabular}{llllllll}
\hline \multicolumn{7}{l}{ Number of bristles (number of crossings) } \\
& A-5 & A-4 & A-3 & A-2 & A-1 & Adult female & Adult male \\
\hline Deeveya & & & & & & & \\
D. bransoni & 0 & 1 & 1 & $2(2-3)$ & $2(5)$ & $2(5)$ & $2(5)$ \\
D. exleyi & nd & nd & nd & nd & nd & $2(5)$ & nd \\
D. hirpex & nd & nd & nd & nd & nd & $2(5)$ & nd \\
D. jillae & nd & 1 & nd & $2(3)$ & nd & nd & nd \\
D. medix & nd & nd & nd & nd & nd & $2(5)$ & $2(5)$ \\
D. spiralis & nd & nd & nd & nd & nd & $2(5)$ & nd \\
D. styrax & nd & nd & nd & nd & nd & $2(5)$ & $2(5)$ \\
Spelaeoecia & & & & & & & \\
S. capax & nd & nd & nd & nd & nd & $2(5)$ & $2(3)$ \\
S. cubensis & nd & nd & nd & nd & $2(2)$ & $2(2)$ & $2(2)$ \\
\hline
\end{tabular}

\section{Danielopolina Kornicker \& Sohn 1976}

Type species. Danielopolina carolynae Kornicker \& Sohn 1976.

Composition. This genus contains two subgenera D. (Humphreysella) Kornicker \& Danielopol 2006 in Kornicker et al. 2006 and D. (Danielopolina) Kornicker et al. 2006. Members of both subgenera are represented in the present collection.

Correction. Kornicker \& Iliffe (1998: 84) stated Danielopolina species A was collected in Open Rock Cave. The collection site should have been listed as Oven Rock Cave.

Diagnosis of subgenera. Humphreysella is without a posterior bristle on the protopod of the second antenna. Danielopolina bears a posterior bristle on the protopod of the second antenna.

Discussion of first antennae. The first and second segments of the first antennae of the adult female holotype and paratype of D. palmeri are linear (Fig. 12a-c), whereas those segments of the adult female first antennae of the holotype and a paratype of D. exuma Kornicker \& Iliffe 1998 illustrated by Kornicker \& Iliffe (1998: fig. 51d-f) form a right angle. The first and second segments of the first antenna of another adult female of a paratype of D. exuma examined herein also form a right angle (Fig. 13j). A survey of some of the literature in which species of Danielopolina have been described (Kornicker \& Iliffe 1989a, 1998, 2000) shows that some illustrations of the first antennae have linear first and second segments, and some show the two segments at right angles, and juveniles as well as adults of both sexes have first antennae of both forms. 
Examination of whole specimens showed that when the first and second segments are at right angles, the first antenna is partly withdrawn inside the carapace; whereas when the two segments are linear segments twoeight extend horizontally outside the carapace between the anterior edges of the valves. Apparently, when an extrinsic muscle is taut, segments one and two are linear. The various angles between the first and second segments of first antennae of species of Thaumatoconcha illustrated by Kornicker \& Sohn (1976: fig. 7) indicate that a similar mechanism also operates in members of that genus.

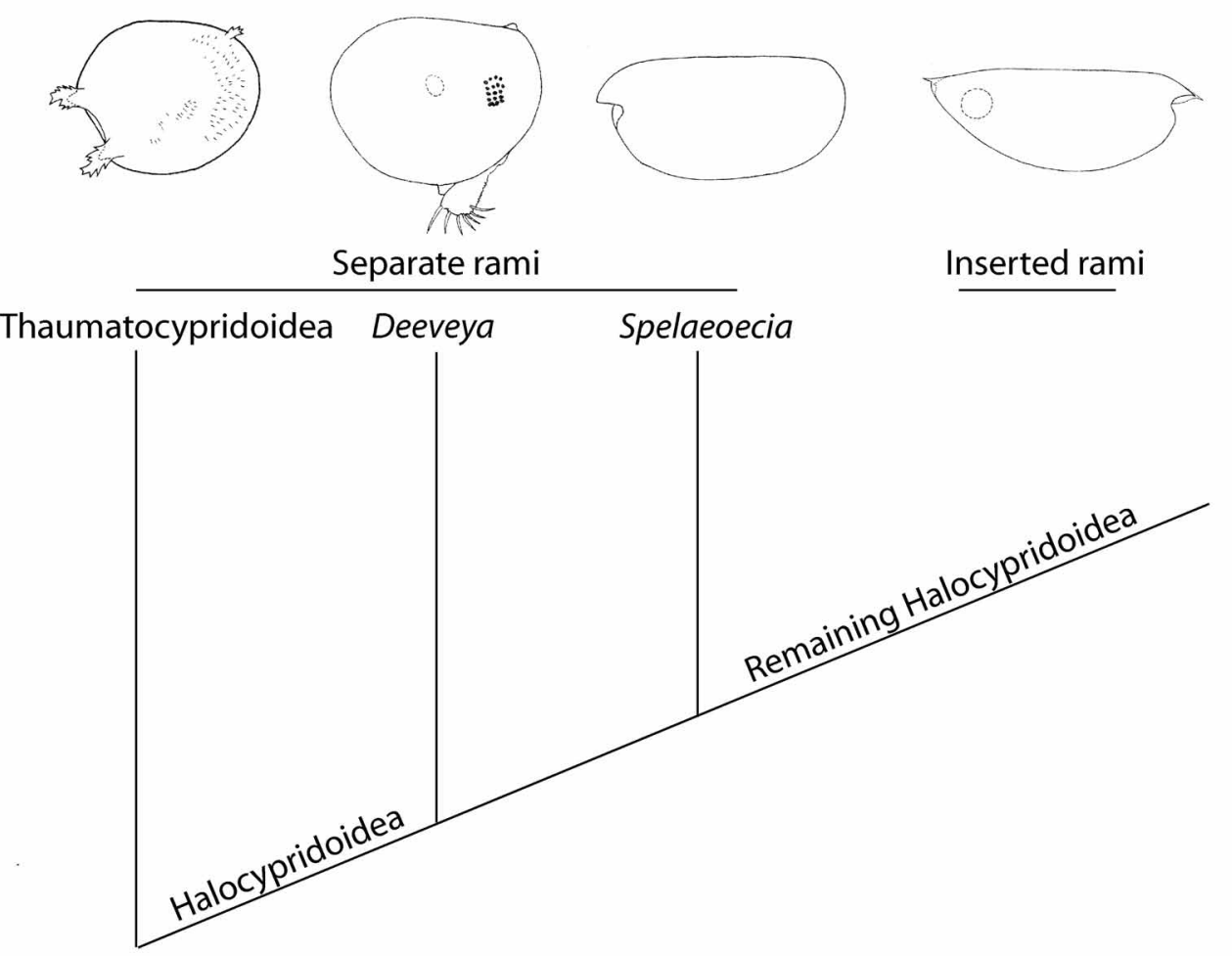

FIGURE 9. Possible evolutionary sequence of Halocypridina based on whether male copulatory organ has separate or inserted rami and carapace shape.

\section{Subgenus Humphreysella Kornicker \& Danielopol in Kornicker et al. 2006}

Type species. Danielopolina orghidani (Danielopol 1972).

Diagnosis. Protopod of second antenna without posterior bristle.

Composition and distribution. This subgenus contains eight species from anchialine inland habitats: $D$. (H.) bahamensis Kornicker \& Iliffe 1989a, Bahamas; D. (H.) elizabethae Kornicker \& Iliffe 1992, Jamaica; D. (H.) exuma Kornicker \& Iliffe 1998, Bahamas; D. (H.) kakuki Kornicker \& Iliffe 2000, Bahamas; D. (H.) orghidani Danielopol 1972, Cuba; D. (H.) styx Kornicker and Iliffe 1989c, Galapagos Islands; D. (H.) wilkensi Hartmann 1985, Canary Islands; D. (H.) palmeri n. sp., Bahamas.

\section{Danielopolina (H.) palmeri n.sp.}

Figs. 10-13a-i

Etymology. Named posthumously in honor of British cave diver Rob Palmer, a pioneering explorer of the blue holes of the Bahamas and author of two books (Palmer 1985, 1997) and numerous articles. Rob never returned from a deep dive in the Red Sea in 1997. The type locality for this species was first explored by Rob Palmer.

Holotype. USNM 1021375, adult female on two slides and in alcohol. 
Type locality. Sanctuary Blue Hole, South Andros Island, Great Bahama Bank, Sta 99-061.

Paratypes. Type locality, Sta 99-061: USNM 1021376, adult female. USNM 1021377, two early instars (probably second instars, length and height without processes $(\mathrm{mm}): 0.38,0.27 ; 0.28,0.23$ ).

Distribution. Type locality.

Description of adult female (Figs. 10-13a-i). Carapace subround in lateral view with fairly straight margin between anterior and anteroventral processes (Fig. 10); hinge line straight (Fig. 11e). Short anterior and anteroventral processes with bases just lateral to valve edge; fragile spines on processes mostly broken off on holotype (Fig.11a); spines on processes completely broken off by dissecting needle leaving small firm triangular protuberance (Fig. 11a); a similar posterodorsal process in same place on each valve. Bristles present along edges of valve, those along anteroventral edge divided distally (Fig. 11e).

Ornamentation: Much of surface ornamentation missing on surface of carapace of holotype. Approximate location of some reticulations and spines of holotype shown in Fig. 11a, and minute subelliptical papillae forming walls of reticulations shown in Fig. $11 b$; papillae at intersections of reticulate walls generally with small spines; minute spines forming rows near valve edges. Surface ornamentation well preserved on paratype (Fig. 10): minute papillae forming walls of reticulations, with spines at intersections; spines forming row just within valve edge and along dorsal edge of valve.

Selvage (Fig. 11d,e): Broad lamellar prolongation with smooth outer edge present along anterior, ventral, and posterior edges of valves.

Infold (Fig. 11e): Broad infold present along anterior, ventral, and posterior margins of valves.

Central adductor muscle attachments (Figs. 10, 11a,e): Comprising about 8 radially arranged attachments.

Carapace size (mm): USNM 1021375, length without processes 0.53 , height without processes 0.47 . USNM 1021376, length with anterior and posterodorsal processes 0.61 , length without processes 0.49 , height with anteroventral and posterodorsal processes 0.45 , height without processes 0.42 .

First antenna (Figs. 11f, 12a-c): 1st and 2nd segments linear (not forming right angle). 1st segment with 1 dorsal bristle and 1 lateral bristle oriented posteriorly. 2nd segment with 1 dorsal bristle. 3rd and 4th segments fused but place of boundary indicated by slight indentation in ventral margin. 5th segment with long terminal ventral filament. 6th segment bare. 7th segment with 2 long ventral bristles (b-bristle shorter than lateral c-bristle). 8th segment with 3 bristles (d-bristle shorter, f-bristle about one-half length of e-bristle).

Second antenna (Fig. 12d): Protopod bare. Endopod 3-segmented but with 2 nd and 3rd segments fused. 1st segment with dorsal a- and b-bristles. 2nd segment with 2 long terminal bristles and indistinct, minute, distal, lateral spine near dorsal margin. 3rd segment narrow with short terminal bristle. Exopod 8 segmented: 1st segment divided weakly into long proximal and short distal parts; bristles of segments 2-7 long with indistinct natatory hairs; 8th segment with 2 bristles.

Mandible (Fig. 13a-c): Coxa endite with proximal and distal sets of teeth separated by space; proximal set comprising 4 broad cusps plus triangular tooth close to distal set of teeth (Fig. 13a); surface between cusps and surfaces just proximal to cusps with slender spines; 1 spinous bristle with base just posterior and another with base just anterior to triangular tooth; distal set of teeth consisting of 2 flat teeth, each with cusps; 1 slender bristle with base medial to distal set of teeth. Basis (Fig. 13b): tooth of endite with 5 triangular teeth, each with minute marginal cusp on each side (cusps on anterior 4 teeth better defined); posterior edge of endite spinous, with 2 short distal bristles (distal of these tubular with blunt tip); anterior margin of endite with long ringed bristle near midlength; lateral side of endite with 4 bristles ( 3 long, 1 short) near midlength and 1 short distal bristle; medial side of endite with 2 proximal bristles and long spines near midlength (spines not shown). Endopod 3 segmented (1st and 2nd segments of left limb fused, but interpreted to be an aberrancy (Fig. 13b); right limb with suture between 1st and 2nd segments (Fig. 13c)): 1st segment with lateral spines; 2nd segment with distal lateral spines, 1 ringed distal ventral bristle, 2 ringed distal medial bristles with bases near ventral margin, and 2 ringed dorsal bristles; 3rd segment with dorsal and medial spines (medial spines 
not shown), 2 terminal lateral bristles (1 at midwidth about twice length of endopod and with distal marginal spines), 1 at ventral edge almost one-half length of bristle at midwidth and with distal marginal spines (longest spines at midlength), 3 shorter ringed terminal medial bristles, and 1 short ringed subterminal bristle on ventral margin.

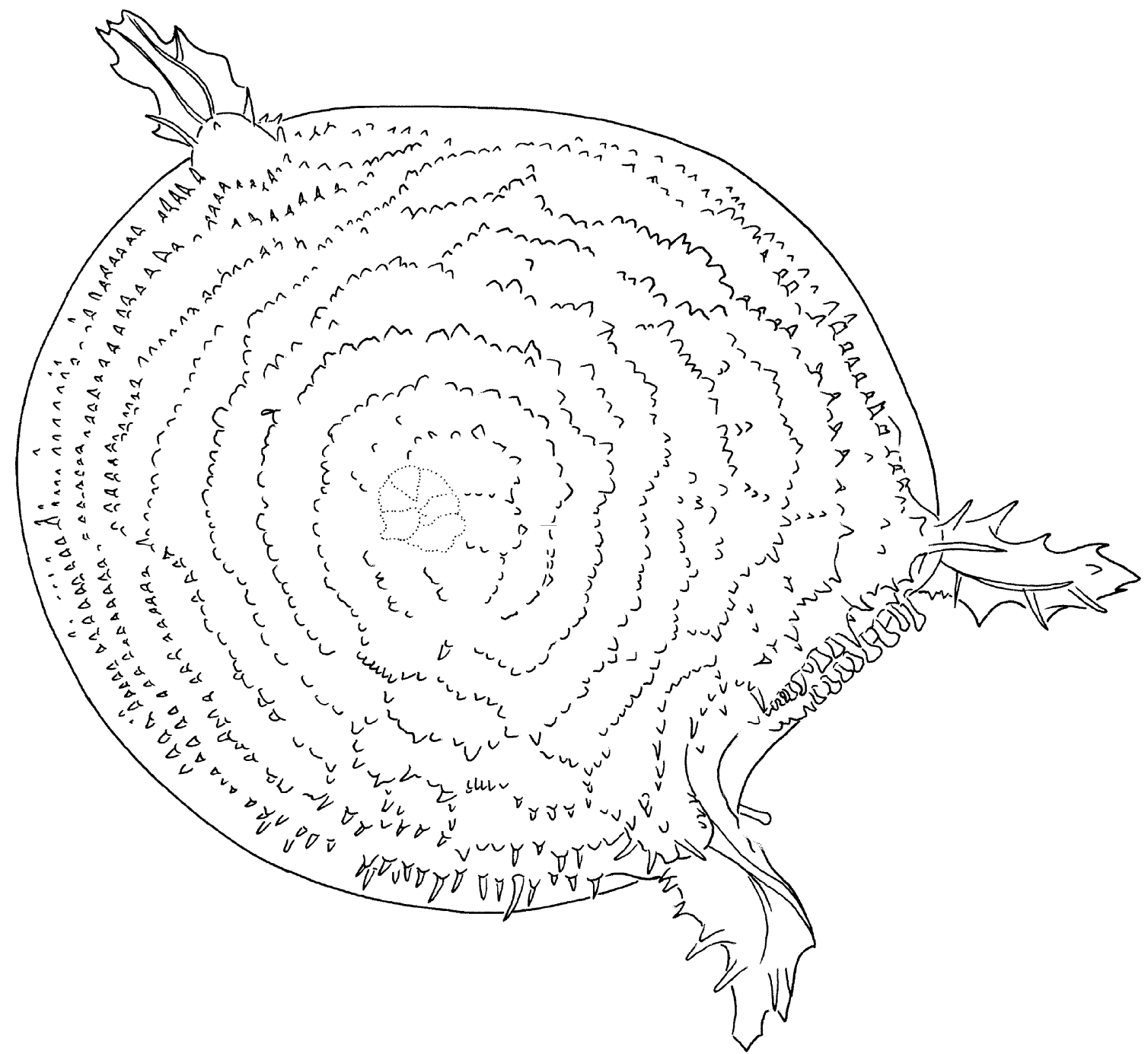

FIGURE 10. Danielopolina palmeri, new species, paratype, USNM 1021376, adult female, complete specimen from right side, length without processes $0.49 \mathrm{~mm}$, with processes $0.61 \mathrm{~mm}$.

Maxilla (Fig. 13d,e): Endite I with about 10 bristles ( 3 tubular); endite II with about 6 bristles ( 2 tubular); endite III with about 5 bristles (1 tubular). Coxa with long spinous dorsal bristle. Basis with 2 ventral bristles ( 1 spinous bristle near base of endite III, 1 terminal tubular bristle). Endopod 2 segmented: 1 st segment with 3 dorsal bristles and 3 distal bristles on or near ventral margin; 2nd segment with stout, straight, unringed, nonarticulated, terminal claw and 4 ringed articulated bristles (1 medial tubular, 3 lateral (longest somewhat clawlike, spinous)).

Fifth limb (Fig. 13d,f-h): Epipod bristles not counted. Boundary of precoxa and coxa marked by muscle terminating at ventral edge of boundary (Fig. 13g). Precoxa with 6 ventral bristles ( 1 tubular) and 1 medial bristle set back from ventral margin. Coxa with 6 ventral bristles ( 2 claw-like bristles, 2 slender tubular bristles, 2 stout bristles with long marginal spines) and 1 long spinous bristle set back from ventral margin (Fig. $13 g$ ). Basis with 6 bristles on or near ventral margin and 1 spinous medial bristle set back from ventral margin. Exopod bristle long bare. Endopod 2 segmented: 1st segment with 2 ventral bristles near midlength; 2nd segment with 1 long and 2 short bristles. 


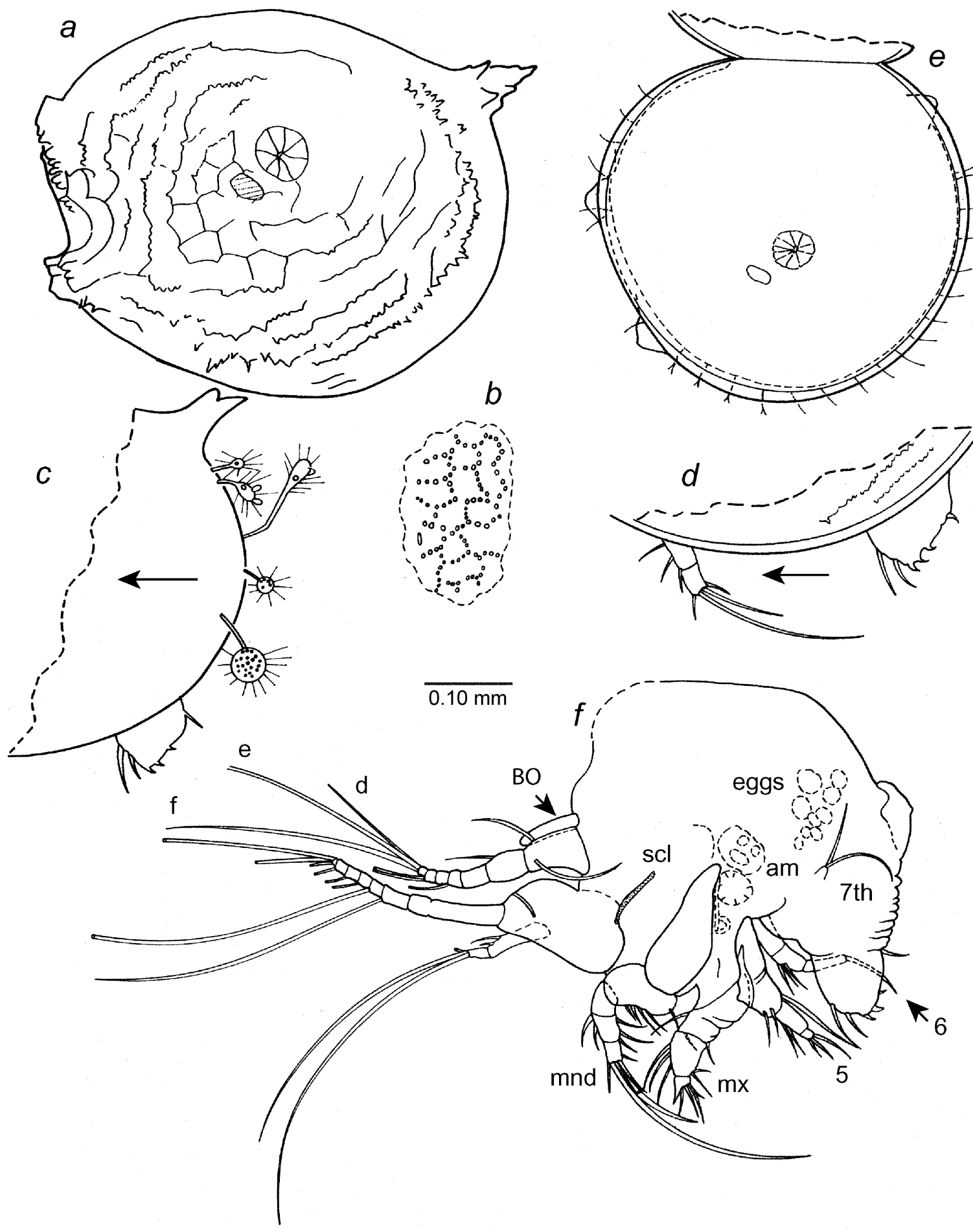

FIGURE 11. Danielopolina palmeri, new species, holotype USNM 1021375, adult female, $a$, complete specimen from left side, length without processes $0.53 \mathrm{~mm} ; b$, detail of surface pustules from " $a$ "; $c$, complete specimen showing projecting furca and attached protistans; $d$, ventral edge of specimen showing projecting mandible and furca; $e$, right valve showing adductor and mandibular muscle attachment scars; $f$, body removed from carapace (maxilla, 5th and 6th are right limbs, others are left limbs (nabs)). Scale equals $0.10 \mathrm{~mm}(b-f)$.

Sixth limb (Fig. 13f,i): Epipod with plumose bristles forming 3 groups: proximal group with 5 bristles; bristles of second group fragmented during dissection; distal group with 4 or 5 bristles. Precoxa spinous, with 1 spinous ventral bristle. Coxa spinous, with 2 spinous ventral bristles. Basis with 3 spinous bristles ( 2 ventral 
and 1 dorsal). Small exopod with 2 unequal spinous bristles. Exopod of left limb medial and close to ventral margin of basis (Fig. 13i); exopod of right limb also medial but close to dorsal margin (Fig. 13f). Endopod 2 segmented: 1 st segment with 2 ventral bristles near midlength; 2nd segment with 2 bristles (1 long terminal and 1 short, subterminal, ventral).

Seventh limb (Fig. 12e). Elongate with 2 long terminal bristles.

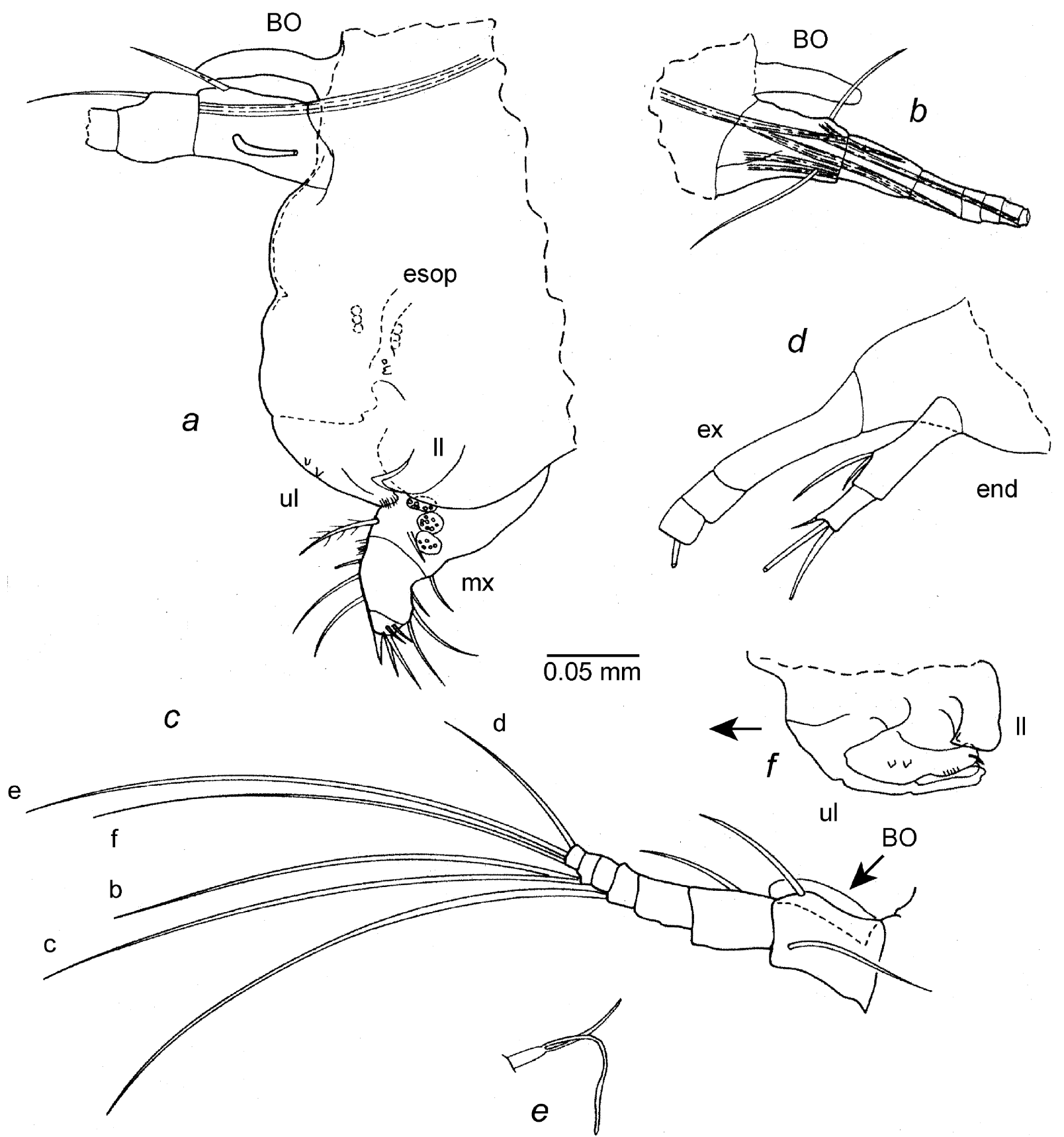

FIGURE 12. Danielopolina palmeri, new species, holotype USNM 1021375, adult female, $a$, anterior of body showing Bellonci Organ, left first antenna, right maxilla, and upper and lower lips (nabs); $b$, right first antenna (mv), and Bellonci Organ and some internal muscles; $c$, left first antenna (lv), and Bellonci Organ; $d$, right second antenna drawn on body, mv (nabs); $e$, left seventh limb, lv; $f$, upper and lower lips drawn on body. Scale equals $0.05 \mathrm{~mm}$. 


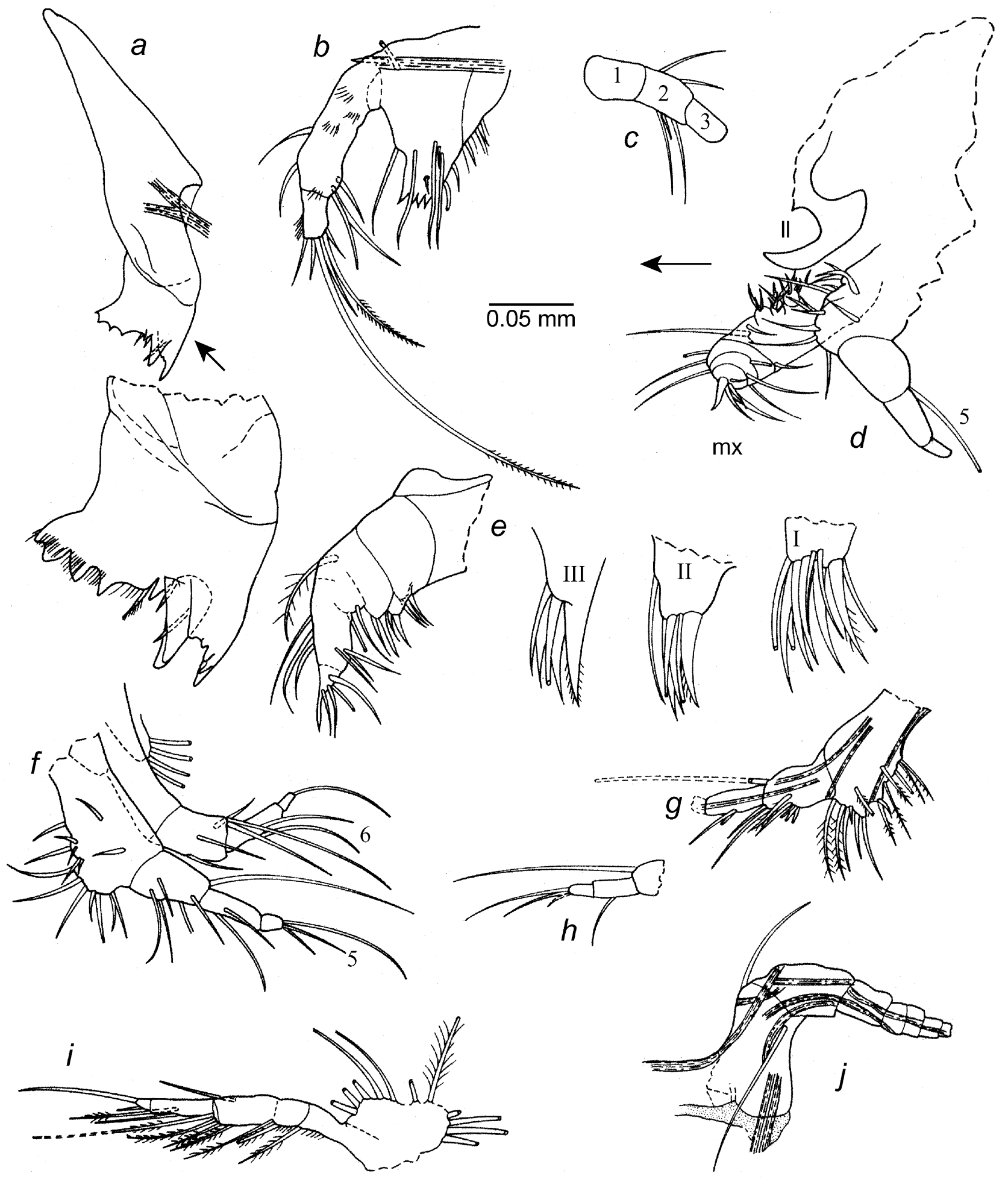

FIGURE 13. Danielopolina palmeri, new species, holotype USNM 1021375, adult female: $a$, coxa of left mandible, lv; $b$, basis and endopod of left mandible, lv; $c$, endopod of right mandible drawn on body, lv (nabs); $d$, right maxilla, right fifth limb (nabs), and left lower lip drawn on body; $e$, left maxilla (nabs) and endites; $f$, right fifth and sixth limbs drawn attached to body, mv; $g$, left fifth limb, mv; $h$, tip of right fifth limb, lv; $i$, left sixth limb, mv (not all bristles of epipod shown). Danielopolina exuma Kornicker \& Iliffe, USNM 194419, adult female: $j$, right first antenna showing some internal muscles, lv (nabs). Scale equals $0.05 \mathrm{~mm}$. 
Furca (Fig. 11c,d,f): Each lamella with 2 long articulated anterior claws and 3 short nonarticulated ventral claws; all claws with indistinct spines along posterior margin (spines not shown); claw 1 indistinctly ringed. Stout unpaired process on posterior of body just proximal to furca.

Bellonci Organ (Figs. 11f, 12a-c): Well defined, elongate, with rounded tip.

Lips (Fig. 12a, f): Anterior face of lip with 2 small processes; tip of upper lip with spines and small process. Lower lip with a triangular process at each side of mouth.

Posterior of body (Fig. 11f): With 9 or 10 short ridges along posterior edge.

Genitalia. None observed.

Eggs (Fig. 11f): With several unextruded eggs.

Gut content: Gut viewed through body filled with brown unidentified particles.

Protistan: Carapace with several elongate and round stemmed protistans along posterior margin (Fig. 11c). Similar protistans also present on dorsal margin of 1 st segment of left 1 st antenna.

Feeding: Endite I of maxilla anterior and projecting farther medially than endites II and III (Fig. 13d).

Remarks. The holotype is interpreted to be an adult female because of the presence of fairly large unextruded eggs. However, genitalia were not observed, so it could be an A-1 female. Paratype USNM 1021376 was not dissected in order not to fragment the ornamentation of the carapace. It is slightly smaller than the holotype, and no unextruded eggs were visible when the body was viewed through the valve, but the valve somewhat obscured the body. The furca has the same number of the claws as the holotype, and the endopod of the second antenna is similar to that of the holotype. The specimen is assumed to be an adult female, but it could be an A-1 female.

Comparisons. The ornamentation of the carapace of $D$. (H.) palmeri differs from that of $D$. (H.) exuma and $D$. (H.) orghidani in having spines at most intersections of reticulate walls and, in general, being more spinous. The carapace of $D$. (H.) palmeri differs from that of $D$. (H.) bahamensis and $D$. (H.) styx in having a posterodorsal elongate process on each valve. The seventh segment of the first antenna of $D$. (H.) palmeri is without the a-bristle, which is present on $D$. (H.) kakuki, D. (H.) styx, D. (H.) wilkensi, and D. (H.) bahamensis. The first endopod segment of the mandible of $D$. (H.) palmeri is without a dorsal bristle, which is present on D. (H.) bahamensis, D. (H.) orghidani, and D. (H.) kakuki. The furca of D. (H.) palmeri differs from that of $D$. (H.) elizabethae in having two articulated claws rather than one on each lamella.

\section{Danielopolina (H.) exuma Kornicker \& Iliffe 1998}

Fig. $13 j$

Danielopolina exuma Kornicker \& Iliffe 1998: 70: figs. 50-60.-2000: 86.

Holotype. USNM 194305, undissected adult female in alcohol.

Type locality. Norman's Pond Cave, Norman's Pond Cay, Lee Stocking Island, Exuma Cays, Great Bahama Bank.

Material. Norman's Pond Cave, Sta. 94-016: USNM 194419, partly dissected adult female paratype on slide and in alcohol. Basil Minn's Blue Hole, Sta 00-001, USNM 1021378, undissected adult male in alcohol; Sta 00-004, USNM 1021379, undissected adult female in alcohol, with large unextruded eggs.

Distribution. Great Bahama Bank: Lee Stocking Island, Exuma Cays: Norman's Pond Cay, (Norman's Pond Cave); Great Guana Cay (Oven Rock Cave); Great Exuma Island (Basil Minn's Blue Hole).

Remarks. Some appendages of a female paratype (USNM 194419) were examined to estimate their variability.

Supplementary description of adult female (Fig. 13j). Carapace size (mm): USNM 1021379, length with anterior process 0.60 , length excluding anterior process 0.54 , height 0.46 . 
First antenna: USNM 194419, 1st and 2nd segments forming right angle (Fig. 13j). Same as 1st antenna of adult female illustrated by Kornicker \& Iliffe (1998: fig. 51d,e).

Second antenna: USNM 194419, except for minute lateral spine-like bristle near dorsal margin of 2nd segment being barely visible using oil immersion objective, endopod similar to those of adult female illustrated by Kornicker \& Iliffe (1998: fig. 51g,h)

Mandible: USNM 194419, endite of basis with 4 lateral bristles (2 long, 2 short) on left limb and 5 on right limb (3 long, 2 short). (Right limb differs from basis of both left and right mandibles of adult female illustrated by Kornicker \& Iliffe (1998: fig. 51j,k) in having 3 instead of 2 long lateral bristles.)

Variability. Second antenna: 2nd endopod segment with minute lateral spine-like bristle near dorsal margin (indistinct on some specimens). Mandible: basis endite with 2 or 3 long lateral bristles.

Supplementary description of adult male. Carapace size (mm): USNM 1021378, length without anterior process 0.48 , height 0.44 .

Remarks. The species is reported for the first time in Basil Minn's Blue Hole.

\section{Subgenus Danielopolina Kornicker et al. 2006}

Type species. Danielopolina carolynae Kornicker \& Sohn 1976.

Diagnosis. Protopod of second antenna with posterior bristle.

Composition and distribution. This subgenus contains three species from anchialine inland habitats and one species from the deep sea: D. (D.) kornickeri Danielopol et al. 2000, Australia; D. (D.) phalanx Kornicker \& Iliffe 1995, Canary Islands; D. (D.) mexicana Kornicker \& Iliffe 1989b, Mexico; D. (D.) carolynae Kornicker \& Sohn 1976, South Atlantic.

\section{Danielopolina (D.) mexicana Kornicker \& Iliffe 1989}

Danielopolina mexicana Kornicker \& Iliffe 1989a: 15, figs. 1, 7, 8.—1998: 62, figs. 43-48.

Holotype. USNM 193312, female on slide and in alcohol.

Type locality. Cenote Maya Blue near Tulum, Quintana Roo, Yucatan Peninsula, Mexico.

Material. Temple of Doom Cenote, Tulum, Quintana Roo, Mexico, Sta 00-007: USNM 1021380, 1 undissected adult female in alcohol.

Distribution. Quintana Roo, Mexico: Cenote Maya Blue and Temple of Doom Cenote.

Correction. Kornicker \& Iliffe (1998: 62) in a "Material" paragraph incorrectly referred Sta 93-039 to Maya Blue Cenote. It should have been Temple of Doom Cenote, as it was listed in the "Appendix" (Kornicker \& Iliffe 1998: 90).

Supplementary description of adult female. Carapace size (mm): USNM 1021380, length with anterior process 0.87 , length excluding anterior process 0.81 , height 0.65 .

Remarks. Kornicker \& Iliffe (1998:90) reported the species to be in the Temple of Doom Cenote in July 1993. The present collection shows that the species continued to inhabit the cenote in July 2000, showing that it was not affected by climatic events occurring during intervening years.

\section{Superfamily Halocypridoidea Dana 1853}

Composition. This superfamily includes the families Deeveyidae Kornicker \& Iliffe 1985, and Halocyprididae Dana 1853. 


\section{Family Deeveyidae Kornicker \& Iliffe 1985, elevation from subfamily rank}

Deeveyinae Kornicker \& Iliffe 1985:476._Angel \& Iliffe 1987:543._Angel 1993:45.

Composition. This family contains the subfamilies Deeveyinae Kornicker \& Iliffe 1985 and Spelaeoeciinae, new subfamily.

\section{Subfamily Spelaeoeciinae, new subfamily}

Type genus: Spelaeoecia Angel \& Iliffe 1987.

Diagnosis. Carapace with rostrum. First antenna with 8 articles, article 1 without bristles, article 2 with 1 dorsal bristle. Endopod of adult male $2^{\text {nd }}$ antenna with clasper generally developed better on right limb. Sixth limb with lobe-like exopod bearing 5 bristles. Bellonci Organ bifid. Copulatory limb of male with two processes, posterior process with either narrow or broad tip.

Composition. At present this subfamily includes only the genus Spelaeoecia Angel \& Iliffe 1987. The great differences in the morphology of the carapaces of species of Spelaeocia and Deeveya are deemed sufficient evidence to require that each genus be referred to a different subfamily.

\section{Spelaeoecia Angel \& Iliffe 1987}

Spelaeoecia Angel \& Iliffe 1987:545, figs. 2-6.—Kornicker 1989:314.—Angel 1993:45.

Type species. Spelaeoecia bermudensis Angel \& Iliffe 1987.

Composition and distribution. The genus contains 11 species from anchialine inland habitats: Bahamas (seven species: S. barri Kornicker 1997 in Kornicker \& Barr 1997, S. parkeri Kornicker et al. 2002, S. hox n. sp., S. sagax Kornicker 1990 in Kornicker et al. 1990, S. capax Kornicker 1990 in Kornicker et al. 1990, S. styx Kornicker 1990 in Kornicker et al. 1990, S. parkeri Kornicker et al. 2002); Bermuda (one species: S. bermudensis Angel \& Iliffe 1987); Cuba (two species: S. saturno Kornicker \& Yager 2002, S. cubensis Kornicker \& Yager 1996); Jamaica (one species: S. jamaicensis Kornicker \& Iliffe 1992); Mexico (Yucatan Peninsula) (one species: S. mayan Kornicker \& Iliffe 1998). The distribution of the Bahamian species is presented in Table 2 and Fig. 6.

Identification of growth stages. Instars A-5 to A-1 are known in the genus, but the A-5 instar is known for only S. styx (Table 7). The numbers of claws and bristles on the lamellae of the furca differ on species and also increase on later growth stages of the same species; therefore, they are useful for identifying species and growth stages (Table 7).

\section{Spelaeoecia styx Kornicker 1990 in Kornicker et al. 1990}

Spelaeoecia styx Kornicker 1990 in Kornicker et al. 1990: 6, figs. 2-8.—Kornicker \& Iliffe 1998: 26, figs. 17-29.— 2000: 85.-Kornicker et al. 2002: 23, figs. 14, 15.

Spelaeoecia exleyi Kornicker \& Iliffe 1998: Table 6 (typographical error, should have been Spelaeoecia styx).

Holotype. USNM 194270, undissected adult male in alcohol.

Type locality. El Dorado Cave, South Andros Island, Great Bahama Bank. 
TABLE 7. Number of claws and bristles on each lamella of caudal furca of growth stages of species of Spelaeoecia and Deeveya (if growth stage is uncertain, number is italicized). ( $\mathrm{F}=$ female, $\mathrm{M}=$ male, - = growth stage unknown.)

\begin{tabular}{|c|c|c|c|c|c|c|c|}
\hline & \multicolumn{7}{|c|}{ Growth Stages } \\
\hline & A-5 & A-4 & A-3 & A-2 & A-1 & Adult $\mathrm{F}$ & Adult M \\
\hline \multicolumn{8}{|l|}{ Spelaeoecia } \\
\hline S. barri & - & 4 & 5 & 6 & 7 & 8 & 8 \\
\hline S. bermudensis & - & - & - & - & 7 & 7 & 7 \\
\hline S. capax & - & 4 & 5 & 6 & 7 & 8 & 8 \\
\hline S. cubensis & - & 4 & - & - & 5 & 5 & 5 \\
\hline S. hox & - & - & - & - & 6 & 6 & $6-7$ \\
\hline S. jamaicensis & - & - & - & - & 6 & - & - \\
\hline S. mayan & - & - & - & - & - & 6 & 6 \\
\hline S. parkeri & - & - & - & - & - & 7 & - \\
\hline S. sagax & - & - & - & 6 & 7 & 8 & 8 \\
\hline S. saturno & - & - & - & - & 7 & 8 & - \\
\hline S. styx & 3 & 4 & 5 & 6 & 7 & 7 & 7 \\
\hline \multicolumn{8}{|l|}{ Deeveya } \\
\hline D. bransoni & 3 & 4 & 5 & 6 & 7 & 7 & 7 \\
\hline D. exleyi & - & 4 & - & - & - & 7 & - \\
\hline D. hirpex & - & - & - & - & 7 & - & - \\
\hline D. jillae & - & 4 & - & 6 & - & - & - \\
\hline D. medix & - & - & - & - & - & 7 & 7 \\
\hline D. spiralis & - & - & - & - & - & 7 & - \\
\hline D. styrax & - & - & - & - & - & 7 & 7 \\
\hline
\end{tabular}

Material. Sanctuary Blue Hole, Sta 99-061: USNM 1021381, 1 adult female in alcohol); USNM 1021382, 6 adult females, 8 adult males, all in alcohol; USNM 1021382 (1 A-1 male, 1 A-1 instar, 1 A-4 instar and 1 A-5 instar, all in alcohol)).

Distribution. Great Bahama Bank: Exuma Cays: Norman's Pond Cay (Norman's Pond Cave); Great Guana Cay (Oven Rock Cave). South Andros Island (El Dorado Cave, Stargate Blue Hole, and Sanctuary Blue Hole).

Supplementary description of adult male. Carapace size (length, height in mm): USNM 1021382, 7 specimens: $1.04,0.52 ; 1.00,0.59 ; 1.04,0.58 ; 1.04,0.53 ; 1.03,0.55 ; 1.04,0.56 ; 1.02,0.60$.

Ornamentation: Carapace with distinct reticulations.

Furca. Each lamella with 7 claws.

Supplementary description of adult female. Carapace size (length, height in mm): USNM 1021382, 6 specimens: $1.02,0.50 ; 0.98,0.47 ; 1.02,0.51 ; 1.00,0.49 ; 0.99,0.56 ; 0.99$ (length only).

Ornamentation: Distinct reticulations.

Furca: Each lamella with 7 claws.

Supplementary description of A-1 instar. Carapace size (length, height in mm): USNM 1021383, 2 specimens: $0.83,0.42$ (male); 0.82, 0.43 (sex unknown).

Ornamentation: With distinct reticulations.

Furca: Each lamella with 7 claws.

Copulatory organ: Male not dissected but slender lobe with 3 short terminal bristles observed on specimen; lobe medial to 5th and sixth limbs. 
Supplementary description of A-4 instar (sex unknown). Carapace size (length, height in mm): USNM 10213783: 0.47, 0.28.

Ornamentation: Carapace with distinct reticulation.

Sixth limb: Present, but not reaching past 5th limb.

Seventh limb: Absent.

Furca: Each lamella with 4 claws followed by small triangular process (incipient 5 th claw).

Supplementary description of A-5 instar (sex unknown). Carapace size (length, height in $\mathrm{mm}$ ): USNM 10213783: 0.37, 0.23 .

Ornamentation: Carapace with distinct reticulations.

Sixth and Seventh limbs: Absent.

Furca: Each lamella with 3 claws followed by small triangular process (incipient 4th claw).

Remarks. This is the first report of the species in Sanctuary Blue Hole.

Correction. Kornicker \& Iliffe (1998: Table 6) listed Spelaeoecia exleyi Kornicker \& Iliffe 1998 [nomen nudum]. It should have read Spelaeoecia styx 1990 in Kornicker et al. 1990.

\section{Spelaeoecia capax Kornicker 1990 in Kornicker et al. 1990}

Spelaeoecia capax Kornicker 1990 in Kornicker et al. 1990: 23, fig. 14.—Kornicker \& Iliffe 1998: 10, figs. 3a, 4-16.2000: 85 .

Holotype. USNM 193449, empty carapace in alcohol (sex and age unknown).

Type locality. Alfonso Dean Blue Hole, Long Island, Great Bahama Bank.

Material. Oven Rock Cave, Great Guana Cay: Sta 98-010: USNM 1021384, 7 specimens in alcohol (3 adult males, 3 adult females, 1 juvenile). Sta 98-012: USNM 1021385, 3 specimens in alcohol (1 adult male, 1 adult female, 1 A-1 male). Sta 98-014: USNM 1021386, 1 adult female in alcohol. Sta 99-066: USNM 1021387, 1 adult male in alcohol; USNM 1021388, 2 adult females in alcohol. Sta 00-005: USNM 1021389, 6 specimens ( 2 adult males, 3 adult females, 1 juvenile). Sta 01-013: USNM 1021390, 8 specimens including adult males.

Distribution. Great Bahama Bank: Exuma Cays: Great Guana Cay (Oven Rock Cave) and Lee Stocking Island, Norman's Pond Cay (Norman's Pond Cave). Long Island (Alphonso Dean Blue Hole).

Supplementary descriptions. Carapace size (length, height in mm): Adult male: USNM 1021418, 2.88, 1.33. Adult female:

USNM 1021387, 2 specimens: 2.90, 1.38; 3.05, 1.38. USNM 1021389, 2 specimens: 3.08, 1.41; 3.01, 1.44 .

Remarks. This species was previously reported in Oven Rock Cave in 1993 (Kornicker \& Iliffe 1998: 90, 91) and 1996 (Kornicker \& Iliffe 2000: 93). The present collection shows that the species continued to be in the cave from 1993 to 2000 and was not affected by climatic events.

\section{Spelaeoecia parkeri Kornicker et al. 2002}

Figs. 14-17

Spelaeoecia parkeri Kornicker et al. 2002: 26, figs. 16-21.

Holotype. USNM 194600, female.

Type locality. Mermaid's Lair, Grand Bahama Island, Little Bahama Bank.

Material. Type locality: Sta. 98-038: USNM 1021391, one adult male on slide and in alcohol; USNM 
1021392, one adult female in alcohol. Sta 98-039: USNM 1021393, one adult female in alcohol. Sta 01-018, USNM 1021394, one specimen. Lucy's Cave, Sweeting's Cay, Grand Bahama Island, Little Bahama Bank, Sta 01-017: USNM 1021395, one adult male, one juvenile, both in alcohol.
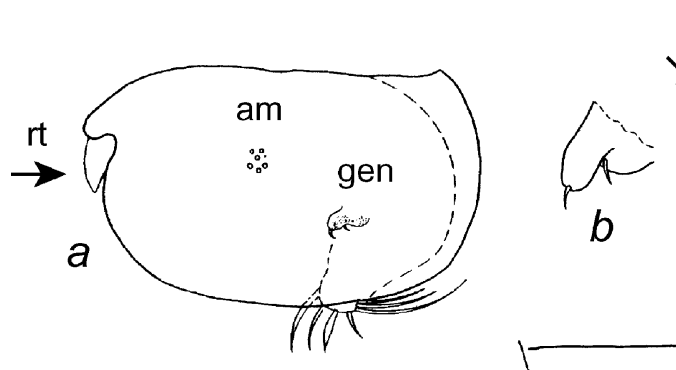

rt.
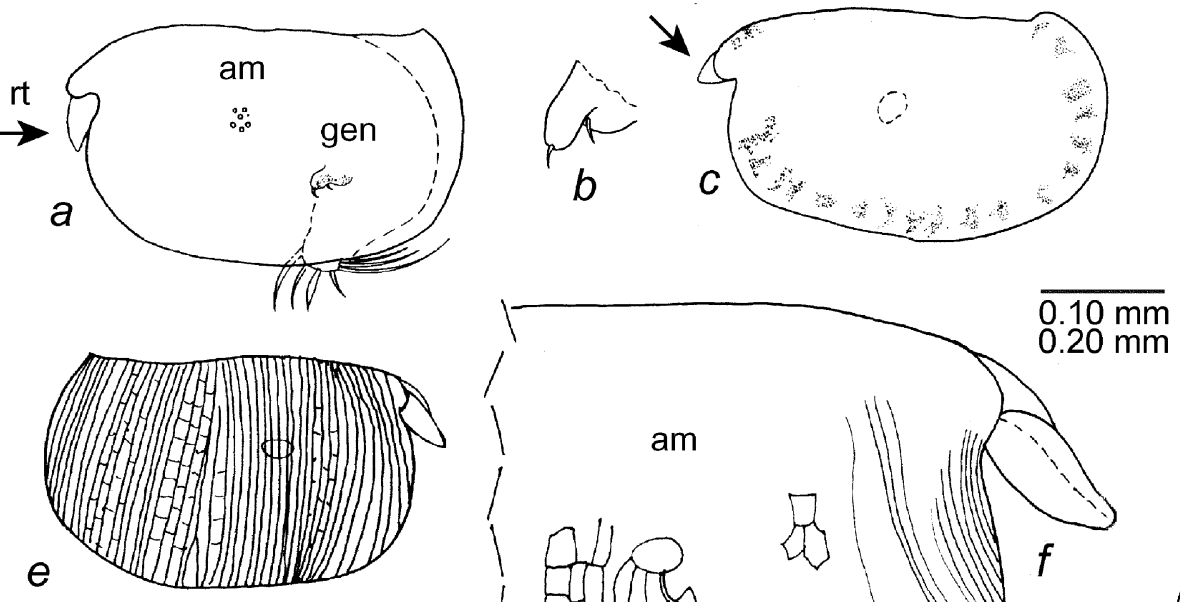

am
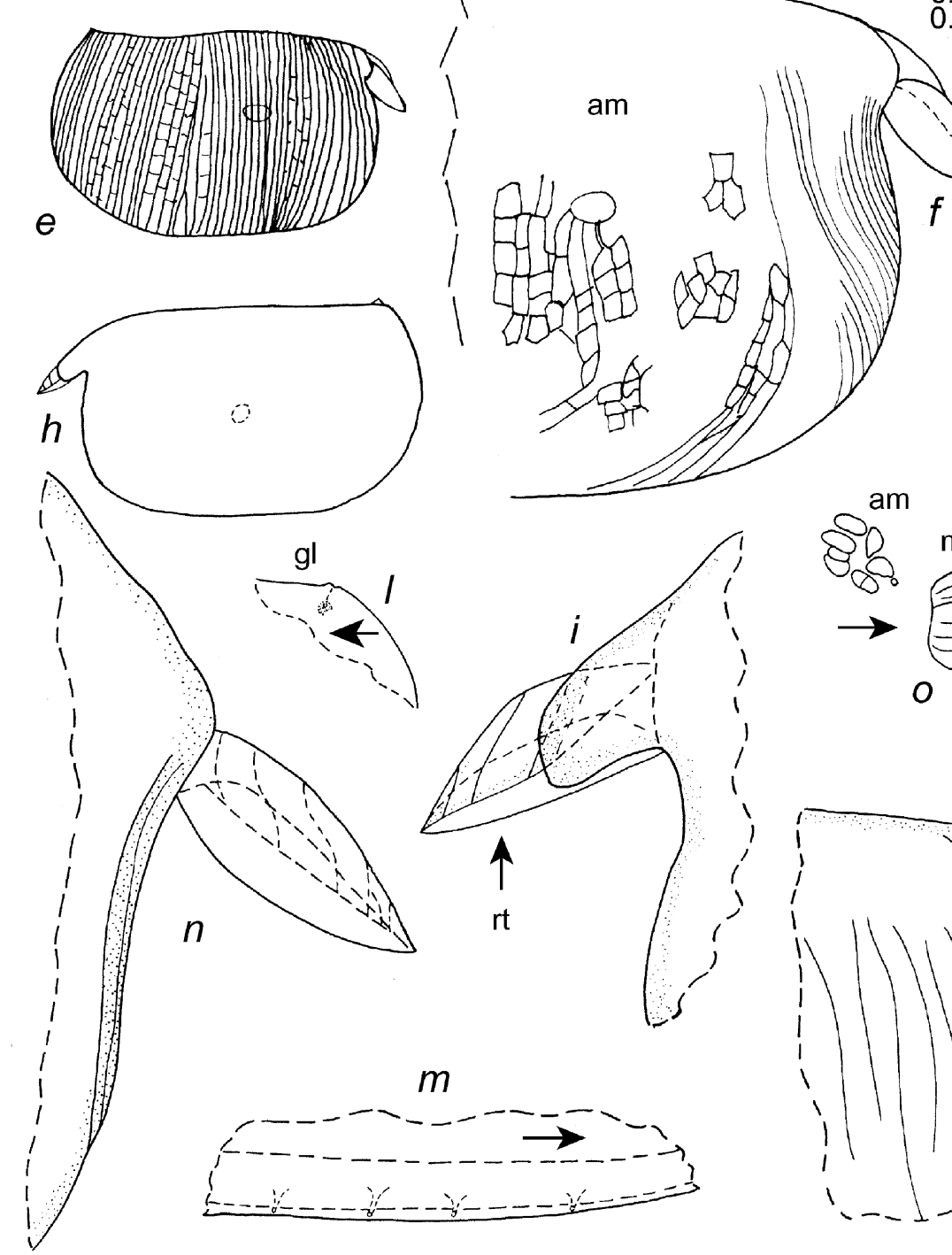

$0.20 \mathrm{~mm}$
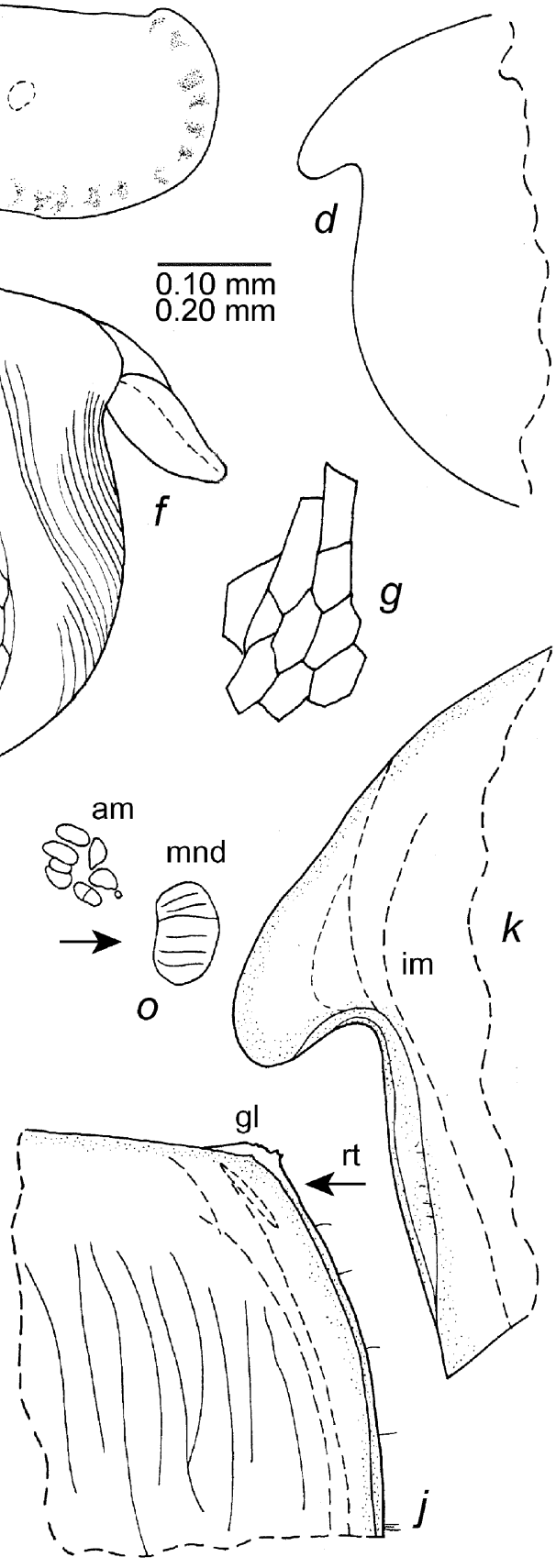

FIGURE 14. Spelaeoecia parkeri Kornicker et al. 2002, USNM 1021392, adult female: $a$, complete specimen from left side, showing adductor muscle attachments, projecting furca, and genitalia as seen through valve, length $1.58 \mathrm{~mm}$, height $0.93 \mathrm{~mm} ; b$, detail of genitalia as seen through valve. USNM 1021393, adult female: $c$, complete specimen from left side, showing glandular processes along edge, length $1.66 \mathrm{~mm}$, height $0.89 \mathrm{~mm} ; d$, outline of anterior of left valve, ov; $e$, complete specimen from right side showing surface striae and reticulations; $f$, detail from " $e$ "; $g$, detail of reticulations in " $f$ ". Adult male, USNM 1021391: $h$, complete specimen from left side, length $1.74 \mathrm{~mm}$, height $0.93 \mathrm{~mm} ; i$, detail of anterior from " $h " ; j$, detail of posterior from " $h " ; k$, detail of anterior of left valve from " $i " ; l$, detail of posterodorsal corner of left valve showing gland, from " $j " ; m$, detail of ventral edge of right valve showing glandular openings, $1 \mathrm{v} ; n$, anterior of right valve, lv; $o$, central adductor muscle scars and mandibular scar of right valve, lv. Scale equals $0.20 \mathrm{~mm}(d, f)$, and 0.10 $\mathrm{mm}(b, g, i-o)$. 


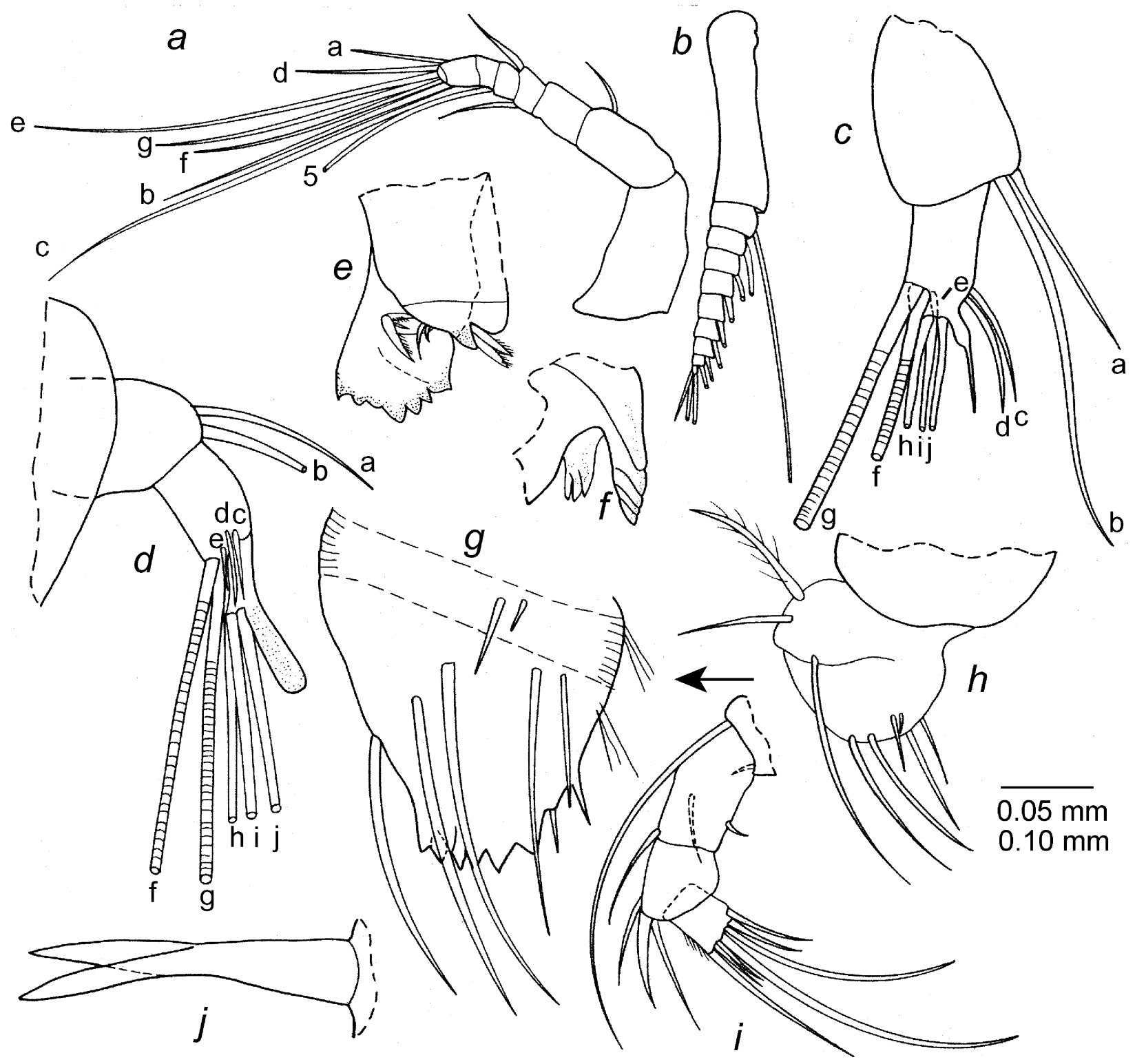

FIGURE 15. Spelaeoecia parkeri Kornicker et al. 2002, USNM 1021391, adult male: a, left first antenna drawn on body, lv; $b$, exopod left second antenna drawn on body, mv; $c$, endopod left second antenna, mv; $d$, endopod right second antenna, lv; $e$, tip coxa of right mandible; $f$, part tip of coxa of left mandible; $g$, tip of basis of left mandible under cover slip, lv; $h$, basis of left mandible drawn on body, lv; $i$, part of basis and endopod of left mandible drawn on body, lv; $j$, Bellonci Organ. Scale equals $0.10 \mathrm{~mm}(a, b, h, i)$, and $0.05 \mathrm{~mm}(c-g, j)$.

Distribution. Little Bahama Bank, Grand Bahama Island, Sweeting's Cay: Mermaid's Lair, depth 17-22 m, and Lucy's Cave, depth 18-25 m.

Discussion. The collection described by Kornicker et al. (2002: 26) contained one female and one early instar. The early instar was referred to $S$. parkeri. Additional specimens of Spelaeoecia collected at the type locality reveal that two species of the genus live in the cave. The early instar has a divided Bellonci Organ with pointed tips indicating that it is indeed S. parkeri, and not the second species, which is described herein as Spelaeoecia hox, and has a divided Bellonci Organ with rounded tips. The female holotype in the original description was questionably identified as an adult. Comparison with adult females in the present collection shows that the holotype is an adult.

In describing the holotype Kornicker et al. (2002: 26) stated, "rostrum of right valve of holotype twisted and appearing falsely as having a pointed tip (Fig. 16a,f)." The additional specimens in the present collection 
show that the pointed tip of the rostrum of the right valve is not false. A second species having a pointed tip on the rostrum of the right valve is Spelaeoecia saturna Kornicker \& Yager 2002.

Supplementary description of adult female (Fig. 14a-g). Glandular masses of minute cells visible from outside of valve just within free margins (Fig. 14c). Posterodorsal corner of right valve with minute bristle in area of projecting glandular process.

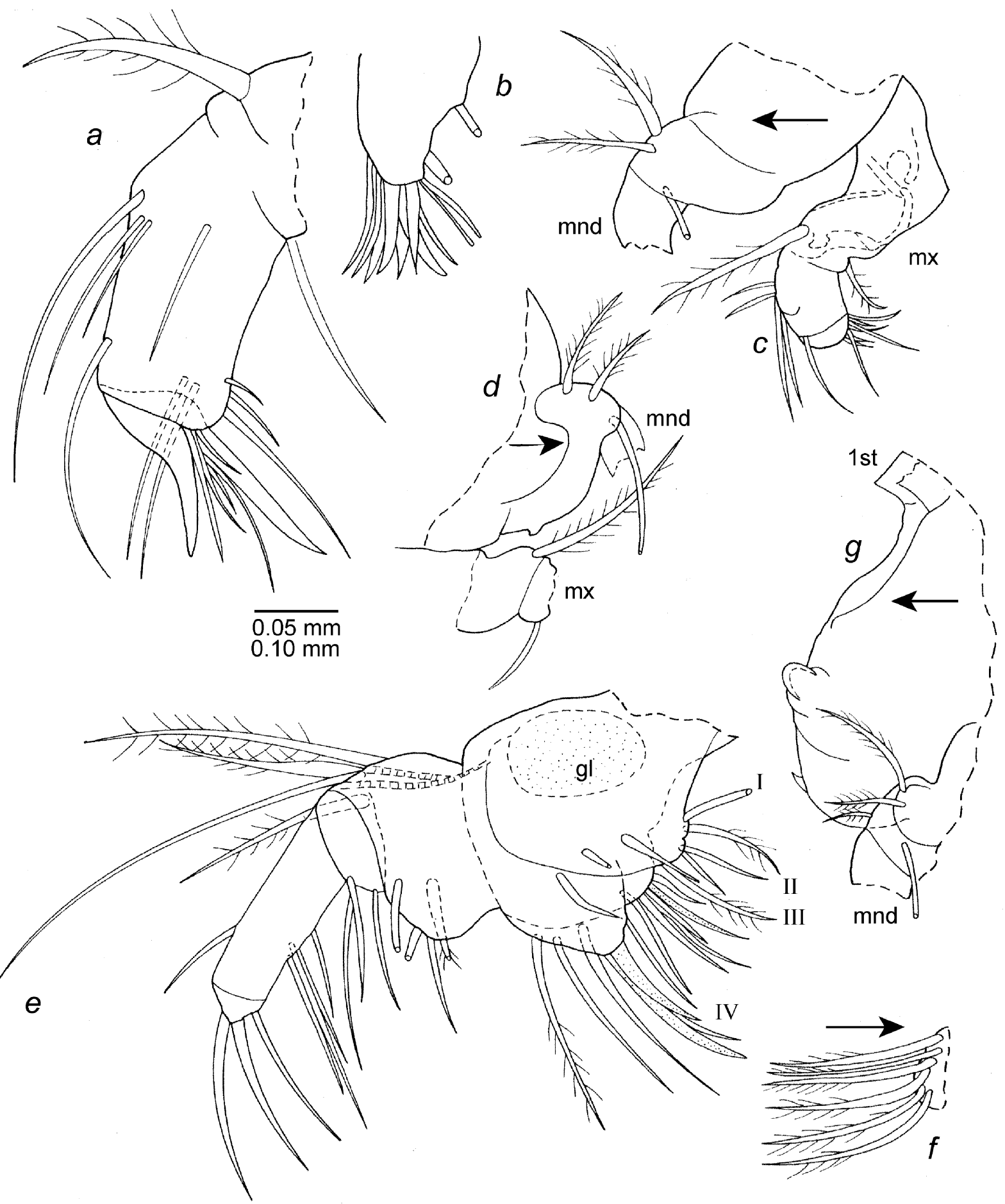

FIGURE 16. Spelaeoecia parkeri Kornicker et al. 2002, USNM 1021391, adult male: $a$, part right maxilla, mv; $b$, endite I right maxilla, mv; $c$, left mandible and maxilla drawn on body, lv; $d$, part right mandible and maxilla attached to body; $e$, left fifth limb, mv; $f$, middle group of epipod bristles of right fifth limb drawn on body, lv; $g$, anterior of body showing part of first antennae and left mandible. Scale equals $0.05 \mathrm{~mm}(a, b, e)$ and $0.10 \mathrm{~mm}(c, d, e)$. 


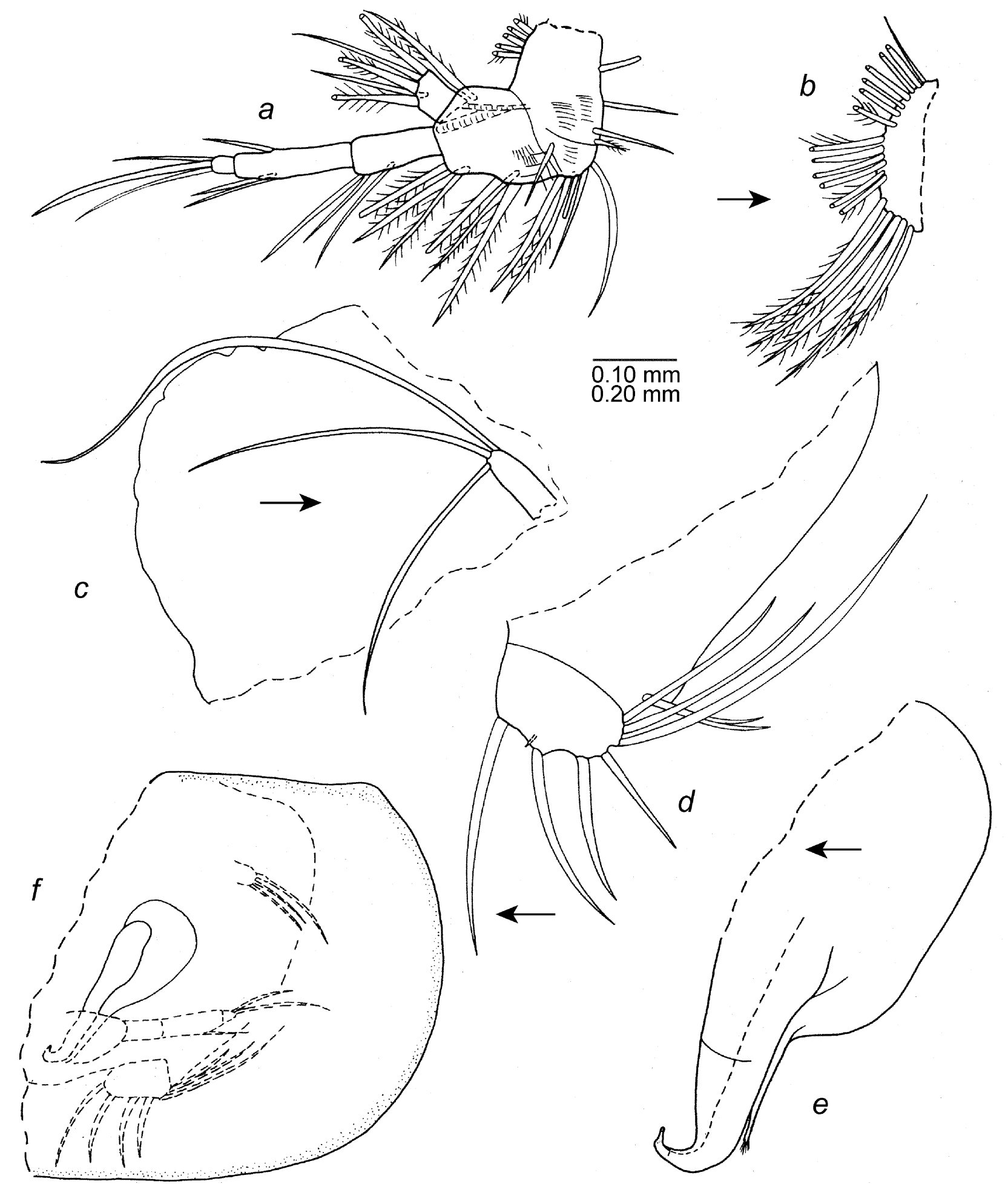

FIGURE 17. Spelaeoecia parkeri Kornicker et al. 2002, USNM 1021391, adult male: $a$, left sixth limb, mv; $b$, epipod right sixth limb drawn on body; $c$, posterior of body and right seventh limb; $d$, posterior of body and left lamella of furca; $e$, copulatory organ; $f$, posterior of body seen through left valve showing copulatory organ, furca, left sixth and seventh limbs. $0.10 \mathrm{~mm}(c, d, e)$ and $0.20 \mathrm{~mm}(f)$.

Ornamentation (Fig. 14e-g): Surface of valves with vertical lineations with some short connecting lineations.

Carapace size (length, height in mm): USNM 1021393, 1.66, 0.89; USNM 1021392, 1.58, 0.93.

Second antenna: With exopod withdrawn inside carapace, distal part of endopod lies lateral to exopod. 
Bellonci Organ: Elongate, bifurcate with pointed tips on branches. (Similar to that of adult male illustrated herein in Fig. 15j).

Genitalia (Fig. 14a,b): Small lobe with terminal bristle anterior to minute bristle.

Description of adult male (Fig. 14h-o, 15-17). Carapace (Fig. 14h-o) similar to that of adult female (Fig. 14a-g).

Central adductor muscle attachments (Fig. 14o): Consisting of about 8 ovoid attachments posterior to large mandibular attachment scar.

Shell glands: Posterodorsal corner of each valve with glandular openings (that of left valve minute) (Fig. $14 j, l$ ). Free margin with small glandular processes along inner edge of valves (Fig. 14m).

Carapace size (length, height in mm): USNM 1021391, 1.74, 0.93.

First antenna (Fig. 15a): Similar to that of adult female except spines not observed on segments or bristles.

Second antenna: Protopod and exopod (Fig. 15b) similar to those of adult female. Endopod with 3 segments: 1st segment with dorsal a- and b-bristles; 2nd segment with 2 terminal f- and g-bristles (g-bristle medial and longer and stouter than f-bristle), 2 slender lateral c- and d-bristles, and 1 smaller lateral e-bristle near base of f-bristle; 3rd segment with equilength h-, i-, and j-bristles; clasper of right limb stout with blunt tip (Fig. 15d); clasper of left limb shorter with long terminal bristle-like spine (Fig. 15c). With exopod withdrawn, distal part of endopod lies lateral to exopod.

Mandible (Figs. 15e-i, 16c, d,g): Only 2 instead of 3 spinous dorsal bristles observed on basis. Limb otherwise similar to that of adult female. Plumose bristles near dorsal margin of basis project anteriorly when mandible in natural position on body (Fig. 16c,d,g).

Maxilla (Fig. 16a-d): Similar to that of adult female. Plumose bristles on dorsal margin of basis projects anteriorly when maxilla in natural position on body (Fig. 16c,d).

Fifth limb (Fig. 16e,f): Epipod with plumose bristles forming 3 groups (ventral and dorsal groups each with 5 bristles, middle group with 6 bristles (Fig. 16f). Protopod interpreted to have 4 endites (because endite sutures are poorly defined, number of bristles on a particular endite approximate); endite I with 2 ventral bristles; endite II with 4 bristles ( 2 ventral, 2 farther from ventral margin); endite III with 6 bristles (1 claw-like); endite IV with 9 bristles ( 2 claw-like); 21 total endite bristles; protopod with oval internal mass of cells questionably interpreted as gland. Basis: ventral margin divided into broad proximal part and narrow distal part; broad proximal part with 3 slender bristles on or near ventral margin and 1 plumose lateral bristle set back from ventral margin; narrow distal part with 3 slender ventral bristles and 1 lateral plumose bristle near dorsal margin. Exopod represented by 3 distal dorsal bristles (longest bare, others plumose). Endopod: 1st segment with 1 distal dorsal bristle and 4 ventral bristle near midlength; 2nd segment with 2 stout claw-like bristles and 1 slender ringed ventral bristle.

Sixth limb (Fig. 17a,b,f): Epipod with plumose bristles forming 3 groups (ventral group with 5 bristles, middle group with 6 bristles, dorsal group with 7 bristles including 1 short dorsal). Proximal protopod separated from basis by suture and divided by suture into 2 parts interpreted to be precoxa and coxa, both with long medial hairs: precoxa with 4 bristles; coxa with 5 or 6 bristles. Basis with long proximal medial hairs near ventral margin and 7 plumose bristles (6 on or near ventral margin, 1 distal lateral near dorsal margin). Exopod well developed, lateral to endopod, with 5 bristles (3 long plumose, 2 shorter bare). Endopod 3-segmented: 1 st segment with 3 ventral bristles; 2 nd segment with 3 bristles ( 2 ventral, 1 dorsal); 3rd segment with 3 long bare terminal bristles (middle bristle longer than others and claw-like), other bristles slender, ringed).

Seventh limb (Fig. 17c,f): Elongate with 3 terminal bristles (1 longer than others).

Furca (Fig. 17d,f): Each lamella with 4 claws followed by 3 bristles (anterior of these very long); minute teeth observed along posterior edges of claws 1 and 2. Minute glandular process present between claws 1 and 2 (closer to claw 2). Long bifurcate unpaired bristle following lamellae.

Bellonci Organ (Fig. 15j): Elongate, bifurcate with pointed tips extending past 1st segment of 1st antennae. 
Lips: Similar to those of adult female. Profile of anterior part of upper lip shown in Fig. $16 \mathrm{~g}$.

Genitalia (Fig. 17e,f): Copulatory organ on left side of body medial to left sixth limb and lateral to furca. Tip of anterior branch with tubular upturned tip. Posterior branch with narrow tip bearing hairs.

Behavior. Each exopod of the second antennae of two females and one male in the collection is withdrawn inside the carapace, and the distal part of each endopod is located lateral to the exopod. This suggests that the endopod flairs outward when the exopod is withdrawn inside the carapace.

Remarks. This species was reported in Mermaid's Lair in 1997 (Kornicker et al. 2002: 26). The present collection shows that it continued to inhabit the cave in 1998. The species is reported for the first time in Lucy's Cave.

\section{Spelaeoecia bermudensis Angel \& Iliffe 1987}

Figs. 18, 19, Tab. 4

Spelaeoecia bermudensis Angel \& Iliffe 1987:545, figs. 2-6.—Kornicker \& Iliffe 1989a: 46, fig. 29.—Kornicker 1989: 314, figs. 1-5.

Type locality. Green Bay Cave, Bermuda.

Material. Bermuda Aquarium saltwater well, Flatts, Bermuda: 2 adult females with unextruded eggs: USNM 1021396, USNM 1021397, both in alcohol.

Holotype. USNM 228468, adult female on five slides.

Distribution. Widespread in Bermudan caves (see Kornicker \& Iliffe 1989a:46). Reported herein for the first time from a saltwater well at the Bermuda Aquarium.

Supplementary description of adult female (Figs. 18, 19). Carapace size (length, height in mm) (Fig. 18a): USNM 1021396, 1.55, 0.86; USNM 1021397, 1.47, 0.87.

Infold: Right valve posterodorsal corner with undulate dorsal margin with minute bristle and large gland (Fig. $18 b, c)$ : Left valve posterodorsal corner with minute separation (pore?) and indistinct internal process, possibly glandular, leading to it (Fig. 18d). Dorsal end of posterior list of each valve thick, sclerotized (Fig. 18c-e).

Sixth limb (Fig. 19a, c): Protopod near distal end of epipod with small thumb-like process containing minute globules appearing to project from lateral side of limb.

Seventh limb (Figs. 18e,f; 19a,b,d): With 3 bristles.

Furca. USNM 1021397 with 7 claws on right lamella (Fig. 18e) and 8 on left.

Eggs (Figs. 18e,f, 19a,b,d,e): USNM 1021397 with 9 unextruded eggs of various sizes. USNM 1021396 with 12 unextruded eggs of various sizes:

Sclerite: Comma shaped sclerite within body dorsal to furca (striated and ventral to sperm in Fig. 19d).

Discussion of eggs. Eggs within the ovaries of the two adult females of $S$. bermudensis studied herein differ considerably in diameter (Table 4; Figs. 18e,f, 19a,e). Presumably, the large eggs were deposited in the ovary prior to the small eggs, and each egg is oviposited when it reaches a certain developmental stage. The percentage increase in diameter of consecutive eggs based on diameter vary from $0 \%$ to $105 \%$. (Table 4). This great difference suggests that either the eggs spurt in growth at different stages or, more likely, that intervals of time separate clutches of eggs, which permit the eggs already formed to grow substantially prior to formation of the following clutch. The eggs in both specimens increased considerably in diameter after reaching about 60 microns. In Table 4, the eggs are grouped into clutches separated on the bases of an arbitrary percentage of more than a $15 \%$ increase in diameter between consecutive eggs. The arbitrary division suggests clutches of one to four eggs. 

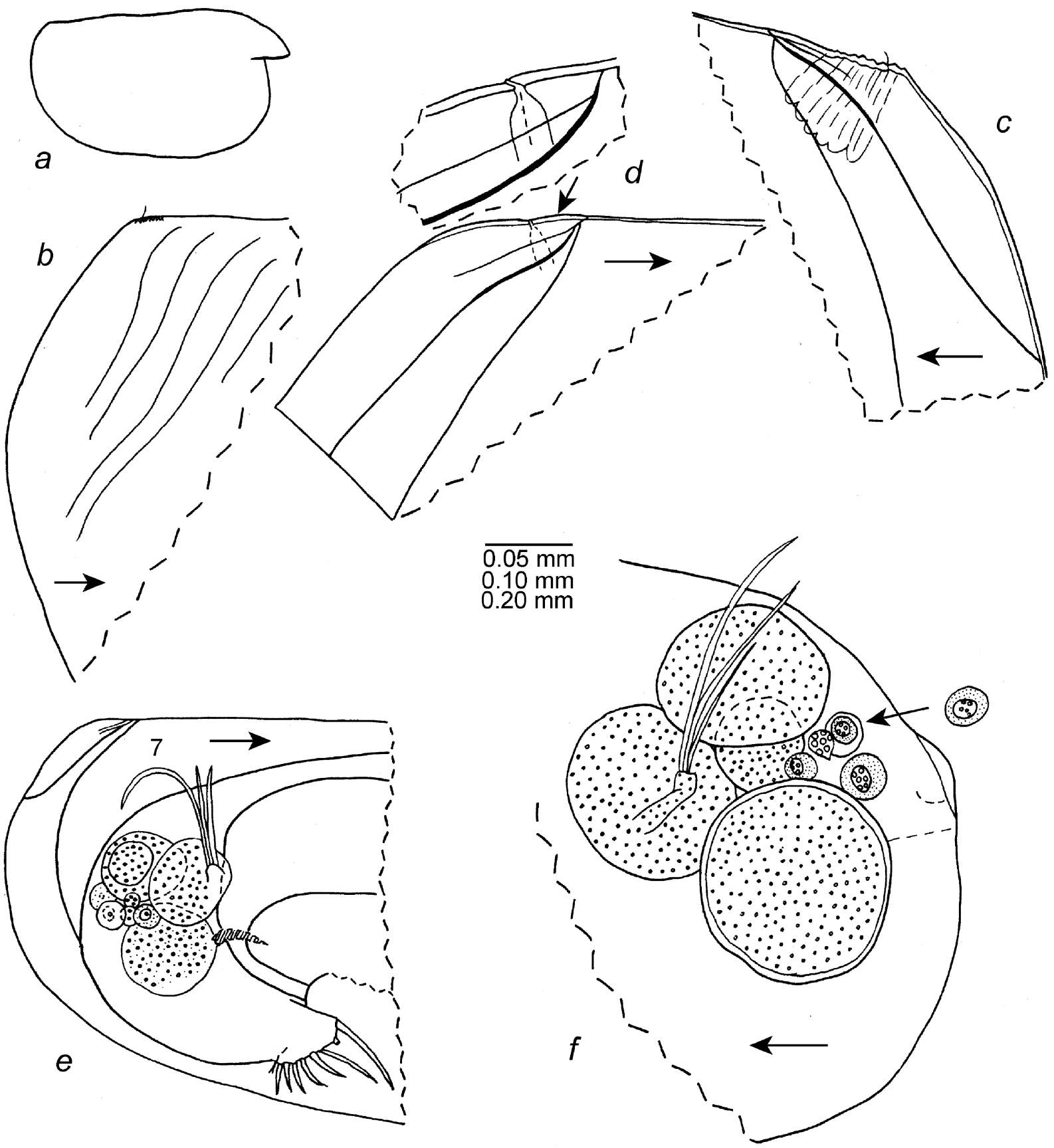

FIGURE 18. Spelaeoecia bermudensis Angel \& Iliffe1987, adult female: USNM 1021397: a, complete specimen from right side, length $1.47 \mathrm{~mm}$; $b$, detail of posterior of complete specimen, from " $a$ "; $c$, inside of posterior dorsal corner of right valve; $d$, inside of posterodorsal corner of left valve; $e$, posterior of body in left valve (right valve removed); $f$, left seventh limb and eggs within body. Scale equals $0.10 \mathrm{~mm}(b, f), 0.05 \mathrm{~mm}(c, d), 60 \mathrm{x}(d)$, and $0.20 \mathrm{~mm}(e)$.

\section{Spelaeoecia hox, new species}

Figs. 20-24

Etymology. Species named for the selector Hox gene.

Holotype. USNM 1021398, adult male on slide and in alcohol.

Type locality. Mermaid's Lair, Grand Bahama Island, Little Bahama Bank, Sta 98-038.

Paratypes. Type locality. Sta 98-038: USNM 1021399, A-1 male in alcohol. Sta 98-039: USNM 1021401, two adult females in alcohol. 


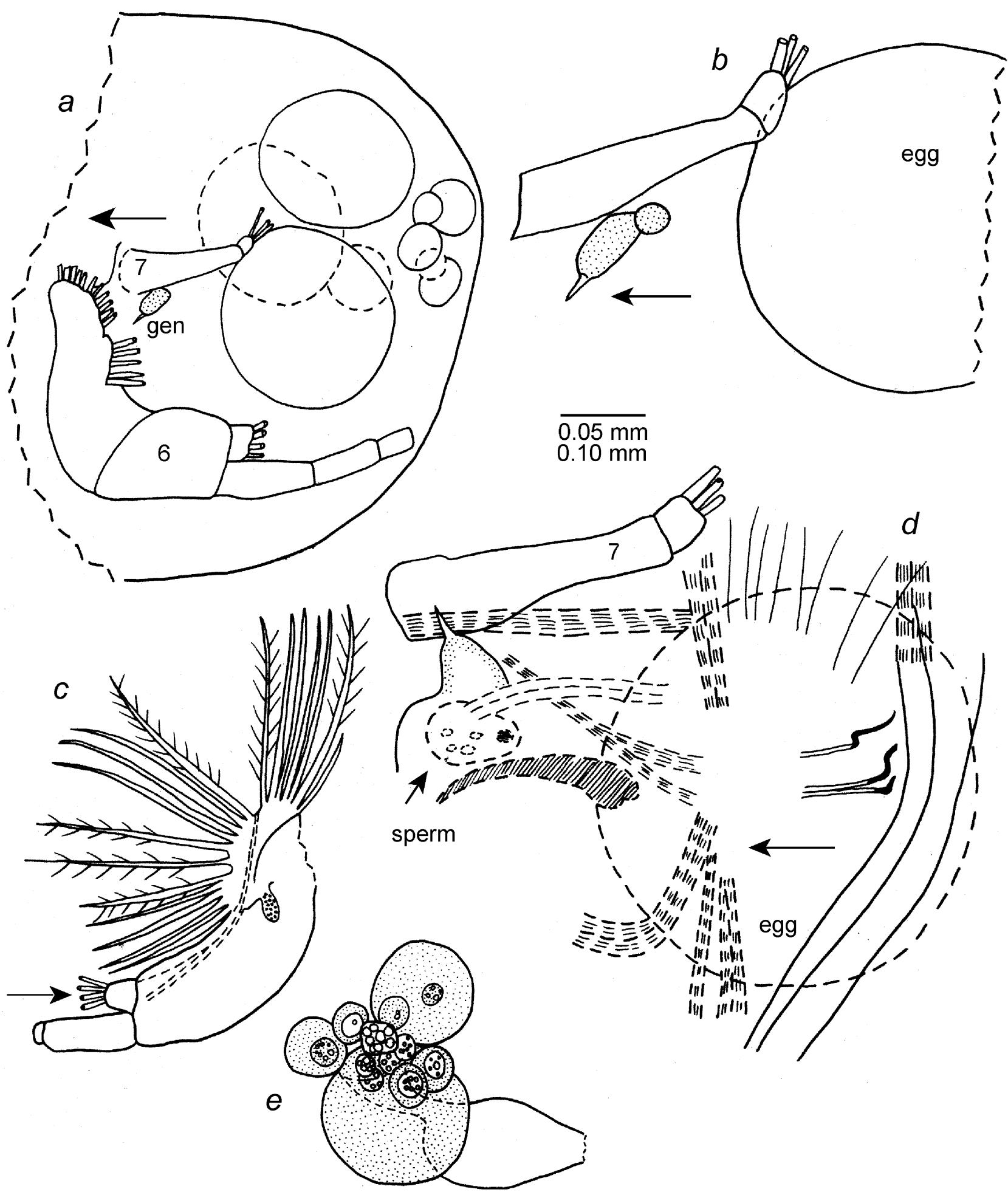

FIGURE 19. Spelaeoecia bermudensis Angel \& Iliffe 1987, adult female: USNM 1021397: $a$, posterior of body showing left sixth limb, left seventh limb, left genitalia, and 9 eggs; $b$, detail from " $a$ "; $c$, right sixth limb, lv; $d$, detail from "a" in slightly different orientation showing muscles and comma-shaped sclerite (wavy filled-in lines may be gonopore). USNM 1021396, adult female: $e$, eggs removed from body. Scale equals $0.10 \mathrm{~mm}(a, c, e), 0.05 \mathrm{~mm}(b, d)$.

Distribution. Little Bahama Bank, Grand Bahama Island (Mermaid's Lair, depth 17-22 m).

Description of adult male (Figs. 20-24a-f). Carapace elongate with rounded rostrum of same length on each valve, and rounded posterior margin (Fig. 20). 
Ornamentation: None visible on preserved specimens, but each valve with numerous minute pores (some shown in Fig. 20). Holotype with round clusters of cells scattered on shell and along free margins of valves (Fig. 20). Indistinct slender bristles present along valve margins. Posterodorsal corner of right valve with elongate bar (Fig. 21c,d) opposite indistinct socket on left valve (Fig. 21b).

Shell glands: Posterior end of dorsal margin of right valve minutely serrate and with internal gland visible through valve (Fig. 21c,d). Posterior end of left valve with single gland (Fig. 21b). Glandular pore canals present along inner edge of anteroventral, ventral, and posterior margins (Fig. 20).

Infold: Broad infold without lists along free margin (Figs. 20, 21b-d).

Central adductor muscle attachments: Consisting of about 11 ovoid attachment scars. Location shown by dashed oval in Fig. 20.

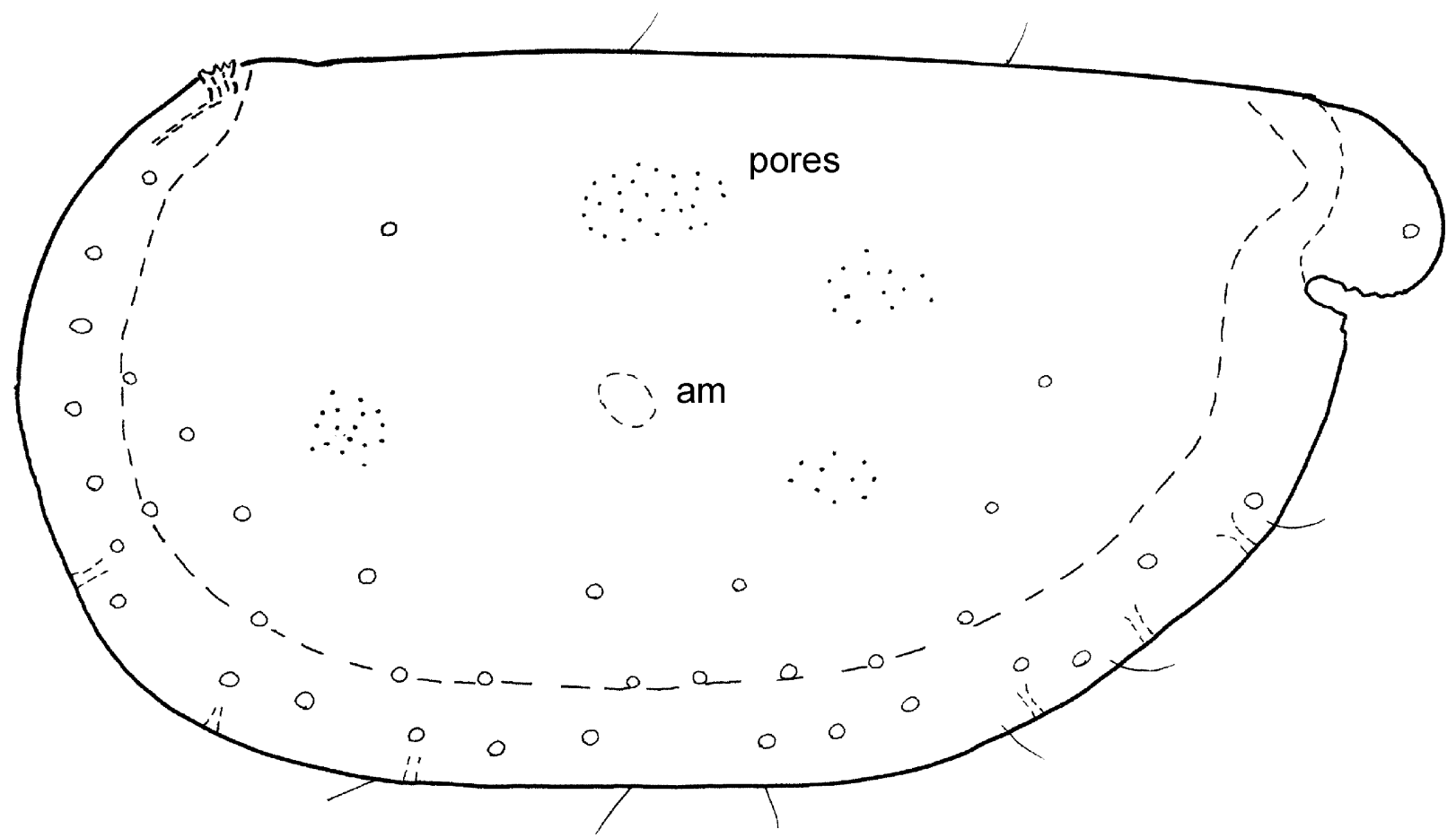

FIGURE 20. Spelaeoecia hox, new species, holotype USNM 1021398 adult male carapace from right side, length 1.07 $\mathrm{mm}$. Open circles are clusters of cells scattered on shell and along free margins of valves.

Carapace size (length, height in mm): USNM 1021398, 1.07, 0.54.

First antenna (Fig. 21e,f): 1st segment with distal ventral spines. 2nd segment with distal dorsal bristle. 3rd segment with long distal ventral bristle. 4th segment with slender dorsal bristle and long stout filamentlike terminal ventral bristle. 5th segment with long filament-like terminal ventral bristle. sixth segment bare. 7th segment with slender a-bristle, long filament-like b-bristle, and longer filament-like c-bristle. 8th segment with long filament-like d-, e-, f-, and g-bristles.

Second antenna (Figs. 21a, 22a-c): Protopodite bare. Endopodite with 3 segments: 1 st segment with 2 slender a- and b-bristles; 2nd segment with short c-, d-, and e-bristles and long filament-like f- and g-bristles (g-bristle stouter than f-bristle); 3rd segment with long filament-like h-, i-, and j-bristles and terminal clublike process with minute terminal spine (process of right limb longer than that of left limb). Exopod with 9 segments: 1st segment divided into long proximal and short distal parts and with long slender terminal bristle (with short marginal spines) reaching well past 9th segment; bristles of segments 2 to 8 stouter and longer than bristle of 1st segment and with natatory hairs; 9th segment with 4 bristles (1 short, 1 medium length, 2 long).

Mandible: Coxa endite with proximal and distal sets of teeth separated by space (Fig. 22d,e): proximal set with 4 stout cusps and spinous bristle at each end; surface between cusps and proximal to cusps with slender 
spines; stout tooth and 2 spinous bristles between proximal and distal sets of teeth. Distal set of teeth comprising two flat teeth, each with 6 or 7 cusps; 1 stout curved spinous process and 1 small bristle proximal to flat teeth (Fig. 22d). Basis: dorsal part with 2 spinous bristles and 1 long slender bristle near base of endopod (Figs. 22f, 23b); distal edge of endite with 7 cusps (Fig. 22g); lateral surface near distal edge with stout tooth; lateral surface of endite with 6 bristles, none entwined; anterior edge with long distal bristle; posterior margin with 2 distal bristles (proximal with pointed tip, distal tubular). Endopod (Figs. 22f, 23a): 1st segment with 3 bristles ( 1 short ventral, 1 long medial, and 1 long, terminal, dorsal). 2nd segment widening distally, with 3 terminal dorsal bristles ( 1 claw-like), and 1 long ventral bristle. 3rd segment with 2 long stout terminal clawlike bristles, 4 or 5 slender terminal bristles (1 lateral and 3 or 4 medial), and dorsal spines.

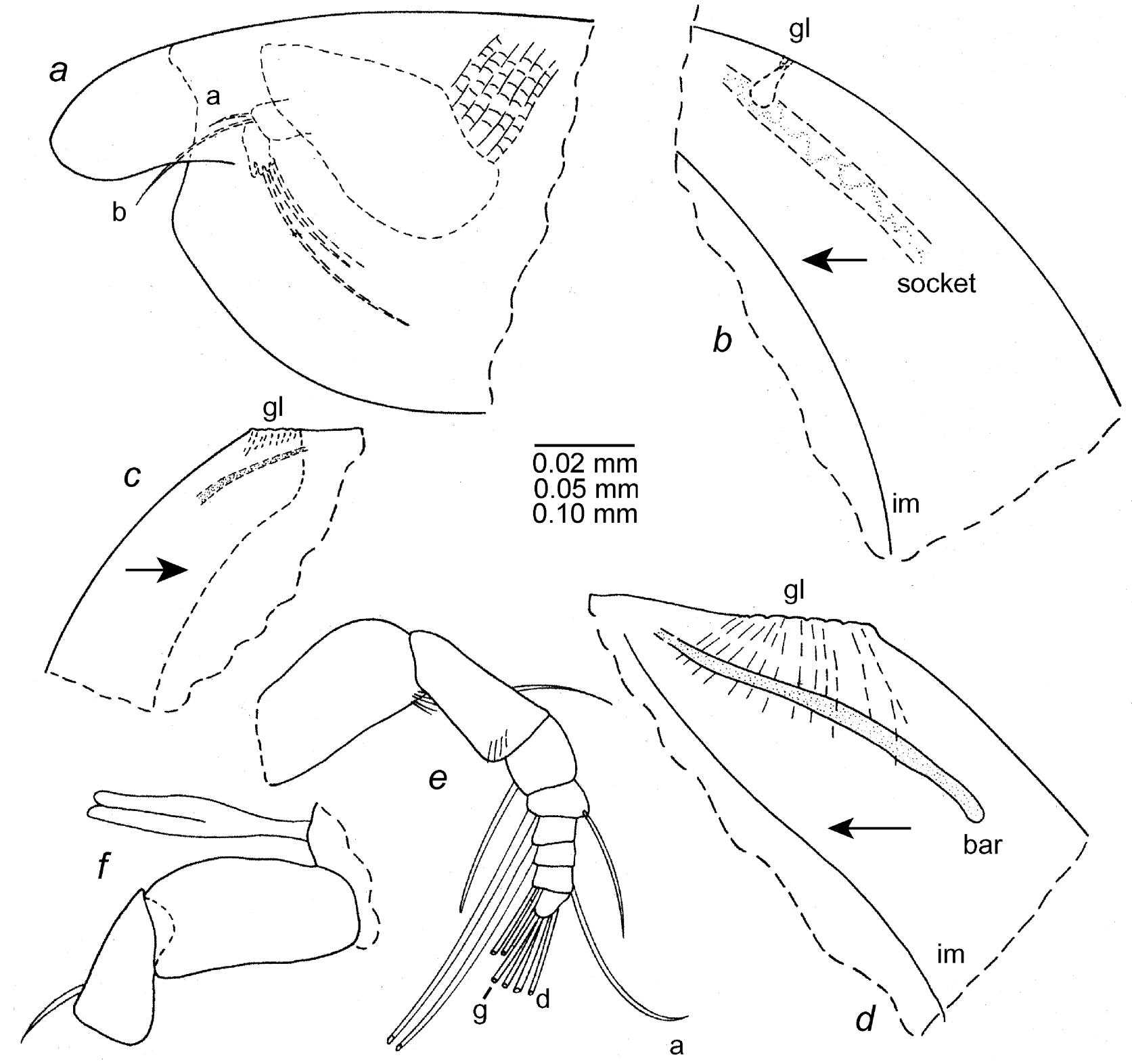

FIGURE 21. Spelaeoecia hox, new species, holotype USNM 1021397, adult male: $a$, anterior of complete specimen showing protopod and endopod of left second antenna; b; posterodorsal corner of left valve showing internal structures, ov; $c$, posterodorsal corner of right valve showing internal structures, ov; $d$, posterodorsal corner of right valve, iv; $e$, right first antenna, lv; $f$, Bellonci Organ and proximal part left first antenna, lv. Scale equals $0.10 \mathrm{~mm}(a), 0.02 \mathrm{~mm}(b, d)$, and $0.05 \mathrm{~mm}(c, f)$. 


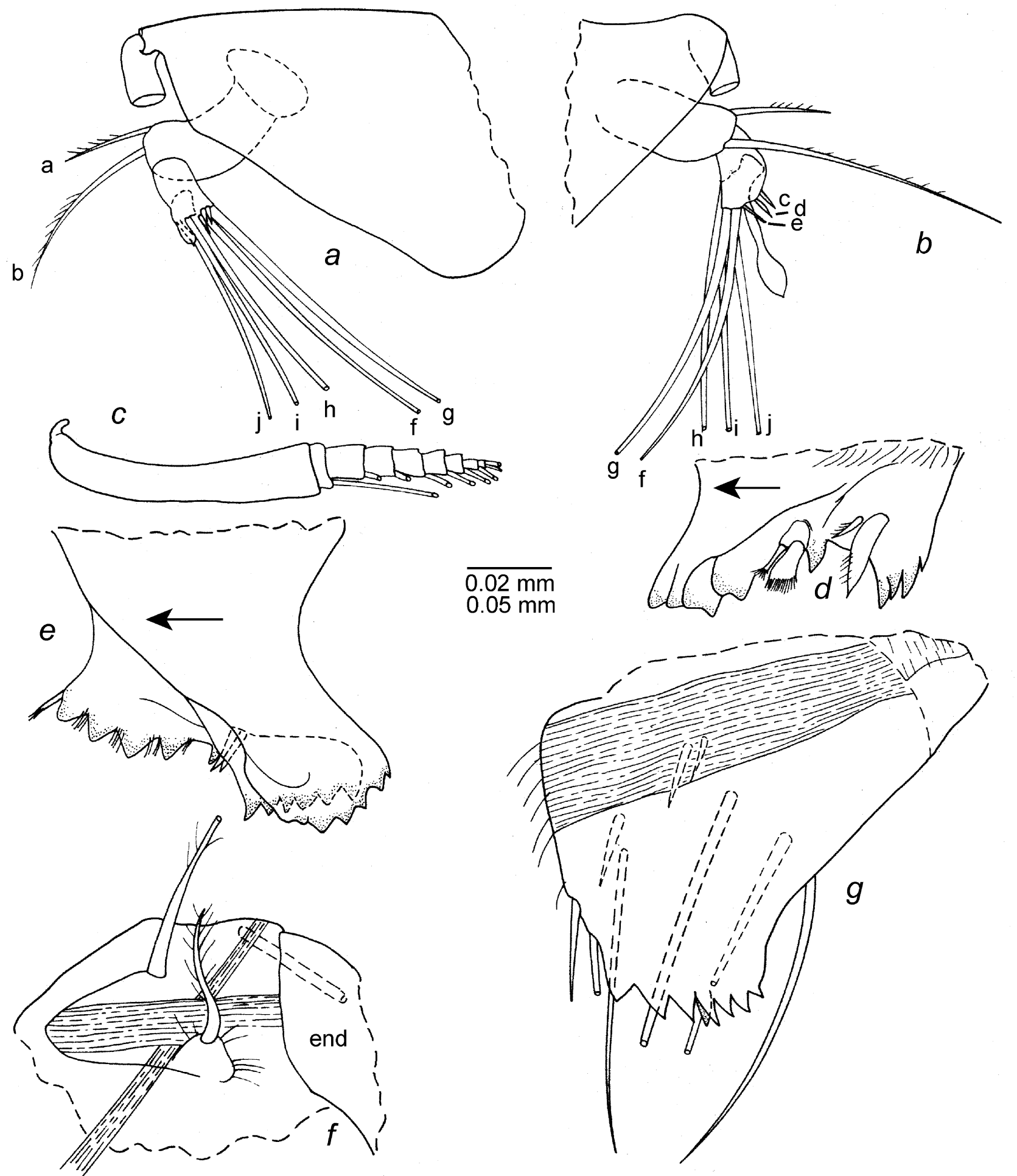

FIGURE 22. Spelaeoecia hox, new species, holotype USNM 1021397, adult male: $a$, left second antenna, lv; $b$, right second antenna, lv; $c$, exopod left second antenna, lv; $d$, tip of coxa of right mandible, mv; $e$, tip of coxa left mandible (distorted), lv; $f$, dorsal part of basis of left mandible, mv; $g$, tip of basis of right mandible, mv. Scale equals $0.05 \mathrm{~mm}(a-$ c) and $0.02 \mathrm{~mm}(d-g)$.

Maxilla (Fig. 23c-e): Endites (Fig. 23e): endite I with 3 proximal and about 8 terminal bristles; endite II with 2 proximal and about 6 terminal bristles; endite III with 1 proximal and about 6 terminal bristles; some endite bristles tubular. Basis with 1 stout plumose dorsal bristle and 1 stout spinous ventral bristle (Fig. 23c). Endopod: 1st segment with about 9 bristles; 2nd segment with 2 claws and 5 bristles (Fig. 23cd). 


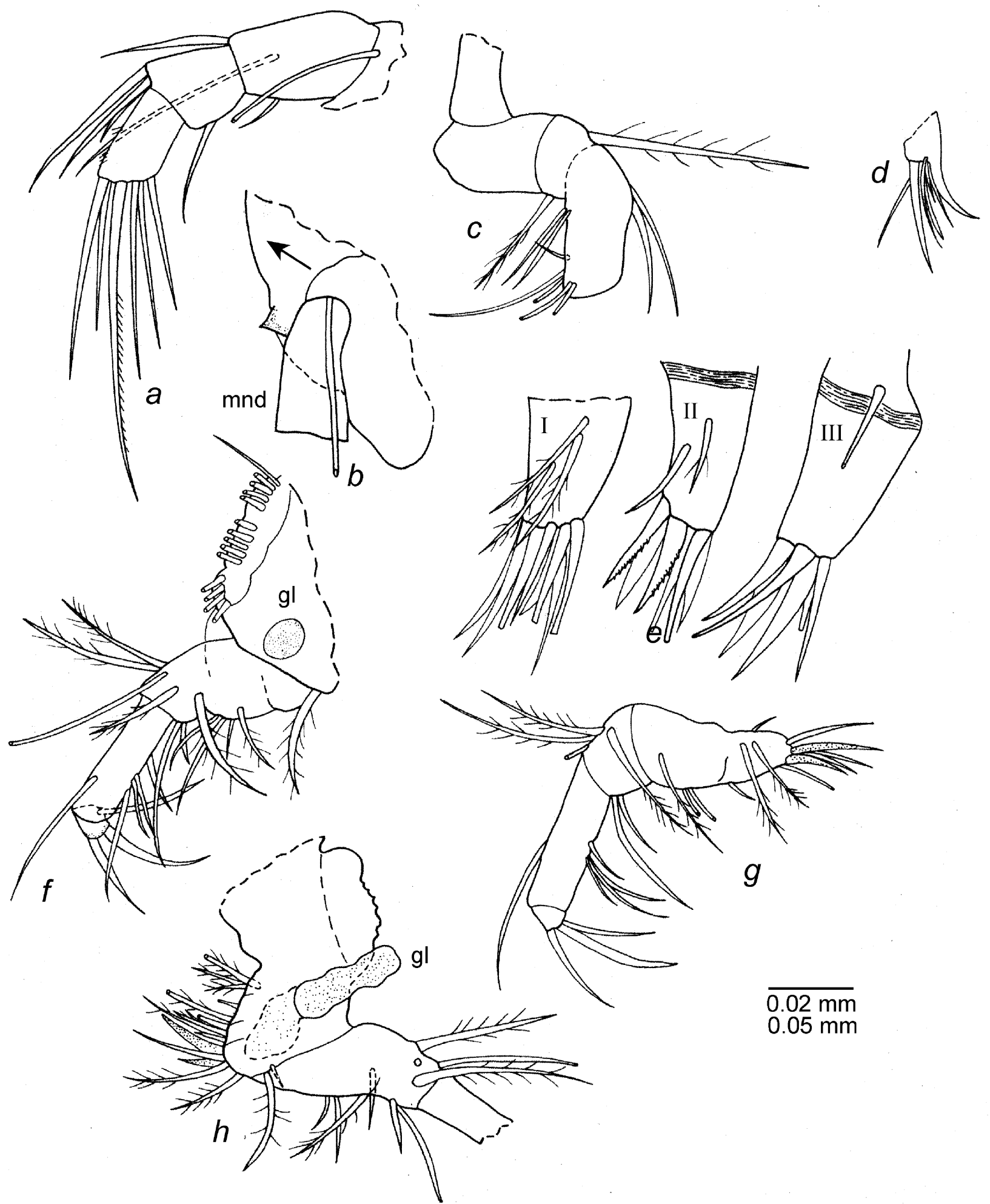

FIGURE 23. Spelaeoecia hox, new species, holotype USNM 1021397, adult male: $a$, left mandible drawn on body, lv; $b$, anterior of body and proximal part of left mandible (nabs); $c$, right maxilla drawn on body, tip missing (nabs); $d$, tip right maxilla, lv; $e$, endites of maxilla; $f$, right fifth limb as seen through shell (stippled process projects laterally, lv; $g$, same drawn loose on slide; $h$, proximal part left fifth limb, lv. Scale equals $0.05 \mathrm{~mm}(a-d, f-h)$ and $0.02 \mathrm{~mm}(e)$.

Fifth limb (Fig. 23f-h): Epipod (Fig. 23f): dorsal group with 1 short (dorsal) and 4 long plumose bristles; middle group with 5 long plumose bristles; ventral group with 4 plumose bristles. Proximal protopod with elongate lateral gland-like organ and 4 endites (Fig. 23h): endite I with 3 spinous bristles; endite II with 2 bristles; endite III with 5 bristles; endite IV with 2 claw-like bristles and 5 slender bristles. Basis with 6 or 7 bris- 
tles (Fig. 23-h). Exopod represented by 3 distodorsal bristles (longest bare, others spinous) (Fig. 23f). Endopod (Fig. 23f,g): 1st segment with distal dorsal bristle and 4 ventral bristles near midlength; 2nd segment with 2 stout claw-like bristles and 1 slender ringed bristle.

Sixth limb (Fig. 24a,b): Epipod (Fig. 24a): dorsal group with about 5 plumose bristles; middle and ventral groups each with 6 bristles. Proximal protopod with about 8 ventral bristles. Basis with about 6 bristles near ventral margin and 1 plumose lateral bristle near dorsal margin (Fig. 24a,b). Exopod well developed with 4 bristles ( 3 plumose, 1 bare). Endopod: 1st segment with 4 ventral bristles; 2nd segment with 3 bristles ( 2 ventral, 1 dorsal); 3rd segment with 3 bristles (middle bristle claw-like).

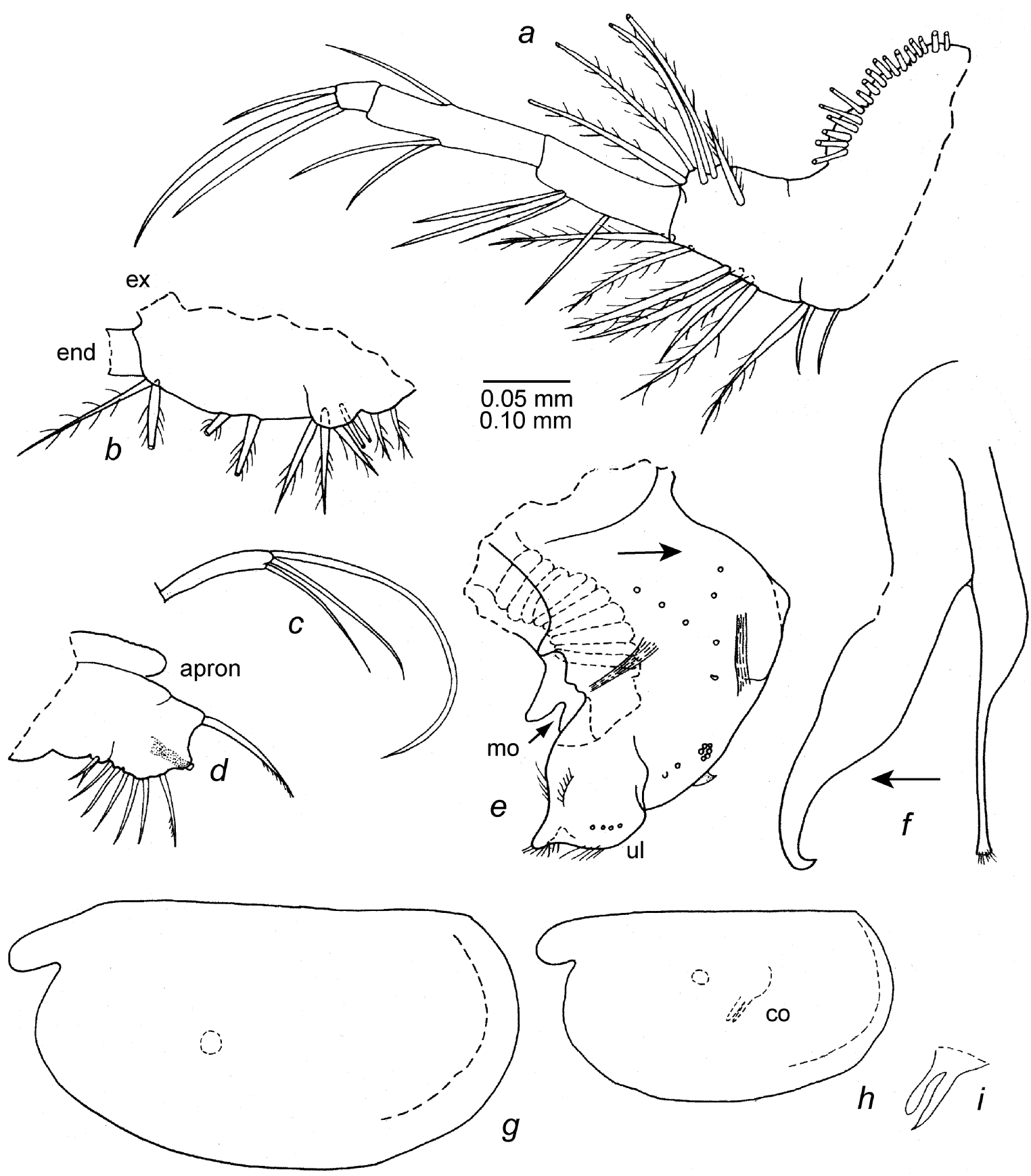

FIGURE 24. Spelaeoecia hox, new species, holotype USNM 1021397, adult male: $a$, right sixth limb, lv; $b$, proximal ventral left sixth limb, mv; $c$, right seventh limb, mv; $d$, right lamella of furca and apron; $e$, anterior of body from right side; $f$, copulatory organ as seen through left valve. USNM 1021401, paratype adult female: $g$, complete specimen, length $1.12 \mathrm{~mm}$. USNM 1021399, paratype A-1 male: $h$, complete specimen, length $0.83 \mathrm{~mm} ; i$, copulatory organ as seen through shell. Scale equals $0.05 \mathrm{~mm}(a, b, d-f)$ and $0.10 \mathrm{~mm}(c)$. 
Seventh limb (Fig. 24c): Elongate with 3 terminal bristles (1 longer than others).

Furca (Fig. 24d): Holotype with 7 claws on right lamella and 6 on left; claws 1 and 2 separated by wide space occupied by large glandular process. Lamellae followed by bifurcate unpaired bristle. Apron anterior to furca.

Bellonci Organ (Fig. 21f): Elongate, bifurcate; each branch with rounded tip.

Upper lip (Fig. 24e): Anterior face of upper lip with 2 small triangular processes (1 on each side); terminal posterior edge spinous. Lower lip lost.

Genitalia (Fig. 24f): On left side of body medial to 6th limb. Posterior branch slender with hirsute slightly widening tip. Anterior branch with recurved tapered tip.

Description of adult female (Fig. 24g). Carapace similar in shape and characters to that of adult male.

Carapace size (length, height in mm): USNM 1021401, 2 specimens: 1.02, 0.52; 1.12, 0.68.

Furca. Each lamella with 6 claws.

Description of A-1 male (Fig. 24h,i). Carapace similar in shape and characters as that of adult male (Fig. 24h).

Carapace size (length, height in mm): USNM 1021399, 0.83, 0.44.

Furca: Each lamella with 6 claws.

Genitalia (Fig. 24h,i): With 2 elongate branches; tip of posterior branch pointed; tip of anterior branch obscured on specimen not removed from carapace.

Comparisons. S. hox is closely related to $S$. bermudensis. The tip of the anterior branch of the copulatory organ of the adult male $S$. hox tapers to a point, whereas that of $S$. bermudensis is blunt (see Kornicker 1989: fig. 2i). The tip of the clasping process on the endopod of the second antenna of the adult male $S$. hox bears a minute terminal spine absent on S. bermudensis (see Kornicker 1989: fig. 2b-d). The infold of the carapace of S. hox is without a list, whereas a list is well developed on S. bermudensis. S. hox is smaller than S. bermudensis. The length of the adult male of $S$. hox is $1.07 \mathrm{~mm}$, whereas that of an adult male of S. bermudensis is 1.37 mm (Kornicker 1989: 320).

The lengths of the two adult females of $S$. hox in the present collection are $1.02 \mathrm{~mm}$ and $1.12 \mathrm{~mm}$, whereas the range of lengths of 15 adult females of USNM 1021402 is $1.43-1.64 \mathrm{~mm}$ (Angel \& Iliffe 1987: 541; Kornicker 1989: 322; Kornicker \& Iliffe, 1989b: 46; herein). The length (0.83 mm) of the A-1 male of $S$. hox in the present collection is smaller than the lengths $(1.25 \mathrm{~mm}$ and $1.27 \mathrm{~mm})$ of the two A-1 males of $S$. bermudensis measured by Kornicker \& Iliffe (1998: 46).

The mandibles of $S$. hox differ from those of $S$. capax Kornicker and $S$. cubensis Kornicker \& Yager in not having two entwined lateral bristles on the basis endite. The valves of $S$. hox differ from those of $S$. barri Kornicker in Kornicker \& Barr 1997 in not having a protuberance on the posterior edge near the dorsal margin. The right valve of $S$. hox differs from that of S. styx Kornicker 1990 in not having the posterodorsal gland on a distinct triangular projection, and the first antenna differs in having a ventral bristle on the third segment. The first antenna of $S$. hox differs from those of $S$. jamaicensis Kornicker \& Iliffe, S. parkeri Kornicker et al. and $S$. sagax Kornicker in having a ventral bristle on the third segment. The appendages of $S$. hox and $S$. mayan Kornicker \& Iliffe are similar. The carapaces differ in that $S$. hox is smaller and has a more elongate rostrum. The carapaces of $S$. parkeri and S. saturno Kornicker \& Yager differ from that of $S$. hox in having the rostrum of the right valve much narrower than that of the left valve.

\section{Spelaeoecia sagax Kornicker 1990 in Kornicker et al. 1990}

Spelaeoecia sagax Kornicker 1990, in Kornicker et al. 1990: 15, figs. 9-13.

Holotype. USNM 193446, adult male. 
Type locality. Sagittarius Blue Hole, Sweeting's Cay, Grand Bahama Island, Little Bahama Bank.

Material. Sagittarius Blue Hole: 29 May 1989: USNM 1021402, 2 specimens (1 adult male, 1 adult female); 29 Mar 1991: USNM 1021403, 10 specimens (4 adult males, 6 adult females); Sta 00-002: USNM 1021404, 5 specimens; Sta 01-016: USNM 1021405, 31 specimens. Virgo Blue Hole, Sweeting's Cay, Grand Bahama Island, Little Bahama Bank, Sta 01-015: USNM 1021406, 3 specimens (1 adult male).

Distribution. Little Bahama Bank, Sweeting's Cay (Sagittarius Blue Hole and Virgo Blue Hole).

Supplementary descriptions. Carapace size (length, height in mm): Adult male: USNM 1021402, 1.68, 0.94. Adult female: USNM 1021402, 1.75, 0.93.

Remarks. Kornicker et al. (1990: 15) reported this species in Sagittarius Blue Hole from collections made in 1984 and 1987. The present collections made in 1989, 1991, and 2002 show that the species has continued to inhabit the cave and was not affected by intermediate climatic events. The species is reported for the first time from Virgo Blue Hole.

\section{Subfamily Deeveyinae Kornicker \& Iliffe 1985}

Type Genus. Deeveya Kornicker \& Iliffe 1985: 476.

Diagnosis. Carapace without rostrum. First antenna with 8 articles, article 1 without bristles, article 2 with 1 dorsal bristle. Endopod of adult male 2nd antenna without clasper. Sixth limb with lobe-like exopod bearing 4 bristles. Bellonci Organ bifid. Copulatory limb of male with 2 processes.

Composition. At present this subfamily includes only the genus Deeveya Kornicker \& Iliffe 1985. The great differences in the morphology of the carapaces of species of Spelaeoecia and Deeveya are deemed sufficient evidence to require that each genus be referred to a different subfamily

\section{Deeveya Kornicker \& Iliffe 1985}

Deeveya Kornicker \& Iliffe 1985: 476.

Type Species. Deeveya spiralis Kornicker \& Iliffe 1985.

Composition and distribution. The genus includes seven species (D. bransoni Kornicker \& Palmer 1987, D. exleyi Kornicker \& Iliffe 1998, D. hirpex Kornicker 1990 in Kornicker et al. 1990, D. jillae Kornicker \& Iliffe 1989a, D. medix Kornicker 1990 in Kornicker et al. 1990, D. spiralis Kornicker \& Iliffe 1985, D. styrax Kornicker 1990 in Kornicker et al. 1990) from anchialine caves in the West Indies. The distribution of species is presented in Table 2.

Identification of growth stages. Members of Deeveya generally live in the deep recesses of caves and apparently do not occur in great numbers, for each collection usually contains only a few specimens. The specimens collected may or may not include adults. Because of the difficulties inherent in collecting specimens of this important taxon, the senior author in prior publications has attempted to differentiate species that were represented in the collections in various developmental stages. When the morphometric characters of the various developmental stages became better known, it was possible to reestimate the stage of development of previously described specimens (Kornicker et al. 2002: Table 5).

The A-3 and A-5 instars of a member of the genus (D. bransoni Kornicker \& Palmer 1987) are described for the first time. As a result, the A-1 to A-5 instars are known in the genus. The A-4 instar of D. bransoni is also described; previously, that instar was known for only D. jillae Kornicker \& Iliffe 1989a.

The data on the furca of the known stages of species of Deeveya suggest that the number of claws on each lamella is useful for discriminating the developmental stage of a specimen (Tables 7,8). 
TABLE 8. Number of furcal claws on growth stages of Deeveya.

\begin{tabular}{ll}
\hline Growth Stage & $\begin{array}{l}\text { Number of furcal claws } \\
\text { on each lamella }\end{array}$ \\
\hline A-5 & 3 \\
A-4 & 4 \\
A-3 & 5 \\
A-2 & 6 \\
A-1 & 7 \\
Adult & 7 \\
\hline
\end{tabular}

TABLE 9. Morphometrics of appendages of different growth stages of Deeveya bransoni. Sex not determined for some instars; morphometrics of both sexes (if known) of each instar combined. ( $\mathrm{a}-\mathrm{g}=$ letters identifying specific bristles, $\mathrm{D}=$ dorsal, $\mathrm{F}=$ female, $\mathrm{M}=$ male, na = no bristles because limb not present, $\mathrm{V}=$ ventral, $-=$ absent, $+=$ present, ? = number of bristles uncertain.)

\begin{tabular}{|c|c|c|c|c|c|c|c|}
\hline & A-5 & A-4 & A-3 & A-2 & A-1 & Adult F & Adult M \\
\hline $\begin{array}{l}\text { Carapace average length } \mathrm{mm} \text { (no. of } \\
\text { specimens) }\end{array}$ & $0.58(2)$ & $0.73(2)$ & $0.92(2)$ & $1.19(4)$ & $1.60(8)$ & $2.03(4)$ & $2.02(2)$ \\
\hline \multicolumn{8}{|l|}{ First Antenna } \\
\hline 1st segment bristles & 0 & 0 & 0 & 0 & 0 & 0 & 0 \\
\hline 2nd segment bristles & 0 & $1 \mathrm{D}$ & $1 \mathrm{D}$ & $1 \mathrm{D}$ & 1D & 1D & $1 \mathrm{D}$ \\
\hline 3rd segment bristles & 0 & $1 \mathrm{~V}$ & $1 \mathrm{~V}$ & $1 \mathrm{~V}$ & $1 \mathrm{~V}$ & $1 \mathrm{~V}$ & $1 \mathrm{~V}$ \\
\hline 4th segment bristles & 0 & $1 \mathrm{D}$ & $1 \mathrm{D}$ & $1 \mathrm{D}$ & 1D & 1D & $1 \mathrm{D}$ \\
\hline 3 rd and 4 th segments fused & + & + & - & - & - & - & - \\
\hline 5th segment bristles & 0 & 0 & $1 \mathrm{~V}$ & $1 \mathrm{~V}$ & $1 \mathrm{~V}$ & $1 \mathrm{~V}$ & $1 \mathrm{~V}$ \\
\hline 6th segment bristles & 0 & 0 & 0 & 0 & 0 & 0 & 0 \\
\hline 7th segment bristles & $\mathrm{c}$ & $\mathrm{a}, \mathrm{c}$ & $\mathrm{a}-\mathrm{c}$ & $\mathrm{a}-\mathrm{c}$ & $\mathrm{a}-\mathrm{c}$ & $\mathrm{a}-\mathrm{c}$ & $\mathrm{a}-\mathrm{c}$ \\
\hline 8th segment bristles & $\mathrm{d}-\mathrm{f}$ & $\mathrm{d}-\mathrm{g}$ & $\mathrm{d}-\mathrm{g}$ & $\mathrm{d}-\mathrm{g}$ & $\mathrm{d}-\mathrm{g}$ & $\mathrm{d}-\mathrm{g}$ & $\mathrm{d}-\mathrm{g}$ \\
\hline \multicolumn{8}{|l|}{ Second Antenna } \\
\hline \multicolumn{8}{|l|}{ Exopod } \\
\hline 1st segment divided & - & - & + & + & + & + & + \\
\hline 1st segment bristles & 0 & 1 & 1 & 1 & 1 & 1 & 1 \\
\hline 2-8 segments bristles & 7 & 7 & 7 & 7 & 7 & 7 & 7 \\
\hline 9th segment bristles & 2 & 2 & 3 & 4 & 4 & 4 & 4 \\
\hline \multicolumn{8}{|l|}{ Endopod } \\
\hline 1st segment bristles & $1 \mathrm{D}$ & $1 \mathrm{D}$ & $1 \mathrm{D}$ & $2 \mathrm{D}$ & $2 \mathrm{D}$ & $2 \mathrm{D}$ & $2 \mathrm{D}$ \\
\hline 2nd segment bristles & $\mathrm{g}$ & $\mathrm{f}, \mathrm{g}$ & $\mathrm{f}, \mathrm{g}$ & $f, g$ & $\mathrm{f}, \mathrm{g}$ & $f, g$ & $f, g$ \\
\hline 3rd segment bristles & $h-j$ & $\mathrm{~h}-\mathrm{j}$ & $h-j$ & $h-j$ & $h-j$ & $h-j$ & $h-j$ \\
\hline \multicolumn{8}{|l|}{ Mandible } \\
\hline \multicolumn{8}{|l|}{ Coxa } \\
\hline Bristles & $4 ?$ & 4 & $6 ?$ & $6 ?$ & 6 & 6 & 7 \\
\hline Teeth & $17 ?$ & $17 ?$ & $16 ?$ & $16 ?$ & 16 & 15,16 & 16,17 \\
\hline \multicolumn{8}{|l|}{ Basis } \\
\hline Proximal dorsal bristles & 1 & 1 & 1 & 1 & 1 & 1 & 1 \\
\hline Bristles near endopod & 1 & 1 & 1 & 1 & 1 & 1 & 1 \\
\hline
\end{tabular}


TABLE 9. (continued)

\begin{tabular}{|c|c|c|c|c|c|c|c|}
\hline & A-5 & A-4 & A-3 & A-2 & A-1 & Adult F & Adult M \\
\hline Distal anterior bristles & 1 & 1 & 1 & 1 & 1 & 1 & 1 \\
\hline Distal posterior bristles & 2 & 2 & 2 & 2 & 2 & 2 & 2 \\
\hline Total distal lateral bristles & 2 & 3 & 5 & 6 & 6 & 7 & 6 \\
\hline Entwined lateral bristles & 0 & 1 & 1 & 2 & 2 & 2 & 2 \\
\hline Distal lateral tooth & 0 & 1 & 1 & 1 & 1 & 1 & 1 \\
\hline Terminal teeth & 5 & 6 & $6 ?$ & $6 ?$ & 6 & 6 & 6 \\
\hline Exopod bristles & 1 & 1 & 2 & 2 & 2 & 2 & 2 \\
\hline \multicolumn{8}{|l|}{ Endopod } \\
\hline 1st segment total bristles & 1 & 1 & 1 & 4 & 6 & 6,7 & 8 \\
\hline 2nd segment total bristles & 2 & 2 & 3 & 4 & 4 & 4 & 4 \\
\hline 3rd segment total bristles & 4 & 4 & 6 & 7 & 7 & 7 & 7 \\
\hline \multicolumn{8}{|l|}{ Maxilla } \\
\hline Endites I-III bristles & $6,6,6$ & $5,5,4$ & $9,8,6$ & $11,9,6$ & $10,9,6$ & $12,13,7$ & $12,13,7$ \\
\hline Coxa dorsal bristles & 1 & 1 & 1 & 1 & 1 & 1 & 1 \\
\hline Basis bristles & 2 & 2 & 2 & 2 & 2 & 2 & 2 \\
\hline \multicolumn{8}{|l|}{ Endopod } \\
\hline 1st segment bristles & 2 & 3 & 6 & 6 & 10 & 11 & 11 \\
\hline 2nd segment bristles & 5 & 5 & 6 & 6 & 7 & 8 & 8 \\
\hline \multicolumn{8}{|l|}{ Fifth Limb } \\
\hline Epipod bristles (total) & 14 & $14 ?$ & 15 & 14 & 16 & 15 & 15 \\
\hline Precoxa and Coxa bristles & 9 & 11 & 15 & 20 & 24 & 26 & 29 \\
\hline Basis bristles & 3 & 4 & 5 & 8 & 10 & 12 & 10 \\
\hline Exopod bristles & 2 & 2 & 2 & 2 & 2 & 2 & 2 \\
\hline \multicolumn{8}{|l|}{ Endopod } \\
\hline 1st segment bristles & 0 & 2 & 3 & 3 & 4 & 5 & 5 \\
\hline 2nd segment bristles & 2 & 3 & 4 & 4 & 4 & 4 & 4 \\
\hline Sixth Limb & - & + & + & + & + & + & + \\
\hline Epipod bristles (total) & na & 13 & 16 & 17 & 18 & 18 & 18 \\
\hline \multicolumn{8}{|l|}{ Precoxa and Coxa } \\
\hline bristles & na & $0 ?$ & 5 & 5 & 8 & 8 & 8 \\
\hline Basis bristles & na & 0 & 4 & 6 & 6 & 7 & 7 \\
\hline Exopod bristles & na & 3 & 4 & 4 & 4 & 4 & 4 \\
\hline \multicolumn{8}{|l|}{ Endopod } \\
\hline 1 st and 2 nd segments fused & na & + & - & - & - & - & - \\
\hline 1st segment bristles & na & 0 & 0 & 2 & 4 & 6 & 6 \\
\hline 2nd segment bristles & na & 0 & 2 & 2 & 3 & 3 & 3 \\
\hline 3rd segment bristles & na & 2 & 3 & 4 & 4 & 4 & 4 \\
\hline Seventh Limb & - & - & + & + & + & + & + \\
\hline Number of bristles & na & na & 3 & 3 & 3 & 3 & 3 \\
\hline \multicolumn{8}{|l|}{ Furca } \\
\hline Number of claws & 3 & 4 & 5 & 6 & 7 & 7 & 7 \\
\hline \multicolumn{8}{|l|}{ Triangular process } \\
\hline after claws & + & + & + & + & - & - & - \\
\hline
\end{tabular}


TABLE 9. (continued)

\begin{tabular}{|c|c|c|c|c|c|c|c|}
\hline & A-5 & A-4 & A-3 & A-2 & A-1 & Adult F & Adult M \\
\hline Unpaired bristle & 1 & 1 & 1 & 1 & 1 & 1 & 1 \\
\hline Bellonci Organ & + & + & + & + & + & + & + \\
\hline $\begin{array}{l}\text { Total number of bristles, claws, and } \\
\text { teeth on one side }\end{array}$ & 122 & 152 & 204 & 225 & 252 & 268 & 272 \\
\hline $\begin{array}{l}\text { Total number of bristles, claws, and } \\
\text { teeth on both sides }\end{array}$ & 244 & 304 & 408 & 450 & 504 & 536 & 544 \\
\hline $\begin{array}{l}\text { Percent increase in total number of } \\
\text { bristles, claws, and teeth between } \\
\text { stages* }\end{array}$ & - & 25 & 34 & 10 & 13 & 6 & 8 \\
\hline $\begin{array}{l}\text { Percent of total increase between } \\
\text { stages** }\end{array}$ & - & 21 & 36 & 14 & 19 & 11 & ca 13 \\
\hline $\begin{array}{l}\text { Percent of total on adult female } \\
\text { present at each stage } * * *\end{array}$ & 45.5 & 56.7 & 76.1 & 83.6 & 94.0 & 100 & - \\
\hline
\end{tabular}

*Percentages were calculated by subtracting the number of bristles, claws, and teeth in one stage from the number in the following stage, then dividing the difference by the number in the first stage and multiplying by 100 .

**Percentages were calculated by dividing the number of bristles, claws, and teeth between successive stage by the total number obtained by subtracting the number on instar I from the number on the adult female and then multiplying by 100. ***Percentages were calculated by dividing the number of bristles, claws, and teeth on each stage by the number on the adult female and then multiplying by 100 .

TABLE 10. Number of bristles on the 1st endopod article of the 5th and 6th limbs of the A-1 instar and adult of species of Deeveya. (nd = no data.)

\begin{tabular}{lllllllll}
\hline & \multicolumn{2}{c}{ Fifth Limb } & \multicolumn{3}{c}{ Sixth Limb } & & \\
& A-1F & A-1M & Adult F & Adult M & A-1F & A-1M & Adult F & Adult M \\
\hline D. bransoni & 4 & 4 & 5 & 5 & 4 & 4 & 6 & 6 \\
D. exleyi & nd & nd & 5 & nd & nd & nd & 6 & nd \\
D. hirpex & 4 & nd & nd & nd & 4 & nd & nd & nd \\
D. medix & nd & nd & 5 & 5 & nd & nd & 6 & 6 \\
D. spiralis & nd & nd & 5 & nd & nd & nd & 6 & nd \\
D. styrax & nd & nd & 5 & 5 & nd & nd & 6 & 6 \\
\hline
\end{tabular}

The stage of development of the male copulatory organ is useful in discriminating between the A-1 instar and the adult, and the stage of development of the female genitalia and the presence of eggs are of some use in discriminating between the A-1 instar and the adult, but these are of less certain value than differences in the copulatory organ of the male (Kornicker et al. 2002: 11).

Although the distributions of bristles on individual appendages of the A-1 instar and adult appear to be fairly similar, it was observed that the total number of bristles at each stage of $D$. bransoni, including the A-1 instar and adult, steadily increased (Table 9, Figs. 25, 26). An examination of Table 9 shows that whereas the numbers of bristles on the first and second antennae and mandible of the A-1 instar and adult are fairly constant, the numbers of bristles on some segments of the maxilla and fifth and sixth limbs of the adult are greater than on the A-1 instar. The numbers of bristles on the first endopod segments of the fifth and sixth limbs, which are fairly easy to count on whole specimens, are listed in Table 10. The data suggest that the numbers of bristles on the first endopod segments of the fifth and sixth limbs may be useful in discriminating between the A-1 instar and adult of species of Deeveya. The stage of development of the A-1 male and the adult male can be ascertained with certainty because of clear differences in the morphology of the copulatory organs. The total numbers of bristles on D. bransoni and Eusarsiella syrinx are compared in Figs. 25 and 26. 
Comparison of carapace lengths of species of Deeveya. Recognition of the three species $D$. bransoni , D. styrax and D. medix (all Kornicker 1990 in Kornicker et al. 1990) are based primarily on differences in the copulatory organ of the adult male. The hypothesis of different species is supported by their carapaces having different lengths (Table 11). The oldest stage known for D. jillae is the A-2 instar. The length of the A-2 instar of $D$. bransoni suggests that the adult $D$. jillae is much smaller than the adult $D$. bransoni.

Collecting depths of species of Deeveya. Depths in anchialine caves at which specimens were collected have been reported for only four species of Deeveya: D. bransoni (22-50 m) (Kornicker \& Palmer 1987:611; herein), D. jillae (0-3 m) (Kornicker \& Iliffe (1989a: 19), D. spiralis (5-7 m), (Kornicker \& Iliffe 1985:476) and D. exleyi $(0-1 \mathrm{~m})$ (Kornicker \& Iliffe 1998:90). Although the data are too few to draw firm conclusions, they suggest that $D$. bransoni lives at greater depths than the other three species. D. bransoni is reported herein from two ocean blue holes at depths of 30-70 m. Some specimens of D. bransoni were collected about $1200 \mathrm{~m}$ inside an ocean blue hole (Crab Cay Cravasse).

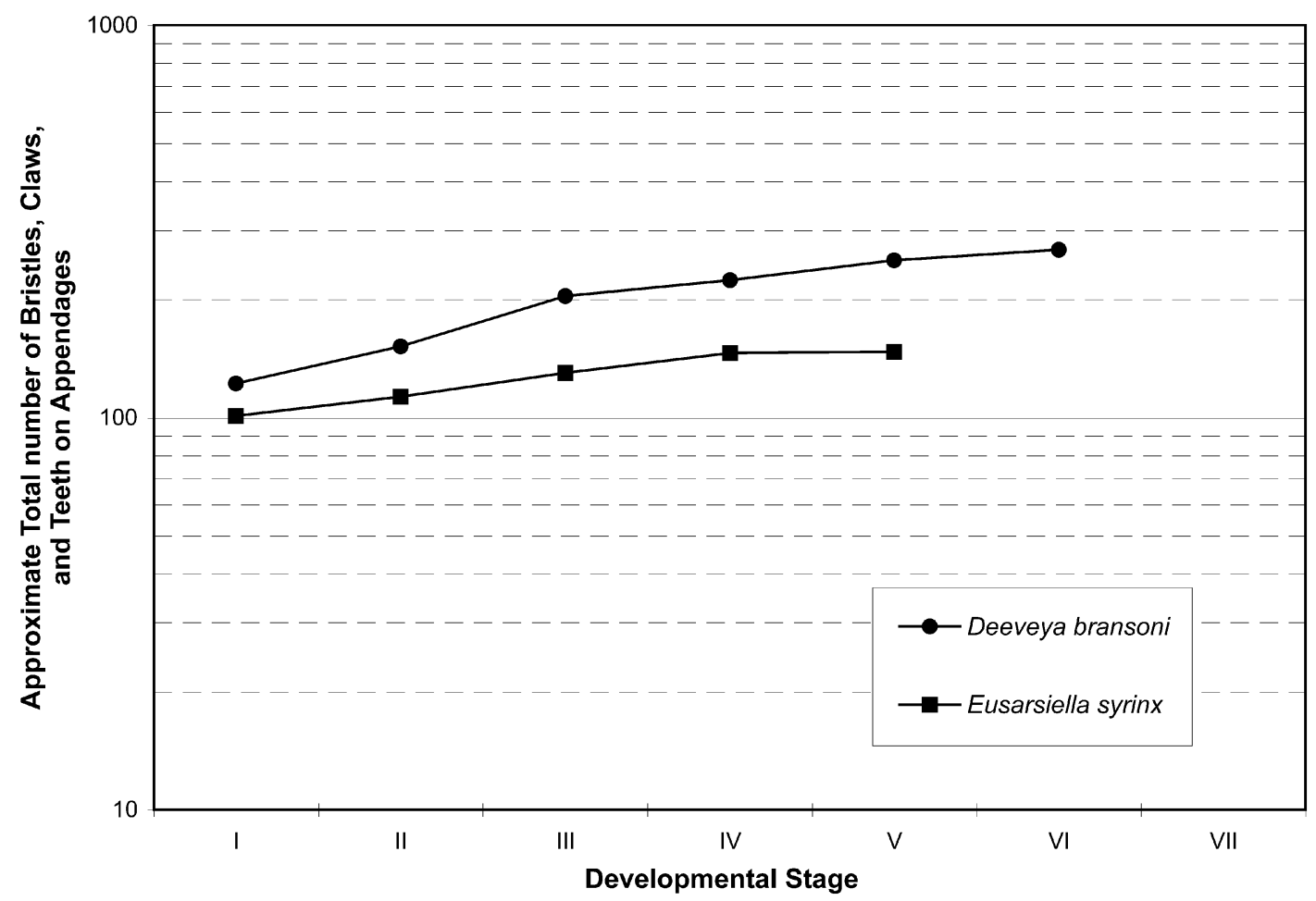

FIGURE 25. Comparison of approximate number of bristles, claws, and spines on instars and adult female appendages of Deeveya bransoni (herein) and Eusarsiella syrinx (herein).

TABLE 11. Comparison of carapace lengths $(\mathrm{mm})$ of selected stages of species of Deeveya. $(\mathrm{nd}=$ no data)

\begin{tabular}{lllll}
\hline & Stage of development & & \\
& $\mathrm{A}-2$ & $\mathrm{~A}-1$ & Adult F & Adult M \\
\hline D. bransoni & 1.20 & 1.60 & 2.08 & 2.02 \\
D. exleyi & nd & nd & 1.83 & $\mathrm{Nd}$ \\
D. hirpex & nd & 2.36 & $\mathrm{nd}$ & $\mathrm{Nd}$ \\
D. jillae & 1.07 & $\mathrm{nd}$ & $\mathrm{nd}$ & $\mathrm{Nd}$ \\
D. medix & $\mathrm{nd}$ & $\mathrm{nd}$ & 1.72 & 1.69 \\
D. spiralis & $\mathrm{nd}$ & $\mathrm{nd}$ & 2.77 & $\mathrm{Nd}$ \\
D. styrax & $\mathrm{nd}$ & $\mathrm{nd}$ & 3.11 & 3.05 \\
\hline
\end{tabular}


Deeveya spiralis Kornicker \& Iliffe 1985: 477, figs. 1-12.—Kornicker \& Palmer 1987: 619, fig. 6.—Kornicker et al. 1990: 37, figs. 22a, 23a-c, 29a, 30.

Holotype. USNM 193117, adult female on slides and in alcohol. (Kornicker \& Palmer 1987: 619 incorrectly reinterpreted the holotype and paratype to be A-1 females.)

Type locality. The Hole, Providenciales Island, Caicos Islands, Turks and Caicos Islands.

Material. Slide of appendages of holotype, USNM 193117.

Distribution. Known only from the type locality.

Supplementary description of adult female. Fifth limb: 1st endopod segment with 4 ventral and 1 dorsal bristles. (This is consistent with the illustration of the limb by Kornicker \& Iliffe (1985: fig. 11a), but their description (p. 490) listed only 4 bristles (3 ventral, 1 dorsal), which is incorrect).

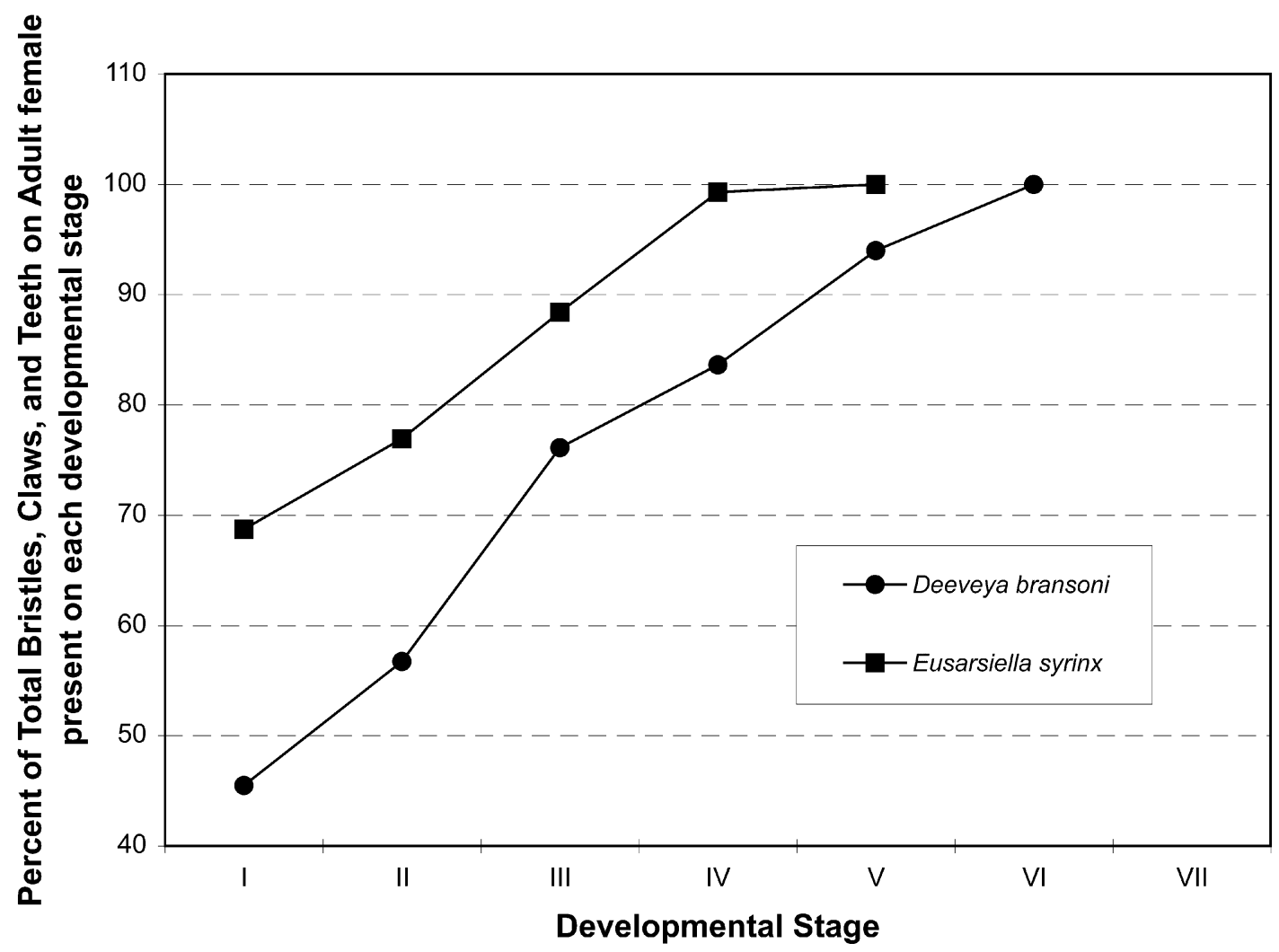

FIGURE 26. Percent of total bristles, claws, and teeth on instars and adult female appendages of Deeveya bransoni and Eusarsiella syrinx.

\section{Deeveya styrax Kornicker 1990 in Kornicker et al. 1990}

Deeveya styrax Kornicker 1990, in Kornicker et al. 1990: 27, figs. 15-21, 22d, 29c, 30.

Holotype. USNM 193451, adult male on slides and in alcohol.

Type locality. Dan's Cave, Abaco Island, Little Bahama Bank.

Material. Type locality: USNM 1021407, 1 adult specimen in alcohol.

Distribution. Little Bahama Bank: Abaco Island (Dan's Cave); Grand Bahama Island, Sweeting's Cay (Sagittarius Blue Hole). 
Supplementary description of adult (sex undetermined). Carapace size ( $\mathrm{mm}$ ): length 3.08, height without tubercle 2.17, height with tubercle 2.26.

Remarks. Specimens were collected previously in Dan's Cave in 1984 and 1985 (Kornicker et al. 1990: 17). The specimen reported upon herein was collected in the cave in 1996 showing that the species continued to be present and had not been affected by intermediate climactic events.

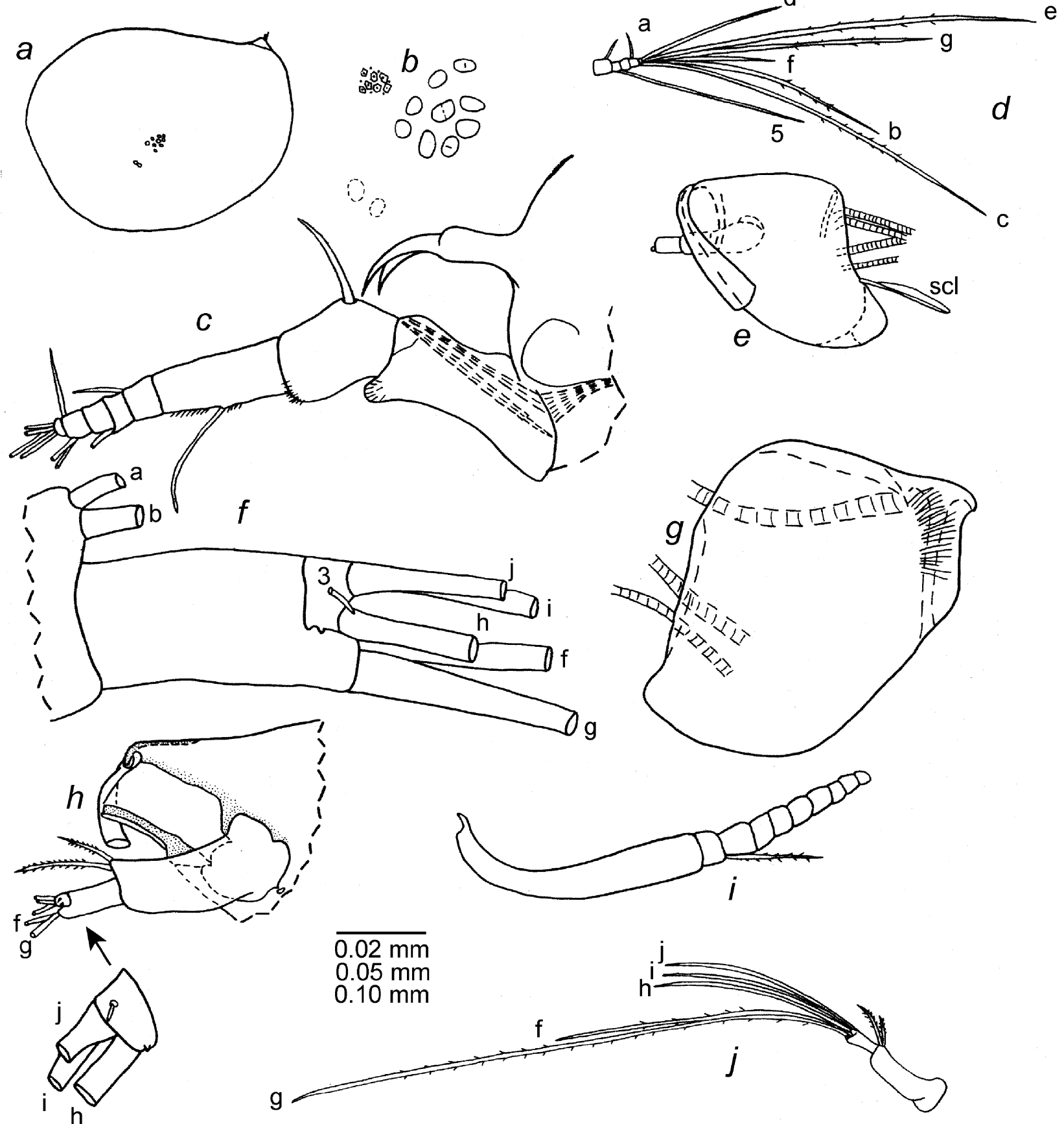

FIGURE 27. Deeveya bransoni Kornicker \& Palmer 1987, USNM 1021408, adult male: $a$, complete carapace with body removed, from left side, length $2.00 \mathrm{~mm}$; $b$, detail of mandibular muscle attachments (dashed), central adductor muscle attachments, and representative reticulations on valve surface; $c$, Bellonci Organ and left first antenna (drawn on body), lv; $d$, distal left first antenna, mv. Left second antenna: $e$, protopod and parts of exopod and endopod, lv (nabs); $f$, part left endopod, mv. Right second antenna: $g$, protopod, lv; $h$, protopod and endopod, mv; $i$, exopod, mv (nabs); $j$, endopod, mv. Scale equals $0.10 \mathrm{~mm}(b, c, g, h), 0.20 \mathrm{~mm}(d, e, j, i)$, and $0.02 \mathrm{~mm}(f)$. 


\section{Deeveya bransoni Kornicker \& Palmer 1987}

Figs. 27-39

Deeveya bransoni Kornicker \& Palmer 1987: 610, figs. 1-5.-Kornicker et al. 1990: 37, figs. 22c, 23d,e, 29b, 30.—Kornicker et al. 2002: 12, figs. 7-12, 13a-k.

Holotype. USNM 193301, A-1 female on slide and in alcohol.

Type locality. Evelyn Green’s Blue Hole, South Andros Island, Great Bahama Bank.
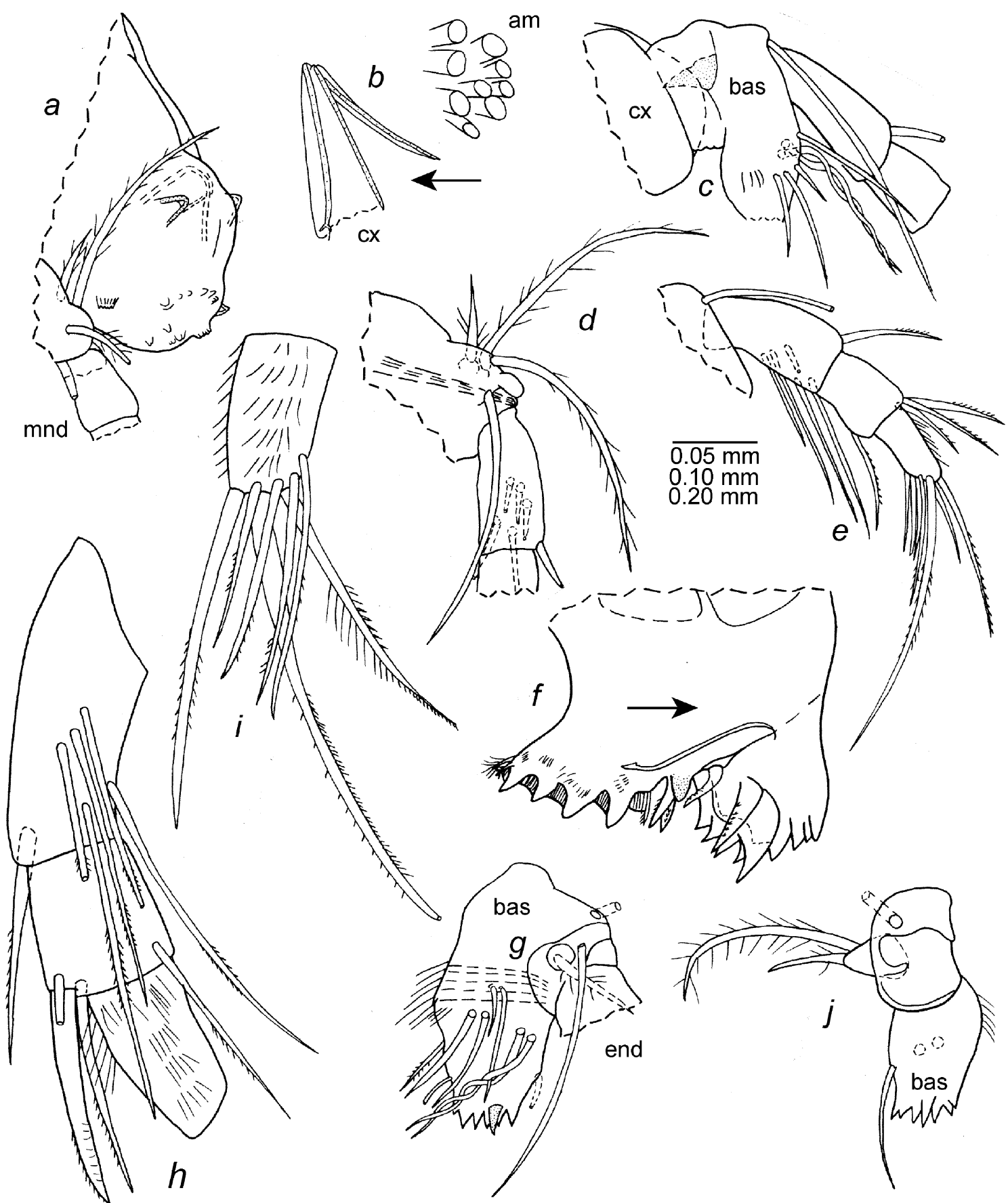

FIGURE 28. Deeveya bransoni Kornicker \& Palmer 1987, USNM 1021408, adult male: mandible: $a$, upper lip with right mandible in place; $b$, proximal tip of left coxa and ends of adjacent central adductor muscles projecting from left side of body, anterior to left, lv. Right mandible: $c-e$, limb drawn attached to body, lv (nabs); $f$, tip of coxa, lv; $g$, basis, lv; $h, i$, endopod, mv. Left mandible: $j$, basis and exopod, mv (nabs). Scale equals $0.10 \mathrm{~mm}(a, b, d, e, g, j), 0.20 \mathrm{~mm}(c)$, and $0.05 \mathrm{~mm}(f, h, i)$. 
Material. Sanctuary Blue Hole, South Andros Island, Sta 99-061: USNM 1021408, adult male on 4 slides and in alcohol; USNM 1021409-1021411, 3 A-1 instars on 1 slide and in alcohol; USNM 1021413, USNM 1022176, 1 A-2 instar in alcohol; USNM 1021414, 1 A-3 instar on 2 slides and in alcohol; USNM 1021415, 1021416, 2 A-3 instars in alcohol; USNM 1021417, 1 A-5 instar in alcohol; USNM 1021418, 1 A-5 instar on 1 slide and in alcohol; USNM 1021419, 1 adult male in alcohol; USNM 1021420-1021424, 5 A-1 instars in alcohol; USNM 1021425, 1 A-4 right valve in alcohol; USNM 10213871 adult male in alcohol (shell fragmented and not measured); USNM 1021427-1021429, 3 adult females in alcohol; USNM 1022177, 1 adult female in alcohol. Double Drop Blue Hole, South Andros Island: Sta 99-055: USNM 1021430, 1 adult female in alcohol; USNM 1021431, 1 A-2 instar in alcohol (left valve broken); Sta 99-056: USNM 1021432, 2 A-2 instars in alcohol; USNM 1021433, 2 A-1 instars in alcohol. Conch Sound Blue Hole, Andros Island: Sta 00023, USNM 1021434, 3 specimens in alcohol; USNM 1021435, 1 specimen in alcohol. Sta 00-023, USNM 1021434, 3 specimens in alcohol. Sta 00-024, USNM 1021435, 1 specimen in alcohol. Sta 01-003: USNM 1021437, 1 A-4 instar; USNM 10214438, 1 A-5 instar in alcohol; USNM 1021439, 27 specimens in alcohol. Sta 01-004, USNM 1021440, 7 specimens in alcohol. Sta 01-012, USNM 1021441, 8 specimens in alcohol.

Distribution. Great Bahama Bank: Andros Island (Evelyn Green's Blue Hole, Stargate Blue Hole, Sanctuary Blue Hole, Double Drop Blue Hole, Conch Sound Blue Hole).

Remarks. Because many appendages of the adult male described in Kornicker et al. (2002: 15) were lost and thus incompletely described, a supplementary description of the adult male is presented herein.

Supplementary description of adult male (Figs. 27-32). Carapace similar in shape and ornamentation to that described in Kornicker et al. (2002:15: fig. 7a-d) (Fig. 27a,b).

Central adductor muscle scars (Fig. 27a,b): With about 9 ovoid scars, 3 indistinctly divided.

Carapace size (length, height in mm): USNM 1021403, 2.00, 1.49; USNM 1021419, 1.98, 1.38.

First antenna: As shown in Figs. 27c,d (appendage lost).

Second antenna (Fig. 27e-j): Protopod with distal lateral spines (Fig. 27g). Endopod 3-segmented (Fig. 27f,h,j): 1st and 2nd segments linear; 1st segment with 2 terminal spinous bristles (proximal a-bristle about one half length of distal b-bristle); 2nd segment with filament-like f-bristle, about one-half length of g-bristle; g-bristle with more-strongly developed rings than f-bristle; both $\mathrm{f}$ - and g-bristles with widely separated minute spines and with tapered tips with terminal papilla; 3rd segment small, separated from 2nd segment by suture, with filament-like h-, i-, and j-bristles (each less than one-half length of g-bristle and with tapering tip and terminal papilla) and with minute medial ventral peg and small medial bristle near midwidth (Fig. 27f,h,j). Exopod 9-segmented (Fig. 27i): 1st segment divided into long proximal and short distal parts; distal part with short ringed bristle with short marginal spines (Fig. 27i); bristle of 2nd segment long, with short ventral spines and dorsal natatory hairs; 9th segment with 4 bristles (longest bristle with dorsal spines and distal natatory hairs, next-to-longest bristle with only minute spines; shorter 2 bristles either bare or with minute spines). Fulcrum attached to posterior edge of protopod more strongly sclerotized along dorsal edge (Fig. 27e).

Mandible (Fig. 28): Coxa endite with proximal and distal sets of teeth separated by space (Fig. 28f); proximal set comprising 4 stout cusps, and with 2 short, spinous, distal bristles on anterior edge and 1 short, spinous, distal bristle on posterior edge; surface between cusps and anterior and posterior to cusps with abundant slender spines. Stout rounded tooth between proximal and distal sets of teeth, with 2 spinous bristles adjacent to tooth. Distal set of teeth comprising 2 flat teeth; proximal tooth with 5 cusps (posterior cusp stouter); distal tooth with 6 or 7 cusps (middle cusp stouter); 2 spinous bristles present lateral to distal set of teeth. Basis with 2 proximal bristles (1 stout plumose, 1 long, slender, either bare or with short spines), and 2 medial plumose bristles (1 long, 1 short) on short process (Fig. 28d, j). Basis endite (Fig. 28g): anterior margin with single bristle; posterior margin with proximal hairs, and 1 short bristle proximal to 1 short distal tubular bristle; medial side with few rows of long hairs near midlength and also just proximal to terminal cusps; lateral side with 6 slender distal bristles ( 2 longer than others and entwined with 5 crossings) and 1 short, stout tooth just proximal to distal edge of endite; ventral edge of endite with 6 terminal cusps ( 5 anterior cusps ser- 
rate proximally, 1 posterior cusp smaller than others). Endopod 3-segmented (Fig. 28e,h,i): 1st segment with 1 spinous, terminal, dorsal bristle, 1 spinous, distal, ventral bristle, and 4 spinous distal medial bristles (left limb of USNM 1021408 with additional lateral bristle); 2nd segment with 3 spinous, terminal, dorsal bristles (1 claw-like on edge of segment and with distal rings), and 1 spinous, terminal, ventral bristle; 3rd segment hirsute medially and along anterior margin, with 4 medial spinous bristles forming row, and 3 stout terminal bristles (middle bristle longest and with smooth, pointed, slightly recurved tip; posterior bristle with long spines at midlength).

Maxilla (Figs. 29, 30): Endite I with 2 proximal long bristles with long proximal hairs and 10 subterminal and terminal bristles (5 tubular, 5 stout, pointed, with either long hairs, minute spines, or minute teeth) (Fig. $29 d$ ); endite II with 2 long proximal bristles with short spines and 11 terminal and subterminal bristles (5 tubular, 6 claw-like with distal marginal teeth) (Fig. 29e); endite III with 1 long proximal bristle with base near basis and with short marginal spines, and 6 terminal bristles ( 2 tubular, 4 claw-like) (Fig. 29f). Coxa with stout plumose dorsal bristle. Basale with 2 bristles (1 tubular near ventral margin, 1 pointed near dorsal margin, both with minute indistinct marginal spines) (Fig. 30). Endopod (Fig. 30): 1st segment with 11 bristles (3 tubular); 2nd segment with hairs along anterior surface, 2 stout pectinate claws, and 6 tubular bristles (3 medial, 3 lateral).

Fifth limb (Fig. 31a-c): Epipod with bristles forming 3 groups: ventral group with 5 bristles; middle group with 6 bristles; dorsal group fragmented on specimen (with at least 3 bristles). Protopod with internal glandular field. Precoxa and coxa with total of 29 claws and bristles. Basis with 10 bristles. Exopod represented by 2 bristles ( 1 long bare, 1 short spinous). Endopod: 1 st segment with 5 bristles ( 4 ventral, 1 dorsal); 2nd segment with 2 stout claw-like bristles and 2 slender bristles.

Sixth limb (Fig. 31d): Epipod with bristles forming 3 groups (ventral group with 5 long setose bristles; middle group with 6 long setose bristles; dorsal group with 7 setose bristles ( 6 long, 1 short dorsal). Precoxa and coxa with total of 8 bristles. Basis with 1 lateral and 6 ventral or medial bristles. Exopod well-developed, with 4 long bristles (1 bare, 3 with long marginal hairs). Endopod: 1st segment with 6 bristles on or near ventral margin; 2 nd segment with 3 bristles ( 2 ventral, 1 dorsal); 3rd segment with 2 stout claw-like pectinate bristles and 2 slender bristles (1 long, ventral, 1 short, medial).

Seventh limb (Fig. 31e): Limb with 3 terminal bristles (1 long, 2 shorter).

Furca (Figs. 31f, 32c): Each lamella with 7 claws (claw 4 slight smaller than claw 3); claws 1-4 with teeth along posterior margin; claws 5-7 with teeth along both margins. Small glandular peg present between claws 1 and 2. Apron bearing muscle present dorsal to anterior edge of lamellae; 2 lobes without internal muscles present between apron and lamellae (Fig. 32c): Lamellae followed by unpaired spinous bristle about same length as claw 3.

Bellonci Organ (Fig. 27c): Well developed, bifurcate at midlength, with each branch tapering to point.

Lips: Upper lip as shown in Figs. 28a, 32a,b. Lower lip a beak-shaped process on each side of mouth (Fig. $32 b)$.

Copulatory organ (Fig. 32c-g): Similar to that illustrated in Kornicker et al. (2002: fig. 8g-j) in having 2 tubular processes at tip of anterior branch, but some variability observed in shape and distribution of minute teeth on large flat tooth (Fig. 32d,e,g).

Posterior of body (Fig. 32c): Unsegmented; posterodorsal edge of posterior of specimen with fringe and small spine, but both could be debris.

Remarks. The third segment of the first antenna of the adult male described herein (Fig. 27c) is more elongate than the third segment of the A-1 female illustrated by Kornicker et al. (1990: fig. 22c).

Supplementary description of adult female (Figs. 33a-d, 39f). Carapace shape similar to that of adult female illustrated in Kornicker et al. (2002: fig. 10a) (Fig. 33a-d). Ornamentation similar to that of adult male (Fig. 39f).

Central adductor muscle attachments (Fig. 33a,b): Consisting of about 12 ovoid scars. 


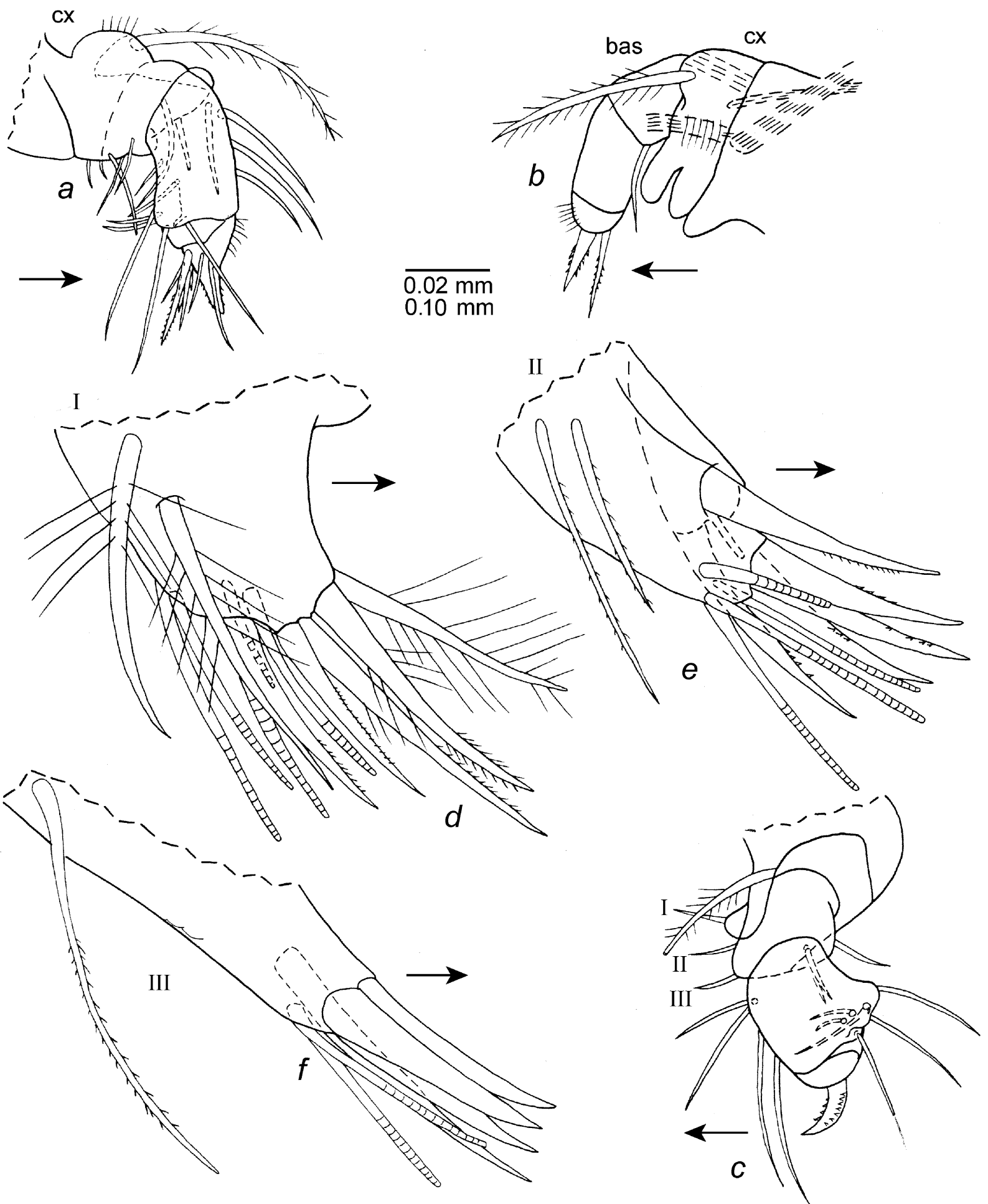

FIGURE 29. Deeveya bransoni Kornicker \& Palmer 1987, USNM 1021408, adult male: maxilla: right limb: $a$, complete limb drawn attached to body, $1 \mathrm{v} ; b$, limb free on slide, mv (nabs). Left limb: $c$, limb free on slide, lv (nabs); d-f, endites I, II, and III, mv. Scale equals $0.10 \mathrm{~mm}(a-c)$ and $0.02 \mathrm{~mm}(d-f)$.

Carapace size (length, height in mm): USNM 1021430, 2.04, 1.56; USNM 1022177, 2.07, 1.57; USNM 1021427, 1.95, 1.44; USNM 1021428, 2.07, 1.44; USNM 1021429, 2.01, 1.36.

Furca: Each lamella with 7 claws. Lamellae followed by unpaired bristle.

Supplementary description of A-1 instar (sex not determined unless noted). Carapace shape and ornamentation (Fig. 39e): Similar to that of adult male. 
Carapace size (length, height in mm): USNM 1021409, female, 1.59, 1.17; USNM 1021410, female, 1.49, 1.16; USNM 1021411, male, 1.59, 1.18; USNM 1021420, male, 1.53, 1.20; USNM 1021421, 1.58, 1.16; USNM 1021422, 1.61, 1.22; USNM 1021423, 1.65, 1.19; USNM 1021424, 1.57, 1.12; USNM 1021433, 2 specimens: $1.62,1.22 ; 1.59,1.19$.

Furca. Each lamella with 7 claws. Lamellae followed by unpaired bristle.

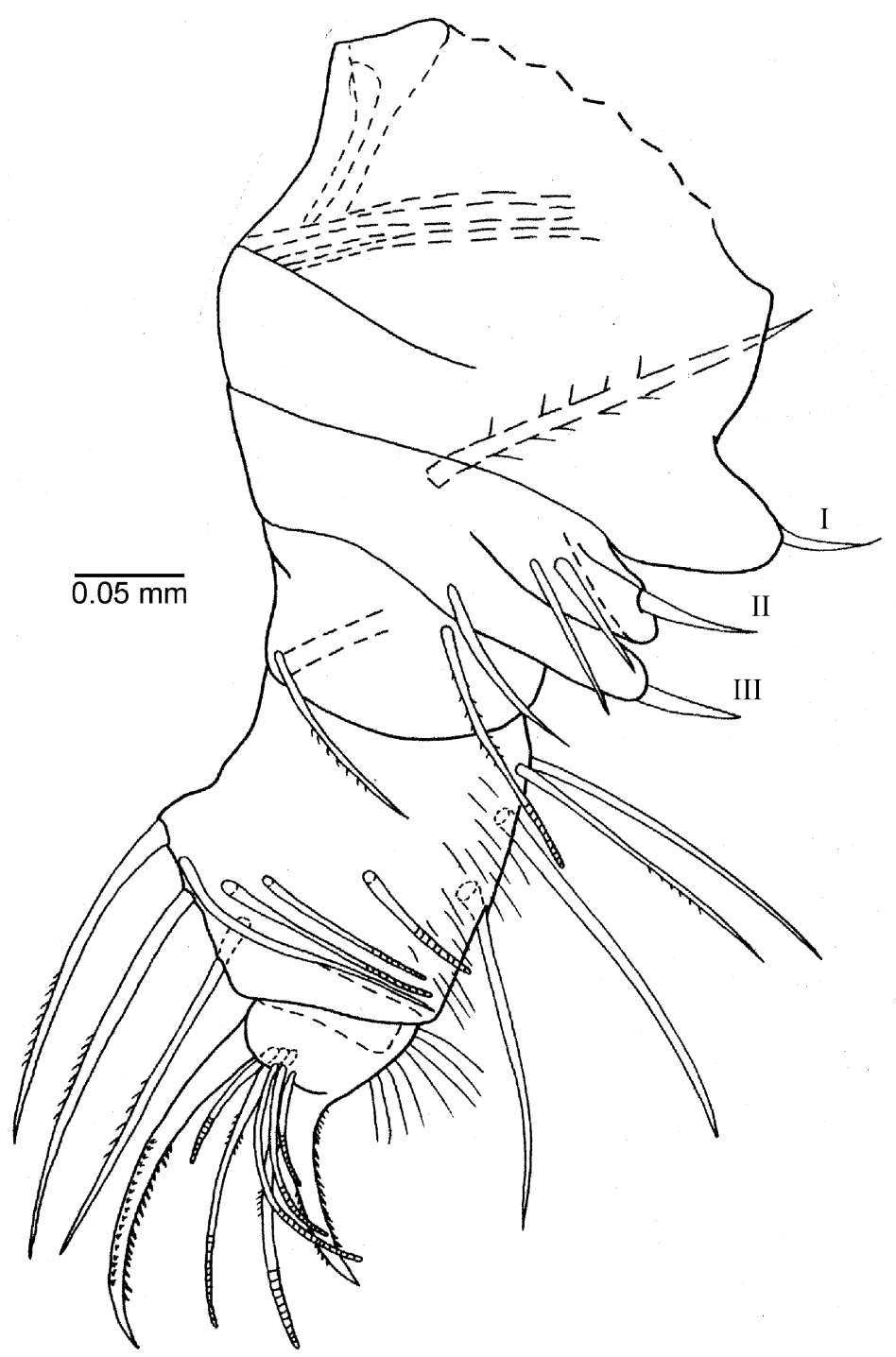

FIGURE 30. Deeveya bransoni Kornicker \& Palmer 1987, USNM 1021408, adult male: left maxilla, mv of endopod (nabs), drawn under cover slip. Scale equals 0.05 .

Supplementary description of A-2 instar (sex not determined). Carapace similar in shape and ornamentation (Fig. 39d) to that of adult male.

Carapace size (length, height in mm): USNM 1021413, 1.20, 0.92; USNM 1021431, 1.17, 0.92; USNM 1022178, 2 specimens: $1.21,0.90 ; 1.17,0.90$.

Second antenna: 9 th exopod segment with 4 bristles.

Maxilla: 2nd endopod segment with 2 claws and 4 bristles.

Sixth limb: Precoxa and Coxa with 5 bristles. Basis with 6 bristles.

Furca: Each lamella with 6 claws followed by small triangular process with pointed or bifid tip (incipient 7th claw). Lamellae followed by unpaired bristle.

Description of A-3 instar (sex unknown) (Figs. 33e-p, 34, 39c). Carapace similar in shape and ornamentation to that of adult male (Figs. 33e, 39c). 
Carapace size (length, height in mm): USNM 1021414, 0.94, 0.72; USNM 1021415, 0.90, 0.72; USNM 1021416, 0.91, 0.71 .

First antenna (Fig. 33f-h): Differs from A-2 instar mainly in having short ventral bristle on 5th segment (just reaching 8th segment), and short b-bristle on 7th segment (about same length as combined lengths of segments 6 and 7). Also, suture separating 3rd and 4th segments only weakly developed. c-bristle slightly shorter than e-bristle; e-bristle long, ringed, and with widely separated marginal spines; d-, f-, and g-bristles filament-like, about $1 / 2$ length of e-bristle.

Second antenna (Fig. 33i): Endopod differs from A-2 instar in having only 1 dorsal bristle on 1 st segment. 9th exopod segment with 3 bristles (1 long, 1 medium, 1 short).
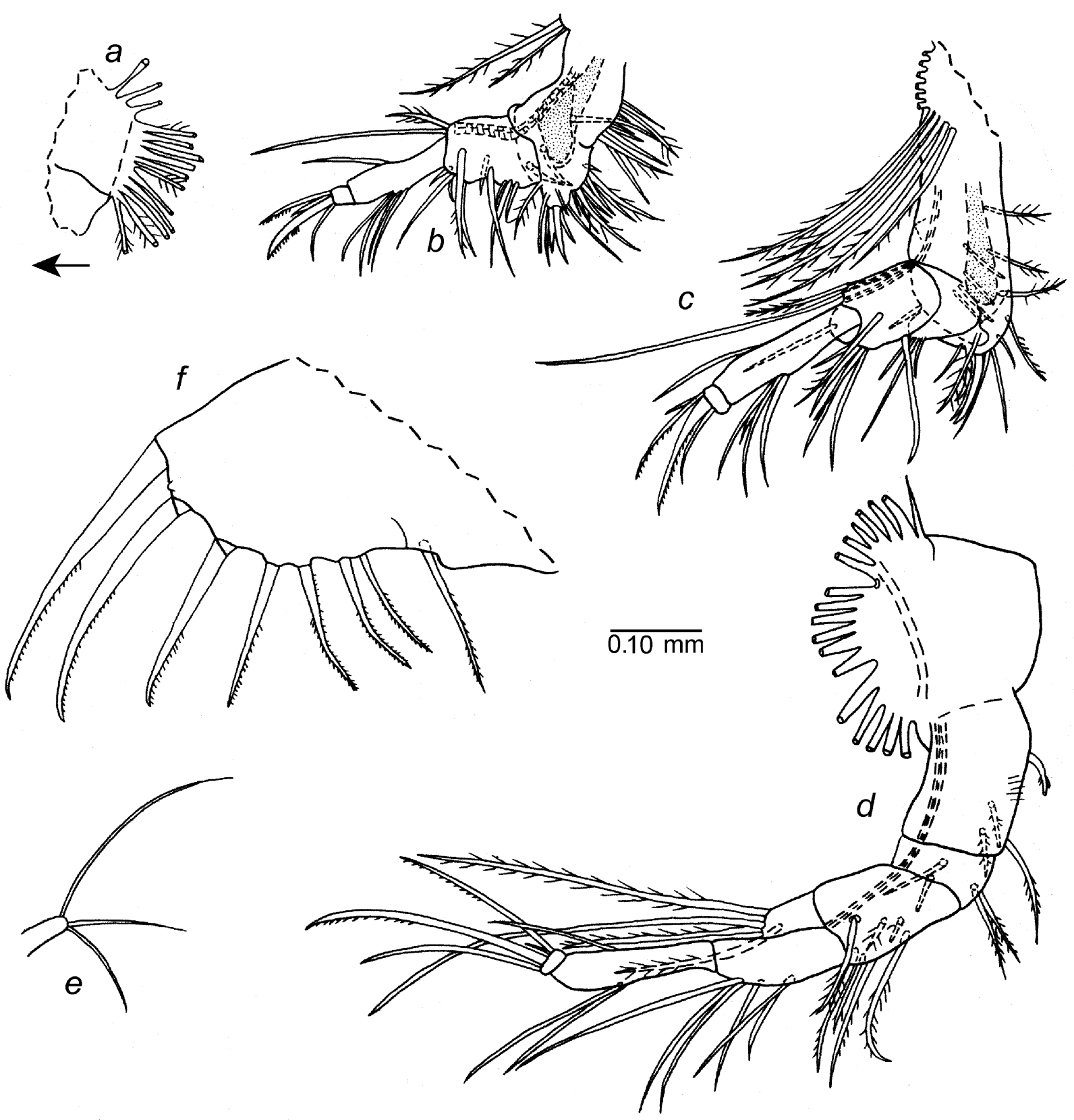

FIGURE 31. Deeveya bransoni Kornicker \& Palmer 1987, USNM 1021408, adult male: fifth limb: $a$, epipod left limb drawn on body, lv (nabs); $b$, left limb loose on slide, mv (nabs); $c$, right limb attached to body, lv (nabs). $d$, left sixth limb loose on slide, mv; $e$, left seventh limb; $f$, left lamella of furca projecting from shell, lv. Scale equals $0.10 \mathrm{~mm}(a-f)$. 


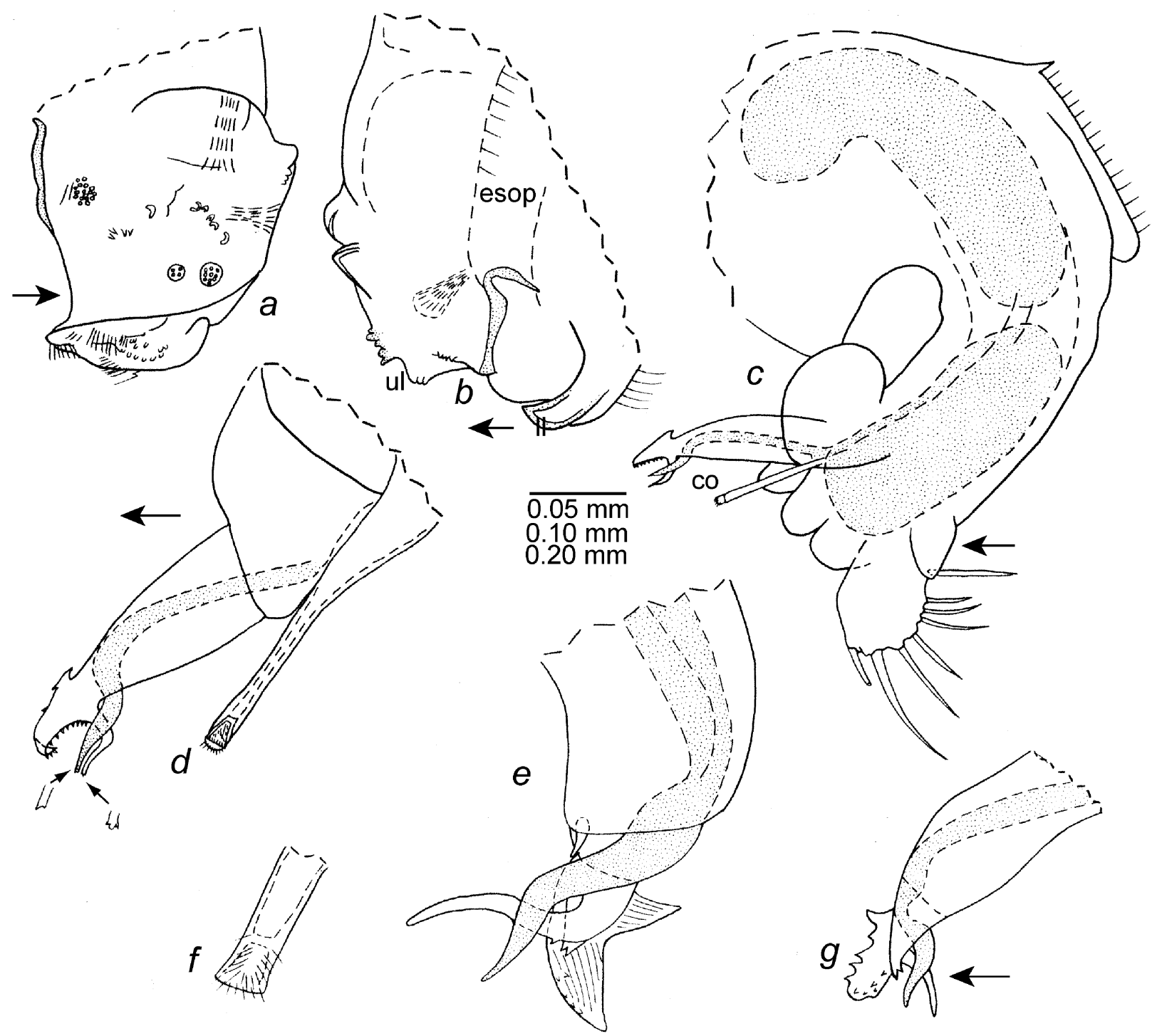

FIGURE 32. Deeveya bransoni Kornicker \& Palmer 1987, USNM 1021408, adult male: $a$, anterior of body and upper lip from right side; $b$, anterior of body, upper lip, and lower lip from left side; $c$, posterior of body from left side; $d$, detail from "c". USNM 1021409, adult male, copulatory limb: $e$, tip of anterior branch from right side; $f$, tip of posterior branch. USNM 1021426, adult male: $g$, copulatory limb, tip of anterior branch. Scale equals $0.10 \mathrm{~mm}(a, b, d, g), 0.20 \mathrm{~mm}$ $(c)$, and $0.05 \mathrm{~mm}(e, f)$.

Mandible: Coxa similar to that of A-2 instar (Fig. 33n). Basis (Fig. 33j,m,o,p) with only 1 of the 2 entwined lateral distal bristles present on the A-2 instar (Fig. 33m,o). Endopod (Fig. 33k-m,o,p): 1st segment with 1 dorsal bristle; 2 nd segment with 1 ventral and 2 dorsal bristles; 3rd segment with 3 short medial bristles forming row and 3 stout terminal bristles (ventral of these bare or with short spines; middle bristle longest, with smooth, pointed, slightly recurved tip and marginal spines; dorsal bristle straight spinous, with short marginal spines).

Maxilla (Fig. 34a): Endite I with 2 proximal and about 7 terminal bristles ( 2 or 3 tubular); endite II with 1 proximal and about 7 terminal bristles ( 1 tubular); endite III with 1 proximal and about 5 terminal bristles (1 tubular). Coxa with stout spinous dorsal bristle. Basis with 2 terminal bristles. Endopod: 1st segment with 3 anterior bristles and 3 distal posterior bristles; 2nd segment with hairs along anterior margin, 2 stout, pectinate, terminal claws, and 4 slender tubular bristles.

Fifth limb (Fig. 34b,c,f,j): Epipod: dorsal group with 4 long bristles; middle group with 6 long bristles; ventral group with 4 long and 1 short bristle. Precoxa and coxa with 15 bristles. Basis with 5 ventral bristles. 
Exopod represented by 2 bristles (1 long, bare, 1 short, spinous). Endopod: 1 st segment with 2 ventral and 1 dorsal bristle; 2nd segment with 2 long and 2 short bristles.

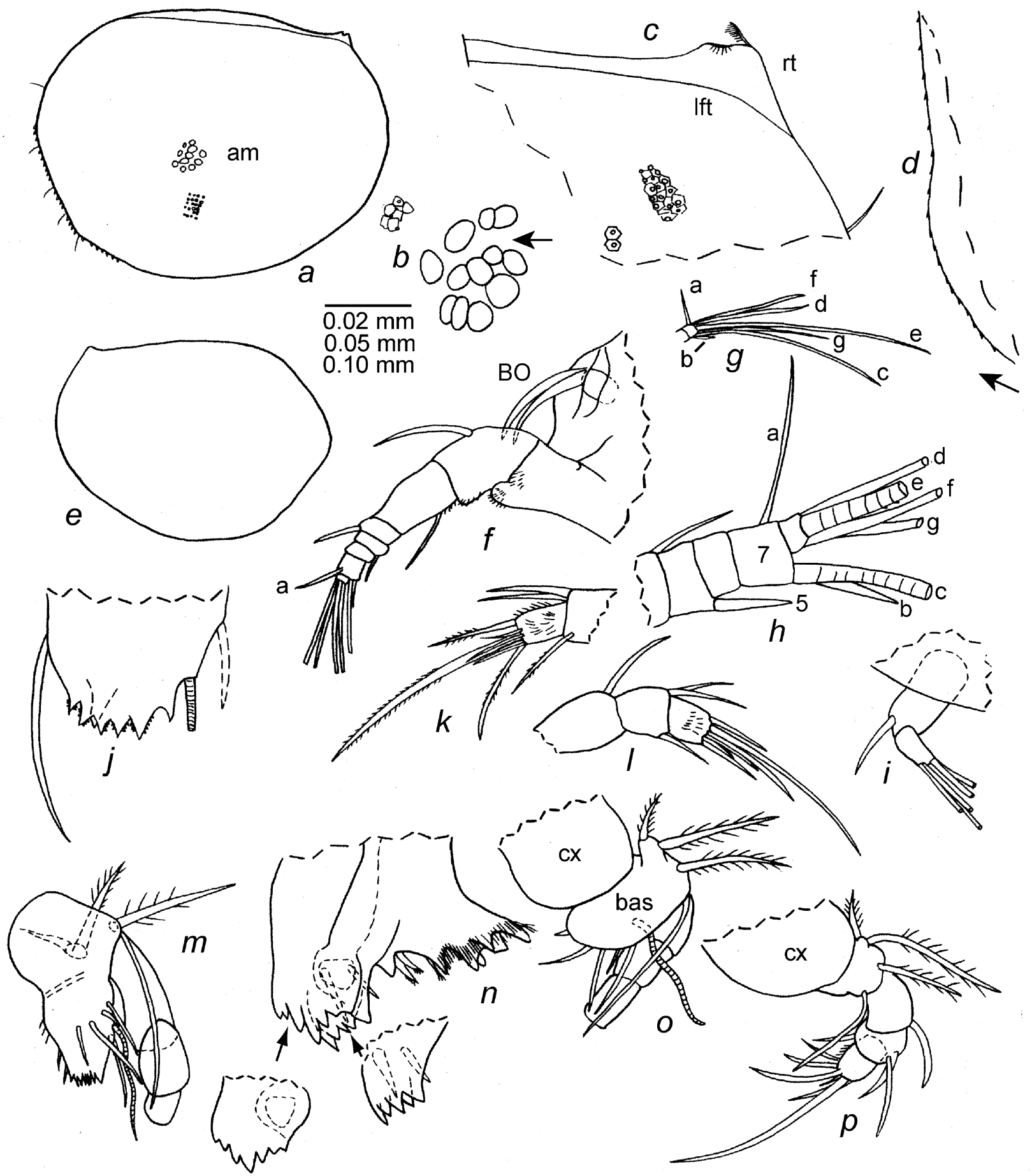

FIGURE 33. Deeveya bransoni Kornicker \& Palmer 1987, USNM 1021430, adult female carapace, length 2.04 mm: $a$, complete carapace from left side showing adductor muscle attachments (ovals) and typical reticulations; $b$, detail from a; $c$, detail of left and right valves showing gland and bristle on right valve; $d$, detail showing slight concavity on anterior of left valve. USNM 1021414, A-3 instar (sex unknown): $e$, complete carapace from right side, length 0.72 mm; $f$, Bellonci Organ and left first antenna drawn on body, lv; $g$, tip of right first antenna projecting from carapace, lv; $h$, tip left first antenna, lv; $i$, endopod of left second antenna, lv; $j$, tip of basis of right mandible, mv; $k$, tip of endopod of right mandible, mv; $l$, tip of endopod of left mandible drawn on body, mv; $m$, basis and endopod right mandible, lv (nabs); $n$, tip of coxa of right mandible, lv; $o$, $p$, right mandible drawn on body, lv (nabs). Scale equals $0.10 \mathrm{~mm}(a b-d, g), 0.05 \mathrm{~mm}(f, i, k-$ $m, o, p)$, and $0.02 \mathrm{~mm}(h, j, n)$. 


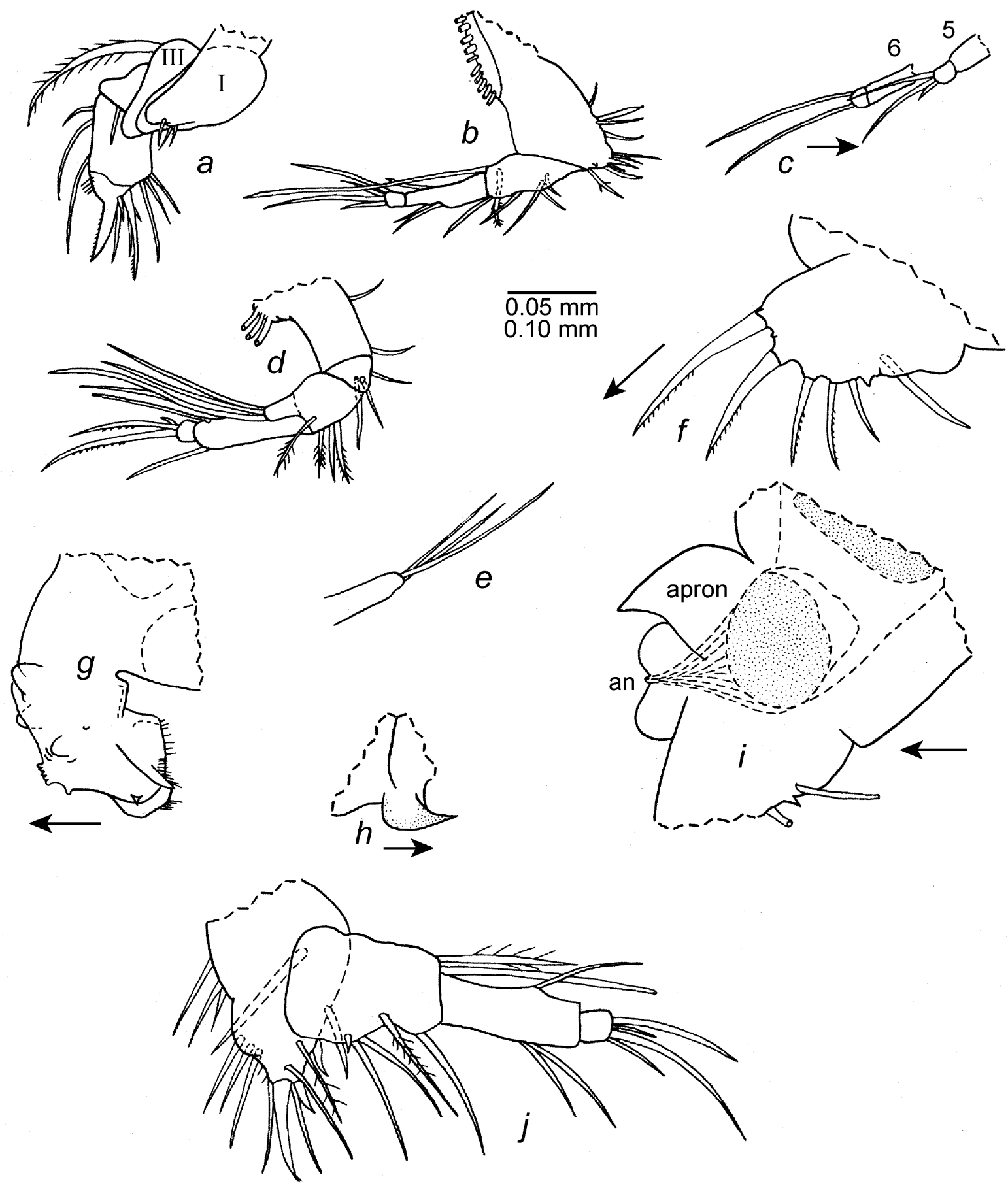

FIGURE 34. Deeveya bransoni Kornicker \& Palmer 1987, USNM 1021414, A-3 instar (sex unknown): $a$, right maxilla, $\mathrm{mv}$ (nabs); $b$, right fifth limb drawn on body, lv; $c$, tips of right fifth and sixth limbs drawn on body, lv; $d$, right sixth limb drawn on body, lv; $e$, left seventh limb, lv; $f$, left lamella of furca, lv; $g$, anterior of body and upper lip; $h$, lower lip; $i$, posterior of body showing apron, anus, and left lamella of furca, lv (nabs). USNM 1021430, A-3 instar (sex unknown); j, left fifth limb drawn on body, lv. Scale equals $0.10 \mathrm{~mm}(b-d, h)$ and $0.05 \mathrm{~mm}(e-g, i, j)$.

Sixth limb (Fig. 34c,d): Tip of limb extends well past tip of 5th limb (Fig. 34c). Epipod: dorsal group with 5 long bristles; middle group with 6 long bristles; ventral group with 1 short and 4 long bristles. Precoxa and coxa with 5 ventral bristles. Basis with 4 bristles. Exopod with 4 long bristles. Endopod: 1st and 2nd segments fused, with 2 bristles ( 1 dorsal, 1 ventral) on 2nd segment; 3rd segment with 2 stout claw-like pectinate bristles and 1 short slender bristle. 
Seventh limb (Fig. 34e): With 3 terminal bristles (1 long, 2 shorter).

Furca (Fig. 34f,i): Each lamella with 5 claws followed by small triangular process with pointed tip (incipient 6th claw). Lamellae followed by unpaired bristle. Small lateral glandular process between claws 1 and 2 . Apron similar to that of adult. (On specimen studied apron separated from furca by 2 lobes, 1 on each side of anus (Fig. 34i)).

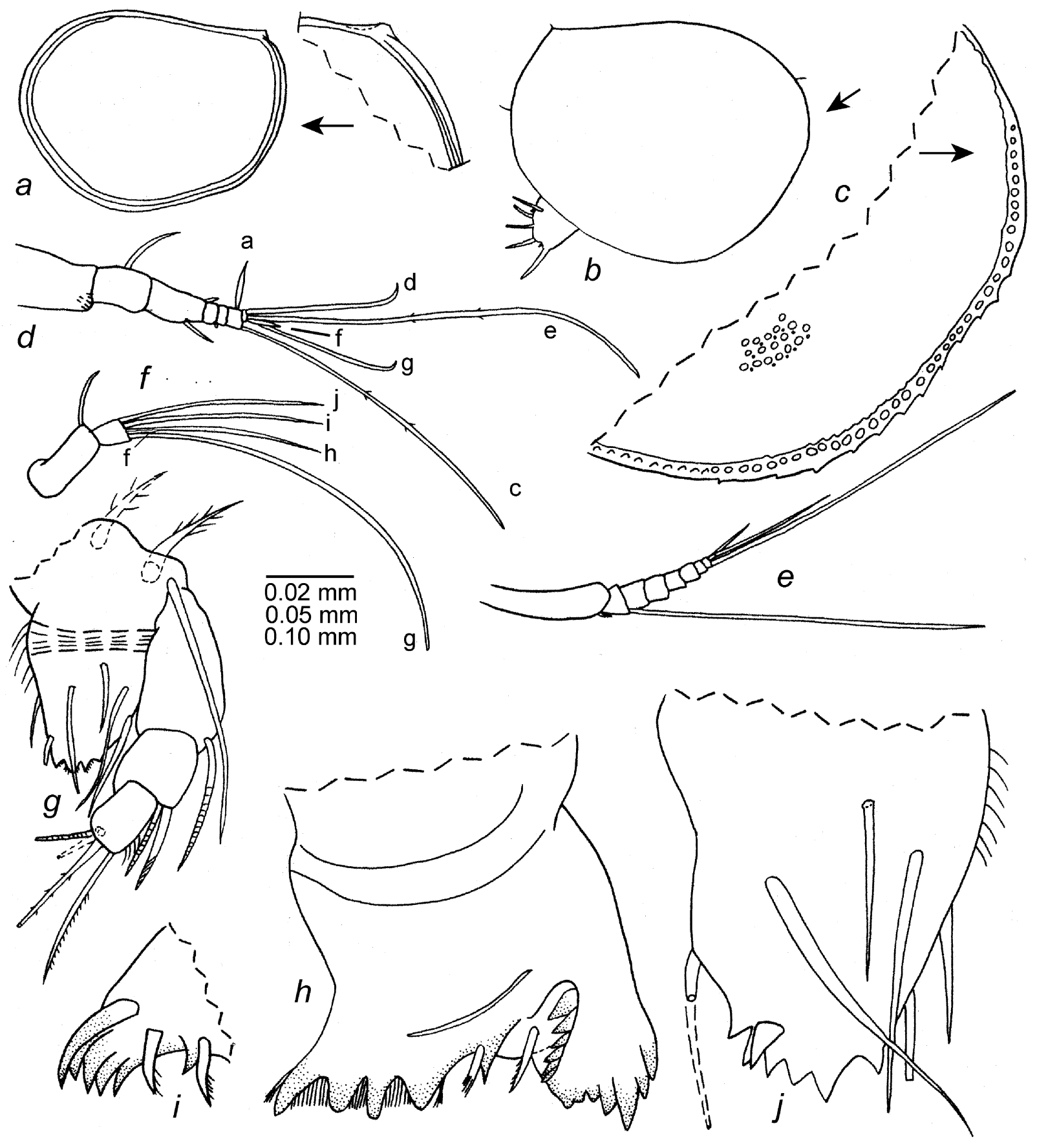

FIGURE 35. Deeveya bransoni Kornicker \& Palmer 1987, USNM 1021425, A-4 instar (sex unknown): $a$, right valve, length $0.73 \mathrm{~mm}$, iv. USNM 1021437, A-4 instar (sex unknown): $b$, complete specimen from right side, length $0.74 \mathrm{~mm}$; $c$, anterior of complete specimen from right side; $d$, right first antenna projecting from carapace, lv; $e$, exopod left second antenna projecting from carapace, lv (nabs); $f$, endopod right second antenna, lv; $g$, basis and endopod right mandible, lv; $h$, tip coxa right mandible, iv; $i$, proximal set of teeth of coxa of left mandible, lv; $j$, distal part basis left mandible, lv. Scale equals $0.10 \mathrm{~mm}(c-f), 0.05 \mathrm{~mm}(g)$ and $0.02 \mathrm{~mm}(h-j)$. 


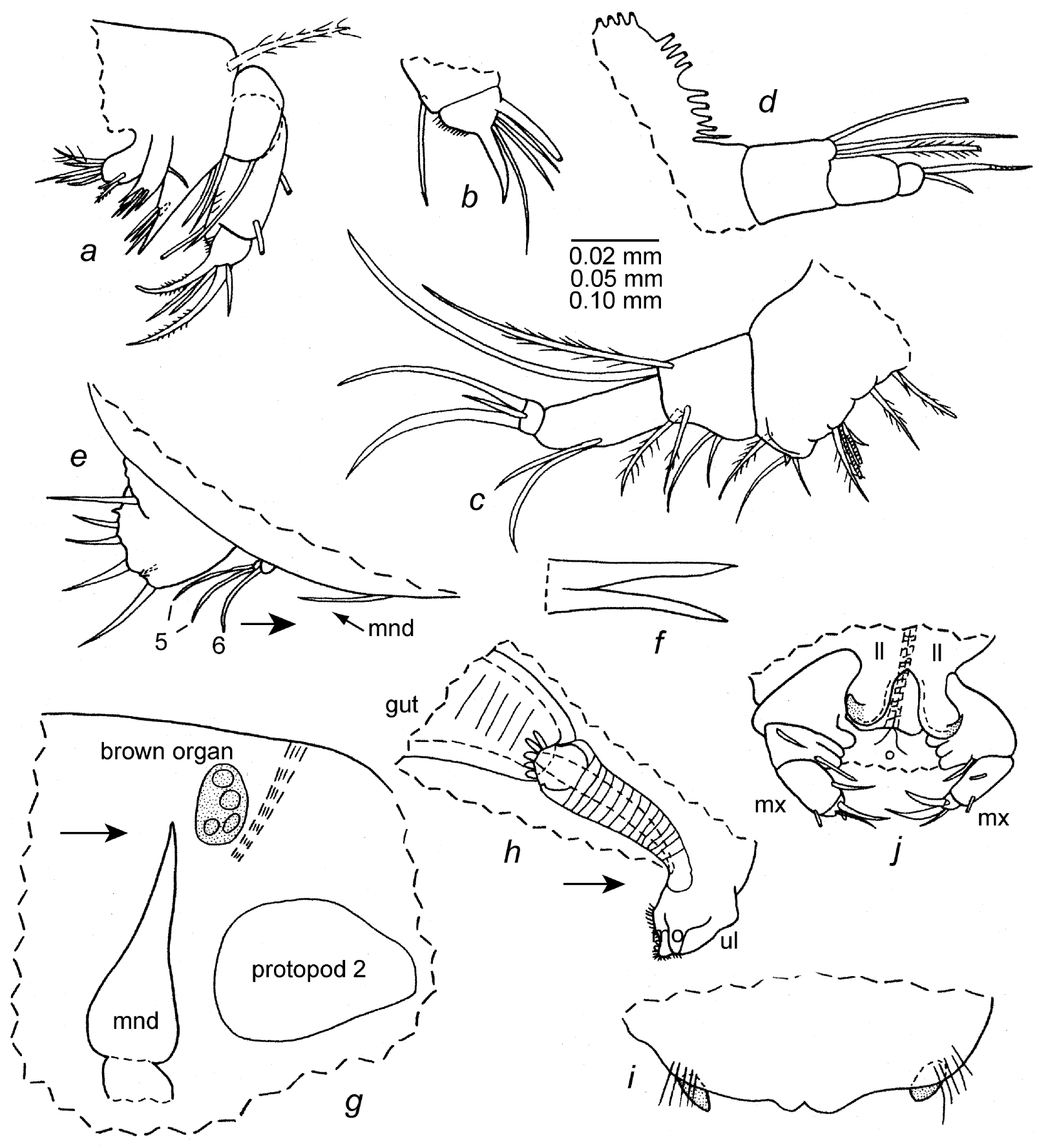

FIGURE 36. Deeveya bransoni Kornicker \& Palmer 1987, USNM 1021437, A-4 instar (sex unknown): $a$, left maxilla, $\mathrm{lv} ; b$, tip right maxilla, mv; $c$, left fifth limb, mv; $d$, right sixth limb, mv (nabs); $e$, right furcal lamella, tips of right mandible, fifth and sixth limbs, lv; $f$, Bellonci Organ; $g$, part of body from right side showing lateral eye, coxa of mandible, and protopod of second antenna; $h$, upper lip and esophagus from right side; $i$, profile of anterior of body, vv or dv; $j$, ventral view of anterior of body showing maxillae and lower lip. Scale equals $0.10 \mathrm{~mm}(a, e, g, h, j), 0.05 \mathrm{~mm}(b-d, f)$ and 0.02 $\mathrm{mm}(i)$.

Bellonci Organ (Fig. 33f): Bifurcate distally, with branches tapering to pointed tip.

Lips: Upper lip (Fig. 34g) and lower lip (Fig. 34h), similar to those of later instars and adults.

Gut content: Gut filled with unidentified amber-colored particulate matter.

Description of A-4 instar (sex unknown) (Figs. 35, 36, 39b). Carapace similar in shape to A-3 instar (Fig. 35a-c). Right valve with small projecting glandular process at posterior end of dorsal margin; process with small bristle. 
Ornamentation (Figs. 35c, 37b): Surface in transmitted light with bright round spots inside very weakly developed reticulations (Fig. 39b). Smaller round bright spots present between larger bright spots, few bristles along valve margins. The spots form concentric circles on the valve surface.

Carapace size (length, height in mm): USNM 1021425, right valve, 0.73, 0.57; USNM 1021437, 0.74, 0.59 .

First antenna (Fig. 35d): 1st segment with spines in distal ventral corner. 2nd segment with 1 dorsal bristle. 3rd and 4th segments fused but indentation on ventral margin indicates place of separation; 3rd segment with 1 ventral bristle; 4th segment with 1 short dorsal bristle. 5th segment bare or with minute ventral terminal nub. 6th segment bare. 7th segment with short a-bristle and long c-bristle with minute widely separated marginal spines. 8th segment with medium d-bristle, long e-bristle with widely separated minute spines and with terminal papilla, medium g-bristle with terminal papilla, and very short f-bristle. 1st and 2nd segments linear.

Second antenna (Figs. 35e,f, 36g): Exopod with 1st segment not divided into 2 parts, with small terminal ventral bristle. Segments 2 to 8 with long ventral bristle. Segment 9 with 2 bristles (1 medium, 1 small). Endopod: segment 1 with 1 dorsal bristle; segment 2 with short f-bristle and long g-bristle; segment 3 fused to segment 2, with long h-, i-, and j-bristles.

Mandible (Figs. $35 g-j, 36 g$ ): Coxa endite with proximal and distal sets of teeth separated by space (Fig. $35 h, i)$ : proximal set comprising 4 stout cusps and with 2 short spinous bristles ( 1 on anterior edge, 1 on posterior edge); surface between cusps with abundant slender spines; stout pointed tooth between proximal and distal sets of teeth, with 1 spinous bristle lateral to tooth. Distal set of teeth comprising 2 flat teeth; proximal and distal teeth each with 6 cusps; stout lateral bristle proximal to proximal tooth. Basis with 2 plumose medial bristles near dorsal margin and 1 long slender lateral bristle near endopod (Fig. 35g). Basis endite: left limb (Fig. 35j): anterior margin with single bristle; posterior margin with proximal hairs and 1 short bristle proximal to short distal tubular bristle; lateral side with 3 bristles (1 long posterior to midwidth, 1 long near posterior margin, 1 short proximal and anterior to long bristles; none entwined); ventral edge of endite with 6 cusps; single lateral tooth near distal edge of endite. Right limb (probably aberrant) (Fig. 35g): differs from left limb in having basis endite with only 4 terminal teeth and no distal lateral tooth). Endopod with 3 segments (Fig. 35g): 1st segment with 1 dorsal terminal bristle; 2 nd segment with 2 dorsal terminal bristles (1 claw-like); 3rd segment hirsute medially and along anterior margin, with 1 medial bristle and 3 terminal bristles.

Maxilla (Fig. 36a,b,j): Endite I with 2 proximal and 5 terminal bristles (1 tubular); endite II with 1 proximal and 4 or 5 terminal bristles ( 2 tubular); endite III with 1 proximal and 4 terminal bristles ( 1 tubular). Coxa with 1 plumose dorsal bristle. Basis with 1 ventral bristle and 1 bristle at midwidth. Endopod with 2 segments: 1 st segment with 2 anterior and 1 posterior bristle. 2nd segment with 2 claw-like bristles and 3 slender bristles; ventral edge of segment bare or with spines.

Fifth limb (Fig. 36c,e): Epipod with plumose bristles forming 3 groups: 4 bristles in dorsal group and 6 in middle group; ventral group fragmented, with 2 bristles on remaining part. Precoxa and coxa with total of 11 bristles and claws ( 2 bristles tubular, 1 claw short tooth-like). Basis with 4 bristles. Exopod represented by 2 long bristles ( 1 bare, 1 plumose). Endopod with 2 segments: 1st segment with 2 distal ventral bristles; 2nd segment with 2 slender claw-like bristles and 1 short slender bristle.

Sixth limb (Fig. 36d,e): Epipod with plumose bristles forming 3 groups: 4 bristles in dorsal and middle groups, 5 in ventral group (ventral bristle short). Precoxa and coxa fragmented during dissection; no bristles observed prior to dissection [instar A-4 of D. jillae bears 1 bristle (Kornicker \& Iliffe 1985: Fig. 15h)]. Basis without bristles. Exopod represented by small lobe with 3 long bristles (inner bristle plumose, others bare). Endopod with 2 segments: 1st segment bare; 2nd segment with 2 terminal bristles. Terminal segment not extending past distal segment of 5th limb (Fig. 36e). Sutures between segments indistinct.

Seventh limb: Absent.

Furca (Fig. 36e): Each lamella with 4 claws followed by small triangular process fused to lamella. Claws 
separated from lamella by suture. Small projecting lateral glandular process present midway between claws 1 and 2. Unpaired lateral bristle present posterior to lamellae.

Bellonci Organ (Fig. 36f): Well developed, bifurcate distally, branches taper to point.
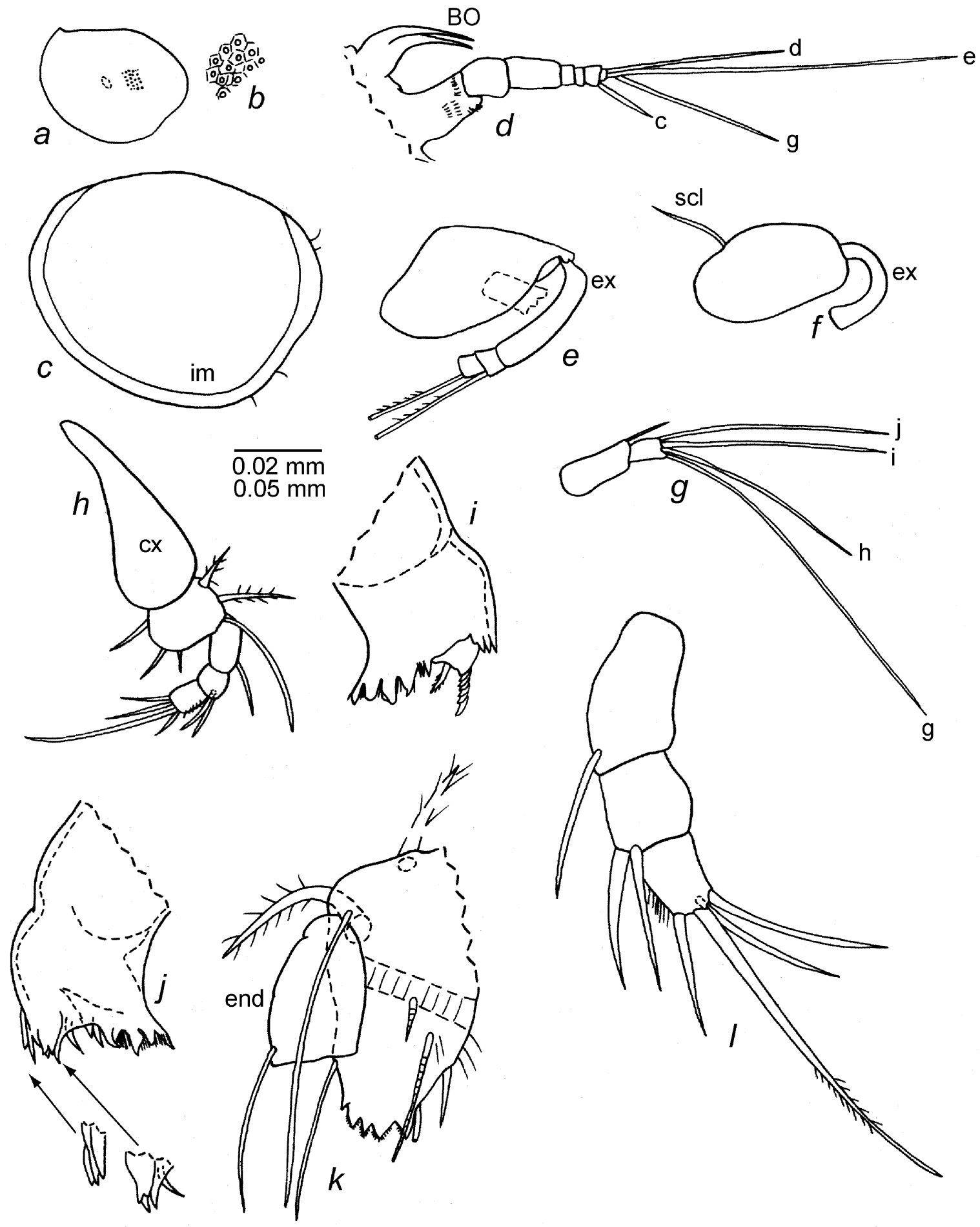

FIGURE 37. Deeveya bransoni Kornicker \& Palmer 1987, USNM 1021418, A-5 instar (sex unknown): $a$, right valve, length $0.57 \mathrm{~mm}$, ov; $b$, detail of surface, from " $a$ "; $c$, left valve, iv; $d$, right first antenna and Bellonci Organ, lv; $e$, part right second antenna, lv; $f$, part right second antenna showing posterior pivot sclerite, lv; $g$, endopod right second antenna, lv. Mandible: $h$, right limb drawn attached to body, lv; $i$, tip of coxa of right limb, lv; $j$, tip of coxa of left limb, $\mathrm{lv}$; $k$, basis and first article of endopod of left limb, lv; $l$, endopod of left limb, lv. Scale equals $0.05 \mathrm{~mm}(b, d-h)$ and 0.02 $\mathrm{mm}(i-l)$. 
Lips: Upper lip (Fig. 36h,i) and lower lip (Fig. 36j), in general, similar to those of A-3 instar. Dorsal end of esophagus with transparent flap-like structures (Fig. 36h).

Brown Organ (Fig. 36g): With 4 ovoid cells.

Gut content: Unidentified matter, somewhat stringy.

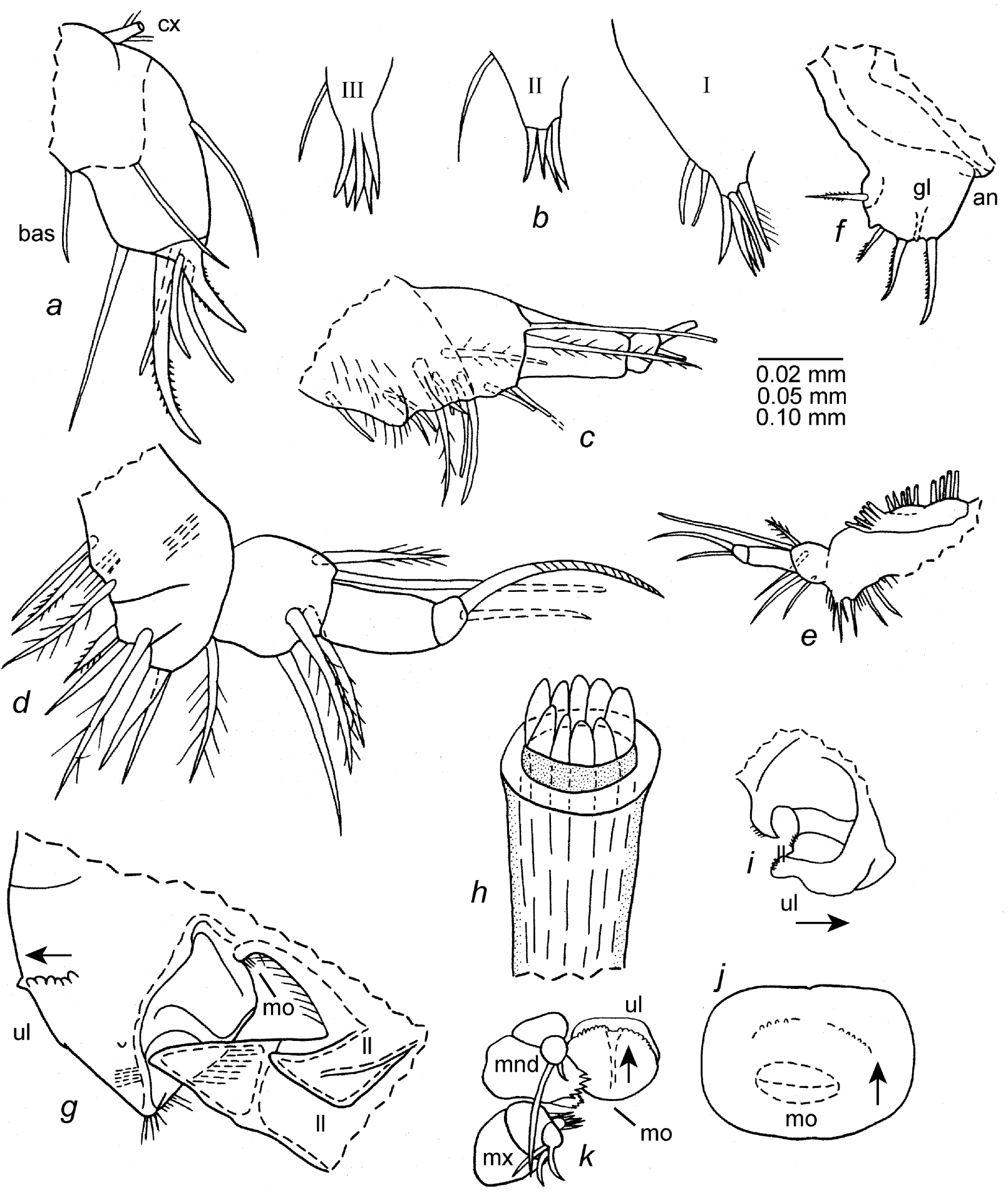

FIGURE 38. Deeveya bransoni Kornicker \& Palmer 1987, USNM 1021418, A-5 instar (sex unknown): $a$, part left maxilla, mv; $b$, endites I, II, and III of left maxilla; $c$, distal part left fifth limb, lv; $d$, right fifth limb, mv; $e$, right fifth limb drawn attached to body, lv; $f$, right lamella of furca, lv; $h$, esophagus and mouth are below bottom end of illustration; $i$, anterior of body and upper and lower lips from right side; $j$, ventral view of upper lip (mouth beneath lip dashed). USNM 1021417, A-5 instar (sex unknown): $k$, ventral view of part of right body showing location of upper lip, right mandible and right maxilla. Scale equals $0.02 \mathrm{~mm}(a-d, g, h), 0.05 \mathrm{~mm}(e, f, i, j)$ and $0.10 \mathrm{~mm}(k)$. 


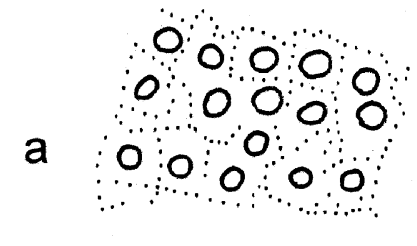

A - 5

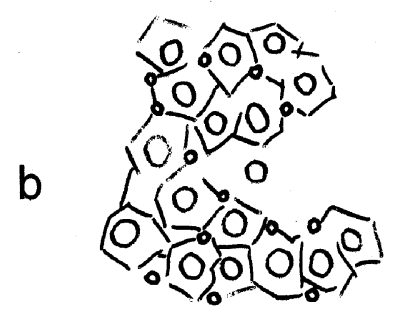

A - 4

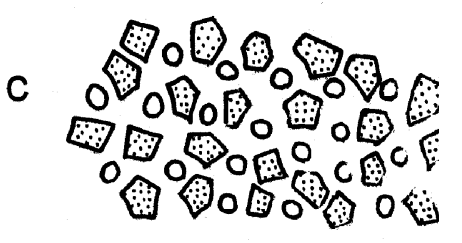

A - 3 d

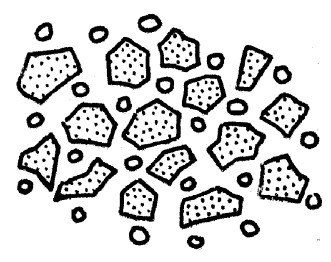

A - 2

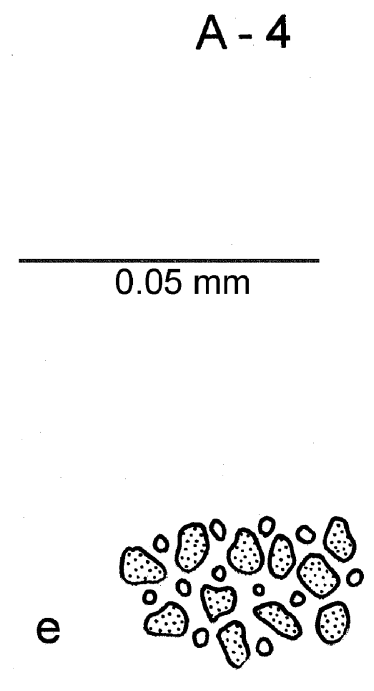

A - 1

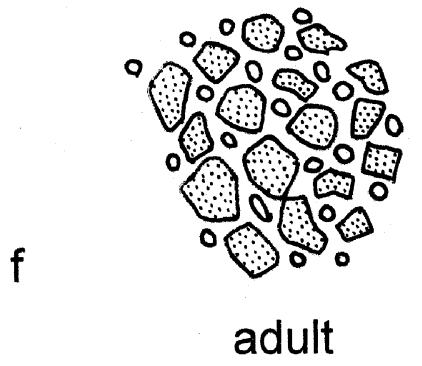

female

FIGURE 39. Deeveya bransoni Kornicker \& Palmer 1987, polygons and disks forming surface structures on carapace: $a$, USNM 1021418, A-5; $b$, USNM 1021437, A-4; $c$, USNM 1021414, A-3; $d$, USNM 1021431, A-2; $e$, USNM 1021410, A-1, female; $f$, USNM 1021430, adult female. Scale equals $0.05 \mathrm{~mm}(a-f)$.

Description of A-5 instar (sex unknown) (Figs. 37-39a). Carapace similar in shape to that of A-3 instar (Fig. 37a,c).

Ornamentation (Figs. 37a,b, 39a): Valve viewed in transmitted light with closely spaced large round bright spots appearing inside very weakly developed reticulations (Fig. 39a). Few single bristles along valve edge.

Infold (Fig. 37c): Broad transparent infold along anterior, ventral, and posterior margins.

Carapace size (length, height in mm): USNM 1021418, 0.57, 0.44; USNM 1021417, 0.59, 0.49; USNM $1021438,0.56,0.46$.

First antenna (Fig. 37d): Differs from A-3 instar in having 3rd and 4th segments fused (without suture separating them), and in lacking a dorsal bristle on the 2nd segment, a ventral bristle on the 3rd segment, a dorsal bristle on the 4th segment, a ventral bristle on the 5th segment, a- and b-bristles on the 7th segment, and an f-bristle on the 8th segment. Also, the c-bristle of the 7th segment is much shorter.

Second antenna (Fig. 37e-g): Endopod differs from A-3 instar in lacking an f-bristle on the 2nd segment (Fig. 37g). Exopod: 1st segment not divided into two parts, and without short terminal bristle present on A-4 instar (Fig. 37e). 9th segment with 2 bristles (1 medium, 1 short). Posterior edge of protopod with slender sclerite (Fig. 37f).

Mandible (Fig. 37h-l): Coxa endite (Fig. 37i, j): proximal set of teeth similar to that of A-3 instar. Stout tooth between proximal and distal sets of teeth and 1 or 2 bristles adjacent to tooth. Distal set of teeth comprising 2 flat teeth (proximal set with 7 cusps; distal set with fewer cusps (exact number of teeth present 
obscured); 1 bristle present lateral to proximal set of teeth. Basis with long slender bristle near insertion of endopod and 2 plumose bristles near dorsal margin (Fig. 37h,k). Basis endite (Fig. 37k): anterior margin with single bristle; posterior margin with proximal hairs, 1 short proximal bristle, and 1 short distal tubular bristle; lateral side with 2 slender bristles; bristles entwined on adult absent; ventral edge of endite with 5 terminal cusps, and without short stout lateral tooth proximal to distal edge. Endopod 3-segmented (Fig. 37l): 1st segment with 1 terminal dorsal bristle and without medial bristles; 2nd segment with 2 terminal dorsal bristles (1 claw-like); 3rd segment hirsute medially and along anterior margin, with 1 medial bristle and 3 terminal bristles.

Maxilla (Fig. 38a,b,k): Endite I with 2 proximal bristles and about 5 terminal bristles; endite II with 1 proximal and 4 or 5 terminal bristles; endite III with 1 long proximal bristle and about 5 terminal bristles (some endite bristles tubular) (Fig. 38b). Coxa with stout plumose dorsal bristle. Basis with 2 terminal bristles. Endopod (Fig. 38a): 1st segment with 2 bristles (1 anterior, 1 tubular); 2nd segment with 2 stout pectinate claws and 3 tubular bristles; anterior edge of segment bare.

Fifth limb (Fig. 38c-e): Epipod: dorsal group with 4 long bristles; middle group with 5 or 6 long bristles; ventral group with 5 bristles (ventral of these shorter). Precoxa and coxa with long hairs and 9 bristles. Basis with 3 bristles. Exopod represented by 2 bristles (1 long bare, 1 shorter plumose). Endopod: 1st segment elongate, bare; 2nd segment with 2 terminal bristles (1 long and clawlike, 1 short). Sutures separating segments indistinct.

Sixth limb and Seventh limbs: Absent.

Furca (Fig. 38f): Differs from A-1 instar in having 3 instead of 5 claws. Anus visible just dorsal to anterior edge of lamellae.

Bellonci Organ (Fig. 37d): Similar to that of A-1 instar.

Lips and mouth (Fig. 38g-k): In general, upper lip similar to that of A-3 instar. Lower lip with a large and a small triangular process. Dorsal end of esophagus with transparent elongate structures (Fig. 38h) (similar structures in A-4 instar).

Gut content: Filled with fine-grained particulate matter containing numerous minute unidentified ovoids.

Remarks. The species is reported for the first time in Conch Sound Blue Hole, Sanctuary Blue Hole, and Double Drop Blue Hole.

Ontogenetic development (Table 9). The present collection includes A-3, A-4, and A-5 instars. An A-4 instar of D. jillae was described by Kornicker \& Iliffe (1989a: 19). In that publication the specimen had been identified erroneously as an A-3 instar (Kornicker et al. 2002:Table 5). The A-3 and A-5 instars of Deeveya have not been described previously.

Carapace: The carapaces of adult and later instars of species of Deeveya are ornamented with walled polygons, and disks that appear bright in transmitted light are present at the intersections of the polygonal walls. In the present collection walled polygons are developed on the carapaces of instars A-1, A-2, and A-3, but only weakly on carapaces of instars A-4 and A-5. The bright disks on the carapace of the A-4 and A-5 instars are relatively larger than those on the carapaces of the later instars as well as that of the adult (Fig. 39). The carapace of the A-4 instar has smaller round bright disks between the larger disks. The large bright disks on instars A-4 and A-5 are interpreted to be forerunners of reticulations, and are no longer present when the reticulations become well developed in later instars and adults. Thus, the large disks on instars A-4 and A-5 are equivalent to reticulations in valves of later instars and adults, and not to the disks on valves of those stages. The smaller disks on valves of the A-4 instar are equivalent to the disks of the adults. The disks form concentric ovals on the valves (this is more apparent on the A-4 instar described herein than on the other stages).

First antenna: Segments 3 and 4 are fused on instars A-5 and A-4 instars and are separated by a suture in later stages. Segment 2 of instar A-5 is without a dorsal bristle but bears 1 dorsal bristle on later stages. Segment 3 of instar A- 5 is without a ventral bristle but bears 1 bristle on later stages. Segment 4 is without a dor- 
sal bristle on instar A-5, but bears either a short node or small bristle on instar A-4, and 1 bristle on later instars. Segment 5 is without a ventral bristle on instars A-5 and A-4 but bears a bristle on later instars; the bristle becomes longer on later instars. The 7th segment of instar A-5 lacks b- and c-bristles, and the 8th segment lacks a g-bristle. The 7th segment on the A-4 instar lacks only the b-bristles, and the 8th segment bears a small g-bristle. Instar A-3 and later stages bear on segments all bristles present on the adult; both the b-bristle of the 7th segment and the g-bristle of the 8th segment become longer on later instars.

Second antenna: Exopod: The 1st segment is not divided into two parts on instar A-5, is partly divided on A-4, and is divided on later stages. The 1st segment is without a bristle on instar A- 5 and bears 1 short bristle on later stages. The 9th segment bears 2 bristles on instars A-5 and A-4, 3 on the A-3 instar, and 4 on later stages. Endopod: 1st segment with 1 dorsal bristle on instars A-5, A-4, and A-3, and 2 dorsal bristles on later stages. 2nd segment without f-bristle on instar A-5 and with bristle on later instars (f-bristle on instar A-4 very small). All stages with g-, h-, i-, and j-bristles.

Mandible: Basis: The distributions of bristles on the mandible of known stages are listed in Table 9. Of particular interest is the distribution of the two distal lateral bristles of the basis that are entwined on later stages. Both bristles are absent on the A-5 instar and one is absent on instar A-4; both bristles are present on the A-3 instar but are not entwined; the bristles cross each other 2 or 3 times on the A- 2 instar, and 4 or 5 times on later stages. A distal lateral tooth present on the basis endite of the A-4 instar and later stages is absent on instar A-5.

Maxilla and fifth limb: See Table 9 for distribution of bristles.

Sixth limb: The 1st and 2nd endopod segments are fused in instars A-5, A-4, and A-3 and separated by a suture in later stages. The limb is absent on instar A-5, is weakly developed and does not extend past the 5th limb on instar A-4, and is well developed and extends past the 5 th limb in later stages.

Seventh limb: The limb with bristles is absent on instars A-5 and A-4 and bears 3 bristles on later stages.

Furca: Each furcal lamella bears 3 claws on instar A-5, 4 claws on instar A-4, 5 claws on instar A-3, 6 claws on instar A-2, and 7 claws on instar A-1 and the adult. Except for the A-1 instar and adult, each lamella of earlier instars bears a small triangular process (incipient claw) following the last claw.

Bellonci Organ: Similar on all known stages.

\section{Deeveya medix Kornicker 1990 in Kornicker et al. 1990}

Fig. 40

Deeveya medix Kornicker 1990 in Kornicker et al. 1990: 44, figs. 22f, 27, 28, 29 f, 30.

Holotype. USNM 193592, adult male.

Type locality. Sagittarius Blue Hole, Sweeting's Cay, Grand Bahama Island, Little Bahama Bank.

Material. Type locality: Collected 29 May 1989: USNM 1021442, 1 adult female in alcohol. Collected 29 Mar 1991: USNM 1021443, 1 adult male, 1 adult female, both in alcohol. Sta 01-016: USNM 1021444, 1 adult female in alcohol; USNM 1021445, 7 specimens in alcohol. Basil Minn's Blue Hole, Great Exuma Island, Great Bahama Bank: Sta 00-001:USNM 1021446, 2 adult females in alcohol; USNM 1021447, 1 partly dissected adult male in alcohol; USNM 1021448, 3 undissected adults in alcohol (sex not determined). Virgo Blue Hole, Sweeting's Cay, Grand Bahama Island, Little Bahama Bank, Sta 01-015: USNM 1021449, 3 specimens in alcohol.

Distribution. Little Bahama Bank, Sweeting's Cay (Sagittarius Blue Hole and Virgo Blue Hole). Great Bahama Bank, Great Exuma Island (Basil Minn's Blue Hole).

Supplementary description of adult female. Carapace Size (length, height in mm): USNM 1021442, 1.69, 1.23; USNM 1021443, 1.66, 1.22.; USNM 1021446, 1.68, 1.28; USNM 1022179, 1.68, 1.28; USNM $1021444,1.70,1.29$. 


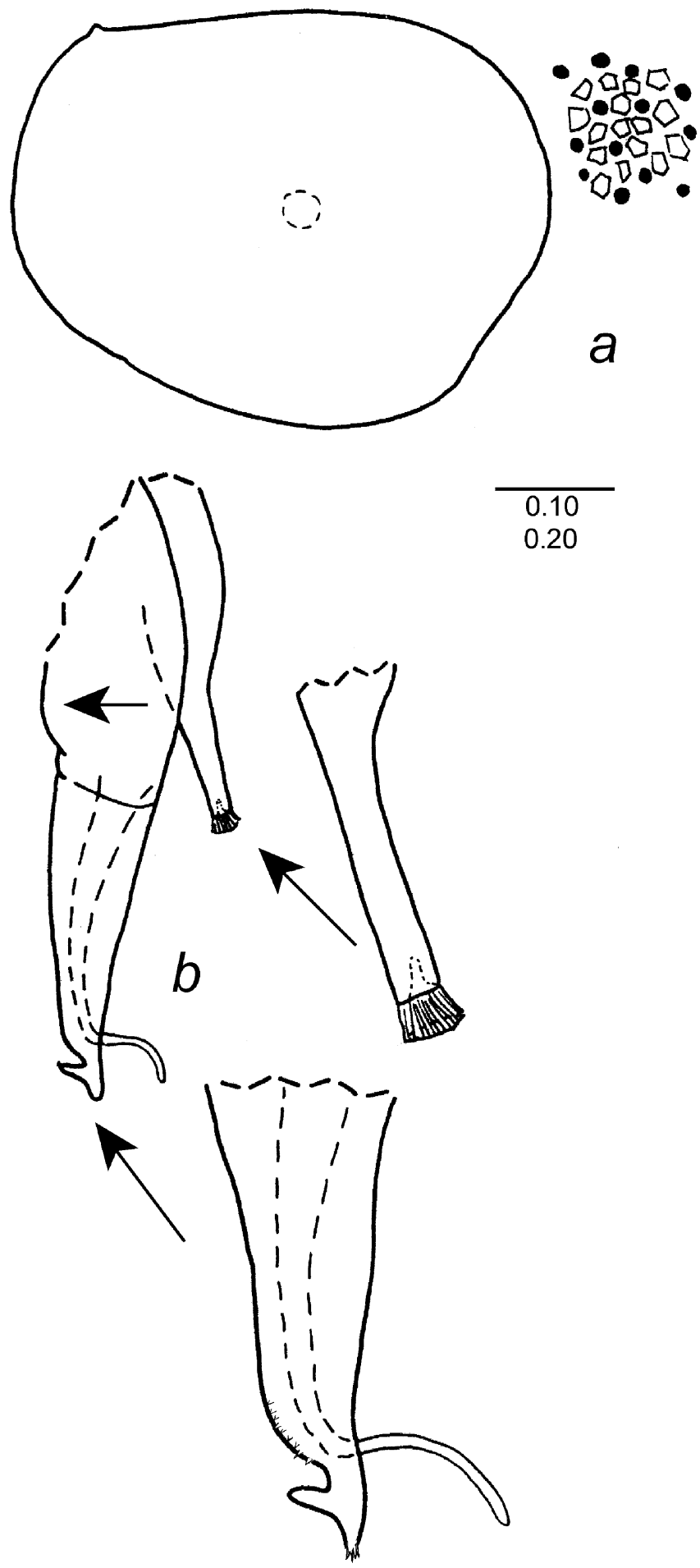

FIGURE 40. Deeveya medix Kornicker 1990 in Kornicker et al. 1990, USNM 1021387, adult male: $a$, complete specimen from right side and detail of surface structures (black spots are bright spots in transmitted light), length $1.70 \mathrm{~mm} ; b$, copulatory organ on left side of posterior part of body. Scale equals $0.10 \mathrm{~mm}$ ( $a$-detail) and $0.02 \mathrm{~mm}(b)$.

Supplementary description of adult male (Fig. 40). Carapace similar in shape and ornamentation to that of holotype (Fig. 40a).

Carapace size (length, height in mm). USNM 1021447, 1.70, 1.31; USNM 1021443, 1.65, 1.17.

Mandible: 1 st endopod segment with 6 bristles (1 anterior, 1 posterior, 4 medial).

Genitalia (Fig. 40b): Similar to that of holotype.

Remarks. Kornicker et al. (1990: 44) reported this species in Sagittarius Blue Hole from collections 
made in 1984 and 1987. The present collections made in 1989 and 2001 from the same cave show that the species continued to live in the cave and was not affected by intervening climactic events. The present collection from Basil Minn's Blue Hole, Great Exuma Island, is the first record of the species from the Great Bahama Bank. The species is reported for the first time in Virgo Blue Hole, Little Bahama Bank.

\section{Deeveya exleyi Kornicker \& Iliffe 1998}

Figs. 41, 42

Deeveya exleyi Kornicker \& Iliffe 1998: 53, figs. 37-42.—Kornicker et al. 2002: 23.

Holotype. USNM 194269, adult female.

Type locality. Oven Rock Cave, Great Guana Cay, Exuma Cays, Great Bahama Bank.

Material. Holotype plus USNM 1021450, A-4 instar (sex unknown) on slide.

Distribution. Great Bahama Bank: type locality and Norman's Pond Cave, Norman's Pond Cay, Exumas.

Supplementary description of adult female (Correction). Kornicker \& Iliffe (1998: 57) described the first endopod segment of the mandible as having two posterior bristles. Examination of the holotype revealed that it has only one posterior bristle as shown in their illustration (Kornicker \& Iliffe 1998: fig. 39f).

Description of A-4 instar (sex unknown) (Figs. 41, 42 ). Carapace oval in lateral view with linear dorsal margin (Fig. 41a). Right valve with small glandular process at posterior end of dorsal margin (not shown).

Ornamentation: Surface in transmitted light with clear round spots (Fig. 41c). Shell between clear spots with abundant fine hair-like striae. Single lateral bristle projecting from midheight of posterior margin; 1 divided lateral bristle anterior to midlength of ventral margin, and 2 single anteroventral bristles (not shown).

Selvage: Broad infold along anterior, ventral, and posterior margins. Broad lamellar prolongation with smooth outer edge along anterior, ventral, and dorsal margins.

Central adductor muscle attachments (Fig. 41b): Consisting of a cluster of about 9 attachments.

Carapace size (length, height in $\mathrm{mm}$ ): USNM 1021450, 0.66, 0.55.

First antenna (Fig. 41d,e): 1st segment with spines in distal ventral corner. 2nd segment with 1 dorsal bristle. 3rd and 4th segment fused, but slight indentation on dorsal margin indicates place of separation; 3rd segment with 1 ventral bristle; 4th segment with 1 short dorsal bristle. 5th segment with minute terminal ventral pointed nub (visible with oil immersion lens). 6th segment bare. 7th segment with short dorsal a-bristle and long ventral c-bristle. 8th segment with long d-, e-, and f-bristles, and short g-bristle. 1st and 2nd segments forming large angle.

Second antenna: Protopodite bare. Exopod with segment 1 partly divided into 2 parts, with small medial bristle near ventral margin. Segments 2 to 8 with long ventral bristle. Segment 9 with 2 bristles (1 short, 1 medium length). Endopod (Fig. 41e,f): 1st segment with 1 dorsal bristle; 2nd segment with short f-bristle and long g-bristle; 3rd segment fused to 2nd segment, with long h-, i-, and j-bristles.

Mandible (Figs. 41 $-k, 42 a$ ): Coxa endite with proximal and distal sets of teeth separated by space (Fig. $41 g, h)$ : proximal set with about 4 stout cusps, surface between and adjacent to cusps with slender spines; stout pointed tooth between proximal and distal sets of teeth with spinous bristle adjacent to tooth. Distal set of teeth comprising 2 flat teeth, each tooth with 3 or 4 cusps (obscured); stout bristle between inner tooth and stout pointed tooth. Basis with 1 long slender bristle and 1 short bristle near base of endopod (Fig. 41i,j), and 2 stout filamentous plumose dorsal bristles (Fig. 42a). Basis endite with single anterior bristle; posterior margin with hairs and 2 short distal bristles (distal of these tubular) (Fig. 41i); lateral side with 2 bristles (none entwined); ventral edge of endite with 5 terminal cusps (posterior of these smaller than others and set back from terminal edge), and 1 lateral tooth set back from edge (Fig. 41i). Endopod (Fig. 41j,k): 1st segment with 1 terminal dorsal bristle; 2 nd segment with 2 or 3 bristles ( 2 dorsal (1 claw-like)), none or 1 ventral; 3rd segment with 4 bristles (1 very long)). 


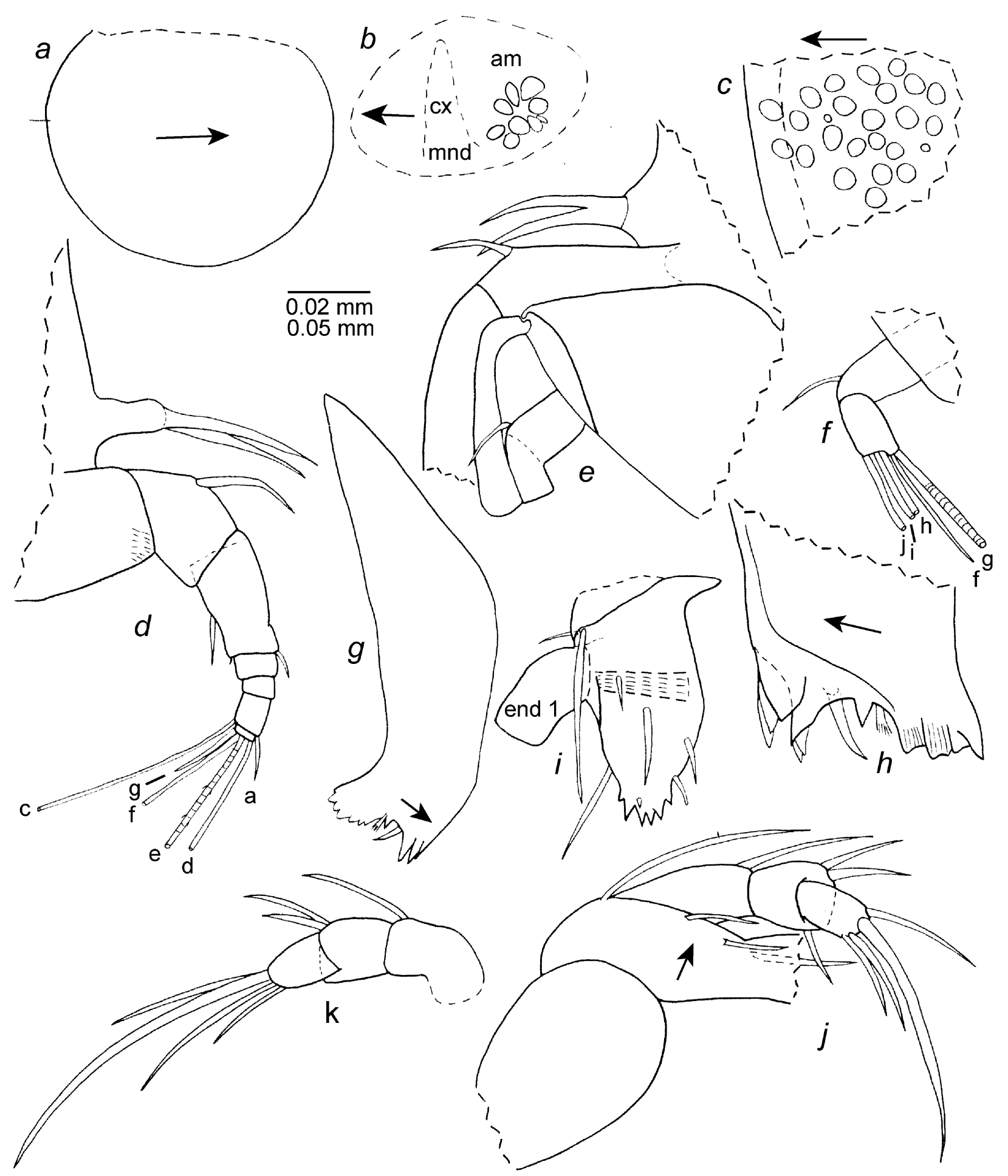

FIGURE 41. Deeveya exleyi Kornicker \& Iliffe 1998, USNM 1021450, A-4 instar, sex unknown: $a$, complete specimen from right side (dorsal margin of specimen disfigured and probable margin dashed), length $0.66 \mathrm{~mm} ; b$, central adductor muscle scars of left valve (dorsal part of mandibular coxa dashed); $c$, round clear spots on surface of left valve; $d$, Bellonci Organ and right first antenna drawn on body, lv; $e$, Bellonci Organ and proximal parts of left first antenna and second antenna as seen through left valve; $f$, endopod left second antenna; $g$, coxa right mandible, $1 v ; h$, tip of coxa of right mandible, mv; $i$, basis and part endopod left mandible, lv; $j$, right mandible drawn on body, lv; $k$, endopod left mandible drawn on body, lv. Scale equals $0.05 \mathrm{~mm}(b-g, i-k)$ and $0.02 \mathrm{~mm}(h)$. 


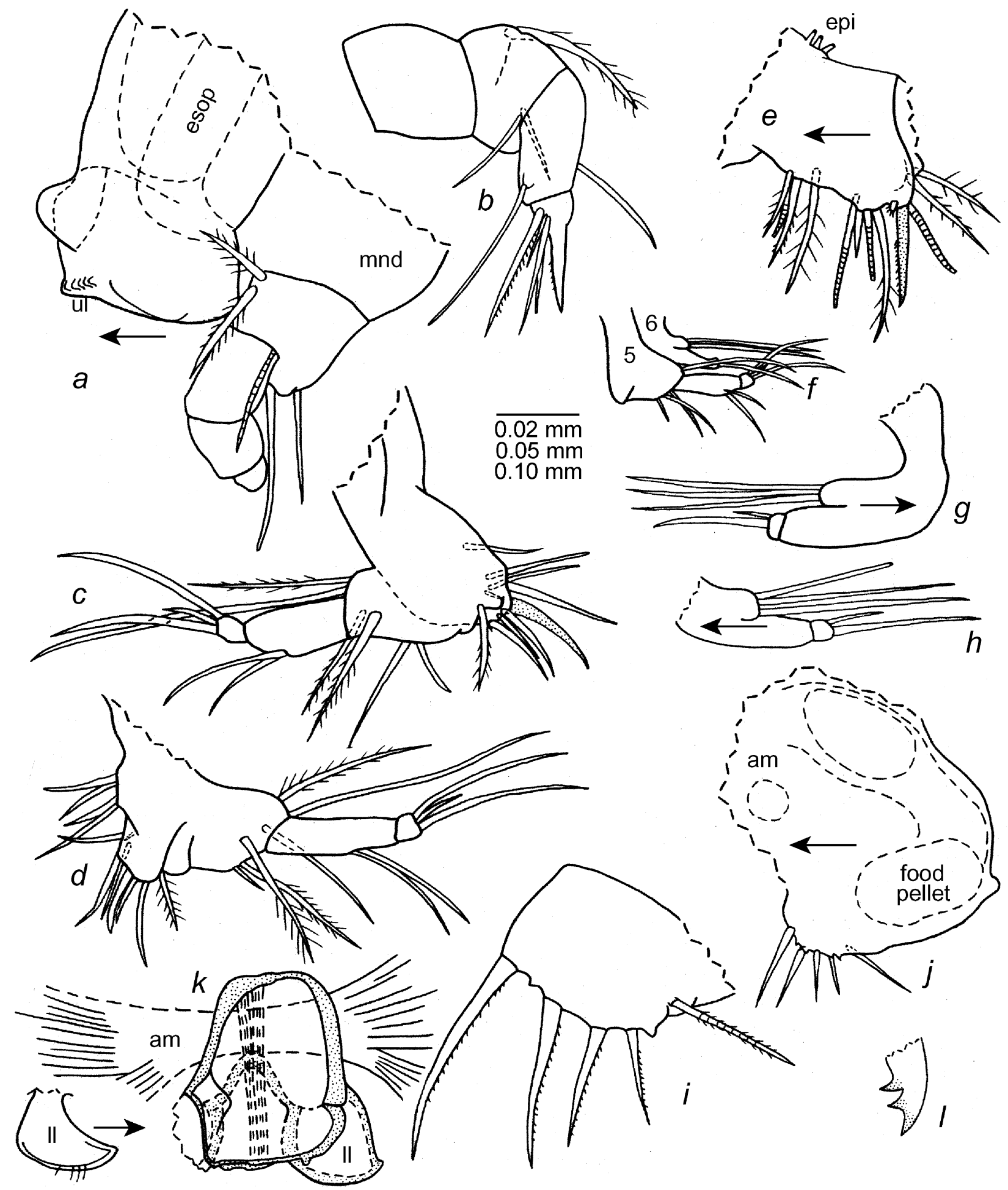

FIGURE 42. Deeveya exleyi Kornicker \& Iliffe 1998, USNM 1021450, A-4 instar, sex unknown: $a$, anterior of body, upper lip, left mandible, lv (nabs); $b$, right maxilla drawn on body, lv (nabs); $c$, right fifth limb drawn on body, lv; $d$, left fifth limb drawn on body, lv; $e$, proximal part left fifth limb, lv; $f$, left fifth and sixth limbs drawn on body; $g$, right sixth limb drawn on body, lv; $h$, left sixth limb drawn on body; $i$, left lamella of furca, lv; $j$, posterior of body from left side with left lamella of furca (dashed circle is location of central adductor muscle scars, dashed ellipses are food pellets); $k$, anterior of part of body, av; $l$, tip of claw in food pellet. Scale equals $0.05 \mathrm{~mm}(a-e, g-i, k), 0.10(f, j)$, and $0.02 \mathrm{~mm}(l)$.

Maxilla (Fig. 42b): Endite I with 7 bristles; endite II with 6 bristles; endite III with 5 bristles. Coxa with plumose dorsal bristle. Basis with 2 terminal ventral bristles. Endopod: 1st segment with 2 or 3 bristles (1 or 2 
anterior, 1 posterior). 2 nd segment with 1 claw-like bristle, 1 long stout spinous bristle, and 3 slender bristles (at least 1 tubular).

Fifth limb (Fig. 42c-f): Epipod with plumose bristles forming 3 groups, with 3 bristles in each group on mounted specimen, but some bristles probably missing (about 13 counted on specimen prior to mounting, but view obstructed). Precoxa and coxa with total of 1 claw and 12 bristles (4 bristles tubular, 1 bristle nub-like, spinous) (Fig. 42e). Basis with 4 bristles. Exopod represented by 2 bristles (1 long bare, 1 plumose). Endopod: 1st segment with 2 distal ventral bristles; 2nd segment with 2 long slender, somewhat clawlike bristles, and 1 short slender bristle.

Sixth limb (Fig. 42f-h): Epipod fragmented, with plumose bristles. Precoxa and coxa without bristles. Exopod represented by small lobe with 3 long bristles. Endopod with 2 segments: 1st segment bare; 2nd segment with 2 terminal bristles (1 long, 1 short). Terminal segment not reaching past terminal segment of 5 th limb (Fig. 42f).

Seventh limb: Absent.

Furca (Fig. 42i,j): Each lamella with 4 spinous claws followed by small triangular process fused to lamella. Claws separated from lamella by suture. Small projecting glandular process midway between claws 1 and 2. Long unpaired bristle present posterior to lamellae.

Bellonci Organ (Fig. 41e): Well developed, bifurcate distally, branches taper to point.

Upper lip (Fig. 42a): Anterior margin of body near upper lip with projecting rounded process on each side; anterior tip of lip with chevron-like processes. Lower lip triangular (Fig. 42k)

Gut content: Specimen with 2 food pellets in gut (length $0.19 \mathrm{~mm}$, width $0.11 \mathrm{~mm}$ ) (Fig. 42j). Each pellet with numerous closely packed amber-colored narrow strips, a few with nodes suggesting teeth, one terminating in a claw (Fig. 42l). The strips appear to be the skeleton of one or more invertebrates and indicate that the species is either a carnivore or scavenger.

Remarks. The A-4 instar from Norman's Pond Cave is referred to D. exleyi because 3 other anchialine ostracodes collected in that cave have also been collected in Oven Rock Cave, the type locality of the species. Each cave is on a different cay in the Exumas. This is the first report of the genus in Norman's Pond Cave. An A-4 instar of the species has not previously been described; the morphology of the present specimen is consistent with what would be expected for an A-4 instar collected at the type locality.

\section{Deeveya sp. A}

Material. Sta 01-001, Guardian Blue Hole, Andros Island, Great Bahama Bank: USNM 1021451, 1 fragmented carapace without soft parts.

Distribution. Andros Island (Guardian Blue Hole).

Description of fragmented carapace. Size of transparent disks of carapace similar in size to those on carapaces of $D$. exleyi, larger than those on carapaces of $D$. bransoni.

Fragment length: Fragment length $(1.73 \mathrm{~mm})$ probably only slightly less than that of complete valve (stage unknown).

Remarks. Although ornamentation of carapace of Deeveya sp. A closely resembles that of D. exleyi, a species that has not been reported from Andros Island, lack of appendages does not permit specific identification. Further collections are warranted from Guardian Blue Hole.

\section{Suborder Cladocopina Sars 1866}

Composition. The order includes the superfamily Polycopoidea Sars 1866. 
Distribution. Worldwide, marine, in shallow and abyssal depths, and in anchialine caves. Cladocopina have been reported from anchialine caves or blue holes in the Canary Islands, Bermuda, Bahamas, Jamaica, and Mexico (herein) (Table 12).

TABLE 12. Worldwide distribution of Cladocopa in anchialine caves and blue holes. ${ }^{*}=$ localities from which ostracodes are reported herein.)

Bahamas, Great Bahama Bank*

Double Drop Blue Hole, South Andros Island

Pseudopolycope helix, herein

Exley's Boiling Blue Hole, South Andros Island

Pontopolycope storthynx, herein

Four Shark Cave, South Andros Island

Pontopolycope storthynx, herein

Bermuda

Cherry Pit cave, Deep Blue Cave, Fern Sink, Green Bay Cave, Palm Cave, Sailor's Choice Cave, Walsingham Cave, Walsingham Sink, Cave, Palm Cave Metapolycope duplex Kornicker \& Iliffe 1989b

Deep Blue Cave, Sailors Choice Cave

Micropolycope eurax Kornicker \& Iliffe 1989b

Tucker's Town Cave

Micropolycope styx Kornicker \& Iliffe 1989b

Bee Pit Cave, Christie's Cave, Fern Sink Cave, Roadside Cave, Tucker's Town Cave, Walsingham Sink Cave

Polycopissa anax Kornicker \& Iliffe 1989b

Canary Islands

Atlantida Tunnel, Jameos del Agua lava tube, Lanzarote

Eupolycope pnyx Kornicker \& Iliffe 1995

Polycopiella species A (Kornicker \& Iliffe 1998:87)

Polycopinae gen. and sp. indet. (Kornicker \& Iliffe 1995:28)

Isla Cozumel, Quintana Roo, Mexico*

Cenote Aerolita

Pseudopolycope helix, herein

Jamaica

Dairy Bull Cave, Discovery Bay

Pontopolycope mylax Kornicker \& Iliffe 1992

\section{Superfamily Polycopoidea Sars 1866}

Composition. The superfamily includes the family Polycopidae Sars 1866.

\section{Family Polycopidae Sars 1866}

Composition. The Polycopidae comprise the subfamilies Polycopinae Sars 1866, and Polycopsisinae Chavtur 1983.

Distribution. Worldwide, marine, in shallow and abyssal depths. One species of Polycopsisinae (Metapolycope duplex Kornicker \& Iliffe 1989b) is widespread in Bermudan caves. Many species of Polycopidae have been reported in anchialine caves or blue holes (Table 12). 


\section{Subfamily Polycopinae Sars 1866}

Composition. The Polycopinae comprise 14 living genera.

Distribution. Worldwide in marine waters, but reported from anchialine caves or blue holes only in the Canary Islands, Bahamas, Bermuda, Jamaica, and Mexico (Table 12).

\section{Pseudopolycope Chavtur 1981}

Type species. Pseudopolycope comandorica Chavtur 1981.

Composition and distribution. Chavtur $(1979,1981,1983,1984,1985)$ referred 10 species to this genus mainly from the Canadian Basin, Arctic Ocean, Kuril and Commander Islands, Sea of Japan, and the KurilKamchatka Trench ("far east seas and adjacent Pacific regions"), and presented a key to the genus (Chavtur 1981: 60; 1983: 95). The new species described herein is the first from an anchialine habitat, depth $18 \mathrm{~m}$, and the first member of the genus reported from the Great Bahama Bank. Kornicker (1959: 72) previously reported Eupolycope bahamensis (Kornicker 1959) (Chavtur 1981: 55) from shallow water in the vicinity of Bimini, Great Bahama Bank.

Remarks. The new species is referred to the genus Pseudopolycope based on the "Key to the Genera of Polycopinae" in Kornicker \& Iliffe (1989b: 68), which is a translation of keys presented in Chavtur (1981: 60; 1983: 95).

\section{Pseudopolycope helix, new species}

Figs. 43, 44

Etymology. The specific name from the Latin helix (coil, spiral, turn) in reference to the coil visible within furcal lamellae of the species.

Holotype. USNM 1021452, undissected adult female in alcohol.

Type locality. Double Drop Blue Hole, South Andros, Great Bahama Bank, Sta 99-055.

Paratype. USNM 1021453, adult female on slide.

Distribution. Type locality and Cenote Aerolito, Isla Cozumel, Quintana Roo, Mexico, Sta 01-011.

Description of adult female (Figs. 43, 44). Carapace oval in lateral view with slight anterior concavity just ventral to rostral bulge (Fig. 43a,b,e). Outer surface of valves appearing smooth, but with faint lines parallel to ventral margin (observed on holotype when immersed in glycerin). Anteroventral edge of valve with minute serrations. Carapace transparent and extremely fragile. Lamellar prolongation of the selvage along the ventral margin serrate (Fig. 43a,b,e).

Central adductor muscle attachments (Fig. $43 a, b, e-g$ ): Indistinct but with closely spaced scars forming oval.

Carapace size (length, height in mm): USNM 1021452, holotype, 0.37, 0.31. USNM 1021453, 0.32, 0.28.

First antenna (Fig. 43c,h,i): 1st and 2nd segments fused, with dorsal hairs; 2nd segment with long, terminal, dorsal bristle. 3rd to 5th segments fused, without bristles. 6 to 8th segments fused, with 5 long terminal bristles.

Second antenna: Protopod bare (Fig. 43j). Endopod (Fig. 43j): 1st segment bare; 2 nd segment with 1 dorsal bristle and 3 terminal bristles; 3rd segment with 6 bristles; some long bristles with proximal rings and long spines. Exopod with 9 segments (Fig. 43k); segments 1 to 8 each with single long bristle; 9 th segment with 2 bristles (1 long, 1 medium length).

Mandible (Fig. 44a): Coxa endite well developed with tapered tip (details not resolved). Basis with 4 ven- 
tral bristles and 1 dorsal bristle. Exopod with broad segment with 1 terminal bristle and indistinct broad 2nd segment or bristle. Endopod: 1st and 2nd segments fused; 1st segment with 3 bristles on or near ventral margin; 2nd segment with 2 long bristles; 3rd segment with 2 long bristles.
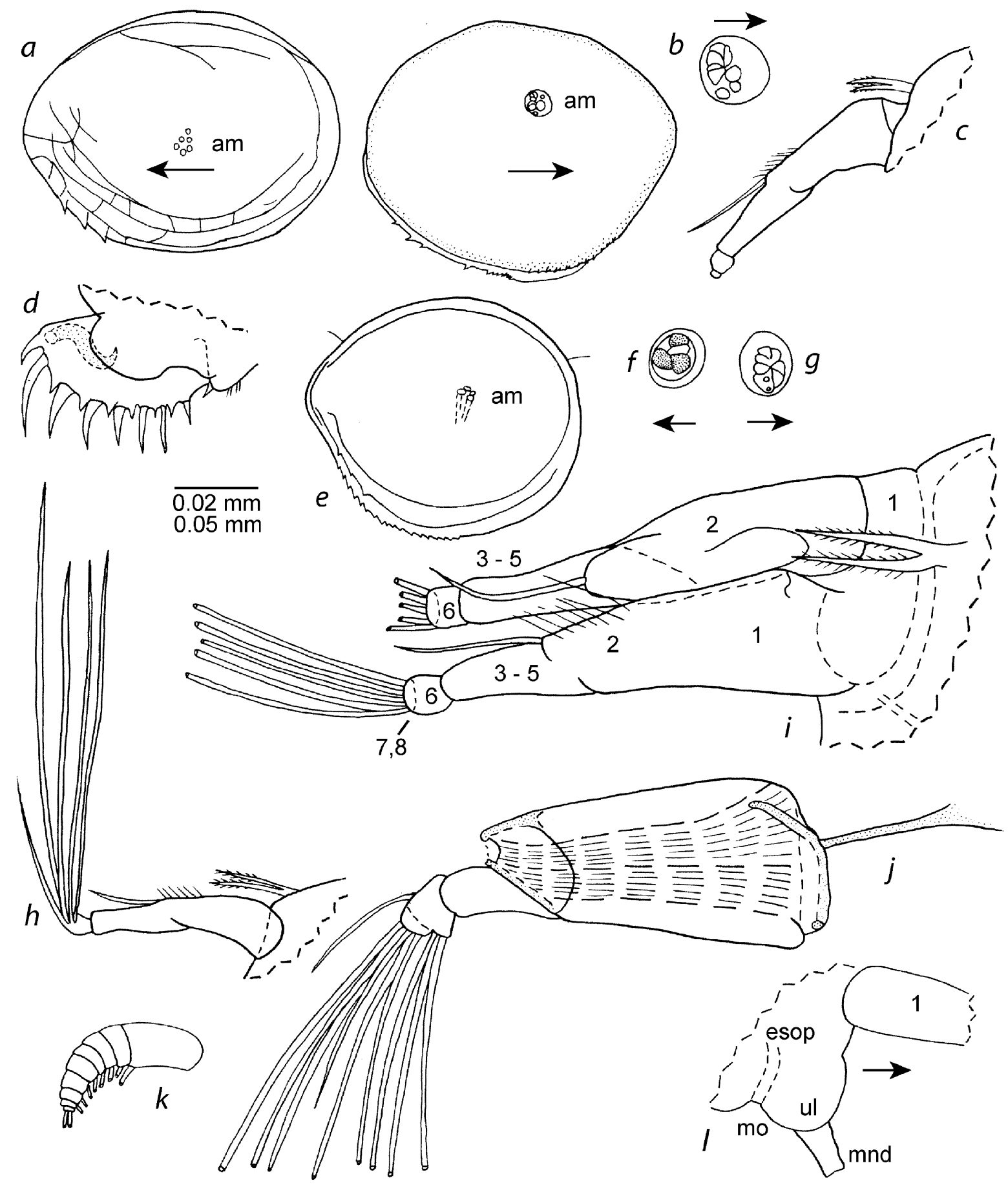

FIGURE 43. Pseudopolycope helix, new species, holotype USNM 1021452, adult female: $a$, complete specimen from left side (slightly tilted), length $0.37 \mathrm{~mm} ; b$, complete specimen from right side and detail of central adductor muscle scars; $c$, Bellonci Organ and left first antenna as seen through left valve (nabs); $d$, left lamella of furca. Paratype USNM 1021453, adult female: $e$, complete specimen from left side, length $0.32 \mathrm{~m} ; \mathrm{f}, \mathrm{g}$, detail of central adductor muscles of left and right valves; $h$, Bellonci Organ and left first antenna as seen through valve (nabs); $i$, Bellonci Organ and left and right first antenna (under cover slip); $j$, protopod and endopod left second antenna, lv; $k$, exopod left second antenna (only proximal part of each bristle shown), lv; $l$, anterior of body from right side showing mouth and esophagus (dashed), upper lip, protopod right second antenna, and segment of left mandible. Scale equals $0.05 \mathrm{~mm}(b$ (detail) $-d, f-h, l)$ and $0.02 \mathrm{~mm}(i-k)$. 

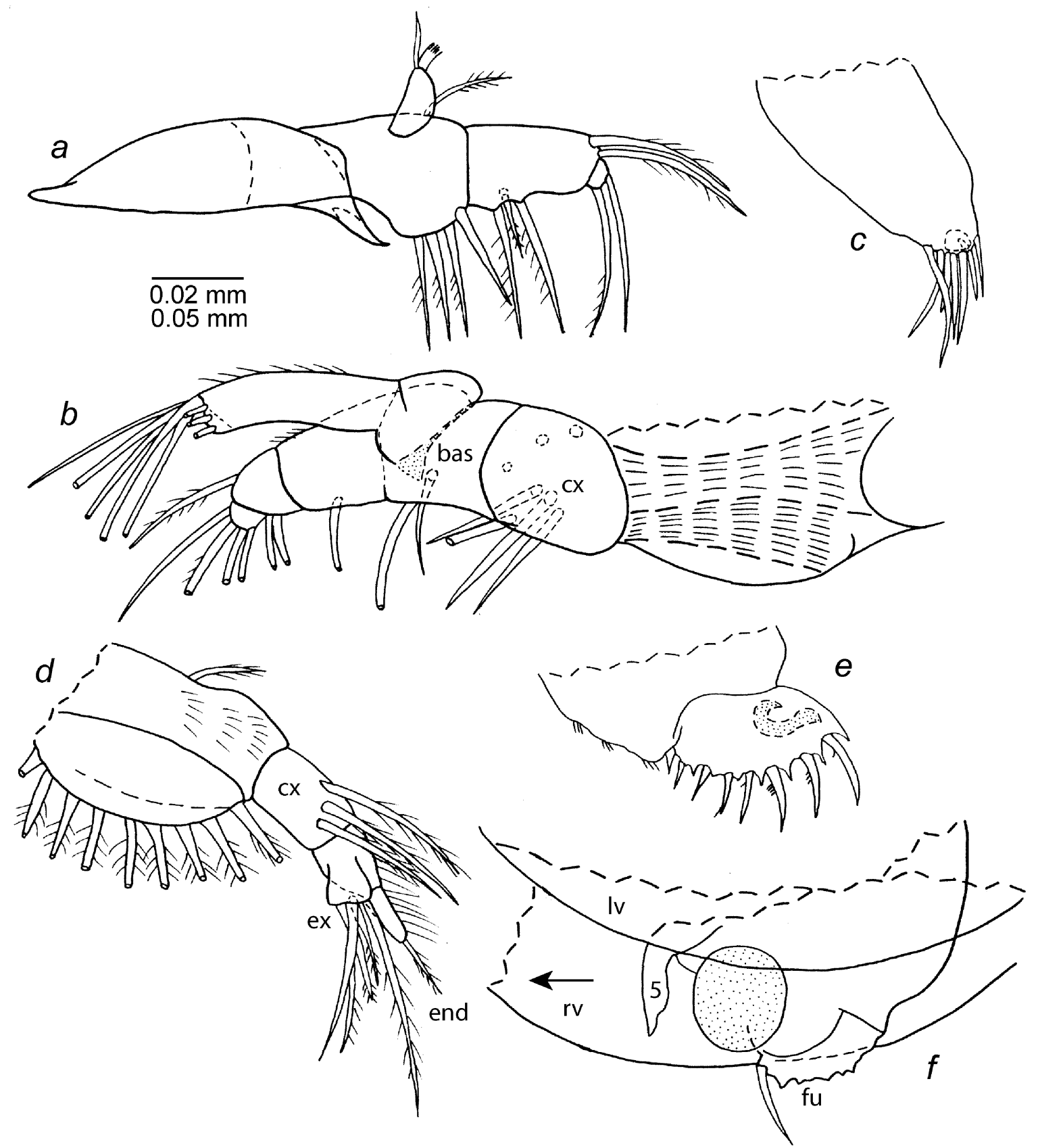

FIGURE 44. Pseudopolycope helix, new species, paratype USNM 1021453, adult female: $a$, right mandible, lv; $b$, left maxilla, lv; $c$, precoxa of right maxilla, lv; $d$, right fifth limb, lv; $e$, posterior of body and right lamella of furca, lv; $f$, part ventral edge of complete specimen slightly open, from left side showing location of left fifth limb and furca (round object unidentified). Scale equals $0.02 \mathrm{~mm}(a-d)$ and $0.05 \mathrm{~mm}(e, f)$.

Maxilla (Fig. 44b,c): Precoxa with about 7 bristles (Fig. 44c). Coxa with about 7 bristles. Basis with dorsal hairs and 2 bristles on or near ventral margin (Fig. 44b). Exopod with dorsal hairs and 8 terminal bristles. Endopod: 1st segment with 1 ventral bristle. 2nd segment with 2 ventral and 1 dorsal bristle. 3rd segment with 4 terminal bristles.

Fifth limb (Figs. 44d,f): Epipod with 9 plumose bristles. Precoxa hirsute, with 1 dorsal bristle. Coxa with 3 bristles. Exopod broad with 4 terminal bristles. Endopod with 2 segments: segment 1 with 1 terminal bristle ventral to base of 2nd segment; 2nd segment hirsute, with 1 spinous terminal bristle. Most bristles faint.

Furca (Figs. 43d, 44e,f): Each lamella with 7 articulated claws; slender spines visible along posterior edge of some claws. Small nonarticulated process between adjacent claws, some with slender protracted tip. 
Stout pointed unpaired process on body proximal to posterior claw. Indistinct coiled process visible within anterior part of lamellae.

Bellonci Organ (Figs. 43c,h,i): 2 spinous bristles joined near base.

Upper lip (Fig. 43l): Anteroventral margin broadly rounded in lateral view (esophagus dashed in Fig. 43l).

Posterior of body (Fig. 43d): With rows of spines dorsal to furca.

Remarks. A round amber-colored sphere filled with minute cells is present within the carapace just anterior to the furca of USNM 1021453 (Fig. 44f). No limbs or structures are visible within sphere, so it is unlikely to be an extruded egg, unless it was aborted. It has no exterior appendages usually present on crustacean parasites.

Comparisons. The new species, $P$. helix is smaller and has a more fragile and transparent carapace than species previously referred to the genus. The carapace of the new species differs from that of Eupolycope bahamensis in not having two small projections along the posteroventral edge of the right valve. The partly coiled structure within the lamellae of the furca of $P$. helix has not been described previously in members of the genus and could be characteristic of the species, although it may have been overlooked on previously described species. The transparency of the valves of the holotype permitted comparison of pertinent appendages with those of the dissected paratype. The undissected holotype is preserved in alcohol because it is a more permanent method than slides.

\section{Pontopolycope Chavtur 1981}

Type species. Polycope compressa Müller 1894.

Composition and distribution. Chavtur (1981: 58) referred three species to this genus from the Bay of Naples and Canadian Basin, Arctic Ocean. Kornicker \& Iliffe (1992: 17) described Pontopolycope mylax Kornicker \& Iliffe 1992 from an anchialine cave in Jamaica.

\section{Pontopolycope storthynx, new species}

Fig. 45

Etymology. The specific name from the Greek storthynx (point, spike) in reference to the spines along the posterior margin of the carapace.

Holotype. USNM 1021454, undissected A-1 female in alcohol.

Type locality. Exley's Boiling Blue Hole, South Andros, Great Bahama Bank, Sta 99-054.

Paratype. USNM 1021455, dissected A-1 female on slide, Sta 99-050.

Distribution. Great Bahama Bank, South Andros: Four Sharks Cave, Exley's Boiling Hole, depth 60-70 m (Table 12).

Description of A-1 female (Fig. 45). Carapace oval in lateral view with pointed rostrum, 4 pointed posterior spines, surface ridges and reticulations; surface between reticulations with pebbly texture (after being in glycerine for several months the ridges, reticulations, and pebbly texture are no longer visible and the rostrum is indistinct.) Anteroventral and ventral margin with broad serrated lamellar prolongation (Fig. 45a,b).

Central adductor muscle attachments (Fig. 45a,b): Comprising 3 individual oval attachments.

Carapace size (length, height in mm): USNM 1021455, length including rostrum and spines 0.30, length without rostrum and spines 0.26 , height 0.23 . USNM 1021454 , length with rostrum 0.30 , length without rostrum 0.26 , height 0.23 .

First antenna (Fig. 45c): Segments 1 to 5 fused; 2nd segment with dorsal hairs and long dorsal bristle. 
Segment 6 with small terminal bristle; segments 7 and 8 fused, with 5 long bristles.

Second antenna: Protopod bare. Endopod obscured on slide; 1st segment elongate bare; 2 distal segments with about 7 long bristles (Fig. 45d). Exopod segments 1 to 8 with single hirsute bristle; segment 9 with 2 bristles (1 short, 1 long).

Mandible (Fig. 45e): Coxa endite well developed with flat serrate tip. Basis with 4 hirsute ventral bristles and 1 dorsal bristle near and medial to exopod. Exopod with 2 segments; 1st segment broad; terminal segment diaphanous (indistinct). Endopod with 2 fused segment: segment 1 with ventral bristle and 2 hirsute terminal bristles; 2nd segment with 2 hirsute terminal bristles; dorsal bristle of 2nd segment longer than others and with long stout spines near tip.

Maxilla (Fig. 45f): Coxa with about 6 bristles. Basis with 2 ventral bristles. Exopod undivided with about 8 terminal bristles. Endopod with 3 segments: segment 1 with 1 ventral bristle; segment 2 with 1 dorsal and 3 ventral bristles; segment 3 with 4 terminal bristles.

Fifth limb: Obscured, approximate morphology and bristles shown in Fig. $45 \mathrm{~g}$.

Furca (Fig. 45i): Each lamella with 6 articulated claws. Small nonarticulated triangular process between adjacent claws and following claw 6. Pointed unpaired process on body posterior to terminal claw. Posterior of body with rows of spines near furca.

Bellonci Organ (Fig. 45h): 2 slender bristles (no marginal hairs observed).

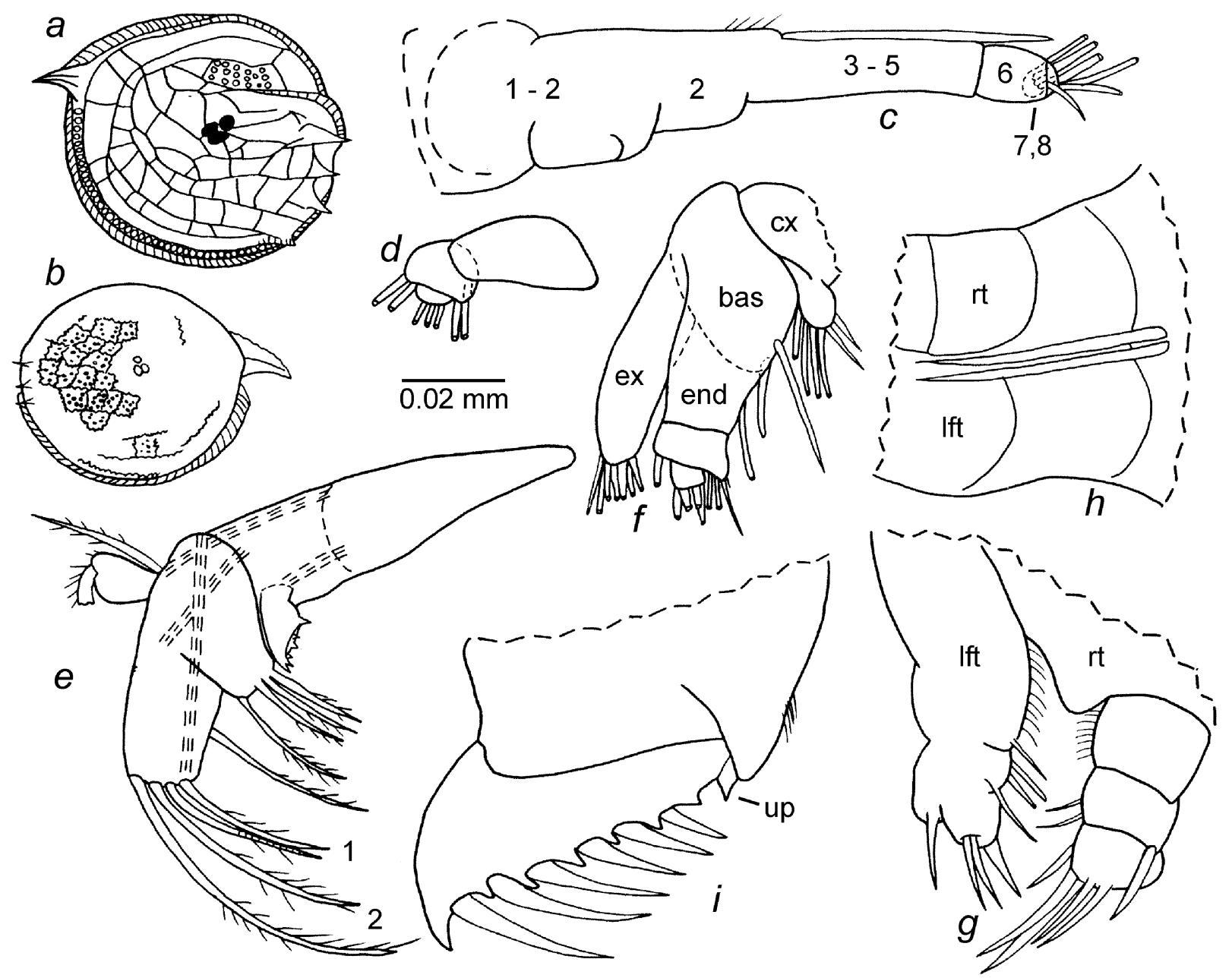

FIGURE 45. Pontopolycope storthynx, new species, holotype USNM 1021454, A-1 female: $a$, complete specimen from left side, length with spine $0.29 \mathrm{~mm}$. USNM 1021455, paratype, A-1 female: $b$, complete specimen from right side, length with spine $0.30 \mathrm{~mm} ; c$, right first antenna, lv; $d$, endopod right second antenna, $\mathrm{dv} ; e$, right mandible, mv; $f$, left maxilla, mv; $g$, ventral view of both fifth limbs; $h$, dorsal view of Bellonci Organ and proximal parts of first antennae; $i$, left lamella of furca, lv. Scale equals $0.02 \mathrm{~mm}(c-i)$. 
Age of specimen. Both specimens in the collection are estimated to be A-1 instars because of having only six claws on each lamella of the furca.

Comparisons. The carapace of the new species P. storthynx differs from those of P. mylax, Pontopolycope rostrata (Müller 1894) and Pontopolycope? moenia (Joy \& Clark 1977) in having three or four posterior spines (appendages unknown for the latter species). The carapace of P. storthynx differs from that of Pontopolycope dentata (Müller 1894) in lacking two dorsal spines. The mandible of $P$. storthynx differs from that of $P$. dentata in having a long bristle just proximal to the exopod and in lacking a bristle on the exopod.

\section{Order Myodocopida Sars 1866}

\section{Suborder Myodocopina Sars 1866}

Distribution. For species reported in the Bahamas (see Table 3).

\section{Superfamily Cypridinoidea Baird 1850}

\section{Family Cypridinidae Baird 1850}

\section{Subfamily Cypridininae Baird 1850}

\section{Skogsbergia Kornicker 1974}

Type species. Skogsbergia minuta Poulsen 1962.

Composition and Distribution. See Kornicker \& Iliffe (2000: 30) and Kornicker et al. (2002: 34).

\section{Skogsbergia lerneri (Kornicker 1958)}

Skogsbergia lerneri (Kornicker 1958).—See Kornicker et al. (2002: 34) for comprehensive synonymy.

Holotype. USNM 122903, whole dry juvenile on slide.

Type locality. Bimini, Great Bahama Bank.

Material. Great Bahama Bank: Angelfish Blue Hole, Stocking Island, Exuma Cays, Sta 98-048: USNM 1021456, 1 specimen. Double Drop Blue Hole, South Andros, Sta 99-056: USNM 1021457, 5 specimens in alcohol. Vortex Blue Hole, Middle Bight, Andros, Sta 99-059: USNM 1021458, 1 specimen in alcohol.

Distribution. See Kornicker et al. (2002: 34). Herein, Great Bahama Bank: South Andros (Double Drop Blue Hole), Andros (Vortex Blue Hole), and Stocking Island (Angelfish Blue Hole).

\section{Superfamily Sarsielloidea Brady \& Norman 1896}

Composition. This superfamily contains the families Sarsiellidae Brady \& Norman 1896, Philomedidae Müller 1906, and Rutidermatidae Brady \& Norman 1896.

\section{Family Philomedidae Müller 1906}

Subfamily Pseudophilomedinae Kornicker 1967 


\section{Harbansus Kornicker 1978}

Type species. Harbansus bradmyersi Kornicker 1978.

Composition and distribution. See Kornicker (1978: 13; 1984: 59).

\section{Harbansus paucichelatus (Kornicker 1958)}

Harbansus paucichelatus (Kornicker 1958). - see Kornicker et al. (2002: 35) for comprehensive synonymy.

Holotype. USNM 122905, dried specimen in poor condition.

Type locality. Bimini, Great Bahama Bank.

Material. Great Bahama Bank, Great Exuma, Exuma Cays: Stocking Island (Bottomly's Blue Hole), Sta 99-065: USNM 1021459, 3 specimens in alcohol; (The Subway), Sta 00-006: USNM 1021460, 1 adult male in alcohol.

Distribution. See Kornicker et al. (2002: 35). Herein, Great Bahama Bank, Great Exuma (Bottomly’s Blue Hole and The Subway).

Supplementary descriptions. Carapace size (length, height in mm). Adult female, USNM 1021459, 1.06, 0.59. Instar III (A-2 instar), USNM 1021459, 0.79, 0.41. Instar I (A-4 instar), USNM 1021459, 0.52, 0.29.

\section{Pseudophilomedes Müller 1893}

Type species. Pseudophilomedes foveolatus Müller 1894.

Composition and distribution. See Kornicker 1984: 33

\section{Pseudophilomedes ferulanus Kornicker 1958}

Figs. 46, 47

Pseudophilomedes ferulana Kornicker 1958: 235, figs. 46: 1a,b, 2a,b: 56A-D.

Pseudophilomedes ferulanus.-Kornicker 1989: 8.

Pseudophilomedes ferulana.-Darby 1965: 64-70, Fig. 10, pls. 11,12.

Not Pseudophilomedes ferulanus.-Kornicker 1967: 8, figs. 1-6, pl. 1.—1969: 119, figs. 3, 4, pl. 11.—1977: 792.1984: 33, figs. 14-16.

Holotype. USNM 113287, adult female on slides.

Type locality. Bimini, Bahamas, Great Bahama Bank.

Material. Great Bahama Bank, Exuma Cays, Great Exuma, Stocking Island (Bottomly's Blue Hole), Sta 99-065: USNM 10214561, 1 specimen on slide and in alcohol.

Distribution. See Kornicker (1984: 33). Herein, Great Bahama Bank, Stocking Island (Bottomly’s Blue Hole).

Description of instar II (sex unknown) (Figs. 46, 47). Carapace elongate with projecting caudal process (Fig. 46a,c,e); incisure forming obtuse-angle (Fig. 46a,b,d).

Ornamentation (Fig. 46b-e): Surface with widely distributed long and medium length bristles; long bristles with broad triangular basal part. Outer edge of rostrum with small nodes (Fig. 46b, d). Ribs, punctations, and reticulations absent on USNM 1021461. 
Infold: Rostral infold broad with 4 long bristles forming row, and 1 minute bristle near ventral end of rostrum (Fig. 46d). Infold of caudal process broad, with 2 indistinct bristles (Fig. 46e). Narrow infold along anteroventral, ventral and posterior margins of valve. Anteroventral infold without bristles or parallel striations.

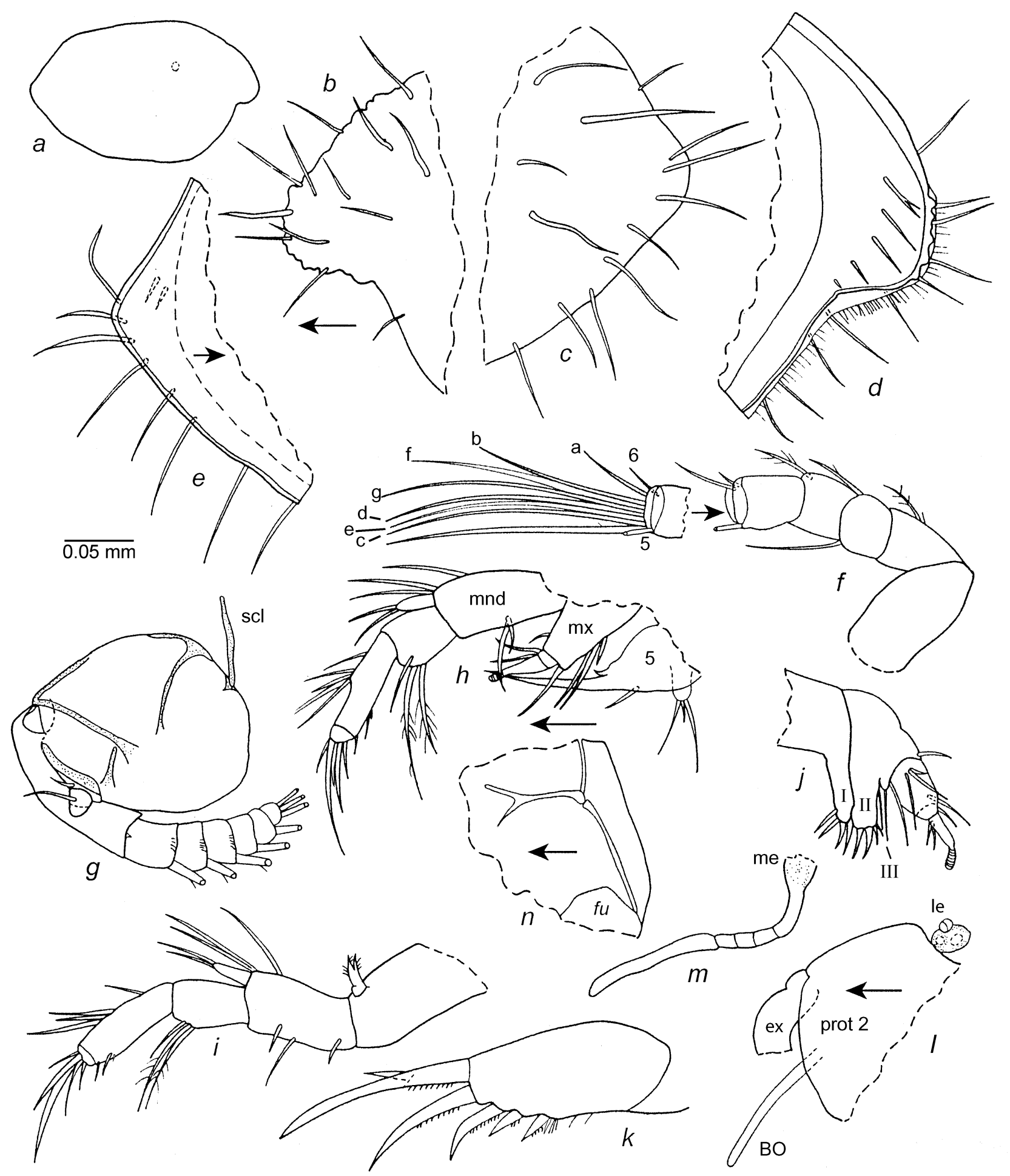

FIGURE 46. Pseudophilomedes ferulanus Kornicker 1958, USNM 1021461, instar II, sex unknown: $a$, complete specimen from right side, length $0.69 \mathrm{~mm} ; b$, anterior of left valve, ov; $c$, posterior of left valve; ov; $d$, anterior left valve, iv; $e$, posterior left valve, iv; $f$, left first antenna drawn on body, lv; $g$, right second antenna, mv; $h$, left mandible, maxilla, and fifth limb drawn on body, lv; $i$, right mandible, mv; $j$, right maxilla, lv; $k$, left lamella of furca, $l v$; $l$, left lateral eye, protopod left second antenna, Bellonci Organ; $m$, Bellonci Organ and medial eye; $n$, posterior of body showing left Ysclerite, ventral end of girdle, and dorsal end of furca. Scale equals $0.05 \mathrm{~mm}(b-n)$. 


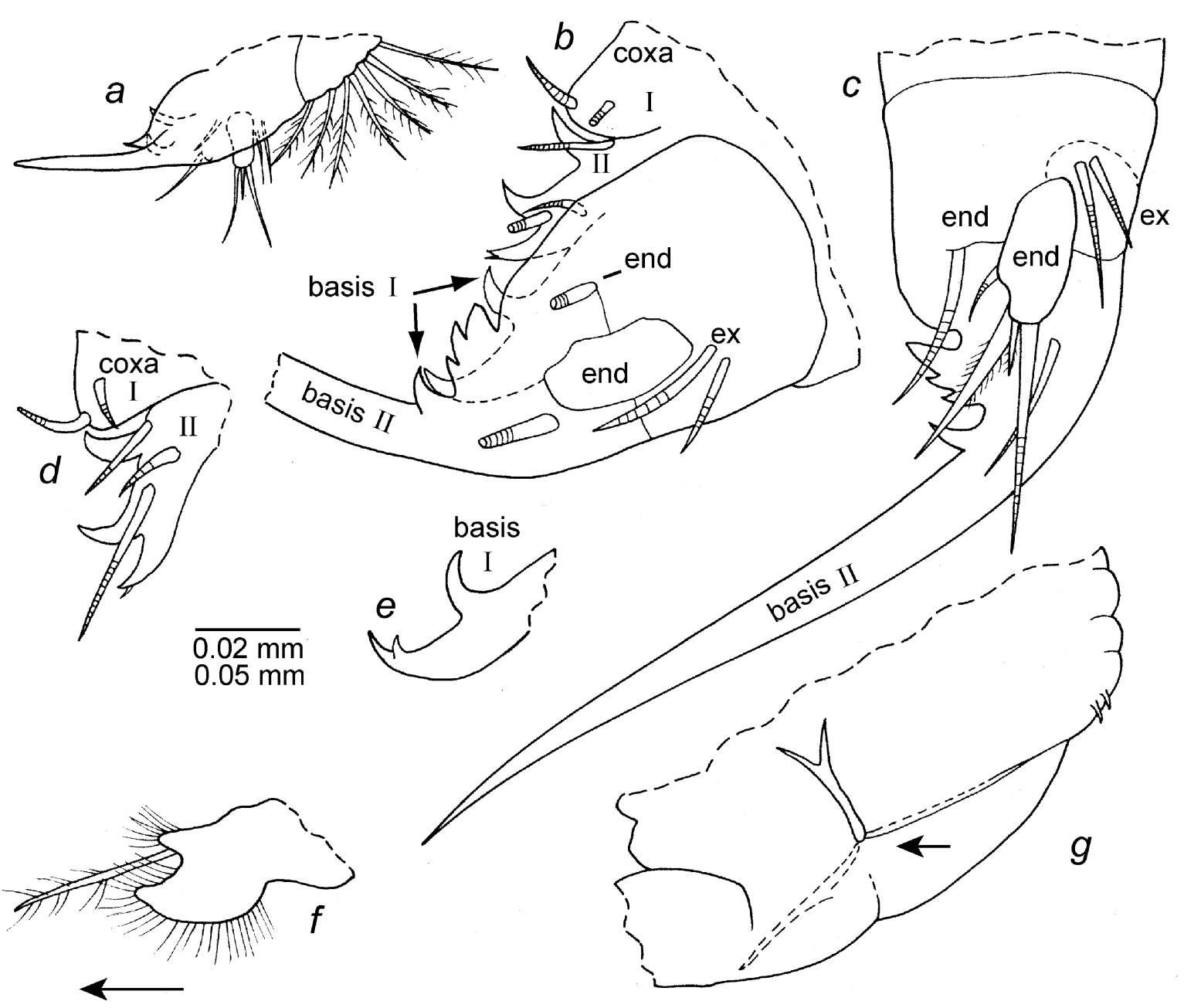

FIGURE 47. Pseudophilomedes ferulanus Kornicker 1958, USNM 1021461, instar II, sex unknown: $a$, left fifth limb, av; $b-e$, right fifth limb, pv; $f$, left sixth limb, lv; $g$, posterior of body showing Y-sclerite, girdle, and posterior end of furca. Scale equals $0.05 \mathrm{~mm}(a, f, g)$ and $0.02 \mathrm{~mm}(b-e)$.

Selvage: Narrow fringed lamellar prolongation along anterior and ventral margins of valve. Prolongation not divided at incisure.

Central adductor muscle attachments: Indistinct on USNM 10214561.

Carapace size (length, height in mm): USNM 10214561, 0.69, 0.41.

First antenna (Fig. 46f): Segment 2 with 1 dorsal bristle. Segment 3 with 2 bristles ( 1 ventral, 1 dorsal). Segment 4 with 1 dorsal bristle. Long ventral bristle of segment 5 with small proximal filament. Segment 6 with small medial bristle near dorsal margin. Segment 7 with 3 bristles: a-bristle about 3 times length of bristle of 6th segment; b-bristle about twice length of a-bristle; c-bristle long, bare. Segment 8 with 4 long bare bristles.

Second antenna (Fig. 46g,ll): Protopodite bare; proximal connecting sclerite fairly linear. Endopod with 2 segments, each with 1 bristle. Exopod: Right limb of USNM 10214561 aberrant in having only 7 segments (Fig. 46g); left limb with 9 segments; terminal segment of left limb with 2 bristle, of right limb with 3 bristles. Most bristles with natatory hairs, some also with slender proximal ventral spines; 1 st segment with minute terminal medial spine-like bristle; some segments with distal spines forming row.

Mandible (Fig. 46h,i): Coxa endite bifurcate, spinous. Basis: dorsal margin with 1 distal and 2 terminal bristles; medial surface with 1 or 2 short bristles near ventral margin; ventral margin with 1 bristle near midlength. Exopod elongate with 2 terminal bristles. Endopod: 1st segment with 3 terminal ventral bristles; 
2nd segment with 4 or 5 bristles on or near dorsal margin and 2 short distal bristles on ventral margin; 3rd segment with 3 slender bristles and 2 claw-like bristles.

Maxilla (Fig. 46j): Endite I with 2 terminal bristles and 2 terminal pectinate claws; endite II with 1 proximal bristle, 2 terminal bristles and 2 terminal claws; endite III with 1 long terminal bristle. Basis with 1 short dorsal terminal bristle and 1 long ventral terminal bristle. Exopod with 3 bristles ( 2 long, 1 short); base of exopod bristles on 1st endopod segment close to distal margin of basis. Endopod: 1st segment with distal dorsal bristle; 2nd segment with 3 short bristles and long terminal finger-like process with annulated narrower distal part.

Fifth limb (Fig. 47a-e): Epipod with 28 spinous bristles. Exopodite represented by 2 short bristles. Coxa with 2 endites: endite I with 2 short bristles; endite II with tooth with 3 prongs and 3 bristles. Basis with 2 endites: endite I anterior with tooth with 2 prongs (distal tooth with small marginal prong on inner edge); endite II posterior with 1 long posterior proximal bristle and long slender tooth; inner edge of tooth with 2 teeth (proxima1 with 3 prongs, distal single). Exopod represented by two bristles. Endopod: segment 1 represented by single bristle on posterior surface; segment 2 elongate with 4 bristles ( 1 short proximal, 3 terminal (stout terminal bristle with stout proximal marginal spines)).

Sixth limb (Fig. 47f): Bilobed with marginal spines and 1 long spinous bristle on smaller lobe.

Seventh limb: Absent.

Furca (Fig. 46k): Each lamella with 5 claws decreasing in length and width posteriorly along lamella. A stout spine adjacent to base of posterior edge of claw 5; additional slender spines along lamella following claw 5. Anterior of right lamella with slender spines near base of claw 1. Claw 1 with stout medially tooth proximal to midlength. All claws with proximal teeth along posterior edge.

Bellonci Organ (Fig. 46l,m): Elongate with rounded tip bearing few spines, and sutures in proximal part.

Eyes: Medial eye only weekly pigmented and small (Fig. $46 \mathrm{~m}$ ). Lateral eye small, pigmented, and with 3 ommatidia (Fig. 46l).

Y-Sclerite (Figs. 46n, 47g): Branching distally.

Discussion. The second instar of a species of Pseudophilomedes has not been described previously. The specimen from Bottomly's Blue Hole provided the opportunity to describe instar II of P. ferulanus. The morphology of the first antenna and sixth limb of the species is consistent with members of the Myodocopina in that the fourth segment of the first antenna bears only a dorsal bristle, and the sixth limb bears only one bristle (see Hiruta 1983: 673). The bristle of the sixth limb of instar II of P. ferulanus is unusually long.

\section{Family Rutidermatidae Brady \& Norman 1896}

Composition and distribution. The Rutidermatidae include two subfamilies, Rutidermatinae Brady \& Norman 1896, and Metaschismatinae Kornicker 1994. Members of the former are widely distributed, and two genera and five species, including a new species described herein, are known from the Bahamas (see Cohen \& Kornicker 1987). The Metaschismatinae includes only one species from the vicinity of Australia (Kornicker 1994:123).

\section{Subfamily Rutidermatinae Brady \& Norman 1896}

Composition. This subfamily includes three genera: Rutiderma Brady \& Norman 1896, Alternochelata Kornicker 1958 and Scleraner Kornicker 1975. 


\section{Rutiderma Brady \& Norman 1896}

Type species. Rutiderma compressum Brady \& Norman 1896.

Distribution. Widespread between latitudes of about $34^{\circ} \mathrm{N}$ and $50^{\circ} \mathrm{S}$ and depths of 1-260 $\mathrm{m}$ (Kornicker 1983: 25). Kornicker et al. (2002: Table 1) incorrectly listed Rutiderma darbyi Kornicker 1983 as being present in an inland blue hole in the Bahamas.

\section{Rutiderma flex, new species}

Figs. 48-51

Etymology. An arbitrary combination of letters.

Holotype. USNM 1021462, adult male on slide and in alcohol.

Type locality. Conch Sound Blue Hole, Andros Island, Great Bahama Bank.

Paratypes. None.

Distribution. Great Bahama Bank: Andros Island (Conch Sound Blue Hole).

Description of adult male (Figs. 48-51). Carapace with short rostrum and caudal process (Fig. 48).

Ornamentation: Carapace with alate posterior process well defined only along dorsal and posterior edges (Figs. 48, 49b). Surface with small round separated fossae (Figs. 48, 49c). Single bristles present along valve margins and widely scattered on lateral surface (Figs. 48, 49c). Anterior margin of rostrum with scalloped edge. Tip of caudal process with minute indentation (Figs. 48, 49b,d,f,g).

Infold: Infold of rostrum with 7 single bristles (Fig. 49c). Anteroventral infold with 10 single bristles forming row (Fig. 49e). Ventral infold anterior to caudal process with about 5 small single bristles forming row (Fig. 49d). Infold of caudal process of each valve somewhat obscured by debris, with pocket with anterior oblique shelf with straight posterior edge without bristles (Fig. $49 d, f$ ); ventral edge of shelf curves posteriorly and terminates in sclerotized process (Fig. 49d,f); posterior edge of shelf with transparent lamellar prolongation; dorsal part of lamellar prolongation of right valve with minute serrations (Fig. 49d); 3 or 4 small bristles present near posterior edge of caudal process (Fig. 49d,f). Lamellar prolongation may be divided at incisure, but obscured by debris.

Central adductor muscle attachments (Figs. 48, 49a,g): Consisting of about 19 ovoid attachments.

Carapace size (length, height in mm): USNM 1021462, 1.21, 0.73.

First antenna (Figs. 49g, 50a,l): 1st segment bare. 2nd segment with proximal dorsal spines, a few distal ventral spines, many faint lateral spines in distal dorsal corner, 1 dorsal bristle, and 1 distal lateral bristle. 3rd segment short, dorsal margin longer than ventral margin, with 3 bristles ( 1 ventral, 2 dorsal). 4 th segment with 4 bristles ( 3 ventral, 1 dorsal). 5th segment small, inserted ventrally between 4th and 6th segments, with stout cylindrical proximal part and 1 stout terminal bristle and many slender terminal filaments (at least 25, only 4 shown). 6th segment with 1 distal dorsal bristle. 7th segment with short a-bristle, stout b-bristle with 2 filaments, and long c-bristle with about 10 filaments. 8th segment with bare filamentous d- and e-bristles, long fbristle with about 11 filaments, and stout g-bristle with 1 or 2 filaments. Both c- and f-bristles almost as long as carapace (Fig. $49 g$ ).

Second antenna: Protopod bare (Fig. 50b,c,l). Endopod with 3 segments (Fig. 50b,c): 1st segment short with 5 bristles (4 proximal, 1 distal); 2nd segment elongate with 2 separated bristles just distal to midlength; 3rd segment elongate and reflexed with 1 proximal and 2 terminal bristles. Exopod with 9 segments (Fig. 50d): 1st segment with 2 or 3 distal ventral spines (Fig. 50d) and minute terminal medial spine (Fig. 50d,e); 2nd segment short with bare ventral bristle almost reaching 5th segment; segments 3-8 with long ventral bristle with natatory hairs; 9 th segment with 5 bristles ( 4 with natatory hairs (dorsal bristle one-half length of others), 1 medial near dorsal margin, minute, bare) (Fig. 50d). 
Mandible (Figs. 48, 50f): Coxa endite represented by 2 minute spines at midheight. Basis: medial surface with 4 proximal bristles ( 2 medium length, 2 minute) near ventral margin; dorsal margin with 3 bristles (1 near midlength, 2 distal longer). Exopodite: lateral near dorsal margin, elongate, about one-half length dorsal margin of 1st endopod segment, with terminal spines. Endopod: 1 st segment short with 2 ventral bristles. 2nd segment elongate, with ventral and medial spines, 3 dorsal bristles, and 6 short distal bristles ( 2 a-bristles, $1 \mathrm{~b}$ bristle, 1 c-bristle, 2 d-bristles). 3rd segment with 5 bristles ( 3 short a-bristles, 1 longer b-bristle, and 1 very long claw-like c-bristle).

Maxilla (Fig. 50g): Limb reduced. Bristles somewhat obscured on limb examined under oil immersion lens. Coxa with plumose dorsal bristle. Basis with bristle near dorsal margin and 2 at midwidth. Endites I-III with total of about 11 bristles. Endopod 2nd segment with about 7 weakly developed bristles. Exopod not observed.

Fifth limb (Fig. 50h): Segmentation unclear. Endopod 2nd segment with 5 ringed bristles. Exopod with 2 distinct ringed bristles. Epipod with about 30 plumose bristles.

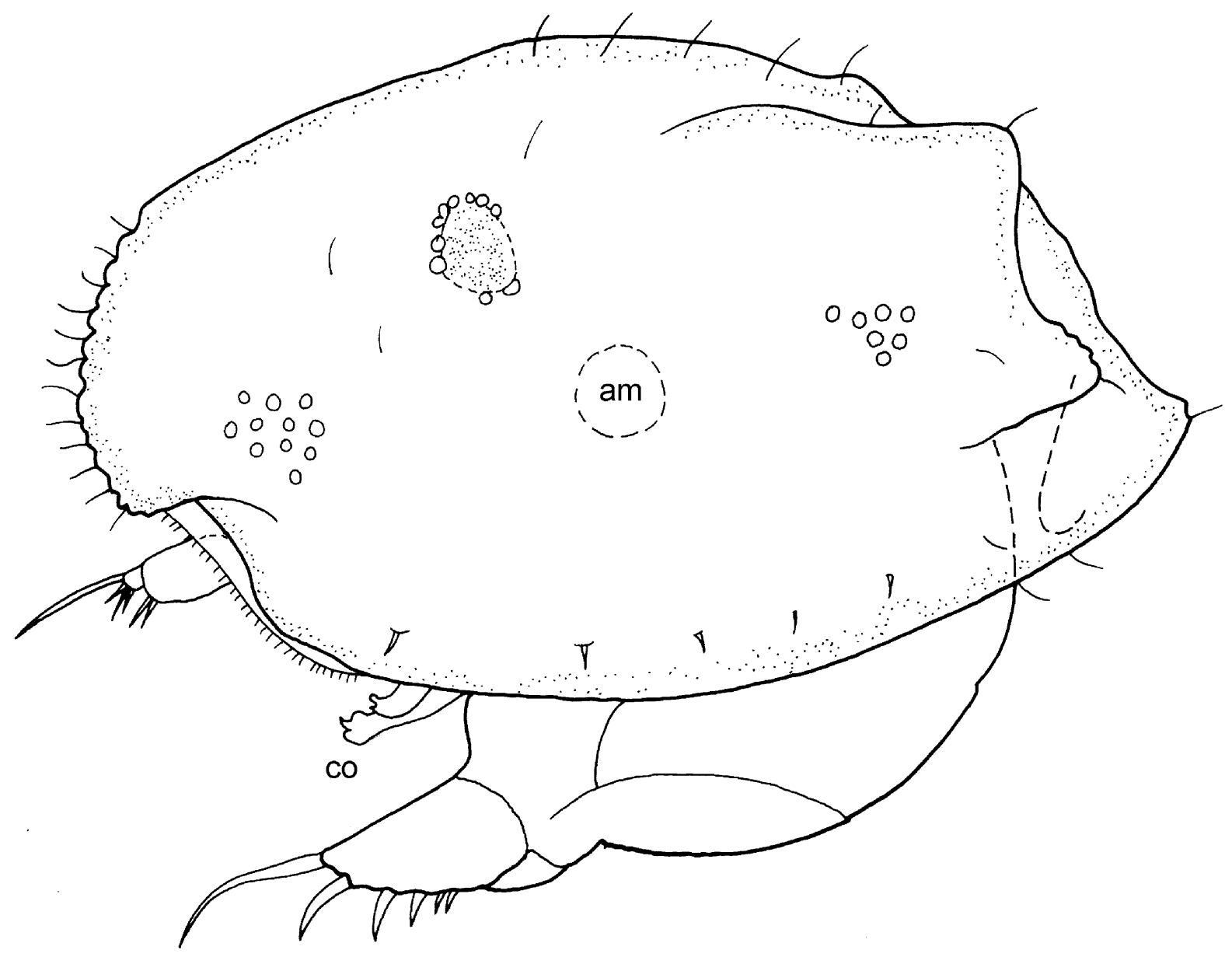

FIGURE 48. Rutiderma flex, new species, holotype USNM 1021462, adult male; complete specimen from left side, length $1.21 \mathrm{~mm}$. 


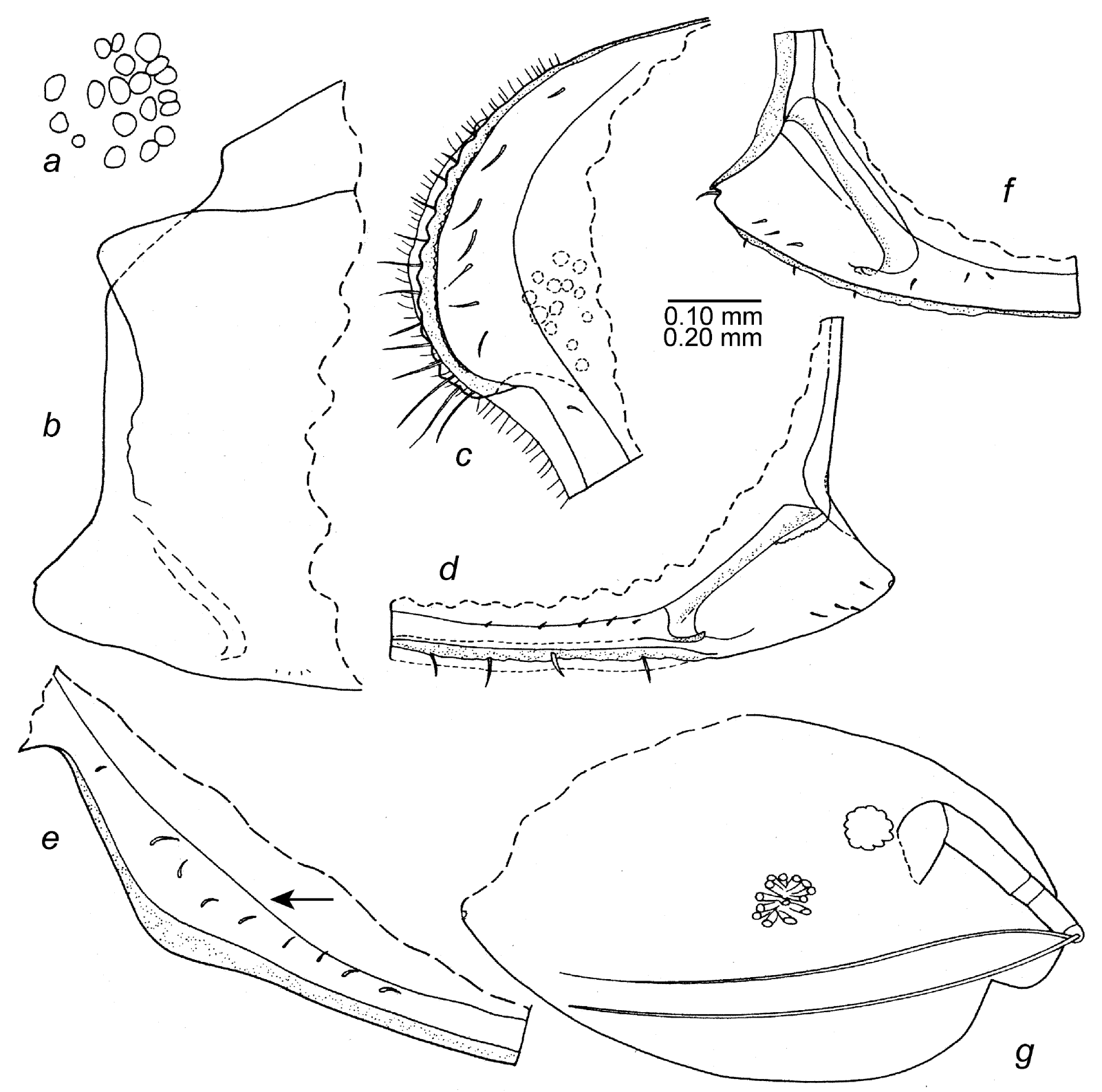

FIGURE 49. Rutiderma flex, new species, paratype USNM 1021462, adult male: $a$, central adductor muscle scars of left valve, ov; $b$, posterior right valve, ov; $c$, anterior right valve, iv; $d$, posterior right valve, iv; $e$, anteroventral margin of right valve, iv; $f$, posterior left valve, iv; $g$, specimen with right valve removed showing ends of central adductor muscles, outline of right lateral eye, and right first antenna, lv (nabs). Scale equals $0.10 \mathrm{~mm}(a-f)$ and $0.20 \mathrm{~mm}(\mathrm{~g})$.

Sixth limb (Fig. 50i): Endite I with 2 bristles; endite II with 2 bristles; endite III with 3 bristles; endite IV with 3 bristles. End segment with 3 anterior bristles and 4 plumose posterior bristles along ventral edge; anterior bristles on small projection. 2 bristles in place of exopod. Posterior edge and medial surface of limb with hairs.

Seventh limb (Fig. 50j): Long, slender, with 3 or 4 proximal bristles (1 or 2 on each side), each with 2 bells, and 4 terminal bristles ( 2 on each side), each with 4 bells. Tip with opposing teeth, 2 on each side.

Furca (Figs. 48, 51b): Each lamella with 4 primary claws followed by 1 or 2 secondary claws; claw 1 with medial and lateral row of teeth (distal teeth smaller); following claws with spines along posterior edge; claws 1 and 2 with proximal medial spines forming row; claws 1-3 with slender distal spines along anterior edge; right lamella anterior to left by width of base of claw 1 . 


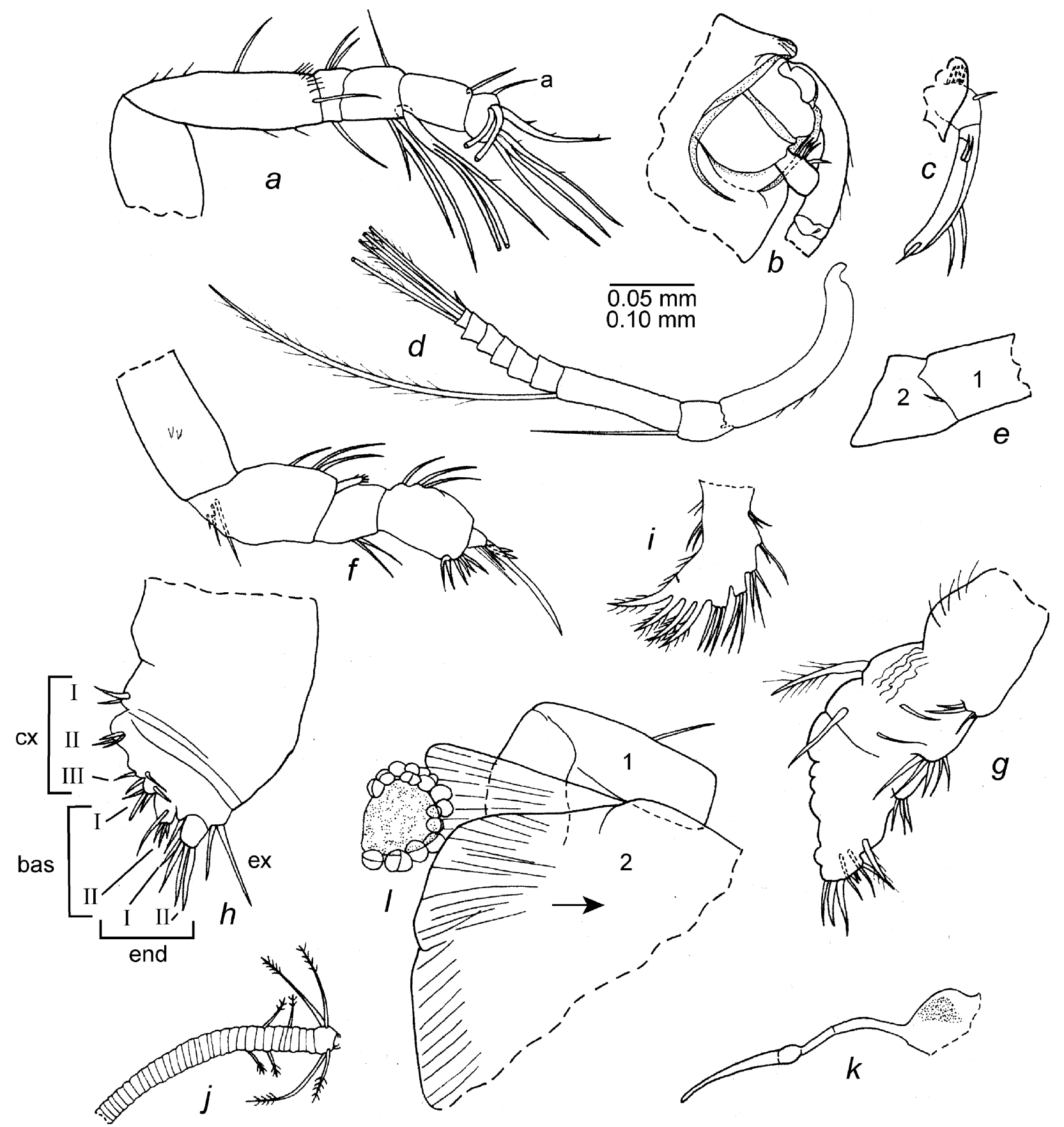

FIGURE 50. Rutiderma flex, new species, paratype USNM 1021462, adult male: $a$, right first antenna drawn on body, lv (nabs); $b$, part left second antenna, mv; $c$, endopod right second antenna, lv; $d$, exopod right second antenna, lv; $e$, articles 1 and 2 left second antenna, mv; $f$, right mandible drawn on body, lv; $g$, maxilla; $h$, right fifth limb drawn on body, lv; $i$, right sixth limb drawn on body, lv; $j$, left seventh limb; $k$, Bellonci Organ and medial eye; $l$, anterior of body from right side showing lateral eye and parts of first and second antenna. Scale equals $0.10 \mathrm{~mm}(a-d, f, i-k, l)$ and $0.05 \mathrm{~mm}(e, g, h)$.

Bellonci Organ (Fig. 50k): Elongate with proximal suture, short wide part near midlength, and pointed tip.

Eyes: Medial eye with black pigment and without dorsal filaments (Fig. 50k). Lateral eye about twice size of medial eye, with numerous divided ommatidia surrounded by black pigment except along edges (Figs. 48, $49 g, 50 l)$.

Upper lip (Fig. 51e): Rounded bare.

Copulatory limb (Figs. 48, 51b-d): Comprising 2 elongate lobes; tip of each lobe with minute sclerotized process and 2 pairs of small bristles. 
Posterior of body (Fig. 51a): Bare. Girdle with ventral end fitting into small socket in dorsal margin of posterior end of Y-sclerite.

Y-Sclerite (Fig. 51a,c): Branching distally; posterior end forming angle.

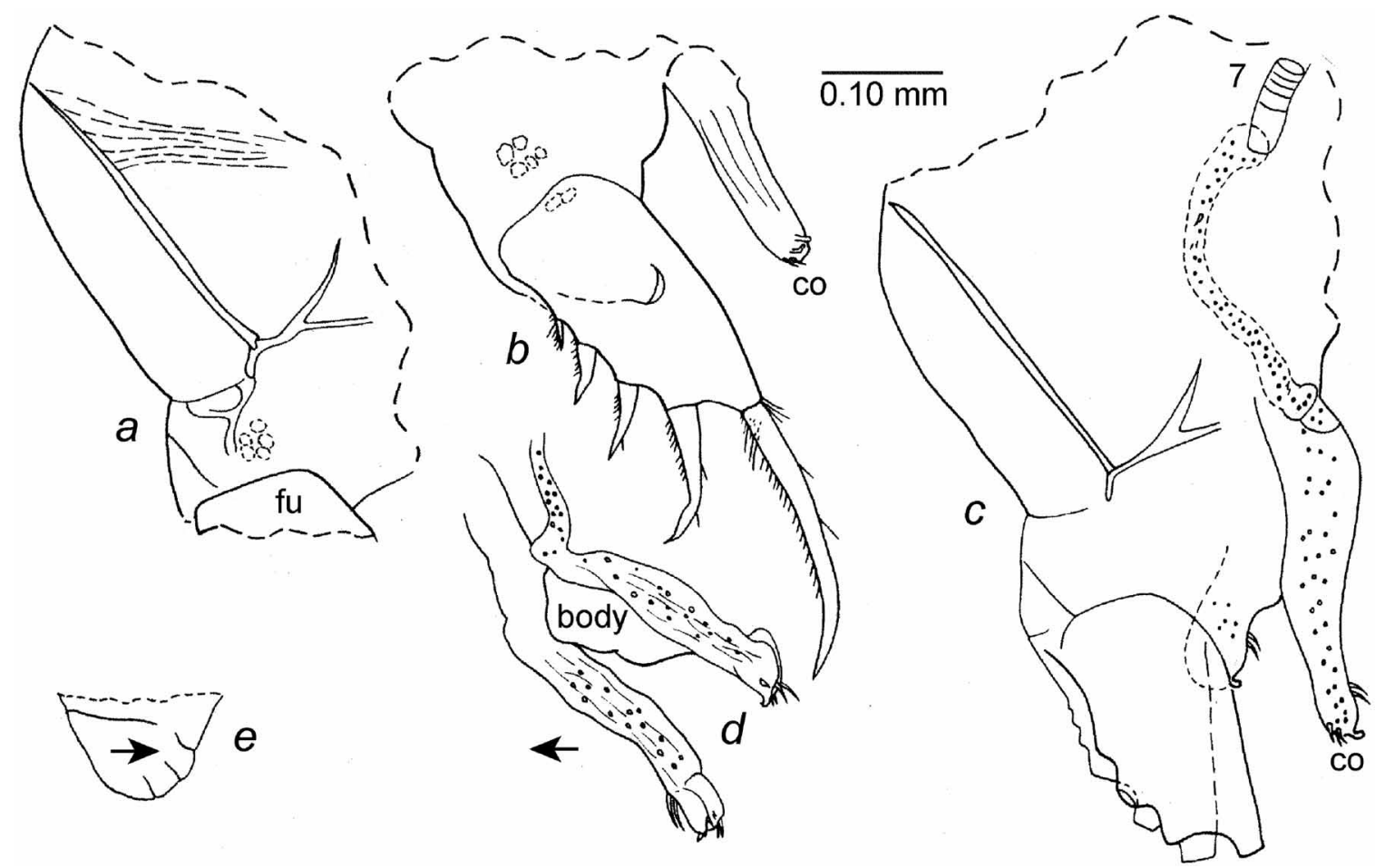

FIGURE 51. Rutiderma flex, new species, paratype USNM 1021462, adult male: posterior of body from right side showing Y-sclerite, girdle, and posterior end of furca; $b$, right lamella of furca and right copulatory organ; $c$, posterior of body from right side showing part right seventh limb; $d$, copulatory organs (right organ at left); $e$, upper lip from right side. Scale equals $0.10 \mathrm{~mm}(a-e)$.

Comparisons. The carapace of the male $R$. flex differs from that of $R$. dinochelatum Kornicker 1958 (Kornicker 1958: fig. 46: 7a,b) in that the upper lateral rib does not extend anteriorly to intersect the anterior edge of the rostrum, and the lower lateral rib does not extend anteriorly to midlength of the carapace. The structure of the posterior edge of the shelf in the anterior part of the pocket of the infold of the caudal process of $R$. flex differs from those of $R$. darbyi Kornicker 1983 (Kornicker 1983: Fig. 23b) and R. schroederi Kornicker \& Iliffe 2000 (Kornicker \& Iliffe 2000: fig. 53c, $d$ (female)). The infold of the rostrum of $R$. flex bears a row of seven bristles compared to 12 on R. mortenseni Poulsen 1965 (Poulsen 1965: fig. 11b). The adult male of $R$. flex is larger than that of $R$. licinum Kornicker 1983, the furca bears one or two instead of three secondary claws, and the basis of the mandible bears four instead of six bristles near the ventral margin.

\section{Family Sarsiellidae Brady \& Norman 1896}

Composition and distribution. The Sarsiellidae include two subfamilies Sarsiellinae Brady \& Norman 1896, and Dantyinae Kornicker \& Cohen 1978. Both subfamilies are present in the Bahamas.

\section{Subfamily Sarsiellinae Brady \& Norman 1896}

Eusarsiella Cohen and Kornicker 1975 
Type species. Sarsiella capsula Norman 1869.

Composition and distribution. Cosmopolitan between latitudes of about $63^{\circ} \mathrm{N}$ and $37^{\circ} \mathrm{S}$. Its known depth range is intertidal to $1120 \mathrm{~m}$ (Kornicker \& Iliffe 2000:30). The genus is well represented in the Bahamas (see Kornicker et al. 2002: Table 1). A new species E. flex is described herein.

\section{Eusarsiella capillaris (Kornicker 1958)}

Fig. 52

Sarsiella capillaris Kornicker 1958: 248, figs. 47: 7a, b; 76A, F, H; 89A, B, D, F, O.

Eusarsiella capillaris (Kornicker 1958).-_Poulsen 1965: 83.-Kornicker 1986: 54, figs. 26-28a-c; pl. 1.

Holotype. USNM 122910, specimen 92-1, whole dry specimen on slide, probably late instar, length $1.15 \mathrm{~mm}$. Type locality. Bimini, Bahamas.

Material. USNM 193115, 1 adult female with body removed from carapace; all in alcohol and from continental shelf southwest of Florida.

Distribution. Bimini, Great Bahama Bank and southwest Florida continental shelf. Known depth range intertidal to $22.5 \mathrm{~m}$.

Discussion. No specimens of E. capillaris are present in the collections from the Bahamas reported upon herein. However, for comparative purposes an adult female from the continental shelf southwest of Florida that had been reported and partly described by Kornicker (1986: 58) was reexamined in order to compare it with other species in the present collection, and a supplementary description of an adult female is presented herein. Appendages were studied while attached to the body and not all details were visible.

Supplementary description of adult female (Fig. 52). Carapace oval in lateral view with projecting tapered caudal process and numerous spinous processes, most with 1 or 2 fairly long bristles with broad base and short broad tapered bristles with rounded tips: ventral and anterior margins with ten processes; posterodorsal margin with 4 processes; location of additional processes shown in Fig. 52a. Surface of valves including processes covered by gel-like substance, not shown in illustration.

Ornamentation (Fig. 52a): Surface with shallow oval fossae, scattered short, recurved, broad spine-like bristles, and scattered small slender spine-like bristles; lateral ridges absent. Edge of valves with long bristles broad proximally and narrow distally, and short spine-like bristles.

Central adductor muscle attachments (Fig. 52a): Comprising about 13 ovoid scars (only 7 shown).

Carapace size USNM 193115: Kornicker(1986: 58) gave length as $1.28 \mathrm{~mm}$, and height as $0.93 \mathrm{~mm}$. Measurements herein of carapace with body removed (carapace had been preserved in alcohol for about 35 years): length $1.15 \mathrm{~mm}$, height $0.85 \mathrm{~mm}$ for right valve, and $1.19 \mathrm{~mm}$ for length of left valve.

First antenna (Fig. 52b): 1st and 2nd segments without bristles. 3rd and 4th segments fused; 3rd segment with 2 bristles ( 1 ventral, 1 dorsal); 4th segment with 3 bristles ( 2 ventral, 1 dorsal). 5th segment with long ventral terminal bristle. 6 th segment fused to 5 th, with small medial bristle near ventral margin. 7 th segment: a-bristle about twice length of bristle of 6th segment; b-bristle medial, longer than a-bristle; c-bristle about same length as bristle of 5th segment. 8th segment: d- and e-bristles shorter than c-bristle, bare, filament-like; f-bristle stout, about two-thirds length of c-bristle; g-bristle shorter than c-bristle and longer than f-bristle.

Second antenna: Endopodite with 3 bristles (2 proximal, 1 terminal) (Fig. 52c). 9th exopod segment with 2 bristles (dorsal small, ventral long).

Mandible (Fig. 52d): Similar to that described for instar IV by Kornicker (1986: 57).

Seventh limb (Fig. 52e): With 2 proximal bristle with 3 or 4 bells, and 6 terminal bristles ( 2 short with 2 or 3 bells, 2 medium length with 4 or 5 bells, 2 long with 5 or 6 bells). Tip of limb with opposing curved teeth, 2 or 3 on each side. 


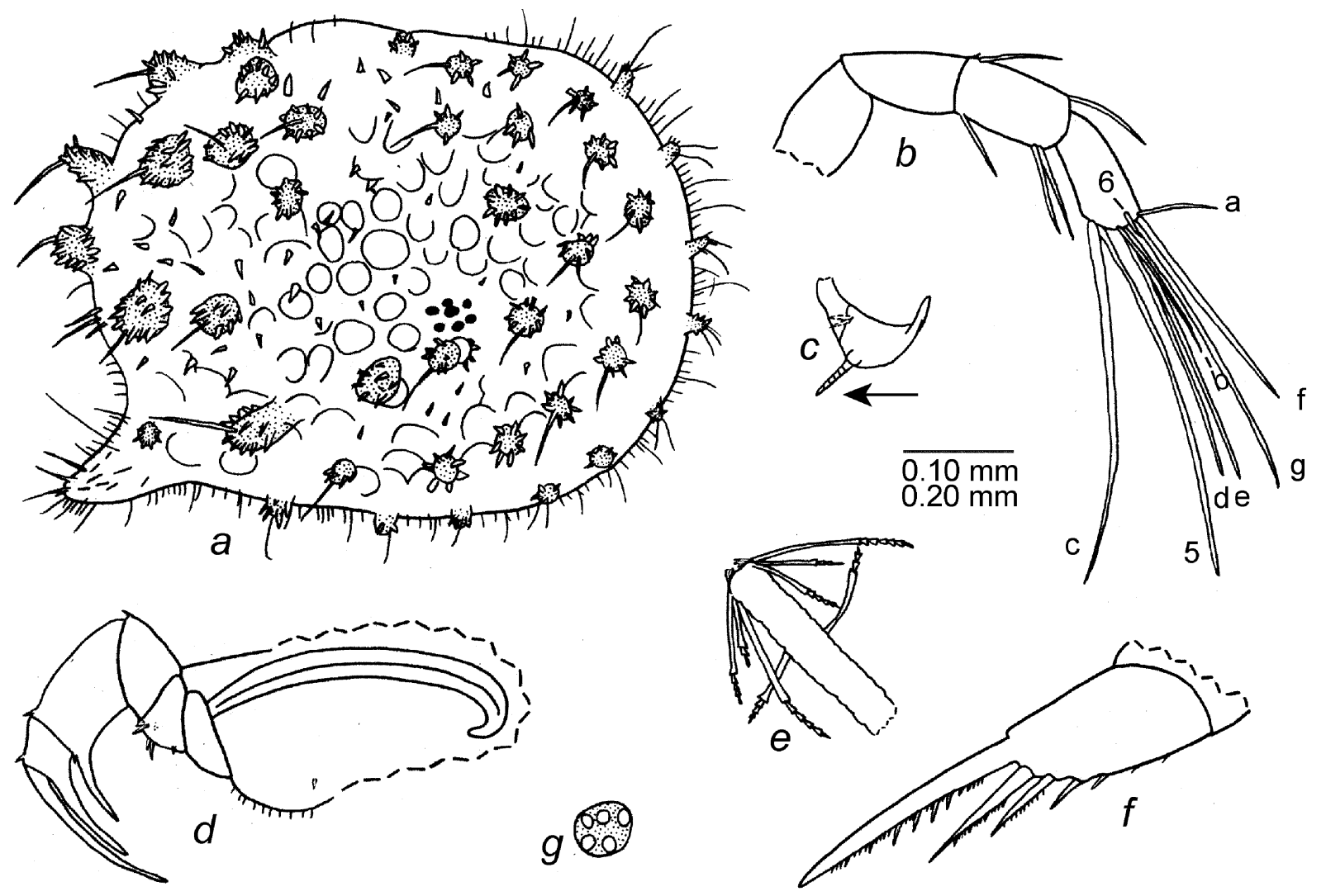

FIGURE 52. Eusarsiella capillaris (Kornicker 1958), USNM 193115, adult female: $a$, complete specimen from right side; $b$, left first antenna drawn on body, lv; $c$, endopod left second antenna drawn on body, mv; $d$, left mandible drawn on body, lv; $e$, left seventh limb, mv; $f$, left lamella of furca drawn on body, lv; $g$, right lateral eye drawn on body. Scale equals $0.20 \mathrm{~mm}(a)$ and $0.10 \mathrm{~mm}(b-g)$.

Furca (Fig. 52f): Right lamella anterior to left by width of base of claw 1. Lamellae following claws without stout spines (two minute spines observed on left lamella). Stout marginal teeth on claws 1 and 2 as shown.

Lateral Eye (Fig. 52g): With 5 ommatidia.

Eggs: Several large unextruded eggs present.

Comparisons. The first antenna of this species is unusual in lacking a dorsal bristle on the second segment of the first antenna (Fig. 52b). Bristles on processes of the carapace of E. capillaris differ from those of Eusarsiella paniculata Kornicker 1986 in being broader and having blunter tips (Kornicker 1986:61).

Remarks. The above description provides details omitted from prior descriptions of the species.

\section{Eusarsiella syrinx, new species}

Figs. 25, 25, 53-56a,b; 57-63, Table 13

Etymology. From the Greek syrinx (pipe).

Holotype. USNM 1021463, undissected ovigerous female in alcohol.

Type locality. Sta 00-019, Mystery Cave, Stocking Island, Exuma Cays, Great Bahama Bank.

Paratypes. USNM 1021464, adult male on 2 slides and in alcohol. USNM 1021465, adult female on 2 slides and in alcohol. USNM 1021466, instar IV (A-1) female on slide and in alcohol. USNM 1021467, Instar III (A-2) (sex unknown) on slide and in alcohol. USNM 1021468, instar II (A-3) (sex unknown) on slide and in alcohol. USNM 1021469, instar I (A-4) (sex unknown) on slide and in alcohol. USNM 1021470 instar I (A4) (sex unknown) undissected specimen in alcohol. 
TABLE 13. Morphometrics of appendages of different growth stages of Eusarsiella syrinx. Sex not determined for some instars; morphometrics of both sexes (if known) of each instar combined. ( $\mathrm{a}-\mathrm{g}=$ letters identifying specific bristles, $\mathrm{D}=$ dorsal, $\mathrm{F}=$ female, Fil. $=$ filamentous, $\mathrm{M}=$ male, na = not applicable, $\mathrm{T}=$ tapered, $\mathrm{V}=$ ventral, $-=$ absent, $+=$ present, ? = number of bristles uncertain.)

\begin{tabular}{lllllll}
\hline & A-4 & A-3 & A-2 & A-1 & Adult F & Adult M \\
\hline $\begin{array}{l}\text { Carapace average length } \mathrm{mm} \\
\text { (no. of specimens) }\end{array}$ & $0.67(2)$ & $0.83(1)$ & $1.02(1)$ & $1.30(1)$ & $1.56(2)$ & $0.98(1)$
\end{tabular}

\section{First Antenna}

1st segment bristles

2nd segment bristles

3rd segment bristles

4 th segment bristles

3rd and 4th segments fused

5 th segment bristles

6th segment bristles

7 th segment bristles

8th segment bristles

Second Antenna

Exopod

1st segment bristles

Segments 2-8 bristles

9th segment bristles

Endopod

1st segment bristles

Anterior

Terminal

2nd segment bristles

Mandible

Coxa bristles (endite)

Basis

Dorsal bristles

Medial bristles

Exopod

Endopod

1st segment total bristles

2nd segment total bristles

3rd segment total bristles

Maxilla

Endites I -III bristles

Coxa dorsal bristles

Basis bristles

Endopod

1st segment bristles

$\begin{array}{llllll}0 & 0 & 0 & 0 & 0 & 0 \\ 0 & 1 & 1 & 1 & 1 & 1 \\ 1 \mathrm{~V}, 1 \mathrm{D} & 1 \mathrm{~V}, 1 \mathrm{D} & 1 \mathrm{~V}, 1 \mathrm{D} & 1 \mathrm{~V}, 1 \mathrm{D} & 1 \mathrm{~V}, 1 \mathrm{D} & 1 \mathrm{~V}, 1 \mathrm{D} \\ 0 & 1 \mathrm{D} & 1 \mathrm{~V}, 1 \mathrm{D} & 2 \mathrm{~V}, 2 \mathrm{D} & 2 \mathrm{~V}, 1-2 \mathrm{D} & 1 \mathrm{~V}, 1 \mathrm{D} \\ + & + & + & + & + & + \\ 1 & 1 & 1 & 1 & 1 & 1(\text { Fil. }) \\ 1 & 1 & 1 & 1 & 1 & 1 \\ \mathrm{a}-\mathrm{c} & \mathrm{a}-\mathrm{c} & \mathrm{a}-\mathrm{c} & \mathrm{a}-\mathrm{c} & \mathrm{a}-\mathrm{c} & \mathrm{a}-\mathrm{c} \\ \mathrm{d}-\mathrm{g} & \mathrm{d}-\mathrm{g} & \mathrm{d}-\mathrm{g} & \mathrm{d}-\mathrm{g} & \mathrm{d}-\mathrm{g} & \mathrm{d}-\mathrm{g}\end{array}$

1

8

2

0

1

na

1

2

3

1

2

3

$6,4,4$

1

1

2

1

2

\section{1}

8

2

8

1

8

1

8

2

2

(1)

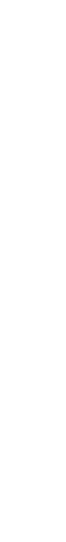


TABLE 13. (continued)

\begin{tabular}{|c|c|c|c|c|c|c|}
\hline & A-4 & A-3 & A-2 & A-1 & Adult F & Adult M \\
\hline \multicolumn{7}{|l|}{ 2nd segment } \\
\hline bristles/claws & $3 / 3$ & $3 / 3$ & $3 / 3$ & $3 / 3$ & $3 / 3$ & $?$ \\
\hline Exopod bristles & 2 & 2 & 2 & 2 & 2 & 2 \\
\hline \multicolumn{7}{|l|}{ Fifth Limb } \\
\hline Epipod bristles & 25 & 30 & 31 & 36 & 35 & 36 \\
\hline Coxa bristles & 1 & 1 & 1 & 1 & 1 & 1 \\
\hline \multicolumn{7}{|l|}{ Basis bristles } \\
\hline Endite I & 2 & $2-3$ & 2 & 2 & 2 & 2 \\
\hline Endite II & 3 & 3 & 3 & 3 & 4 & 3 \\
\hline Exopod bristles & 1 & 1 & 1 & 1 & 1 & 1 \\
\hline \multicolumn{7}{|l|}{ Endopod } \\
\hline 1st segment bristles & 3 & 3 & 3 & 3 & 3 & 3 \\
\hline 2nd segment bristles & 2 & 2 & 2 & 2 & 3 & 2 \\
\hline \multicolumn{7}{|l|}{ Sixth Limb bristles } \\
\hline Endite & 0 & 0 & 2 & 3 & 3 & 3 \\
\hline Terminal segment & 0 & 1 & 12 & 14 & 12 & 15 \\
\hline Seventh Limb & + & + & + & + & + & + \\
\hline Number of bristles & 0 & 0 & 0 & $6 \mathrm{~T}$ & 8 & 4 \\
\hline Terminal spines & - & - & - & + & + & - \\
\hline Furca claws & 3 & 5 & 5 & 5 & 5 & 5 \\
\hline Bellonci Organ & + & + & + & + & + & + \\
\hline $\begin{array}{l}\text { Total number of bristles and claws on one } \\
\text { side }\end{array}$ & 101 & 113 & 130 & 146 & 147 & $145 ?$ \\
\hline $\begin{array}{l}\text { Total number of bristles and claws on both } \\
\text { sides }\end{array}$ & 202 & 226 & 260 & 292 & 294 & $290 ?$ \\
\hline $\begin{array}{l}\text { Percent increase in total number of bristles } \\
\text { and claws between stages* }\end{array}$ & - & 11.9 & 15.0 & 12.3 & 6.84 & $-6.84 ?$ \\
\hline Percent of total increase between stages $* *$ & - & 26.1 & 37.0 & 40.0 & 2.12 & $-2.12 ?$ \\
\hline $\begin{array}{l}\text { Percent of total on adult present at each } \\
\text { stage*** }\end{array}$ & 68.7 & 76.9 & 88.4 & 99.3 & 100 & - \\
\hline
\end{tabular}

*Percentages were calculated by subtracting the number of bristles and claws in one stage from the number in the following stage, then dividing the difference by the number in the first stage and multiplying by 100 .

**Percentages were calculated by dividing the number of bristles and claws between successive stages by the total number obtained by subtracting the number on instar I from the number on the adult female and then multiplying by 100 .

***Percentages were calculated by dividing the number of bristles and claws on each stage by the number on the adult female and then multiplying by 100 .

Distribution. Type locality.

Morphometrics. Morphometrics of appendages of different growth stages are shown in Figs. 25, 26 and Table 13.

Description of adult male (Figs. 53-56a,b). Carapace elongate with incisure forming right angle (Fig. 53). Surface with two lateral ribs connected posteriorly by vertical ridge. Horizontal ridge present between lower rib and ventral margin of valve. Small spinous process near posterodorsal corner of valve connected by 2 rows of small bristles to posterior end of upper horizontal rib. Rostrum formed by process extending anteri- 
orly past anterior edge of valve (Fig. $54 a-c$ ). Caudal process in lateral view forming a $45^{\circ}$ angle.

Ornamentation (Figs. 53, 54c): Surface with shallow round fossae and numerous small single spine-like bristles; bristles mostly between fossae and not restricted to edges of fossae; not more than 8 bristles along edges of fossae. Bristles along ribs, ridges, edges of valves, and near rostrum and caudal process longer and more numerous than those on other surfaces of valves. Few long bristles with broad bases scattered over valve surface. Transparent gel-like substance visible filling space between bristles on ribs, ridges, and valve edges.

Infold: Anterior infold with single small bristle ventral to rostrum (Fig. 54a). Infold of caudal process with proximal vertical row of 3 small bare bristles and two smaller bristles along inner edge (Fig. 54b); posterior infold with 2 setal bristles

Selvage: Narrow selvage with smooth outer edge undivided at incisure

Central adductor muscle attachments: Many small oval attachments (some attachments darkened in Fig. 53).

Carapace size (length, height in mm): USNM 1021464, length with caudal process 0.98 , length without caudal process 0.87 , height 0.59 .

First antenna (Fig. 54d,e): 1st segment bare. 2nd segment with minute dorsal spine near midlength and bare distal dorsal bristle. 3rd and 4th segments fused; 3rd segment with 2 bristles (1 ventral (small with terminal spine), 1 bare dorsal). 4th segment with 2 bare bristles (1 ventral, 1 dorsal). 5th segment small and wedged ventrally between 4th and 6th segments; sensory bristle with abundant thin filaments and stem with 4 short filaments. 6th segment with short bare medial bristle. 7th segment: a-bristle bare, short; b-bristle medial short, bare. 8th segment: c-bristle long with 4 short marginal filaments, d- and e-bristles long, bare; f-bristle shorter than c-bristle, with 2 short marginal filaments; g-bristle as long as c-bristle, with 5 marginal filaments.

Second antenna: Protopod bare (Fig. 55k). Endopod not reflexed, with 2 segments (Fig. 54f): 1st segment with 1 short ringed proximal bristle; 2nd segment with two short ringed terminal bristles. Exopod (Fig. 54g): 1st segment with minute medial spine on distal margin (not shown); bristles of segments 2 and 3 with proximal ventral spines, few proximal dorsal hairs, and distal natatory hairs, bristles of segments $4-8$ with natatory hairs and very few ventral spines; 9 th segment with 2 bristles $(1$ small bare dorsal, other long with natatory hairs); segments $2-8$ with minute indistinct spines forming row along distal lateral margins.

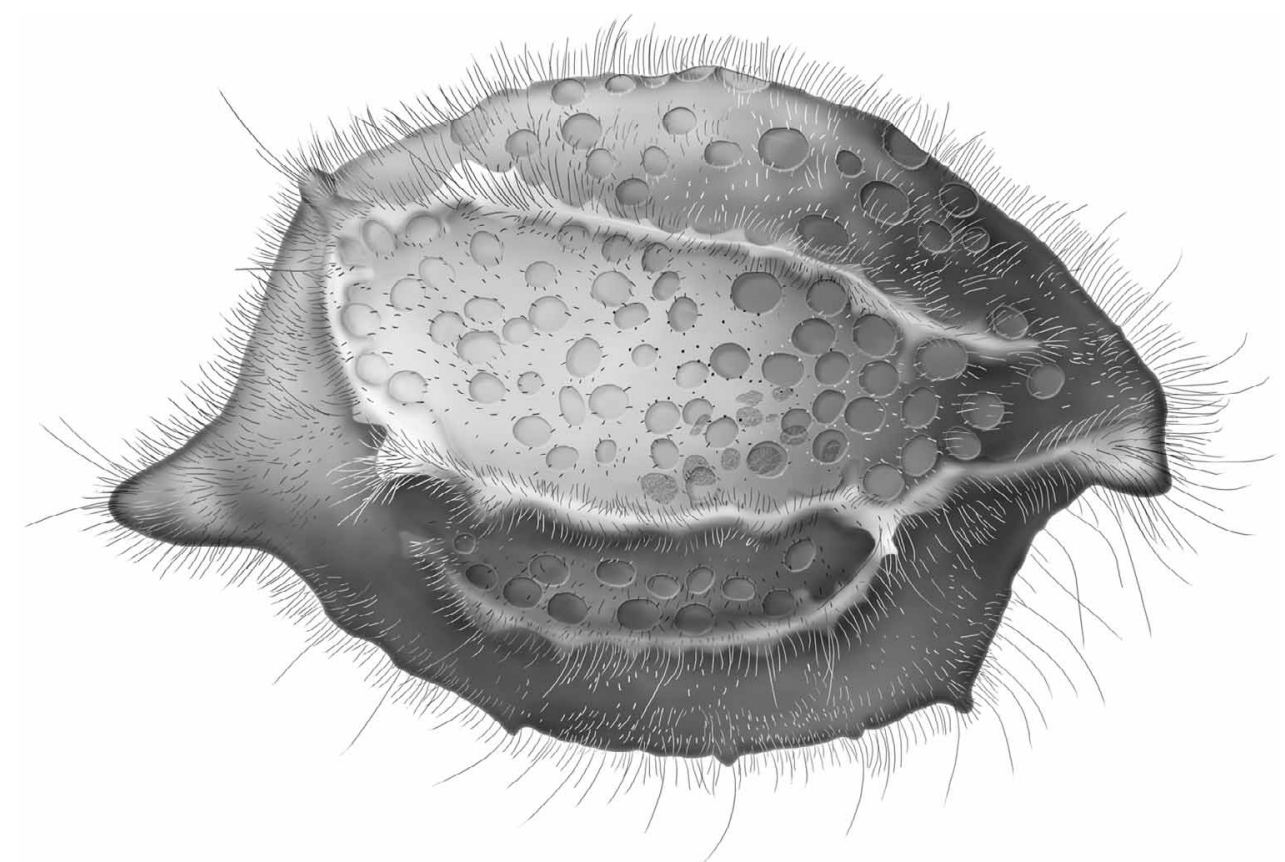

FIGURE 53. Eusarsiella syrinx, new species, paratype USNM 1021464, adult male, complete specimen from right side, length with caudal process $0.98 \mathrm{~mm}$. 


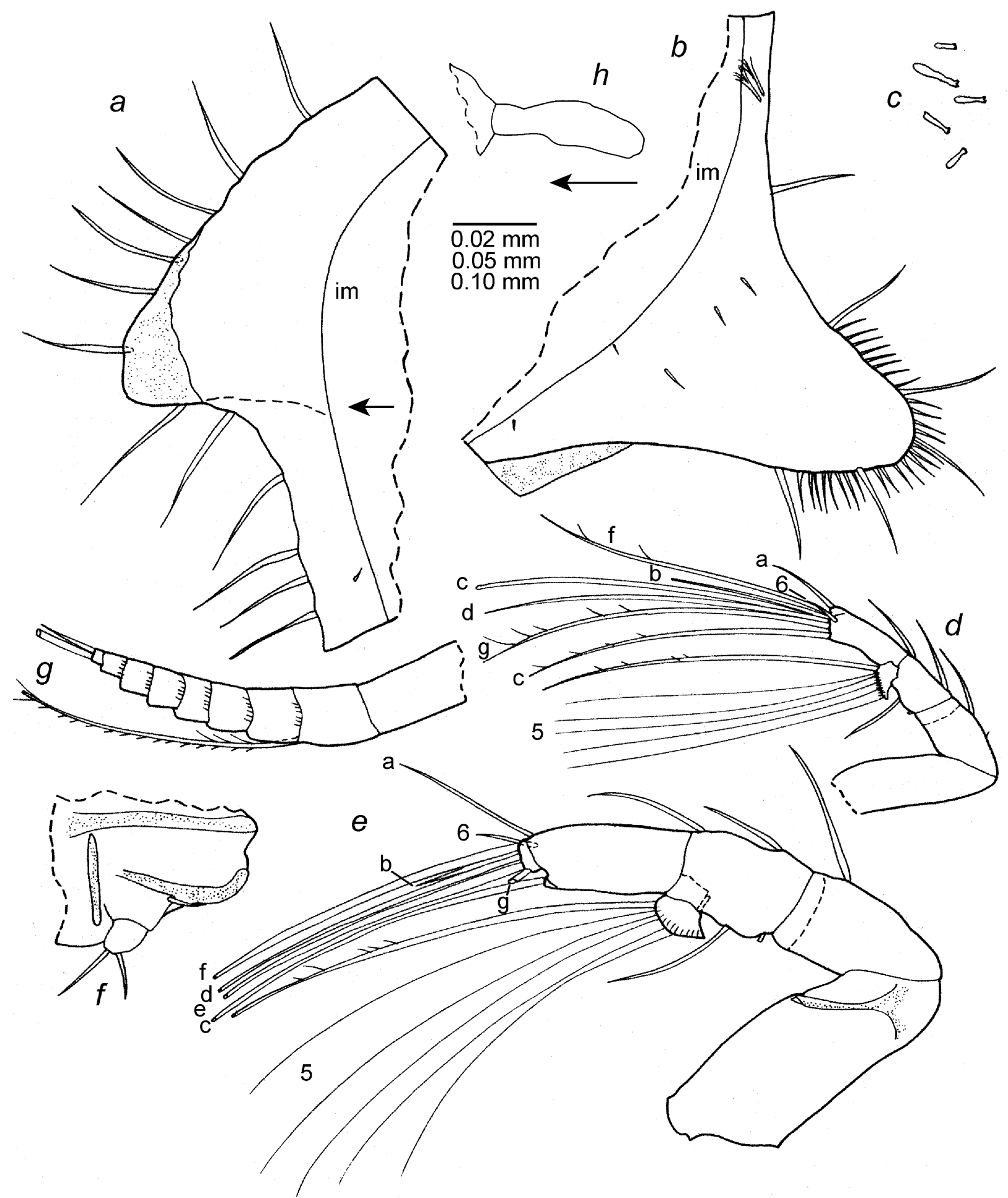

FIGURE 54. Eusarsiella syrinx, new species, paratype USNM 1021464, adult male: $a$, anterior right valve, iv; $b$, posterior right valve, iv; $c$, knobbed surface bristles on rib; $d$, right first antenna, mv; $e$, left antenna, lv; $f$, endopod left second antenna, mv; $g$, exopod right second antenna, lv (nabs); $h$, Bellonci Organ. Scale equals $0.05 \mathrm{~mm}(a, b, e-h), 0.02 \mathrm{~mm}(c)$ and $0.10 \mathrm{~mm}(d)$.

Mandible (Figs. 55a, 56a,b): Coxa endite consisting of short spine. Basis: with 5 proximal bristles on or near ventral margin, 1 medial bristle near midlength, and 3 dorsal bristles ( 2 long, 1 shorter). Exopod consisting of small blunt process. Endopod: 1st segment with 2 ventral terminal bristles (longest with long marginal hairs), 1 subterminal dorsal short bristle-like spine, and numerous medial spines. 2nd segment: ventral margin with 1 or 2 small terminal spine-like bristles and 1 short ringed bristle; dorsal margin with 1 long slender dor- 
sal bristle at midlength, and medial spines along distal edge. 3rd segment with long stout terminal claw with small teeth along ventral margin (medial and lateral row), and 2 small ventral bristles.

Maxilla (Fig. 55b): Reduced. Coxa hirsute. Exopod with 2 stout ringed bristles. Bristles of endites, basis, and endopod indistinct, with total of at least 20 bristles. Remaining bristles indistinct

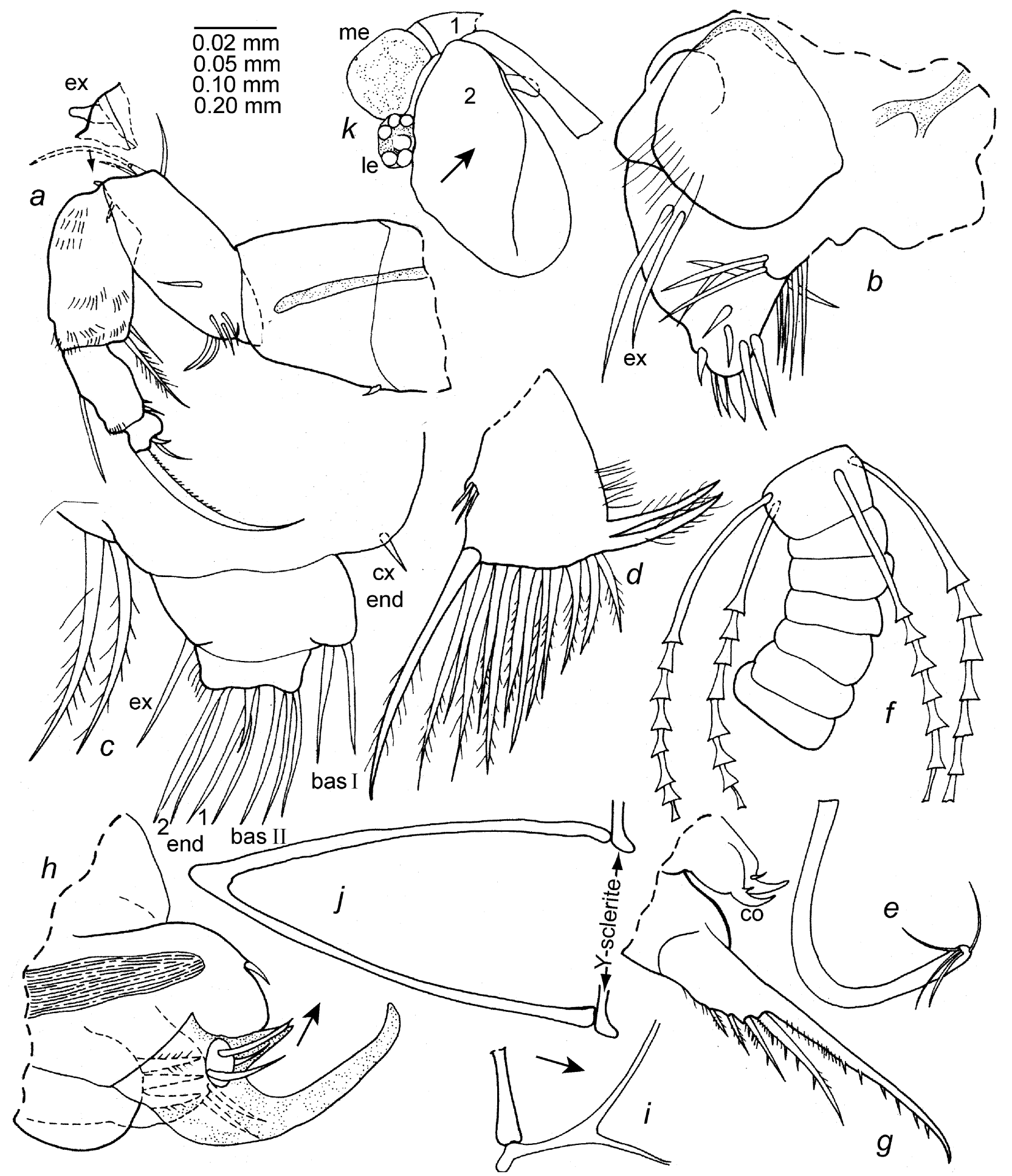

FIGURE 55. Eusarsiella syrinx, new species, paratype USNM 1021464, adult male: $a$, right mandible, mv; $b$, left maxilla, lv; $c$, fifth limb; $d$, right sixth limb, mv; $e$,f, seventh limb; $g$, left lamella of furca (mv) and copulatory organs; $h$, right copulatory organ, lv; $i$, right Y-sclerite and ventral end of right branch of girdle; $j$, posterior view of girdle attached to posterior ends of Y-sclerite (dorsal end to left); $k$, anterior of body from right side showing lateral eye, medial eye, and second antenna (nabs). Scale equals $0.05 \mathrm{~mm}(a, d, i, j), 0.10 \mathrm{~mm}(e, g)$ and $0.20 \mathrm{~mm}(k)$. 

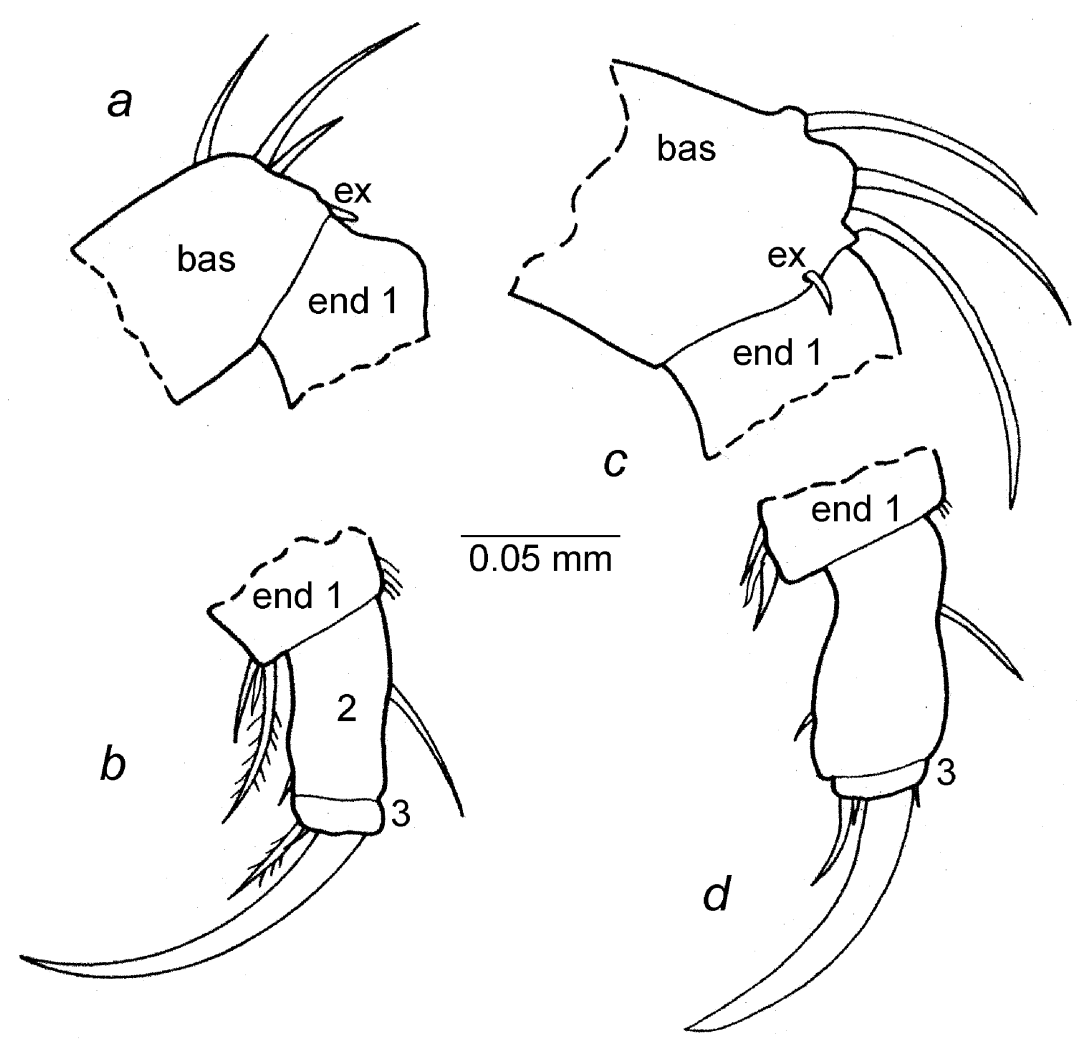

FIGURE 56. Eusarsiella syrinx, new species, paratype USNM 1021464, adult male: $a$, basis, exopod, and proximal part of endopod of left mandible, mv; $b$, endopod left mandible, mv. Eusarsiella warneri Kornicker et al. 2002, USNM 193091, adult male: $c$, basis and proximal part of endopod of right mandible, lv; $d$, endopod left mandible, mv. Scale equals $0.5 \mathrm{~mm}(a-d)$.

Fifth limb (Fig. 55c): Coxa endite with 1 short bristle. Basis: endite I lobate with 2 bristles; endite II with 3 bristles. Endopod: 1st segment with 3 bristles; 2nd segment with 2 bristles. Exopod represented by 1 bristle. Epipod fragmented, with about 36 plumose bristles.

Sixth limb (Fig. 55d): Single endite with 3 small bristles. End segment with bristles forming 2 rows: medial row of 5 bristles with short spines, and 8 lateral bristles with long spines; posterior edge with distal spines and 2 stout plumose bristles immediately adjacent to posterior ventral bristle.

Seventh limb (Fig. 55e,f): Limb long with about 54 well defined segments. Terminal group with 4 bristles, 2 on each side, each bristle with 6 or 7 bells and no marginal spines. Terminus slightly convex, bare.

Furca (Fig. $55 \mathrm{~g}$ ): Each lamella with 5 claws; claw 1 fused to lamella, claws $2-5$ separated from lamella by suture. All claws with teeth along posterior edges and indistinct spines along part of anterior edges. Left lamella with spines along lamella following claws.

Bellonci Organ (Fig. 54h): Elongate with broadly rounded tip.

Eyes: Lateral eye smaller than medial eye, with 5 or 6 ommatidia; eye amber colored (Fig. 55k). Medial eye bare, brown (Fig. 55k).

Posterior of body: Evenly rounded, bare.

Genitalia (Fig. 55g,h): Lobate copulatory organ on each side of body anterior to furca; distal lobe with sclerotized curved tooth and 2 or 3 short bristles. All lobes with few short bristles.

Y-Sclerite (Fig. 55i) and Girdle (Fig. 55i,j): Y-Sclerite branching distally and posterior tip with rightangle. Girdle forming one arch-shaped sclerite.

Gut content: Unrecognizable particulate matter.

Description of adult female (Figs. 57-60). Carapace oval in lateral view with long tapered backward- 
pointing caudal process and without incisure (Fig. 57). Surface with 2 lateral ribs connected posteriorly by diagonal rib terminating posteriorly with backward-pointing spinous node. Upper lateral rib with 6 nodes, 5 of these with long terminal bristle. Lower lateral rib with 6 nodes, 5 of these with long terminal bristle. Row of 3 long bristles present near anterior part of shell between the 2 ribs. Row of 3 nodes bearing 1 or 2 long terminal bristles present between lower rib and ventral margin of valve; 1 node with long terminal bristle present near anterior end of caudal process. Outer edge of valve with 16 nodes bearing 1 or 2 long bristles. All nodes and ribs covered with small bristles with knobby tips.

Ornamentation (Figs. 57, 58 ): Surface with shallow oval fossae with bare bottoms. Scattered small bristles with knobby tips present between fossae and on ribs and nodes (Fig. 58b). Anterior and ventral margins with long bristles with broad section at distal two-thirds and pointed tips, and shorter slenderer bristles with pointed tips (these medial to the long bristles). Tip of caudal process with 2 bristles ( 1 near dorsal end, 1 near ventral end) with 4 shorter bristles between them. Valve including ribs and nodes coated with transparent gellike substance filling space between the short bristles.

Infold: Anterior infold with small bristle near midheight (Fig. 58f). Infold of caudal process with vertical row of 4 to 6 bristles and 2 small bristles near inner margin of infold (Fig. 58e). Posterior infold with 2 setal bristle ventral to midheight.

Selvage: Lamellar prolongation extending well past tip of caudal process. Lamellar prolongation broad along anterior and ventral margins and with smooth outer edge.

Central adductor muscle attachments: Each valve with 10 or 11 oval attachments (Figs. 57, 58a).

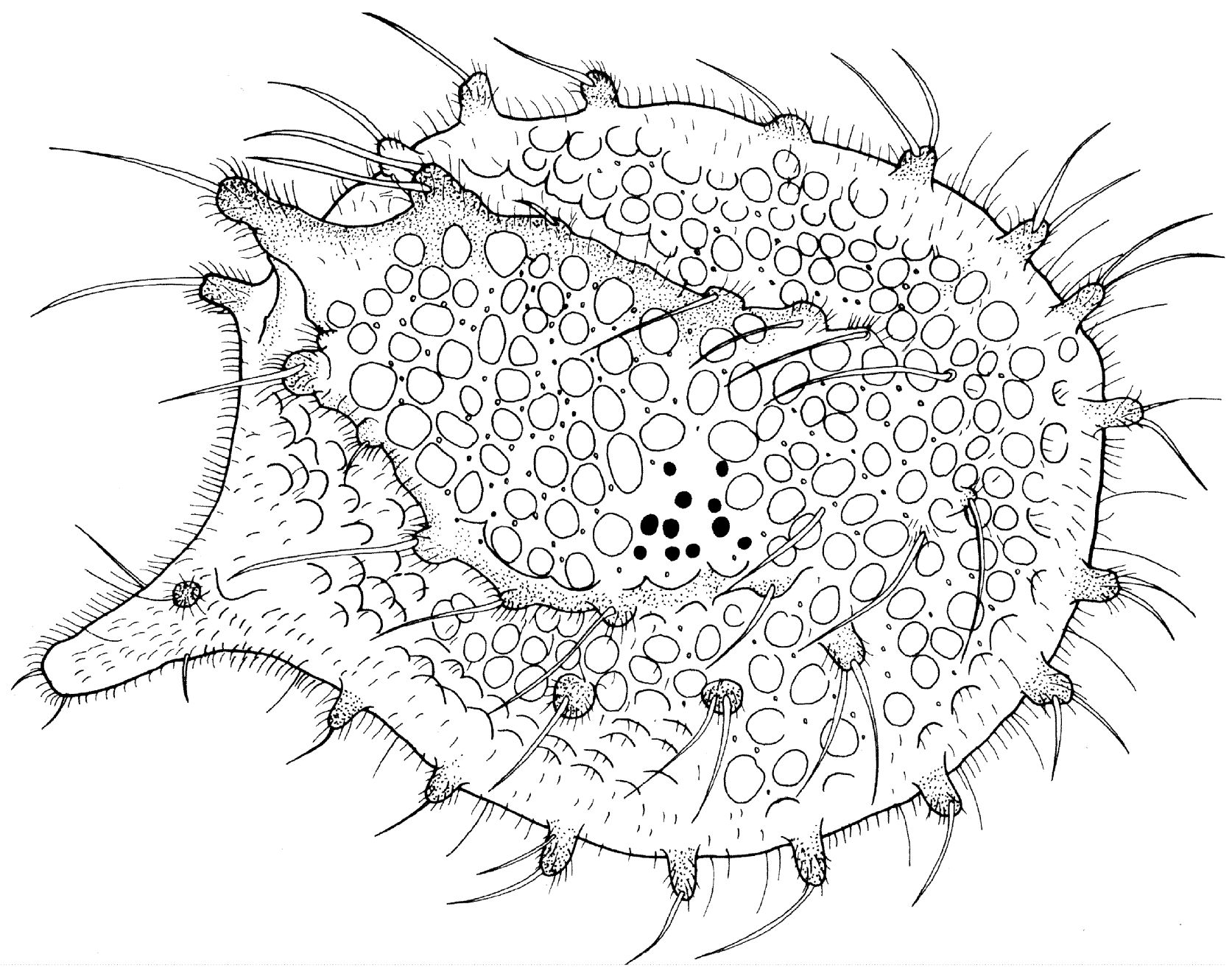

FIGURE 57. Eusarsiella syrinx, new species, paratype USNM 1021465, adult female, complete specimen from right side, length with caudal process $1.57 \mathrm{~mm}$. 

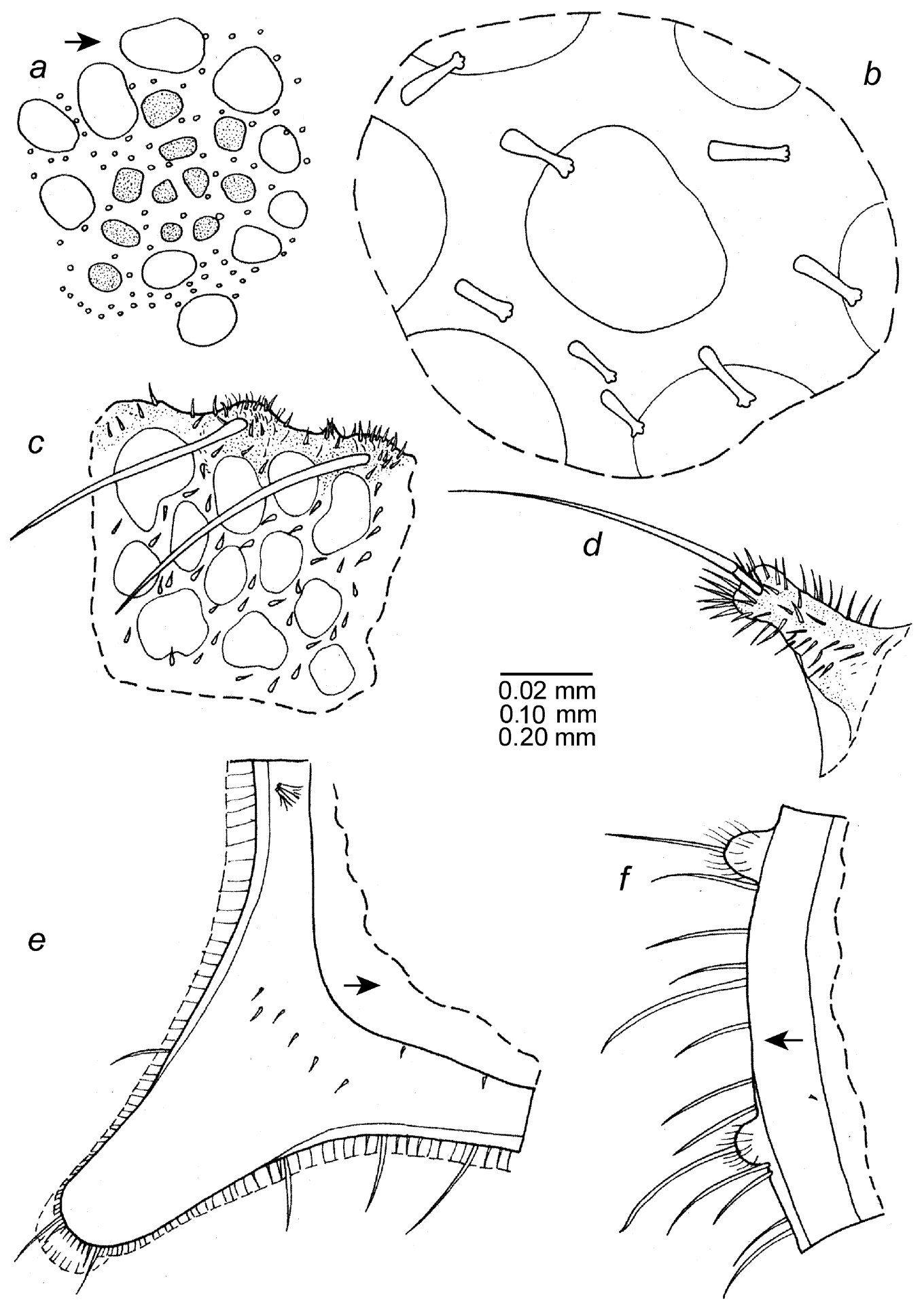

FIGURE 58. Eusarsiella syrinx, new species, paratype USNM 1021465, adult female: $a$, oval fossae and central adductor muscle attachments (stippled) and bases of short bristles on right valve, ov; $b$, fragment of valve showing fossae and short bristles, ov; $c$, detail from Figure 57 showing upper rib (stippled) and two bristles, ov; $d$, detail from Figure 57 showing posterodorsal process, ov; $e$, caudal process of left valve, iv; $f$, anterior edge of right valve, iv. Scale equals 0.10 $\mathrm{mm}(a, c-e), 0.02 \mathrm{~mm}(b)$ and $0.20 \mathrm{~mm}(f)$.

Carapace size (length, height in mm): USNM 1021465, length with caudal process 1.57 , length without caudal process 1.35 , height 1.18. USNM 1021463, length with caudal process 1.54, length between anterior edge and tip of posterior node, 1.48, length without caudal process or posterior node, 1.37, height 1,19. 


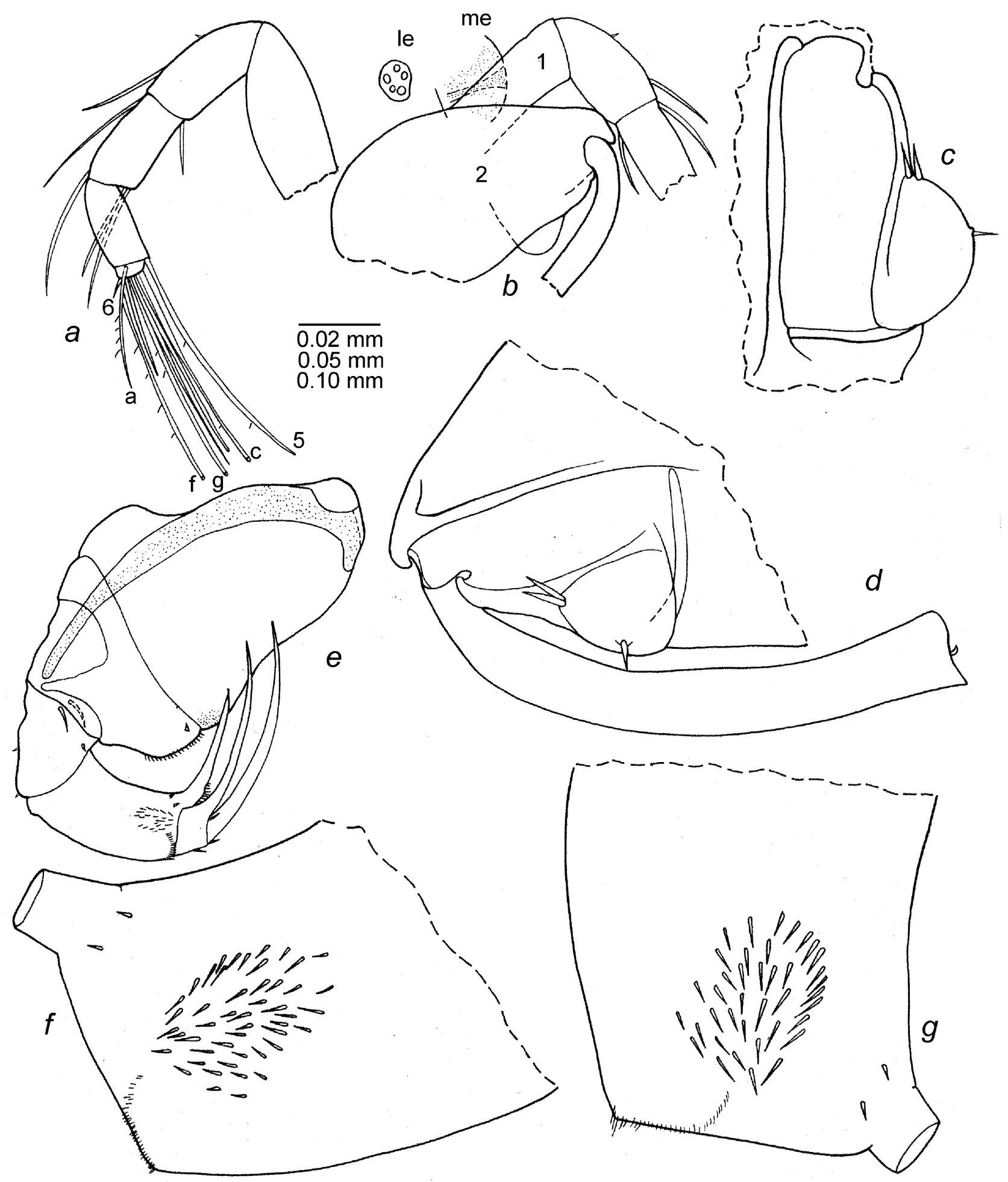

FIGURE 59. Eusarsiella syrinx, new species, paratype USNM 1021465, adult female: $a$, left first antenna drawn on body, lv; $b$, anterior of body showing right lateral eye, medial eye, and parts first and second antennae; $c$, endopod left second antenna, mv; $d$, part right second antenna, mv; $e$, right mandible, mv; $f, g$, medial spines on first endopod article of left and right mandibles. Scale equals $0.10 \mathrm{~mm}(a, b, e), 0.05 \mathrm{~mm}(c, d)$ and $0.02 \mathrm{~mm}(f, g)$.

First antenna (Fig. 59a,b): 1st segment bare. 2nd with minute dorsal spine near midlength and bare distal dorsal bristle. 3rd and 4th segments fused; 3rd with 2 terminal bristles (1 ventral, 1 dorsal); 4th segment with 3 or 4 terminal bristles ( 2 ventral, 1 or 2 dorsal). 5 th segment with long sensory bristle with 4 minute marginal 
filaments. 6th segment with short medial bristle. 7th segment: a-bristle short with indistinct marginal spines; b-bristle about same length as a-bristle, bare; c-bristle about same length as bristle of 5th segment, with 2 minute marginal filaments. 8th segment: d- and e-bristles shorter than bristle of 5th segment, bare with blunt tips; f-bristle about same length as d-bristle, with 4 minute marginal filaments; g-bristle as long as bristle of 5th segment, with 2 minute marginal filaments; b-, c-, f, and g-bristles with terminal spine.

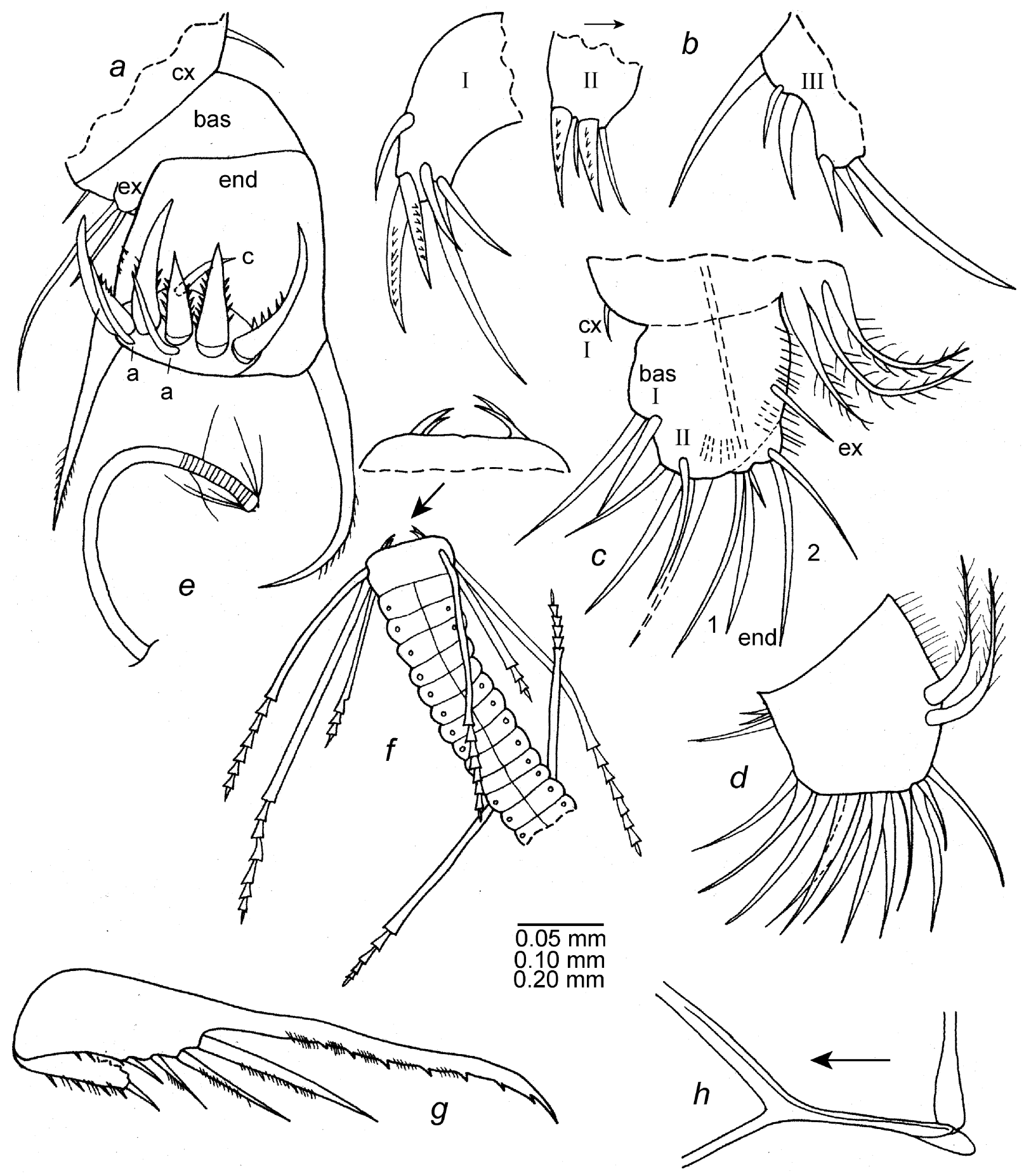

FIGURE 60. Eusarsiella syrinx, new species, paratype USNM 1021465, adult female: $a$, part left maxilla, mv; $b$, endites I-III, left maxilla, mv; $c$, fifth limb; $d$, left sixth limb, lv; $e, f$, left and right seventh limbs; $g$, right lamella and part left lamella of furca; $h$, left Y-sclerite and ventral end of girdle, lv. Scale equals $0.05 \mathrm{~mm}(a-d, f, h), 0.20 \mathrm{~mm}(e)$ and $0.10 \mathrm{~mm}$ $(g)$. 


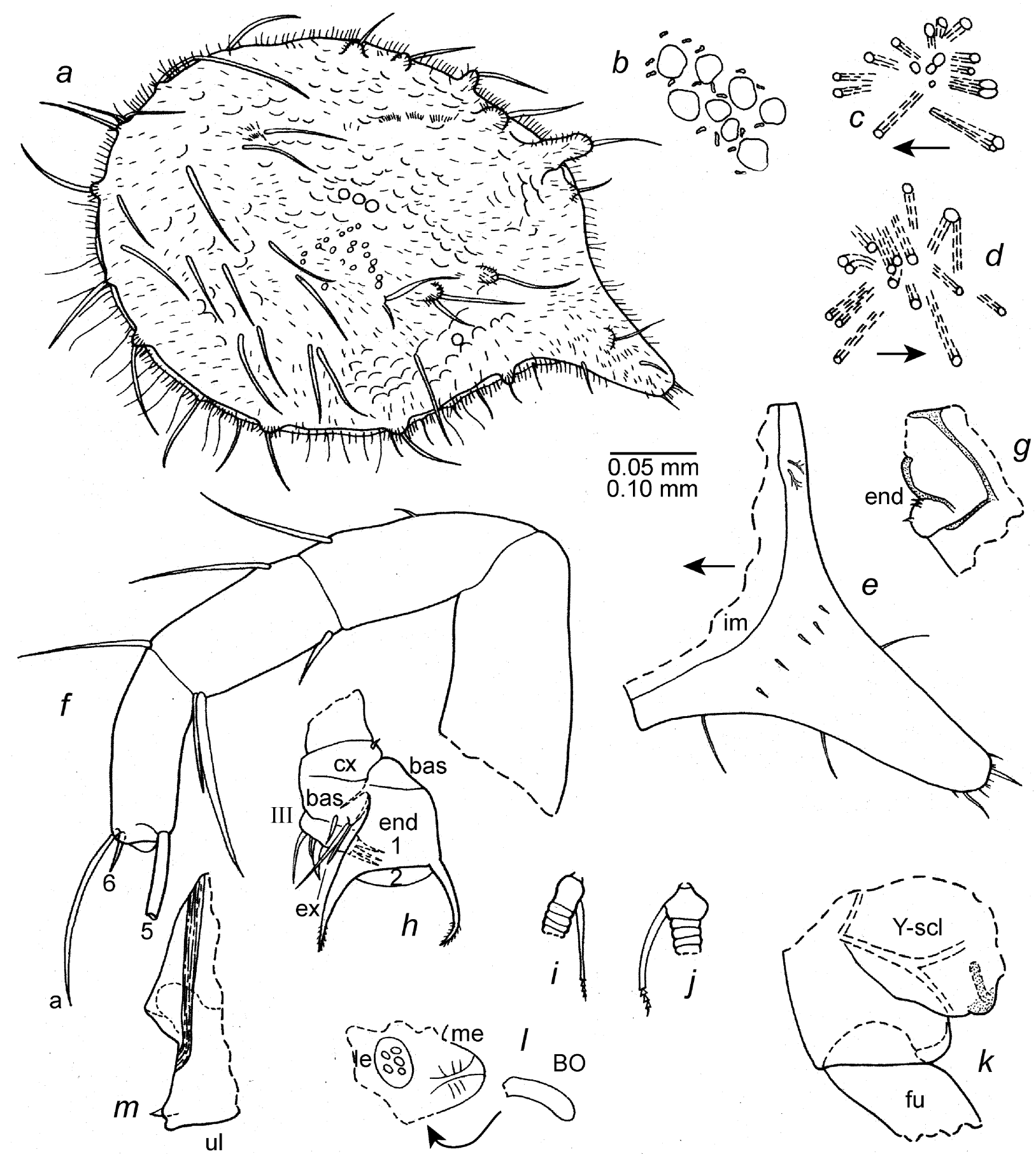

FIGURE 61. Eusarsiella syrinx, new species, paratype USNM 1021466, instar IV (A-1) female: $a$, complete specimen from left side, length including caudal process $1.30 \mathrm{~mm} ; b$, detail of surface showing fossae and bristles with knobby tips; $c, d$, central adductor muscles of left and right valves, ov; $e$, caudal process right valve, iv; $f$, left first antenna, lv (nabs); $g$, endopod right second antenna, mv; $h$, right maxilla drawn on body, lv; $i, j$, part of left and right seventh limbs; $k$, posterior of body from right side showing part of furca, Y-sclerite, and ventral end of girdle; $l$, right lateral eye, medial eye, and detached Bellonci Organ; $m$, anterior of body and upper lip. Scale equals $0.10 \mathrm{~mm}(b-e, g-m), 0.05 \mathrm{~mm}(f)$.

Second antenna (Fig. 59b-d): Protopodite bare (Fig. 59b,d). Endopod with 1 segment with 2 ringed anterior bristles and short unringed terminal bristle (Fig. 59c,d). Exopod: 1st segment with short medial recurved spine (Fig. 59d); bristles of segments 2-8 with stout proximal ventral spines and distal natatory hairs; 9th segment with 2 bristles (1 small bare (dorsal), 1 long with proximal ventral spines and distal natatory hairs.) 
Mandible (Fig. 59e-g): Ventral part of precoxa adjacent to coxa with brown pigment in transmitted light (reddish in reflected light). Coxa endite consisting of short stout spine; ventral margin of coxa with short hairs. Basis with 3 medial bristles (shorter bristle closer to ventral edge); dorsal margin with 2 minute bristles (1 distal to midlength, 1 terminal). Exopod absent. Endopod: 1st segment with 38 to 47 distal medial spines, row of minute medial spines near distal margin (row extends to posterior edge of segment), and 2 minute medial spines near base of stout ventral claw; ventral claw with proximal row of minute teeth along dorsal edge. 2nd segment with minute dorsal spine-like bristle and stout ventral claw. 3rd segment with 2 minute bristles (1 ventral, 1 dorsal) and stout terminal claw.

Maxilla (Fig. 60a,b): Endite I with 6 bristles; endite II with 4 bristles; endite III with 6 bristles (Fig. 60b). Coxa with short dorsal bristle (Fig. 60a). 1 small bristle on basis near exopod. Exopod with 2 bristles. Endopod: 1st segment with spinous alpha- and beta-bristles. 2nd segment with 2 lateral a-bristles, 1 medial c-bristle, and 5 pectinate terminal bristles; 4th terminal bristle from anterior end longer than others.

Fifth limb (Fig. 60c): Epipod with 35 plumose bristles. Coxa endite with 1 short bristle. Basis with 2 endites: endite I lobate with 2 bristles; endite II with 4 bristles. Endopod with 2 fused segments: segment 1 with 3 bristles ( 1 short); segment 2 with 2 bristles. Exopod represented by 1 short bristle. Limb hirsute.

Sixth limb (Fig. 60d): Single endite with 3 bristles. End segment with 12 bristles (5 medial, 7 lateral) separated by space from 2 posterior plumose bristles

Seventh limb (Fig. 60e,f): Each limb with 2 proximal bristles, each with 5 bells, and 6 terminal bristles, each with 3 to 7 bells; distal 15 segments proximal to terminus slightly broader than proximal segments, each with sclerotized midline, and a small amber colored round cell near outer edge (Fig. 60f). Terminus with opposing teeth ( 2 or 3 on each side (exact number difficult to resolve)). Bristles without marginal spines.

Bellonci Organ: Lost. Elongate with rounded tip based on organ of A-1 female shown in Fig. 61 l.

Furca (Fig. 60g): Each lamella with 5 claws; lamella following claws of left side with numerous spines; only few spines on right lamella. Claws 1 to 4 with teeth along posterior edges; claw 1 with 3 or 4 stouter teeth near midlength; tips of claws pointed. Right lamella anterior to left by width of claw 1, and with few minute spines along anterior edge near base of claw.

Eyes (Fig. 59b): Lateral eyes small, each with 5 amber-colored ommatidia. Medial eye larger than lateral eye.

Genitalia: Small oval amber-colored area present anterior to Y-sclerite, but it may not be genitalia.

$Y$-Sclerite (Fig. 60h): With usual ventral branch.

Posterior of body: Evenly rounded, bare.

Gut content: USNM 1021465 with 1 rotaloid foraminiferan in posterior end of gut.

Eggs: USNM 1021463 with 4 eggs in marsupium; length of 1 egg $0.22 \mathrm{~mm}$.

Description of instar IV (A-1) female (Fig. 61). Shape of carapace in lateral view differs from that of adult female in having an oblique posterior margin (Fig. 61a).

Ornamentation (Fig. 61a,b): Carapace without parallel ribs present on carapace of adult female and with fewer nodes. Surface with shallow round fossae; except for those near middle of valve, fossae appear as crescents open to valve margin. Surface between fossae with small bristles with knobbed tips (Fig. 61b). Tip of caudal process with 2 bristles ( 1 at ventral end, 1 near dorsal end) and few shorter bristles between them.

Infold: Anterior infold with small bristle near midheight. Infold of caudal process with vertical row of 4 or 5 bristles and 2 small bristles near inner margin of infold (Fig. 61e). Posterior infold with 2 setal bristles ventral to midheight.

Selvage: Narrow selvage with smooth outer edge undivided at incisure and extending past tip of caudal process.

Central adductor muscle attachments (Fig. 61a,c,d): With 16 to 18 ovoid attachments.

Carapace size (length, height in mm): USNM 1021466, length with caudal process 1.30, length without caudal process 1.14 , length from anterior edge to posterior end of posterior node 0.81 , height 1.10. 
First antenna (Fig. 61f): 1st segment bare. 2nd with minute dorsal spine near midlength and distal dorsal bristle with few indistinct marginal spines. 3rd and 4th segments fused; 3rd with 2 terminal bristles (1 ventral, 1 dorsal); 4th segment with 3 bristles ( 2 ventral, 1 dorsal). Long ventral bristle of 5th segment with 2 minute marginal filaments. 6th segment with short bare medial bristle. 7th segment: a-bristle bare, about same length as 5th segment; b-bristle same length as a-bristle; c-bristle same length as bristle of 5th segment, with 2 minute marginal filaments. 8th segment: d-and e-bristles shorter than c-bristle, bare with blunt tips; f-bristle shorter than c-bristle, about same length as d-bristle, with 1 minute proximal filament; g-bristle about same length as c-bristle, with 4 minute marginal filaments (2 proximal filaments longer than others). b-, c-, f-, and g-bristles with terminal spine.

Second antenna: Protopod and exopod (including number of bristles and their spination) similar to those of adult female. Endopod with single segment with 2 ringed anterior bristles and short unringed terminal bristle (Fig. 61g).

Mandible: Basis with 3 medial bristles (shortest closer to ventral margin). Limb otherwise similar to that of adult female. Ventral area of precoxa just adjacent to coxa with brown pigment.

Maxilla (Fig. 61h): Endite I with 6 bristles; endite II with 4 bristles; endite III with 6 bristles similar to those of adult female. Coxa, basis, endopod, and exopod similar to those of adult female.

Fifth limb: Epipod with 36 plumose bristles. Coxa endite with 1 short bristle. Basis with 2 endites: endite I with 2 bristles; endite II with 3 bristles. Endopod with 2 fused segments: segment 1 with 3 bristles (2 long, 1 short); segment 2 with 2 long bristles. Exopod represented by 1 short bristle.

Sixth limb: Single endite with 3 bristles ( 2 short medial, 1 longer terminal); end segment with 12 bristles (6 lateral, 6 medial) followed by 2 posterior plumose bristle.

Seventh limb (Fig. 61i,j): Each limb with 2 proximal tapered bristles, each with 3 bells, and 4 terminal tapered bristles, each with 4 bells. Terminus with minute opposing teeth ( 1 or 2 on each side).

Bellonci Organ (Fig. 61l): Elongate with rounded tip.

Furca (Fig. 61k): Each lamella with 5 claws similar to those of adult female. Anterior claw of right lamella anterior to anterior claw of left lamella by width of base of claw 1. Lamella following right claw with 2 fairly stout spines, that of left claw with 5 fairly stout spines.

Eyes (Fig. 61l): Lateral eye small with 5 amber colored ommatidia. Medial eye larger than lateral eye, bare, light amber in color.

Upper lip (Fig. 61m): With projecting rounded tooth-like tip .

Genitalia: Absent.

Y-Sclerite (Fig. 61k): With usual ventral branch.

Posterior of body: Evenly rounded, bare.

Gut content: With unrecognizable amber colored particles.

Eggs: Absent.

Description of instar III (A-2) (sex unknown) (Fig. 62). Shape of carapace in lateral view similar to that of instar IV female (Fig. 62a). Valves including nodes coated with transparent gel-like substance filling space between the short bristles.

Ornamentation (Fig. 62a): Ribs absent. Nodes, in general, similar to those of instar IV female, less developed than those of adult female. Fossae of USNM 1021458 more distinct than those of instar IV female and adult female described above; many fossae rectangular making surface of valves appear reticulate. Surface with many long bristles distributed, in general, in same manner as in instar IV female. Surface between fossae with minute bristles with knobby tips.

Infold: Anterior infold with small bristle near midheight. Infold of caudal process with vertical row of 3 bristles and 1 or 2 small bristles near inner margin of infold. Posterior infold with 2 setal bristles ventral to midheight.

Selvage: Lamellar prolongation extending well past tip of caudal process. Lamellar prolongation broad 
along anterior and ventral margins and with smooth outer edge.

Central adductor muscle attachments (Fig. 62b): Each valve with about 13 oval attachments.

Carapace size (length, height in $\mathrm{mm}$ ): USNM 1021467, length including caudal process 1.02, length excluding caudal process 0.85 , length from tip of posterior node to anterior margin of valve 0.81 , height 0.69 .

First antenna (Fig. 62c): 1st segment bare. 2nd with minute dorsal spine near midlength and distal dorsal bristle. 3rd and 4th segments fused; 3rd with 2 bristles ( 1 ventral, 1 dorsal); 4th with 2 bristles ( 1 ventral, 1 dorsal). 5th segment with long bristle with 3 minute filaments. 6th segment with small medial bristle. 7 th segment: a-bristle short; b-bristle about same length as a-bristle; c-bristle about same length as bristle of 5th segment, with 3 minute marginal filaments. 8th segment: $d$ - and e-bristles longer than b-bristle, bare with blunt tips; f-bristle shorter than c-bristle, with 1 minute marginal filament; g-bristle as long as c-bristle, with 4 small marginal filaments ( 2 proximal filaments longer than others).

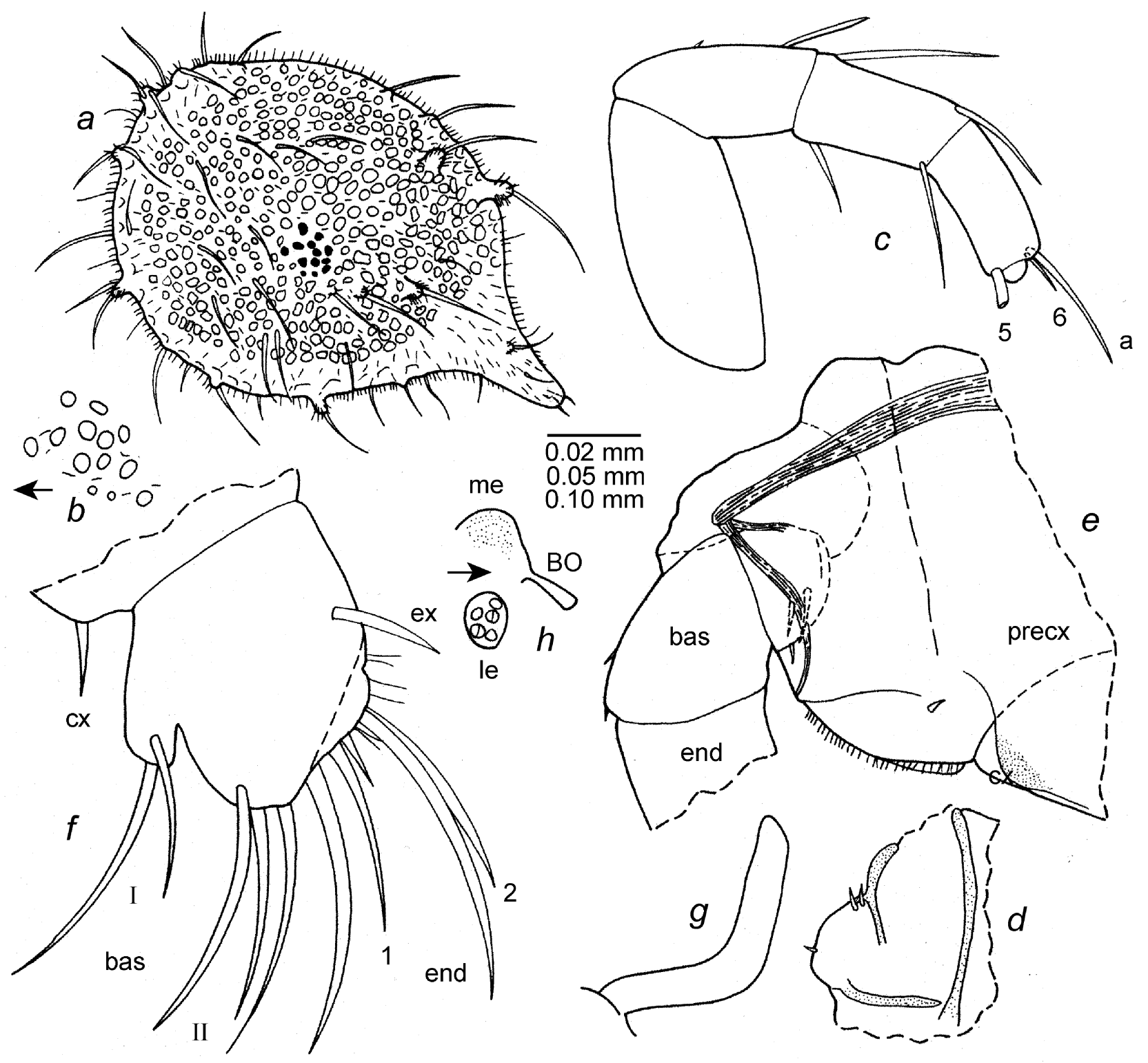

FIGURE 62. Eusarsiella syrinx, new species, paratype USNM 1021467, instar III (A-2) (sex unknown): $a$, complete specimen, length including caudal process $1.02 \mathrm{~mm} ; b$, central adductor muscle scars left valve, ov; $c$, right first antenna, lv (nabs); $d$, endopod right second antenna, mv; $e$, part right mandible, mv (nabs); $f$, fifth limb; $g$, right seventh limb; $h$, medial eye, Bellonci Organ, and right lateral eye drawn on body. Scale equals $0.10 \mathrm{~mm}(b, g, h), 0.05 \mathrm{~mm}(c-e)$ and 0.02 $\mathrm{mm}(f)$. 
Second antenna: Protopod, exopod, and endopod (Fig. 62d) similar to those of both instar IV and adult female.

Mandible (Fig. 62e): Coxa, endopod similar to those of both instar IV and adult female. Basis with 3 medial bristles (shortest closer to ventral margin) and 2 minute dorsal bristles ( 1 distal to midlength, 1 terminal). Ventral area of precoxa adjacent to coxa with brown pigment in transmitted light similar to area observed on instar IV female.

Maxilla: Endites I, II, and III, coxa, basis, endopod, and exopod with similar number of bristles present on both instar IV and adult female.

Fifth limb (Fig. 62f): Epipod with 31 plumose bristles. Single endite with 1 bristle. Basis with 2 endites: endite I with 2 bristles; endite II with 3 bristles. Endopod with 2 fused segments: segment 1 with 3 bristles (2 long, 1 short); segment 2 with 2 long bristles. Exopod represented by short bristle.

Sixth limb: Single endite with 2 bristles (1 terminal, 1 shorter proximal); end segment with 10 or 11 bristles separated by space from 2 plumose posterior bristles.

Seventh limb (Fig. 62g): Elongate, without rings, bare.

Furca: With 5 claws similar to those of both instar IV and adult female. Spines following claws on lamella. Positions of left and right lamella relative to each other similar to those of both instar IV and adult female.

Bellonci Organ (Fig. 62h): Elongate with broad rounded tip.

Eyes (Fig. 62h): Lateral eye with 5 amber-colored ommatidia. Medial eye slightly larger than lateral eye, amber-colored.

Posterior of body: Evenly rounded, bare.

Genitalia: Absent.

Y-Sclerite: With ventral branch.

Gut content: Posterior gut empty. Inner face of posterior gut lobate.

Eggs: None.

Description of instar II (A-3) (sex unknown) (Fig. 63). Carapace similar in shape to that of the instar III instar (Fig. 63a). Ribs absent, nodes few and small.

Ornamentation (Fig. 63a): Surface with shallow round fossae (only few shown in Fig. 63a). Surface between fossae with short bristles with knobby tips. Few long bristles with broad bases on valve surface. Long bristles present along anterior and ventral margins. Tip of caudal process with 2 bristles ( 1 near dorsal end, 1 near ventral end). Transparent gel-like substance visible filling space between bristles and along valve edges.

Infold: Anterior infold with small bristle near midheight. Infold of caudal process with 2 or 3 bristles near anterior end and 2 minute bristles near inner margin of infold. Posterior infold with 2 setal bristles near midheight.

Selvage: Lamellar prolongation extending well past tip of caudal process.

Central adductor muscle attachments (Fig. 63b): About 11 closely oval attachments visible.

Carapace size (length, height in $\mathrm{mm}$ ): USNM 1021468, length with caudal process $0.83 \mathrm{~mm}$, length without caudal process 0.72 , height 0.60 .

First antenna (Fig. 63c): 1st segment bare. 2nd segment with minute dorsal spine at midlength and short distal dorsal bristle. 3rd segment fused to 4th; 3rd segment with 2 bristles (1 ventral, 1 dorsal); 4th segment with dorsal bristle reaching middle of 5th segment. 5th segment with long ventral bristle with 2 minute proximal filaments. 6th segment with short medial bristle. 7th segment: a-bristle short; b-bristle about same length as a-bristle; c-bristle same length as bristle of 5th segment, with 2 minute marginal filaments. 8th segment: dand e-bristle shorter than c-bristle, bare with blunt tips; f-bristle slightly shorter than d- and e-bristles, with minute proximal marginal filament; g-bristle as long as c-bristle, with 2 small proximal marginal filaments.

Second antenna: Protopod bare. Exopod similar to that of instar III, with bent terminal spine-like medial bristle on 1st segment and 2 bristles on 9th segment (Fig. 63e). Endopod with single segment with short prox- 
imal ringed anterior bristle and small unringed terminal bristle on small node (node could be interpreted to be 2nd segment) (Fig. 63d).

Mandible (Fig. 63f): Precoxa with brown pigment at ventral margin adjacent to coxa. Coxa endite consisting of short stout spine; ventral margin of coxa with short hairs. Basis: medial surface near ventral margin with 3 bristles (shortest bristle closer to ventral margin); dorsal margin with 1 minute spine-like bristle distal to midlength and similar bristle subterminal. Endopod similar to that of instar III.

Maxilla: Coxa, basis, endopod, and exopod similar to that of A-2 female. Endite I with 6 bristles; endite II with 4 bristles; endite III with 6 bristles similar to those of adult female.

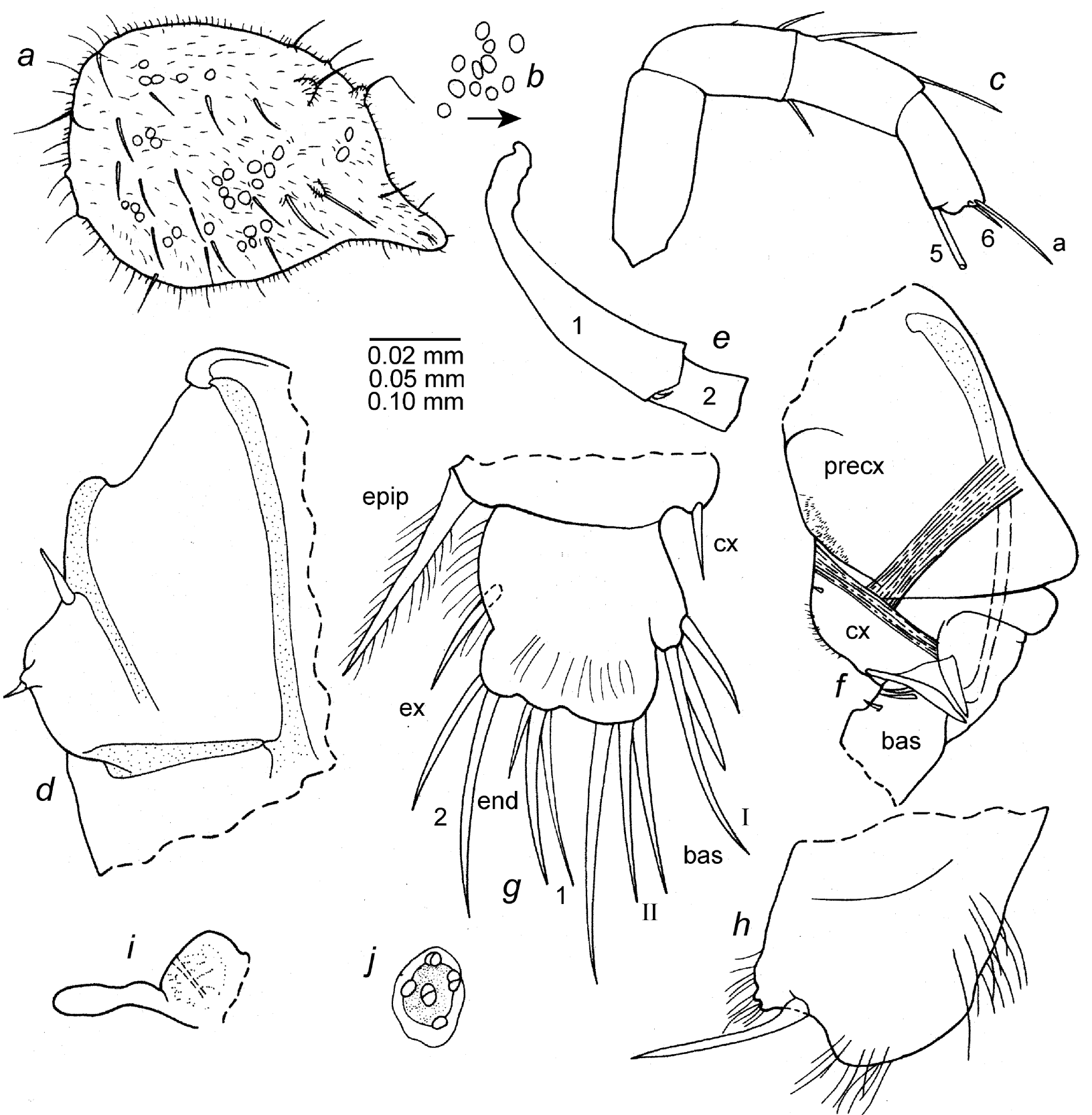

FIGURE 63. Eusarsiella syrinx, new species, paratype USNM 1021468, instar II (A-3) (sex unknown): $a$, complete specimen from left side, length with caudal process $0.83 \mathrm{~mm} ; b$, central adductor muscle scars right valve, ov; $c$, right first antenna, lv (nabs); $d$, endopod right second antenna, mv; $e$, articles 1 and 2 of exopod right second antenna, mv (nabs); $f$, proximal part of left mandible, mv (nabs); $g$, right fifth limb, lv; $h$, left sixth limb, lv; $i$, medial eye and Bellonci Organ; $j$, lateral eye. Scale equals $0.10 \mathrm{~mm}(b), 0.05 \mathrm{~mm}(c, e, f, i, j)$ and $0.02 \mathrm{~mm}(d, g, h)$. 
Fifth limb (Fig. 63g): Epipod with about 30 bristles. Coxa endite with 1 short bristle. Basis with 2 endites: Endite I lobate with 2 or 3 bristles; endite II with 3 bristles. Endopod with 2 segments: segment 1 with 3 bristles; segment II with 2 bristles. Exopod represented by 1 short bristle.

Sixth limb (Fig. 63h): Lobate with 1 bristle near midwidth; margin of limb hirsute.

Seventh limb: Short, bare.

Furca: Each lamella with 5 claws similar to those of instar III. Spines on lamellae following claws similar to those of instar III. Right lamella anterior to left by width of base of claw 1 .

Bellonci Organ (Fig. 63i): Elongate with broadly rounded tip

Eyes: Lateral eye with 5 amber-colored ommatidia (Fig. 63j). Medial eye larger than lateral eye, light brown in color (Fig. 63i).

Posterior of body: Evenly rounded, bare.

Genitalia: absent.

Y-Sclerite: With ventral branch.

Gut content: Unrecognizable particulate matter.

Description of instar I (A-4) instar (sex unknown) (Figs. 64, 65). Carapace similar in shape to that of Instar II instar. Ribs and nodes absent. Surface with scattered long bristles and numerous small bristles with knobby tips. Anterior and ventral margins with numerous long bristles. Surface coated with transparent gellike substance filling space between short bristles.

Ornamentation (Fig. 64a): Surface with weakly developed oval fossae with bare bottoms. Surface between fossae with scattered long bristles and numerous short bristles with knobby tips. Anterior and ventral margins with long and medium length bristles with pointed tips. Tip of caudal process with 2 bristles ( 1 near ventral end, 1 near dorsal end) and smaller bristles between them.

Infold: Anterior infold with small bristle near midheight. Selvage of caudal process with none (left valve) or 1 small bristle (right valve) near anterior end and 2 small bristles at inner edge of infold. Posterior infold with 1 setal bristle ventral to midheight.

Selvage: Lamellar prolongation of selvage extending well past tip of caudal process. Lamellar prolongation broad along anterior and ventral margins and with smooth outer edge.

Central adductor muscle attachments (Fig. 64a,b): USNM 1021469 with about 20 muscle that appeared as jumbled mass when viewed through shell. Individual muscles not forming tight bundle usually extending from valve to valve in myodocopids. Muscles in USNM 1021470 appear of normal tightly bundled type when viewed through valves (valves not opened).

Carapace size (length, height in $\mathrm{mm}$ ): USNM 1021469, length with caudal process 0.68 , length without caudal process 0.59 , height 0.48 . USNM 1021470 , length with caudal process 0.66 , length without caudal process 0.56 , height 0.46 .

First antenna (Fig. 64c): 1st segment bare. 2nd segments with minute distal dorsal spine (in about same location as bristle on later stages). 3rd and 4th segments fused; segment 3 with 2 bristles (1 ventral, 1 dorsal); segment 4 bare. 5th segment with long ventral bristle. 6th segment with small medial bristle. 7 th segment: abristle 2 or 3 times length of bristle of 6th segment; b-bristle about same length as a-bristle; c-bristle about same length as bristle of 5th segment. 8th segment: d- and e-bristles only slightly shorter than c-bristle; f-bristle shorter than d-bristle; g-bristle about same length as c-bristle. Bristle of 5th segment and c-, f-, and g-bristles without marginal filaments.

Second antenna (Fig. 64d,e): Protopod and exopod similar to those of instar II, 9th segment with 2 bristles (1 long, 1 short). Endopod with 1 segment with minute terminal spine-like bristle (Fig. 64e).

Mandible (Fig. 64f,g): Coxa and endopod similar to those of instar II. Ventral part of precoxa adjacent to coxa without brown color. Basis: medial surface with 3 bristles (shortest bristle closer to ventral margin); dorsal margin with 2 distal minute spine-like bristles.

Maxilla (Figs. 64h-j, 65a): Coxa, basis, and exopod similar to those of instar II. Endopod: 1st segment 
with alpha- and beta-bristle; 2nd segment with 2 a-bristles, 1 c-bristle, and 3 end bristles. Endite I with 6 bristles; endite II with 4 bristles; endite III with 4 bristles ( 2 anterior, 2 posterior).

Fifth limb (Fig. 65b): Epipod with 25 plumose bristles. Coxa endite with 1 short bristle. Basis with 2 endites: endite I with 2 bristles, endite 2 with 3 bristles. Endopod with 2 segments: segment 1 with 3 bristles, segment 2 with 2 bristles. Exopod with 1 short bristle. Limb hirsute.

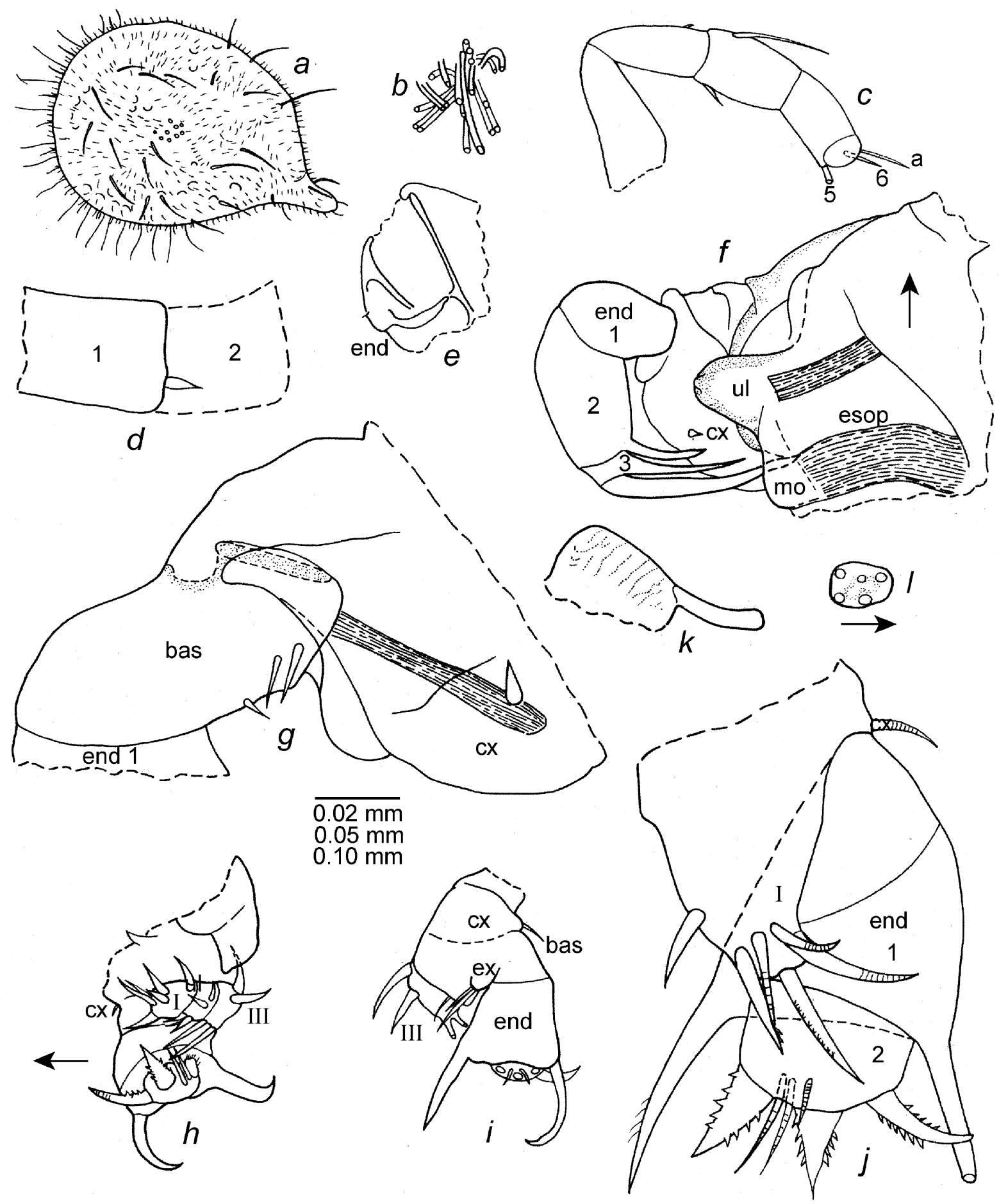

FIGURE 64. Eusarsiella syrinx, new species, paratype USNM 1021469, instar I (A-4) (sex unknown): $a$, complete specimen from left side, length with caudal process $0.68 \mathrm{~mm} ; b$, central adductor muscles as viewed through right valve; $c$, right first antenna drawn on body, lv (nabs); $d$, first and second articles of exopod of right second antenna, mv (nabs); $e$, endopod and part of protopod of right second antenna, mv; $f, g$, right mandible, mv; $h$, right maxilla drawn on body, mv; $i$, right mandible drawn on body, lv; $j$, left maxilla, mv (nabs); $k$, Bellonci Organ and medial eye; $l$, right lateral eye. Scale equals $0.10 \mathrm{~mm}(b), 0.05 \mathrm{~mm}(c, e, f, h, i, k, l)$ and $0.02 \mathrm{~mm}(d, g, j)$. 


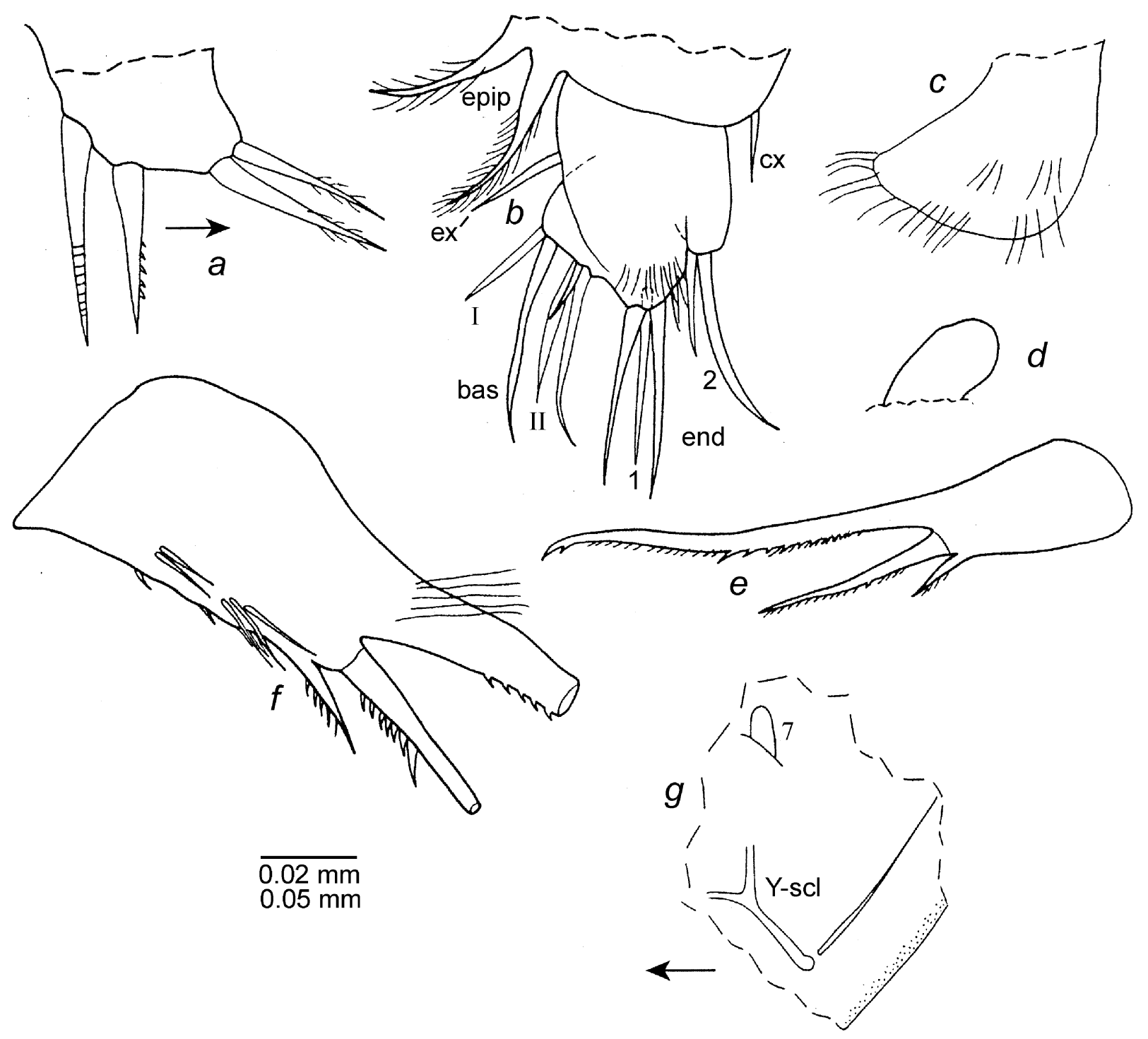

FIGURE 65. Eusarsiella syrinx, new species, paratype USNM 1021469, instar I (A-4) (sex unknown): $a$, endite III right maxilla, lv; $b$, right fifth limb, lv; $c$, right sixth limb, mv; $d$, right seventh limb; $e$, left lamella of furca, lv; $f$, left lamella of furca, mv; $g$, posterior of body from left side showing seventh limb, Y-sclerite, and girdle. Scale equals $0.02 \mathrm{~mm}(a-$ $d, f)$ and $0.05 \mathrm{~mm}(e, g)$.

Sixth limb (Fig. 65c): Hirsute, without bristles.

Seventh limb (Fig. 65d,g): Minute indistinct bare lobe.

Furca (Fig. 65e,f): Each lamella with 3 claws; claws 1 and 3 fused to lamella. Claw 1 with few stout teeth and numerous small teeth (teeth proximal to midlength longer and stouter than those distal to midlength); claw 2 with small teeth and few slightly longer teeth; claw 3 with few small teeth. Lamellae following claws with spines. Long medial hairs forming row at base of claw 1. Few long medial spines proximal to claw 3. Right lamella anterior to left by width of base of claw 1 .

Bellonci Organ (Fig. 64k): Short with broadly rounded tip.

Eyes: Lateral eye with 5 amber-colored ommatidia (Fig. 64l). Medial eye larger than lateral eye, with brown color (Fig. 64k).

Upper lip (Fig. 64f): Broadly rounded with small lateral process at tip.

Posterior of body: Evenly rounded, bare.

Genitalia: Absent. 
Y-Sclerite: With ventral branch (Fig. 65g). Girdle weakly developed (Fig. 65g).

Gut content: Unidentified particulate matter.

Remarks. The adult male, adult females and juveniles referred to this species were collected in the same sample. The adult male and female of many sarsiellids differ considerably in morphology of both the carapace and appendages, and one cannot always with certainty refer them to the same species. The referral here is supported by the morphology of the short bristles covering the carapaces of both the male and female. The bristles have a knobby tip on both the male and female, and the locations of the bristles relative to the shallow fossae are similar on both the adult male and female. The knobby tip is smaller on the adult male than on the adult female. The knobby bristles are also present on juveniles. The small knobby tips are seen best when the valve is viewed at high magnification (40X or 100X objective) and preferably with the valve under a cover slip. A few early instars of sarsiellids in the sample, which do not have bristles with knobby tips, are referred to Eusarsiella sp. indet.

Comparisons. Male: The valves of the male E. syrinx differ from those of the adult male E. ryanae Kornicker \& Iliffe 2000 in having a less elongate caudal process and less abundant short spine-like bristles, especially along edges of fossae and, also, fewer bristles on the infold of the caudal process (three compared to six or seven). The endopod of the second antenna of E. syrinx bears one bristle on the first segment compared to two bristles on E. ryanae. The first antenna of E. syrinx bears one ventral bristle on the fourth segment compared to two bristles on E. ryanae. The exopod of mandible of $E$. syrinx is a short bare blunt process, whereas that of $E$. ryanae is longer and spinous. The second segment of the endopod of the second antenna of $E$. syrinx is much longer than that of E. warneri Kornicker et al. 2002. The exopod of the mandible of E. syrinx is a short blunt process, whereas that of E. warneri is a small bristle (Fig. 56c). Parts of the mandible of E. warneri and E. syrinx are compared in Fig. 56. E. syrinx differs from the adult male designated Eusarsiella sp. X by Kornicker et al. (2002: 63) in having both no proximal bristles on the seventh limb and a second segment on the endopod of the second antenna (see Kornicker 1958: figs. 74c, 75c). The mandible of the adult male $E$. syrinx differs from that of the adult male E. styx Kornicker \& Iliffe 1989b, in having a smaller and bare exopod and a longer terminal claw on the third endopod segment.

Female: The carapace of E. syrinx differs from that of E. ryanae in that the short bristles on the outer surface have knobby rather than pointed tips and in the carapace having many more nodes. The first antennae of E. capillaris (Kornicker 1958) and Eusarsiella sp. X (Kornicker et al. 2002: 63) differ from those of E. syrinx in not having a dorsal bristle on the first segment. The carapace of $E$. syrinx is much larger than that of $E$. cornuta Poulsen 1965, and the endopod of the second antenna of the former bears a terminal bristle absent on the latter. The precoxa of the mandible of the adult female and instars II to IV of E. syrinx have ventrally adjacent to the coxa a brown or reddish brown area not described in previous sarsiellids. However, its presence on other species may not have been sufficiently noticed to be included in their descriptions. The basis of the mandible of E. syrinx bears three bristles near the ventral margin compared to six on E. ryanae. In the "Key to the Species of Eusarsiella" in Kornicker (1986:44-47) which includes 35 species from the West Atlantic and Gulf of Mexico, the female E. syrinx keys out to Eusarsiella cornuta Poulsen 1965. The carapace of E. cornuta differs from that of E. syrinx in lacking projecting processes along the outer margin. The carapaces of two species described from Bermuda, Eusarsiella absens (Kornicker 1981) and Eusarsiella styx Kornicker \& Iliffe $1989 \mathrm{~b}$, differ from that of E. syrinx in lacking projecting processes along the margins.

Ontogeny and Sexual Dimorphism (Table 13, Figs. 25, 26). Carapace: Posterior margins of instars in lateral view are oblique, whereas the margin of the adult female is vertical. The posterodorsal part of the carapace of the adult female is broader than on instars, no doubt to accommodate eggs. The carapace of the adult male differs from those of instars and the adult female mainly in having a prominent rostrum.

Ornamentation: Adults have prominent ribs which are absent on instars. Prominent nodes on the adults progressively become less prominent in younger instars. Visibility of fossae is in part a function of preservation, because they are quite apparent on an instar II (USNM 1021467 but are less apparent on other instars. 
They are quite visible on both adult females in the collection. The number and distribution of long bristles appear similar in the adult female and instars. Short bristles with knobbed tips are present on all specimens.

Infold: The anterior infold of instars and adult bear a small bristle near midheight. The adult female caudal process bears 4 to 6 bristles forming vertical row; the numbers decrease in progressively younger instars, and none are present on instar I. A broad infold is present at all stages.

Selvage: A broad lamellar prolongation with a smooth outer margin is present on all stages. It extends well past the posterior end of the caudal process and is undivided at the anterior margin of valves.

Central adductor muscle attachments: The number of muscle attachments given herein is those seen through the outside of each valve, and the differences observed for the stages are in large part the result of their being partly obscured on some specimens. In one of the first instars (USNM 1021469) the individual muscle strands are loosely packed (Fig. 64b), but in the second instar I (USNM 1021470) in the collection the strands are tightly bound together, as is normal for myodocopids.

Carapace size: Growth factors based on total length including the caudal process for the few specimens in the collection are: Instar I to instar II, 1.24; II to III, 1.23; II to IV, 1.27; IV to adult female, 1.30; and IV to adult male, 0.75 .

First antenna: The 3rd and 4th segments are fused in all stages. The 5th segment is wedged ventrally between the 4th and 6th segments in the adult male. The 6th segment is well developed only in the adult male; in other stages the segment is fused to the 5th segment and, at most, consists of a narrow band. Segment 2 is without a dorsal bristle on instar I, and bears 1 dorsal bristle on later stages. Segment 4 is without bristles on instar I, bears 1 dorsal bristle on instar II, 1 ventral and 1 dorsal bristle on instar III as well as on the adult male, and 2 ventral and 2 dorsal bristles on remaining stages. The ventral bristle of the 5 th segment is without marginal filaments on instar I and bears numerous long marginal filaments on the adult male; on other stages the bristle contains a few minute marginal filaments. The c-bristle of the 7th segment and the d-, f-, and g-bristles of the 8th segment are without filaments on instar I and bear a few minute filaments on later stages.

Mandible: Limb similar in instars and adult female; $e . g$., each of 3 endopod segments bears a strong ventral terminal claw, and limb is without an exopod. Adult male very different; $e$. $g$., a strong claw present only on 3rd endopod segment, and limb bears a small exopod.

Maxilla: Limb similar in instars and adult female, except endite III of instar I with four bristles compared to 6 in other stages. Male limb reduced and all bristles except those of exopod very weakly developed (difficult to count).

Fifth limb: Number of epipod bristles increases from 25 on instar I to 35 on adult female and 36 on adult male, otherwise instars and adult female similar. Limb of adult male reduced.

Sixth limb: Limb without bristles on instar I, with 1 bristle on instar II, and with many bristles on other stages.

Seventh limb: Limb bare on instars I to III, becoming longer on each succeeding stage. Instar IV female limb with 6 bristles, adult female limb with 8, and adult male limb with 4. Instar IV and adult female limbs with terminal opposing spines, which are absent on adult male.

Furca: Each lamella with 3 claws on instar I and 5 claws on other stages.

Bellonci Organ: Present and similar on all stages (lost during dissection on an adult female examined herein).

\section{Eusarsiella paniculata Kornicker 1986}

Figs. 66-68

Eusarsiella paniculata Kornicker 1986, 58: figs. 28d-g, 29, 30.

Holotype. USNM 157973, ovigerous female on slide and in alcohol. 
Type locality. West Florida continental shelf, depth $58.5 \mathrm{~m}$.

Material. Sta 00-025, Conch Sound Blue Hole, Andros Island, Great Bahama Bank: USNM 1021471, one instar A-1 female on slide and in alcohol; USNM 1021472, one A-1 male in alcohol; USNM 1021473, one A-2 instar (sex unknown) in alcohol.

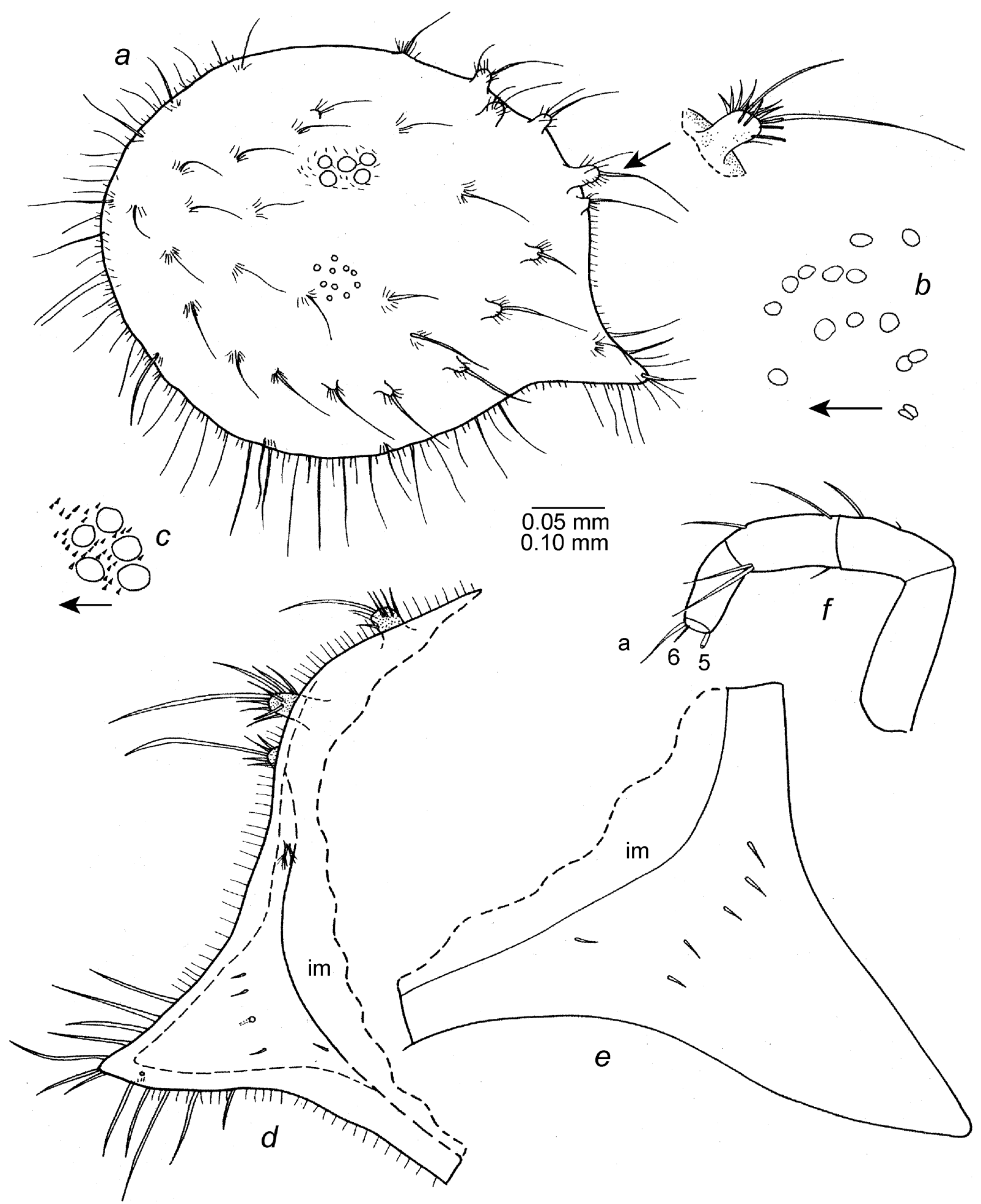

FIGURE 66. Eusarsiella paniculata Kornicker 1986, USNM 1021471, A-1 female: $a$, complete specimen from left side, length with caudal process $1.26 \mathrm{~mm} ; b$, central adductor muscle scars of left valve, ov; $c$, round fossae and small pointed spines on surface of left valve, ov; $d$, caudal process of left valve, iv; $e$, caudal process of right valve, iv; $f$, right first antenna, $\mathrm{mv}$ (nabs). Scale equals $0.10 \mathrm{~mm}(b-d, f)$ and $0.05 \mathrm{~mm}(e)$. 


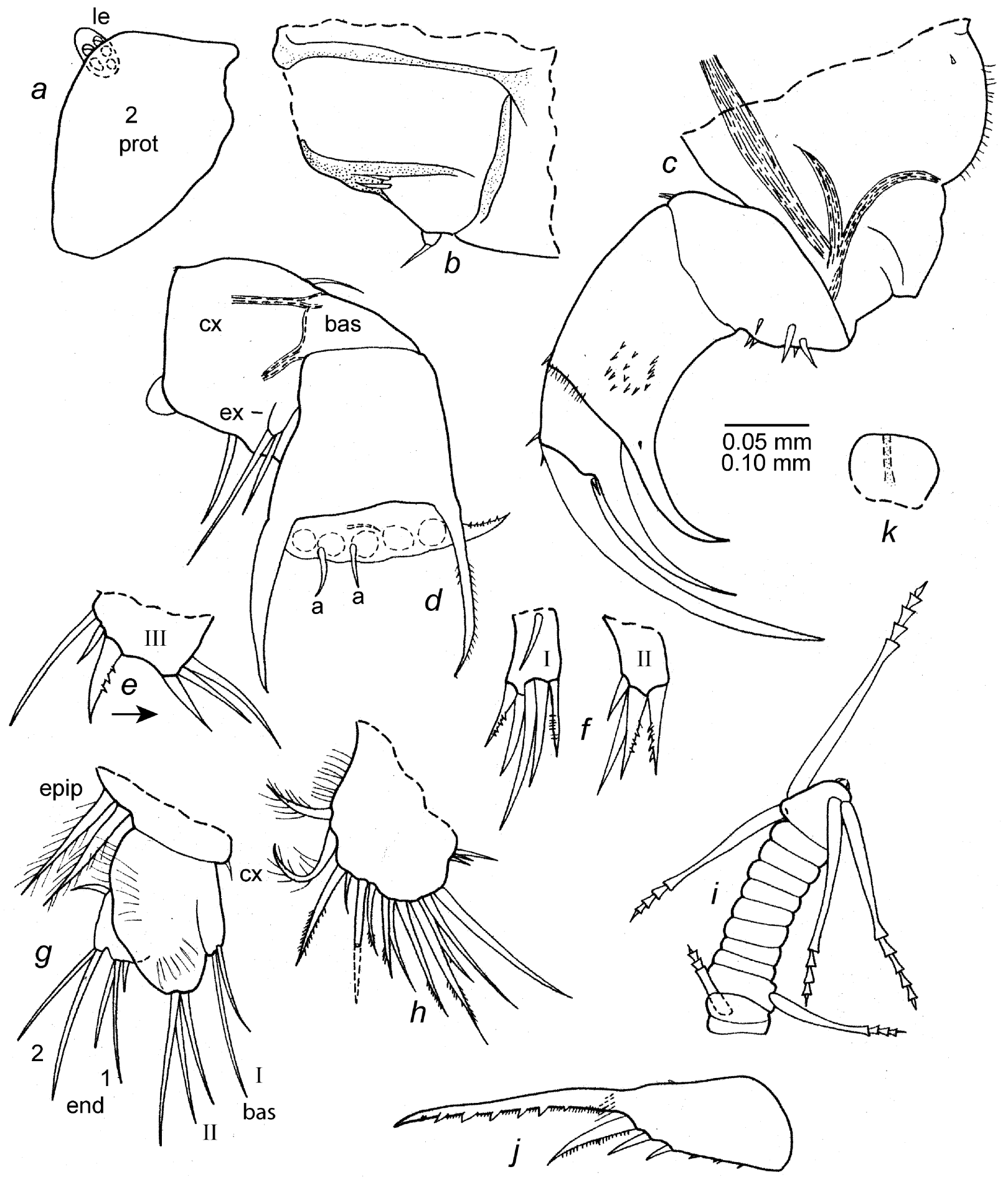

FIGURE 67. Eusarsiella paniculata Kornicker 1986, USNM 1021471, A-1 female: $a$, protopod right second antenna and right lateral eye, lv; $b$, endopod right second antenna, mv; $c$, right mandible drawn on body, mv; $d$, right maxilla drawn on body, lv; $e$, endite III right maxilla, lv; $f$, endites I and II left maxilla, mv; $g$, right fifth limb drawn on body, lv; $h$, right sixth limb drawn on body, lv; $i$, left seventh limb; $j$, left lamella of furca, $1 \mathrm{v} ; k$, medial eye.Scale equals $0.10 \mathrm{~mm}$ $(a, j, k)$ and $0.05 \mathrm{~mm}(b-i)$.

Distribution. West Florida continental shelf, depth 22.5-58.5 m. Conch Sound Blue Hole (about $365 \mathrm{~m}$ inside cave), Andros Island, Great Bahama Bank, depth $25 \mathrm{~m}$.

Description of A-1 female (Figs. 66-68a,b). Carapace oval in lateral view with pointed caudal process triangular in lateral view (Fig. 66a). Surface with gel-like substance coating valves and short bristles. 
Ornamentation (Fig. 66a,c): Surface with numerous processes bearing short tapered bristles, 1 very long bristle, and 1 shorter more slender bristle (Fig. 66a); surface with shallow round fossae with bare bottoms; surface between fossae with small spine-like pointed bristles of various lengths; spines also abundant along valve edge including caudal process.

Infold: Anterior infold with minute bristle near midheight. Infold of caudal process with 4 or 5 bare bristles forming vertical row and 1 similar bristle closer to the inner edge of infold (Fig. 66d,e).

Selvage: Broad lamellar prolongation with smooth outer edge present along entire margin and extending well past tip of caudal process.

Central adductor muscle attachments (Fig. 66b): consisting of about 14 ovoid scars.

Carapace size (length, height in mm): USNM 1021472, length including caudal process 1.26, length excluding caudal process 1.14 , height 0.96 .

First antenna (Fig. 66f): 1st segment bare. 2nd with dorsal bristle. 3rd and 4th segments fused; 3rd with 2 terminal bristles ( 1 ventral, 1 dorsal); 4 th with 3 bristles ( 2 ventral, 1 dorsal). 5th segment with long ventral bristle with minute proximal filament. 6th segment with short medial bristle. 7th segment: a-bristle longer than bristle of sixth segment; b-bristle slightly shorter than a-bristle; c-bristle long, with 2 minute proximal filaments. 8th segment: d- and e-bristle long, bare; f-bristle long; g-bristle long with 2 minute proximal filaments.

Second antenna (Fig. 67a,b): Protopodite bare (Fig. 67a). Endopod with 2 segments: segment 1 broad with 2 ringed anterior bristles; segment 2 short with ringed terminal bristle about same length as bristles of 1st segment (Fig. 67b). Exopod: 1st segment with short recurved medial spine; bristles of segments 2-8 with stout proximal ventral spines and distal natatory hairs; 9th segment with 2 bristles (1 long with proximal ventral spines and distal natatory hairs, 1 short bare).

Mandible (Fig. 67c): Coxa endite consisting of short stout spine; ventral margin of coxa with short hairs. Basis with 6 bristle with 3 medial, 3 smaller on ventral margin, and 2 spine-like small dorsal subterminal bristles. Exopod absent. Endopod: 1st segment with distal medial spines, row of medial spines along distal margin, 3 stouter terminal dorsal spines, and minute spine-like medial bristle at base of stout ventral claw. 2nd segment with minute terminal dorsal bristle and stout ventral claw. 3rd segment with 2 minute bristles (1 ventral, 1 dorsal) and stout terminal claw.

Maxilla (Fig. 67d-f): Endite I with 6 terminal bristles; endite II with 4 bristles; endite III with 6 bristles. Coxa with short dorsal bristle. Basis with 1 bristle near exopod. Exopod with 2 bristles. Endopod: 1st segment with spinous alpha- and beta-bristles. 2nd segment with 2 lateral a-bristles, 1 medial c-bristle, and 5 pectinate terminal bristles.

Fifth limb (Fig. 67g): Epipod with 35 plumose bristles. Coxa with small bristle. Basis with 2 endites: endite I with 2 bristles; endite II with 3 bristles. Endopod with 2 fused segments: segment 1 with 3 bristles; segment 2 with 2 bristles. Exopod represented by short bristle. Limb hirsute.

Sixth limb (Fig. 67h): Single endite with 3 bristles (1 longer than others). End segment with 11 bristles plus 2 plumose posterior bristles.

Seventh limb (Fig. 67i): Each limb with 6 tapered bristle (2 proximal with 3 or 4 bells; 4 terminal with 4 or 5 bells). Terminus with minute terminal teeth. Each limb with 69-72 rings.

Furca (Fig. 67j): Each lamella with 5 claws with claw 1 fused to lamella. Claw 1 with 5 stout teeth, many small teeth, and long spines forming medial row near base; claws 2 and 3 with small teeth; claw 5 very small. Left lamella with ventral spines following claws and posterior to right lamella by width of claw 1 at base. Both lamellae with small anterior spine at about midheight.

Bellonci Organ: Lost during dissection.

Eyes: Lateral eye with 5 divided, amber-colored ommatidia (Fig. 67a). Medial eye larger than lateral eye (Fig. 67k).

Genitalia? (Fig. 68b): Broad rounded lobe on each side of longer tapered lobe, all bare. Each rounded 
lobe with duct (containing minute globules) terminating anterior to Y-sclerite.

$Y$-Sclerite (Fig. 68a,b): With ventral branch.

Posterior of body (Fig. 68a): Posterior of body smooth, bare. Posterodorsal part of body dorsal to girdle scalloped.

Gut content: Copepod and unidentified crustacean.

Remarks Concerning Genitalia. The process just anterior to the anus that is questionably designated the genitalia herein is a puzzle. The ducts on each side show it to be part of the specimen and not foreign. Except for not being paired and being bare, it resembles the male copulatory limb more than it does female genitalia.

Description of A-1 male (Fig. 68c,d). Carapace shape, ornamentation, infold, and selvage similar to those of A-1 female (Fig. 68c). Gel-like coating present.

Carapace size (length, height in mm): USNM 1021472, length with caudal process 1.17, length without caudal process 1.04 , height 0.88 .

First antenna: Distribution of bristles similar to those of A-1 female.

Second antenna: Protopod and exopod similar to those of A-1 female. Endopod with 2 segments (Fig. 68d): segment 1 with 2 ringed anterior bristles; segment 2 with 3 ringed bristles slightly longer than those of segment 1.

Mandible: Details not studied, but limb in general similar to that of A-1 female.

Maxilla: Endite I, coxa, basis, exopod, and endopod similar to those of A-1 female. Endites II and III obscured.

Fifth limb: Epipod with 37 bristles. Remainder of limb similar to that of A-1 female.

Sixth limb: Obscured, but in general, similar to that of A-1 female.

Seventh limb: Number of bristles similar to those of A-1 female. Terminal segment without teeth.

Furca: Similar to that of A-1 female.

Bellonci Organ: Obscured.

Eyes: Lateral eye with 5 divided amber-colored ommatidia. Medial eye obscured.

Posterior of body: Similar to that of A-1 female.

Genitalia: Obscured.

$Y$-Sclerite: With ventral branch.

Gut content: Unidentified fragments.

Description of A-2 instar (sex unknown). Carapace shape similar to that of A-1 female (Fig. 68e).

Ornamentation: Nodes less well developed than on A-1 female (only posterodorsal node shown in Fig. 68 ); others mostly represented by long and short bristles. Gel-like coating present.

Carapace size (length, height in mm): USNM 1021473, length including caudal process 0.93, length without caudal process 0.80 , height 0.66 .

Furca: Similar to that of A-1 female.

Comparisons. The female carapace of E. paniculata differs from that of E. syrinx in having a rounded rather than a pointed tip on the caudal process and in having more processes projecting outward from the valve edge. The bristles on the carapace processes of E. capillaris are broader and have blunter tips than those on E. paniculata. The carapace of Eusarsiella cornuta Poulsen 1965 from the West Indies is without processes along the shell edge.

Discussion. Kornicker (1986: 58) described an adult female. An A-1 female and male and an A-2 instar are described herein. The right valve of the A-1 male was removed, and the description of appendages is based on views of the specimen within the left valve. The A-2 instar was not opened. The identification of the sexes of the A-1 male and female is based on the A-1 male having three bristles on the second segment of the endopod of the second antenna and not having teeth at the tip of the seventh limb. The A-1 female bears one terminal bristle on the second segment of the second antenna and minute terminal teeth on the seventh limb. 


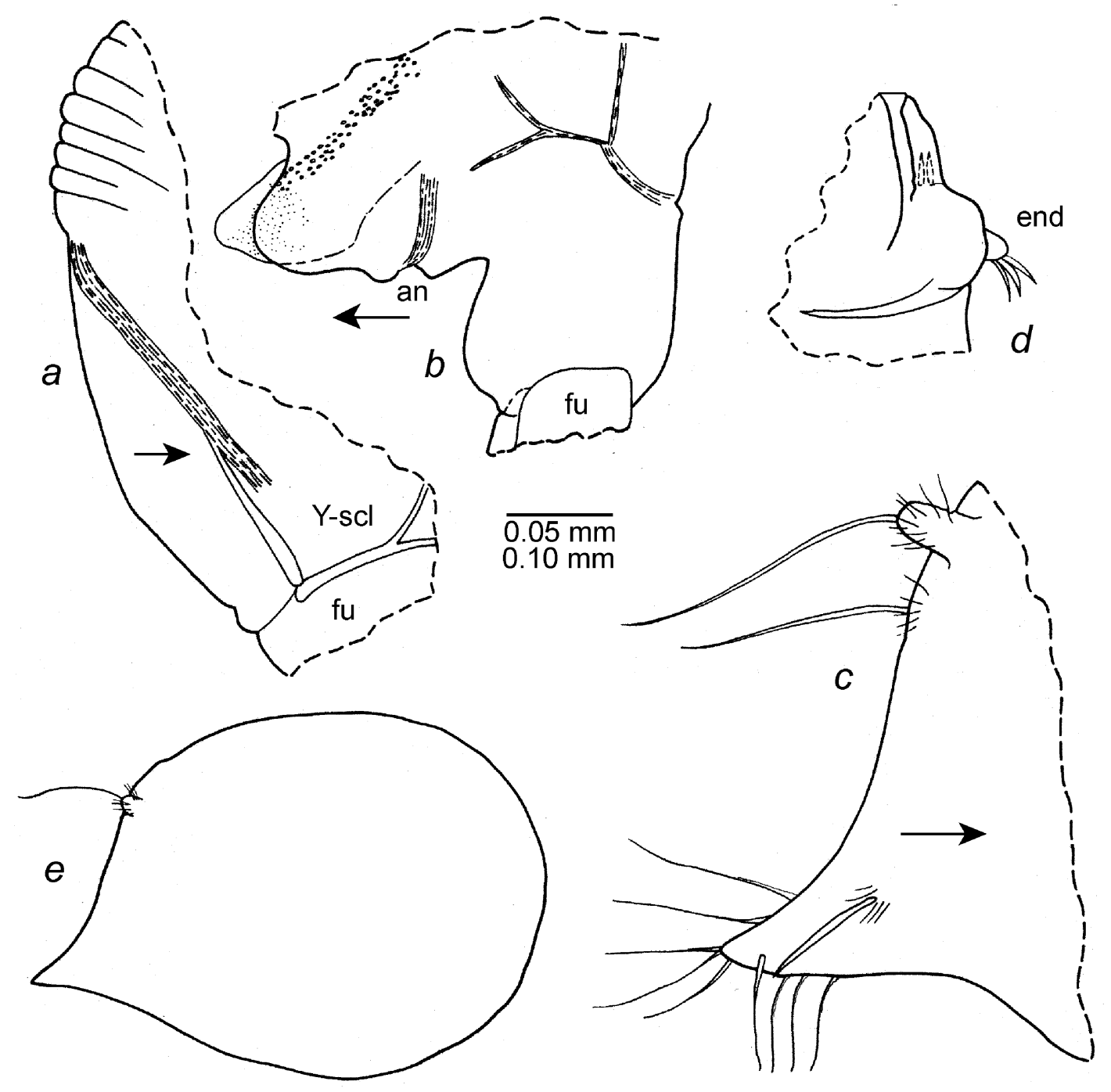

FIGURE 68. Eusarsiella paniculata Kornicker 1986, USNM 1021471, A-1 female: $a$, posterior of body from right side; $b$, posterior of body from left side; USNM 1021472, A-1 male: $c$, posterior of right valve, lv; $d$, endopod of right second antenna drawn on body, lv. USNM 1021473, A-2 instar (sex unknown): $e$, complete specimen from right side, length with caudal process $0.93 \mathrm{~mm}$. Scale equals $0.10 \mathrm{~mm}(a, b)$ and $0.05 \mathrm{~mm}(c-e)$.

\section{Eusarsiella fax, new species}

Figs. 69-72

Etymology. From the Latin fax (torch, firebrand).

Holotype. USNM 1021474, A-1 female on slide and in alcohol.

Type locality. Sta 00-025, Conch Sound Blue Hole, Andros Island, Great Bahama Bank.

Paratypes. USNM 1021475, undissected A-1 instar (sex unknown) in alcohol. USNM 1021476, undissected A-1 instar (sex unknown) in alcohol. USNM 1021477, A-1 male on slide and in alcohol.

Distribution. Type locality.

Description of A-1 female (Figs. 69-71a,b). Carapace oval in lateral view with triangular pointed caudal process (Figs. 69, 70c). Surface with 2 lateral ribs with pebbly surface and several nodes bearing a long bristle but no short broad bristles (Fig. 69).

Ornamentation (Figs. 69, 70a-c): Very short spines covering caudal process and remainder of valves, 
appearing pebble-like along valve edges and on ridges. Surface of holotype with fossae with irregular outline, some with inward-pointing minute spines along edges. Surface coated with gel-like substance.

Infold: Anterior infold with minute bristle at midheight. Infold of caudal process with 3 bristles (Fig. 70c). Two setal bristles present dorsal to caudal process.

Selvage: Lamellar prolongation with smooth outer edge along valve margins. Prolongation with serrated margin extends well past tip of caudal process.

Carapace size (length, height in mm): Holotype, USNM 1021474, length including caudal process 0.94, length without caudal process 0.83 , height 0.72 .

First antenna (Fig. 70d): 1st segment bare. 2nd segment with dorsal bristle and 2 spines. 3rd and 4th segments fused: segment 3 with 2 bristles (1 ventral, 1 dorsal); 4th segment with 2 or 3 bristles ( 1 (right limb) or 2 (left limb) ventral, 1 dorsal). 5th segment with long ventral bristle with minute filament near midlength (not shown). 6th segment with short medial bristle. 7th segment: a-bristle short, b-bristle about same length as abristle, c-bristle as long as bristle of 5th segment, with minute distal filament (not shown). 8th segment: $d$ - and e-bristles slightly shorter than c-bristle, bare with blunt tips, f-bristle shorter than c- bristle, g-bristle about same length as c-bristle.

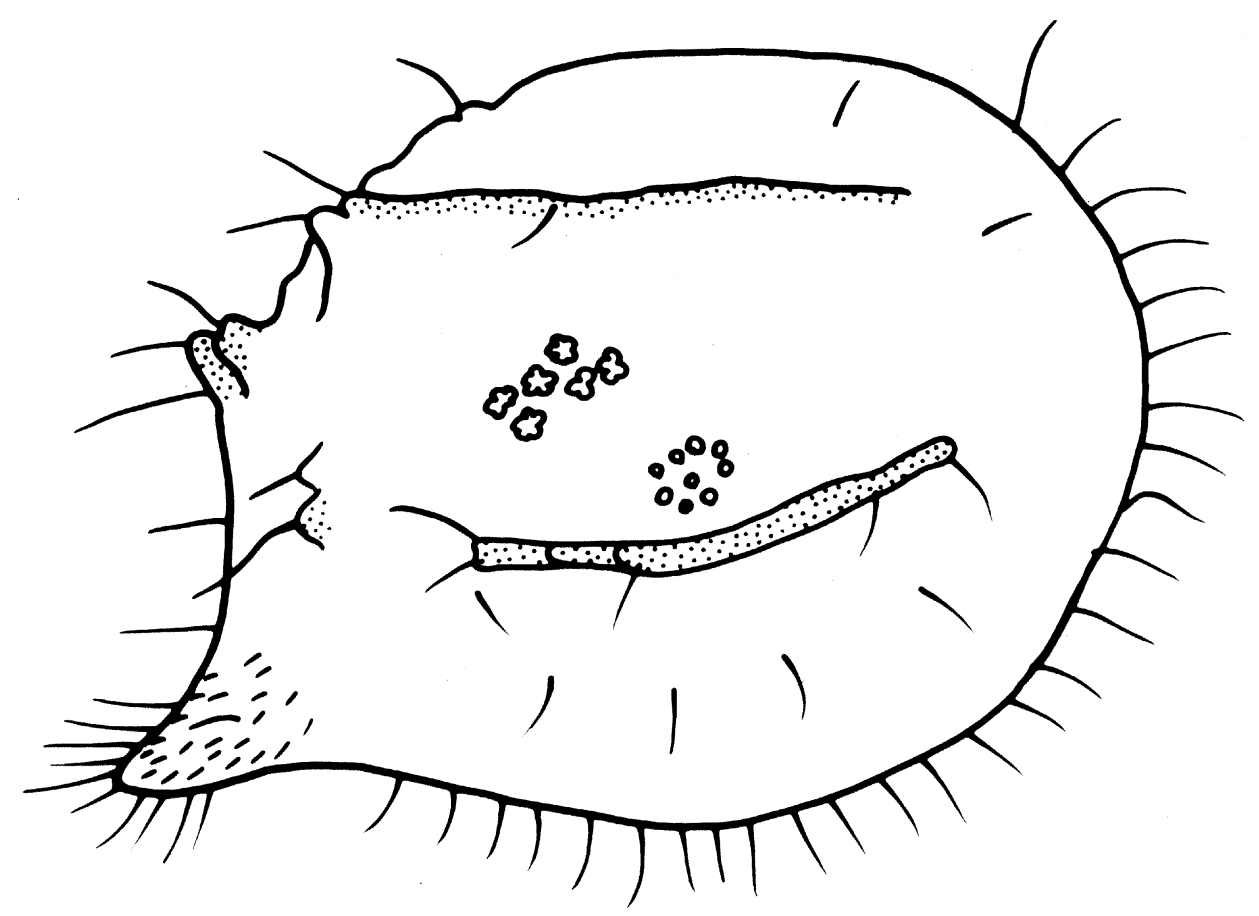

FIGURE 69. Eusarsiella fax, new species, holotype USNM 1021474, A-1 female, complete specimen from right side, length with caudal process $0.94 \mathrm{~mm}$.

Second antenna: Protopod bare. Exopod: 1st segment with small recurved medial spine; segments 2-8 with long bristle with proximal spines and distal natatory hairs; 9th segment with 2 bristles (1 long with proximal spines and distal natatory hairs, 1 short bare). Endopod with 2 fused segments: 1 st segment with 1 (right limb) or 2 (left limb) ringed dorsal bristles; segment 2 tapering distally, bare (Fig. 70e).

Mandible (Fig. 70f): Coxa endite consisting of short stout spine; ventral margin of coxa with short hairs. Basis: medial side near ventral margin with 4 short bristles; ventral margin with 2 minute bristles; dorsal margin with 2 small distal bristles. Exopod absent. Endopod: 1st segment with distal medial spines, row of minute medial spines along distal margin (row extends to stout spine on dorsal edge of segment), and stout ventral claw with proximal row of minute teeth along dorsal edge; minute medial spine-like bristle at base of stout claw. 2nd segment with minute dorsal bristle and stout ventral claw. 3rd segment with 2 minute bristles (1 ventral, 1 dorsal) and stout terminal claw. 


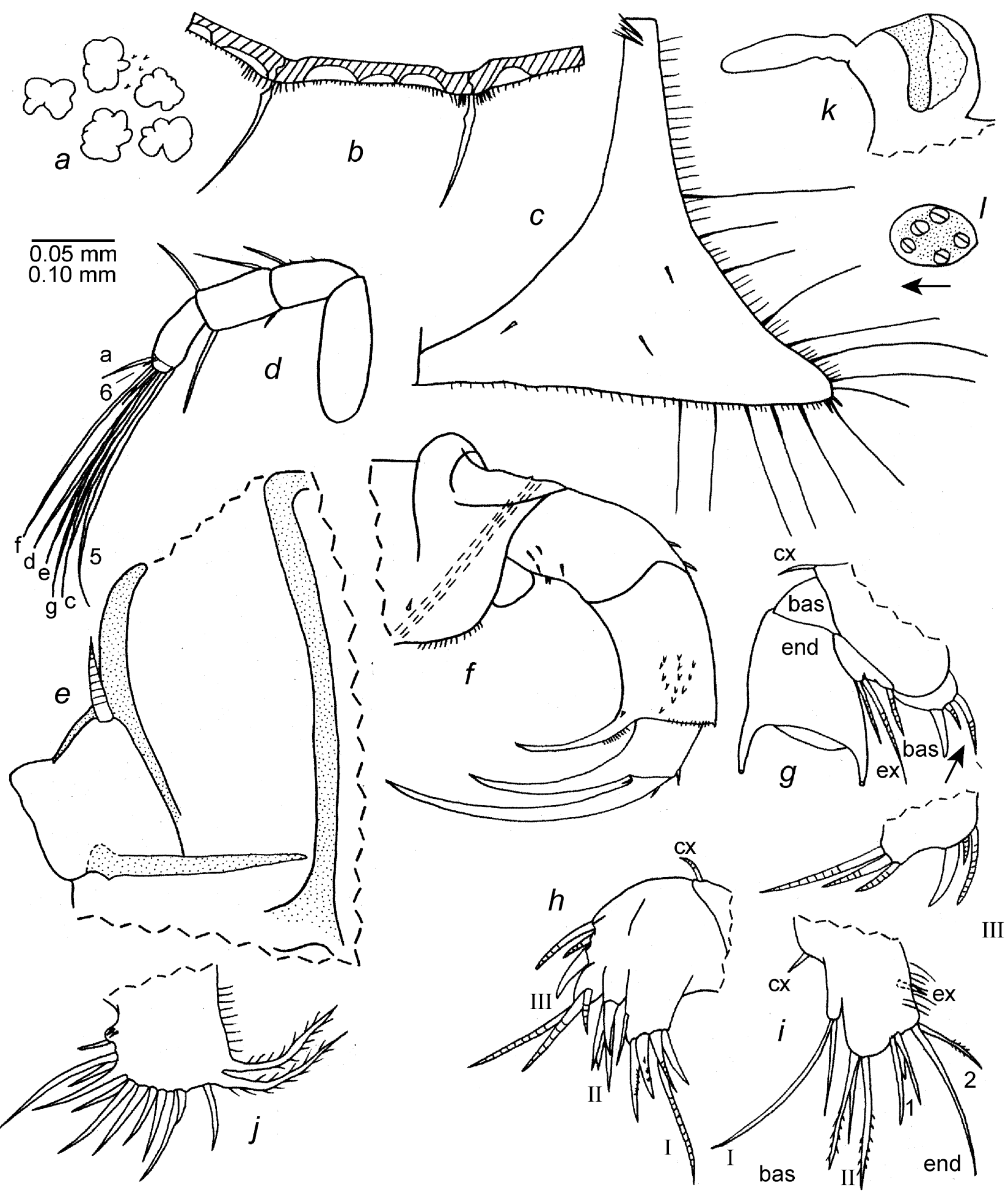

FIGURE 70. Eusarsiella fax, new species, holotype USNM 1021474, A-1 female: $a$, detail of fossae on right valve; $b$, fragment of valve edge showing fossae and bristles; $c$, caudal process right valve, iv; $d$, right first antenna, mv; $e$, endopod right second antenna, mv; $f$, left mandible, mv; $g$, left maxilla, lv (nabs); $h$, endites right maxilla, mv; $i$, fifth limb; $j$, left sixth limb, mv; $k$, medial eye and Bellonci Organ; $l$, right lateral eye, mv. Scale equals $0.05 \mathrm{~mm}(a-c, e-l)$ and 0.10 $\mathrm{mm}(d)$.

Maxilla (Fig. 70g,h): Endite I with 6 bristles; endite II with 4 bristles; endite III with 6 bristles. Coxa with short dorsal bristle. Basis with single bristle near exopod. Exopod with 2 bristles. Endopod with 2 segments: segment 1 with alpha- and beta-bristles; segment 2 with 2 a-bristles, 1 c-bristle, and 5 pectinate end bristles. 
Fifth limb (Fig. 70i): Coxa endite with 1 short bristle. Basis with 2 endites: endite I with 2 bristles; endite II with 3 bristles. Endopod with 2 fused segments: segment 1 with 3 bristles (1 short); segment 2 with 2 bristles. Exopod represented by short bristle. Limb hirsute. Epipod with about 34 plumose bristles.

Sixth limb (Fig. 70j): Single endite with 3 bristles (1 terminal and 2 shorter proximal). End segment with 11 bristles plus 2 posterior plumose bristles.

Seventh limb (Fig. 71a): Each limb with 6 tapered bristles ( 2 proximal with 3 or 4 bells; 4 terminal with 4 or 5 bells). Tip with small opposing teeth. Each limb with about 62 annulae plus a terminal segment.

Furca (Fig. 71b): Each lamella with 5 claws; claw 1 with stout teeth and smaller teeth between them; claws 2 to 4 with small teeth; claw 1 with long medial spines near base; claw 4 of left lamella with long thin spines along anterior edge. Anterior edge of right lamella with small spine proximal to claw; left lamella with few spines along ventral edge following claw 5. Right lamella anterior to left by width of claw 1 at base.

Bellonci Organ (Fig. 70k): Elongate with rounded tip.

Eyes: Lateral eye with 5 amber ommatidia; brown pigment between ommatidia (Fig. $70 l$ ). Medial eye larger than lateral eye, with brown pigment (Fig. 70k).

Genitalia: None observed.

Y-Sclerite: With ventral branch (Fig. 71b).

Posterior of body: Evenly rounded.

Gut content: Unidentified fragments.

Eggs: Absent.

Description of A-1 male (Figs. 71c-k, 72). Carapace similar in shape and ornamentation to that of A-1 female (Fig. 71c,d). Surface with gel-like coating.

Infold: Anterior infold with minute bristle near midheight. Infold of caudal process with 3 small bare bristles plus paired bristles closer to inner margin of infold (Fig. 71e). Posterior infold with 2 setal bristles.

Selvage: Similar to that of A-1 female.

Carapace size (length, height in $\mathrm{mm}$ ): USNM 1021477, length including caudal process 0.86 , length without caudal process 0.77 , height 0.64 .

First antenna: 1st segment bare. 2nd segment with bare dorsal bristle. 3rd and 4th segments fused: 3rd segment with 2 bristles ( 1 ventral, 1 dorsal); 4th segment with 3 bristles ( 2 ventral, 1 dorsal). 5th segment with long ventral bristle with 3 minute filaments. 6th segment with short medial bristle. 7th segment: a-bristle short, b-bristle about same length as a-bristle, c-bristle about same length as bristle of 5th segment, with 3 minute filaments, $d$ - and e-bristles slightly shorter than c-bristle, bare with blunt tips; f-bristle shorter than cbristle, with 2 minute filaments; g-bristle about same length as c-bristle, with 3 small filaments.

Second antenna: Protopodite bare. Exopodite similar to that of A-1 female. Endopod with 2 (possibly 3 ) fused segments (Fig. $71 f, g$ ): 1st segment with 2 ringed anterior bristles; terminal segment small, tapered, with short terminal pointed process.

Mandible (Fig. 71h): Similar to that of A-1 female.

Maxilla (Fig. 71i,j): Similar to that of A-1 female.

Fifth limb (Fig. 71k): Epipod with about 32 plumose bristle. Coxa endite with 1 small bristle. Basis: endite I lobate with 2 bristles; endite II with 3 bristles. Endopod: 1st segment with 3 bristles; 2nd segment with 2 bristles. Exopod represented by 1 bristle.

Sixth limb (Fig. 72a): Single endite with 3 bristles (1 terminal, 2 smaller and proximal). End segment with 11 bristles followed by 2 posterior plumose bristles (marginal spines not shown).

Seventh limb (Fig. 72b): Each limb with 4 tapered terminal bristles with 3 or 4 bells. Tip smooth.

Furca (72c): Similar to that of A-1 female.

Bellonci Organ (Fig. 72d): Elongate with rounded tip.

Eyes (Fig. 72d): Lateral eye with 5 amber-colored ommatidia and brown pigment between ommatidia. Medial eye larger than lateral eye, with brown pigment. 
Lips: Stippled in Fig. 71h; also shown in Fig. 72e.

Posterior of body (Fig. 72c): Evenly rounded and bare ventral to girdle.

Genitalia (Fig. 72f): A single tapered lobe on each side of body; 3 minute bristles near tip of each lobe.

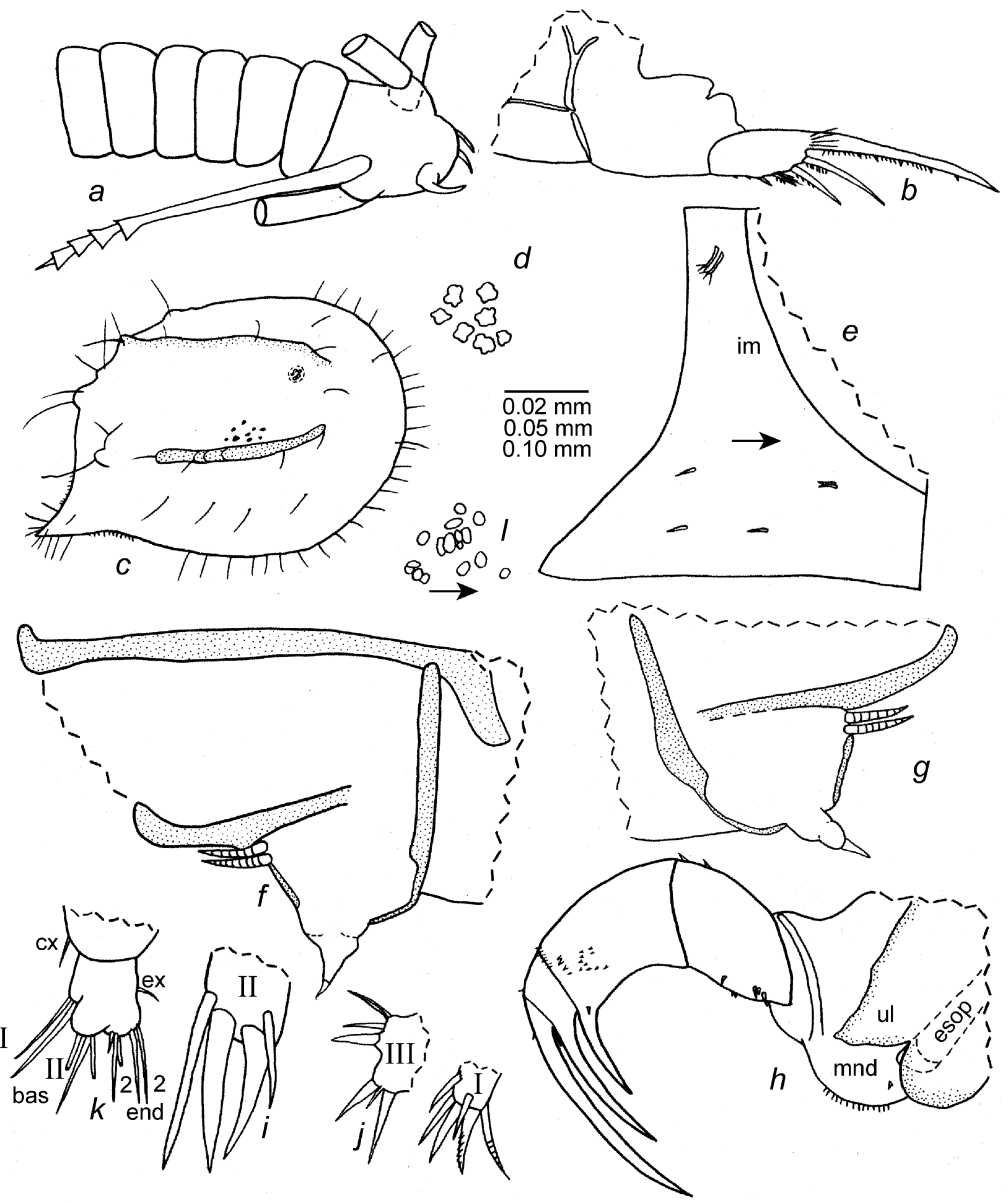

FIGURE 71. Eusarsiella fax, new species, holotype USNM 1021474, A-1 female: $a$, seventh limb; $b$, left lamella of furca, mv and right Y-sclerite. Paratype, USNM 1021477, A-1 male: $c$, complete specimen from right side, length with caudal process $0.86 \mathrm{~mm} ; d$, detail of fossae from " $c$ "; $e$, caudal process of left valve, iv; $f, g$, endopods of right and left second antenna, mv; $h$, left mandible, mv; $i$, endite II right maxilla, mv; $j$, endites I and III of maxilla; $k$, fifth limb. Paratype, USNM 1021476, A-1 instar (sex unknown); $l$, central adductor muscle attachments of right valve. Scale equals $0.02 \mathrm{~mm}(a, f, g, i), 0.10 \mathrm{~mm}(b, d, e, l)$, and $0.05 \mathrm{~mm}(e, h, j, k)$. 

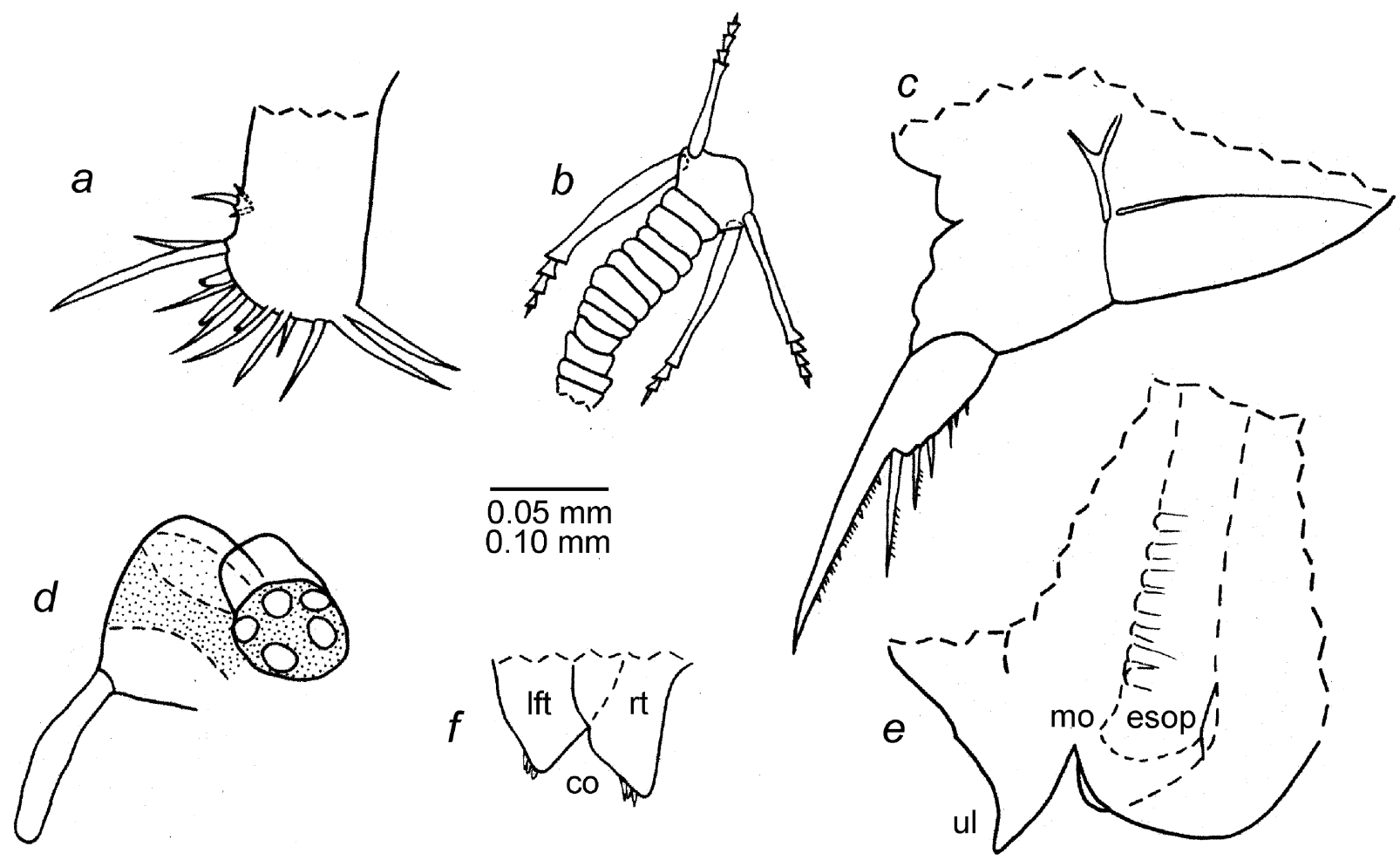

FIGURE 72. Eusarsiella fax, new species, paratype USNM 1021477, A-1 male: $a$, left sixth limb, lv; b left seventh $\operatorname{limb} ; c$, left lamella of furca and left Y-sclerite, lv; $d$, medial eye, Bellonci Organ, and left lateral eye; $e$, view of lips and esophagus from left side, anterior to left; $f$, left and right copulatory organs, anterior to right. Scale equals $0.05 \mathrm{~mm}$ $(a, b, d-f)$ and $0.10 \mathrm{~mm}(c)$.

Y-Sclerite (Fig. 72c): With ventral branch.

Gut content: Unidentified crustacean fragments.

Description of A-1 instar (sex unknown) (Fig. 71l). Carapace similar in shape and ornamentation to those of A-1 female and male.

Carapace size (length, height in mm): USNM 1021475, length including caudal process 0.99 , length without caudal process 0.85 , height 0.73 ; USNM 1021476 , length including caudal process 0.93 , length without caudal process 0.81 , height 0.68 .

Central adductor muscle attachments: USNM 1021476 with about 16 ovoid attachments (Fig. 71l).

\section{Comparisons}

The irregular outlines of fossae on the carapace of E. fax are unusual; the fossae of previously described species having fossae are evenly rounded. The carapace of the new species resembles that of Eusarsiella cornuta Poulsen 1965, which is known only from an adult female collected in the Virgin Islands (Poulsen 1965:106). The edges of the fossae on the carapace of that species are crenulate, but the fossae are more rounded than those of $E$. fax.

\section{Eusarsiella species indeterminate}

Material. Sta 99-050, Four Shark Blue Hole, South Andros, Bahamas: USNM 1021478, one undissected instar in alcohol. Sta 99-053, South Bight \#2 Blue Hole, South Andros, Great Bahama Bank: USNM 1021479, three undissected instars in alcohol. Sta 00-006, The Subway, Great Exuma, Great Bahama Bank: USNM 1021479, one undissected late instar in alcohol. Sta 00-019, Mystery Cave, Stocking Island, Georgetown, Great Exuma, Great Bahama Bank: USNM 1021481, three undissected instars in alcohol. Sta 00-025, Conch 
Sound Blue Hole, Andros Island, Great Bahama Bank, USNM 1021482, one undissected crushed instar in alcohol. Sta 00-027, Four Shark Blue Hole, Andros Island, Great Bahama Bank: USNM 1021483, one undissected instar in alcohol.

\section{Eurypylus Brady 1869}

Type species. Eurypylus petrosus Brady 1869: 141, monotypy.

Composition and distribution. Genus with 10 species, widespread, known depth range shallow water to 142 m (Kornicker \& Iliffe 2000: 45).

\section{Eurypylus hapax Kornicker \& Iliffe 2000}

Figs. 73-75

Eurypylus hapax Kornicker \& Iliffe 2000: 45, figs. 27-29.—Kornicker et al. 2002: 64, figs. 46, 47.

Holotype. USNM 194494, instar IV female in alcohol.

Type locality. Exuma Sound, Great Bahama Bank, depth $142 \mathrm{~m}$.

Material. Sta 00-019, Mystery Cave, Stocking Island, Great Exuma, Great Bahama Bank: USNM 1021484, one instar II female on slide and in alcohol; USNM 1021485, one instar III female on slide and in alcohol; USNM 1021486, two instar III females in alcohol; USNM 1021487, one instar IV female in alcohol.

Distribution. Great Bahama Bank: Crab Cay Crevasse, Mystery Cave, and Exuma Sound; depth 35-140 m.

Description of instar II female (Figs. 73, 74). Carapace similar in shape to that of instar IV male illustrated by Kornicker et al. (2002: fig. 46a) (fig. 73a). Anterior rostrum indicated by minute overlap at midheight of anterior margin of carapace (Fig. 73a,e,f). Posterior edge of caudal process linear (Fig. 73a-c). Anterior and anteroventral margin of valves slightly rugose (Fig. 73f). Extent of attached dorsal margin indicated in Fig. $73 b$.

Ornamentation (Fig. 73a,c): Single bristles numerous along valve margins and scattered over valve surface. Row of about 6 short straight bristles present along outer edge of caudal process.

Infold: Infold of caudal process with about 10 bristles forming row along inner margin and 2 small bristles near midwidth (Fig. 73d). Two setal bristles present just dorsal to caudal process. Usual bristle on anterior infold near rostrum not observed with certainty.

Selvage: Lamellar prolongation with smooth outer edge present along free margins and extending past posterior end of caudal process.

Central adductor muscle attachments (Fig. 73a,b): Consisting of about 17 small oval attachments.

Carapace size (length, height in mm): USNM 1021484, 0.66, 0.50.

First antenna (Fig. 74a,b): 1st segment bare. 2nd segment with distal dorsal bristle. 3rd and 4th segments fused; 3rd segment with dorsal bristle; 4th segment with terminal dorsal bristle and few terminal ventral spines. Sensory bristle of 5th segment long with 2 minute distal spines and terminal spine. 6th segment fused to 5 th segment, with short terminal dorsal bristle with base on medial side. 7th segment: a-bristle almost twice length of bristle of sixth segment; b-bristle medial, slightly longer than a-bristle; c-bristle about same length as sensory bristle of 5th segment, narrower in distal half. 8th segment: d-bristle obscured but appearing to be only slightly longer than b-bristle, filament-like, bare; e-bristle almost same length as c-bristle, filament-like distally, bare; f-bristle about two-thirds length of c-bristle, bare; g-bristle same length as c-bristle, bare. Tips of c-, f-, and g-bristles with terminal spine. 
Second antenna: Protopod bare (Fig. 74e). Endopod with single segment with 1 short proximal anterior bristle (Fig. 74d). Exopod (Fig. 74c): 1st segment with small terminal medial bristle; bristles of segments 2-7 with proximal ventral spines and distal natatory hairs; bristle of 8th segment with few ventral spines and distal natatory hairs; 9th segment with 2 bristles (ventral bristle with distal natatory hairs, dorsal bristle short, bare). Sclerite attached to posterior edge of protopod slender and slightly curved proximally (Fig. 74e).
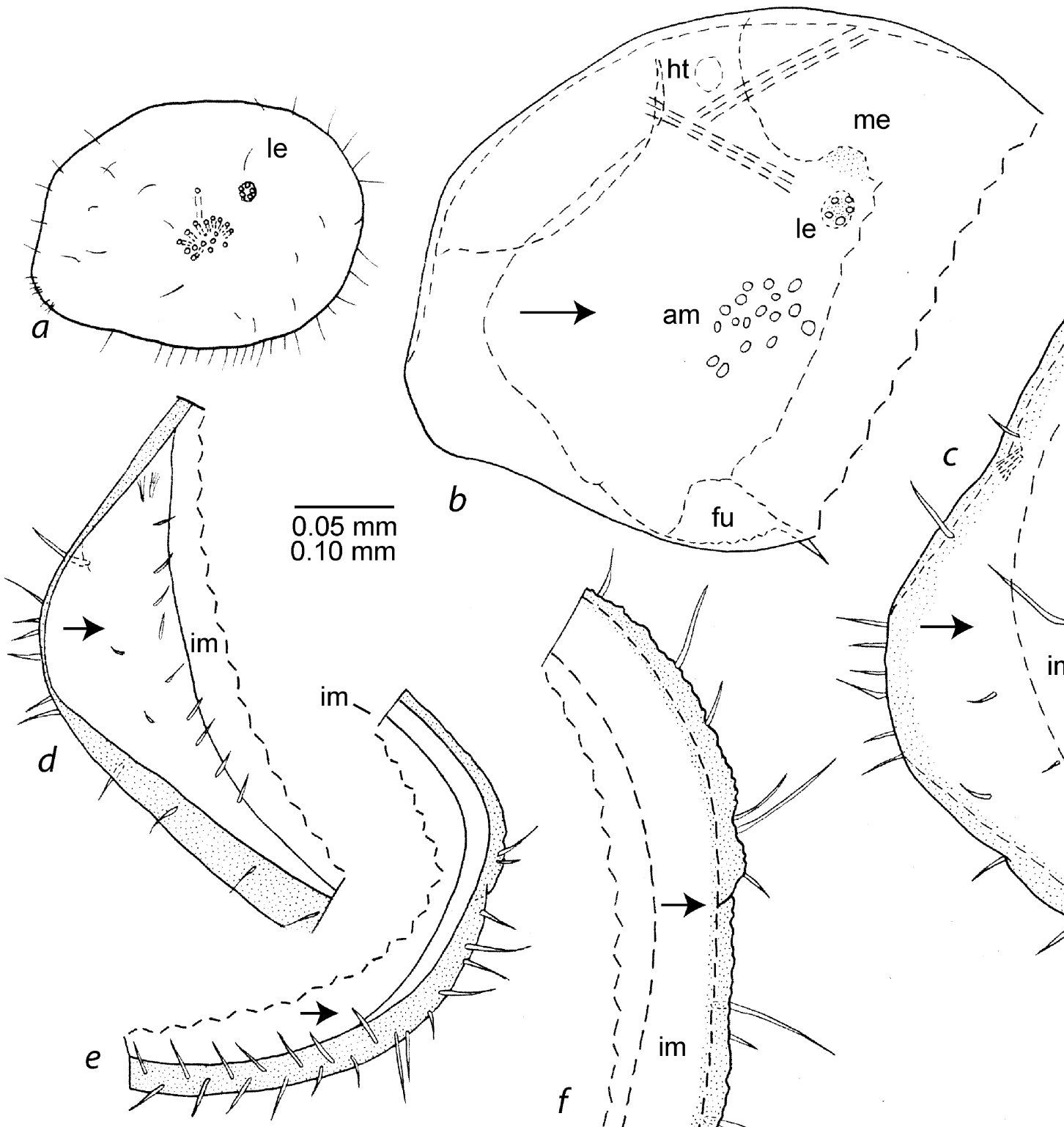


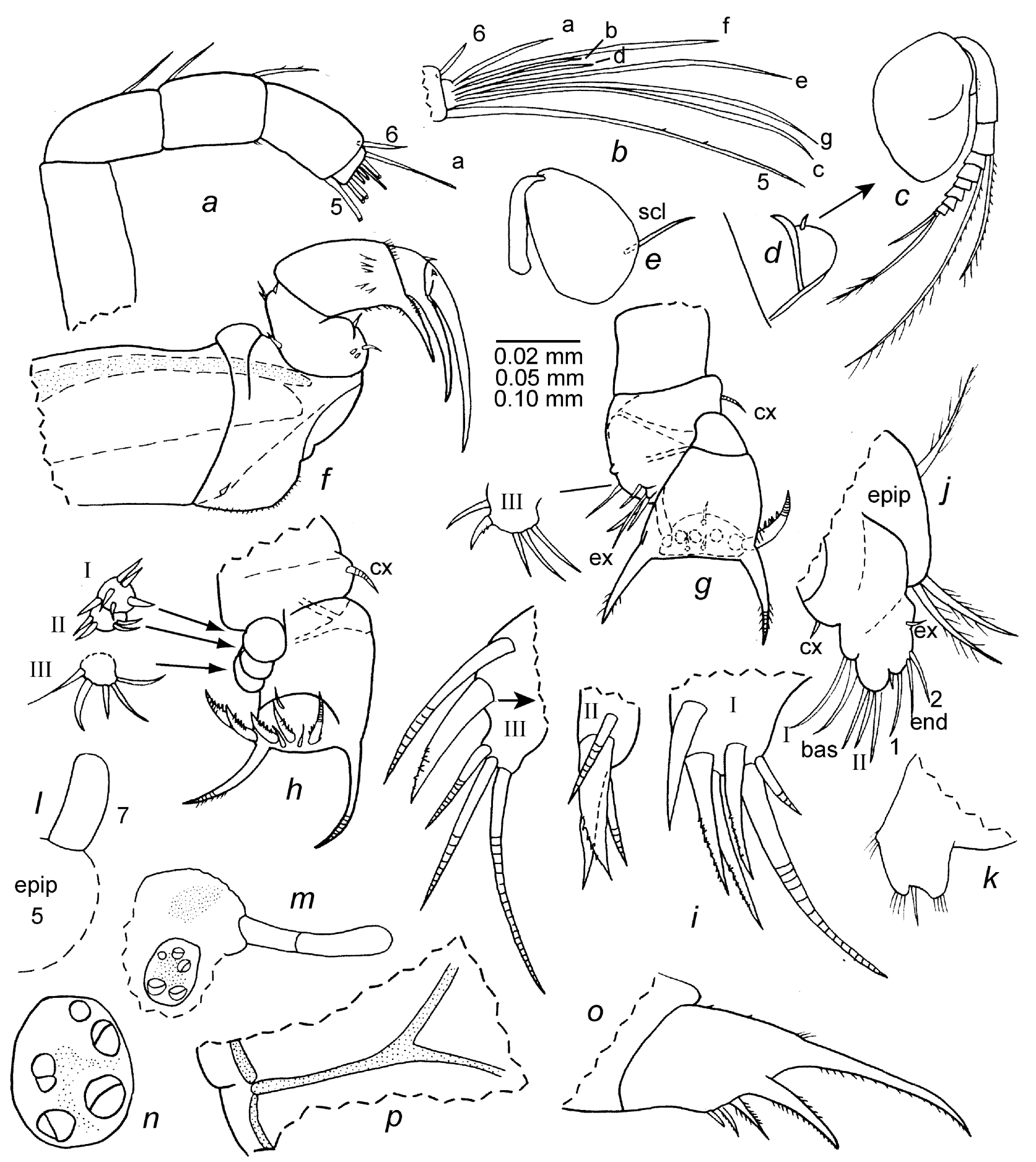

FIGURE 74. Eurypylus hapax Kornicker \& Iliffe 2000, USNM 1021484, instar II female: $a, b$, right first antenna as seen through shell, lv; $c$, right second antenna as seen through shell, lv (nabs); $d$, endopod right second antenna, lv; $e$, left second antenna showing pivot sclerite, lv (nabs); $f$, left mandible, mv; $g$, right maxilla and endite III, lv; $h$, left maxilla and endites, mv; $i$, endites I-III right maxilla; $j$, right fifth limb, mv (nabs); $k$, right sixth limb, lv; $l$, left seventh limb and dashed outline of epipod of right fifth limb; $m$, right lateral eye, medial eye and Bellonci Organ; $n$, right lateral eye, mv; $o$, right lamella of furca, lv; $p$, right Y-sclerite. Scale equals $0.05 \mathrm{~mm}(a, b, d, f-h, j-o), 0.10 \mathrm{~mm}(c, e)$, and $0.02 \mathrm{~mm}(i, n, p)$.

Maxilla (Fig. 74g-i): Endite I with 6 bristles ( 4 claw-like); endite II with 4 bristles ( 2 claw-like); endite III with 5 bristles (2 posterior (1 claw-like pectinate), 3 anterior) (Fig. 74i). Coxa with short dorsal bristle (Fig. $74 g, h)$. Exopod with 3 bristles (1 long, 2 short). Basis with bristle near exopod. Endopod: 1st segment with distal spines on anterior margin and stout pectinate alpha- and beta-bristles; 2nd segment with 2 a-bristles, $1 \mathrm{c}$ - 
bristles, and 5 pectinate end bristles (middle bristle shortest).

Fifth limb (Fig. 74j): Epipod with about 27 plumose bristles. Coxa endite with 1 short bristle. Basis with 2 endites: endite I lobate with 2 terminal bristles; endite II with 3 terminal bristles. Endopod with 2 fused segments: 1st segment with 2 bristles (1 short); 2 nd segment with 2 terminal bristles. Exopod represented by 1 short bristle.

Sixth limb (Fig. 74k): Small with 2 spinous lobes and between them 1 bristle.

Seventh limb (Fig. 74l): Short bare lobe.

Furca (Fig. 74o): Each lamella with 5 or 6 claws; right lamella with 5 claws, left lamella with 6 claws; left lamella with spines following claw 6; claws 1 and 2 stout, nonarticulated; remaining claws articulated, and decreasing in size posteriorly along lamella; claws 1-4 with teeth along posterior edge (those on claw 4 minute); claws 2 and 3 with fine spines along anterior edge. Anterior edge of right lamella anterior to left lamella by about two-thirds of width of claw 1, with long spines near base of claw 1 and few minute anterior proximal spines.

Bellonci Organ (Fig. 74m): Elongate, broadening to rounded tip, and with indistinct suture near midlength.

Eyes (Figs. 73a,b, 74m,n): Medial eye bare with amber colored pigment in vicinity of midlength. Lateral eye smaller than medial eye, with 5 ommatidia (4 divided; undivided ommatidium medial to others) and brownish pigment.

Upper lip: Projecting anteriorly, bare.

$Y$-Sclerite (Fig. 74p): With ventral branch typical for family.

Heart (Fig. 73b): Oval in lateral view.

Gut content: Amber colored unrecognizable particulate matter.

Description of instar III female (Fig. 75). Carapace similar in shape to that of instar II female except posterodorsal corner more rounded (Fig. 75a).

Ornamentation (Fig. 75a,c): Similar to that of instar II female.

Infold: Anterior infold with minute bristle ventral to rostrum (Fig. 75c). Infold of caudal process similar to that of instar II female.

Selvage: Similar to that of instar II female.

Central adductor muscle attachments (Fig. 75a,b): Consisting of 19 ovoid attachments.

Carapace size (length, height in mm): USNM 1021485, 0.75, 0.58. USNM 1021486, 2 specimens: 0.73, $0.56 ; 0.79,0.68$.

First antenna: Differs from that of instar II female in having 2 ventral spines on fused 3rd and 4th segments ( 1 at midlength, 1 subterminal), and 1 terminal ventral bristle on 4 th segment.

Second antenna: Similar to that of instar II female except tip of endopod slightly tapered (Fig. $75 d$ ).

Mandible: Similar to that of instar II female.

Fifth limb: Epipodite with 30 plumose bristles. Remainder of limb similar to that of instar II female.

Sixth limb (Fig. 75e): Single endite with 1 bristle; end segment with 8 bristles followed by space and 2 stout posterior bristles.

Seventh limb (Fig. 75f): Elongate, bare, with indistinct narrowly separated sutures and rounded tip.

Furca (Fig. 75g): With 5 claws on right lamella and 6 on left, similar to those on instar II female; few spines present on lamellae following claws. Right lamella with few proximal anterior spines and longer spines near base of claw 1. Right lamella anterior to left by width of base of claw 1 .

Bellonci Organ: Similar to that of instar II female.

Eyes (Fig. 75h): Medial eye and lateral eyes similar to those of instar II female.

Upper lip: With bare anterior projection (upper lip stippled in Fig. $75 g$ ).

Posterior of body (Fig. 75f): With two clusters of spines at posterodorsal corner just anterior to dorsal end of girdle. 


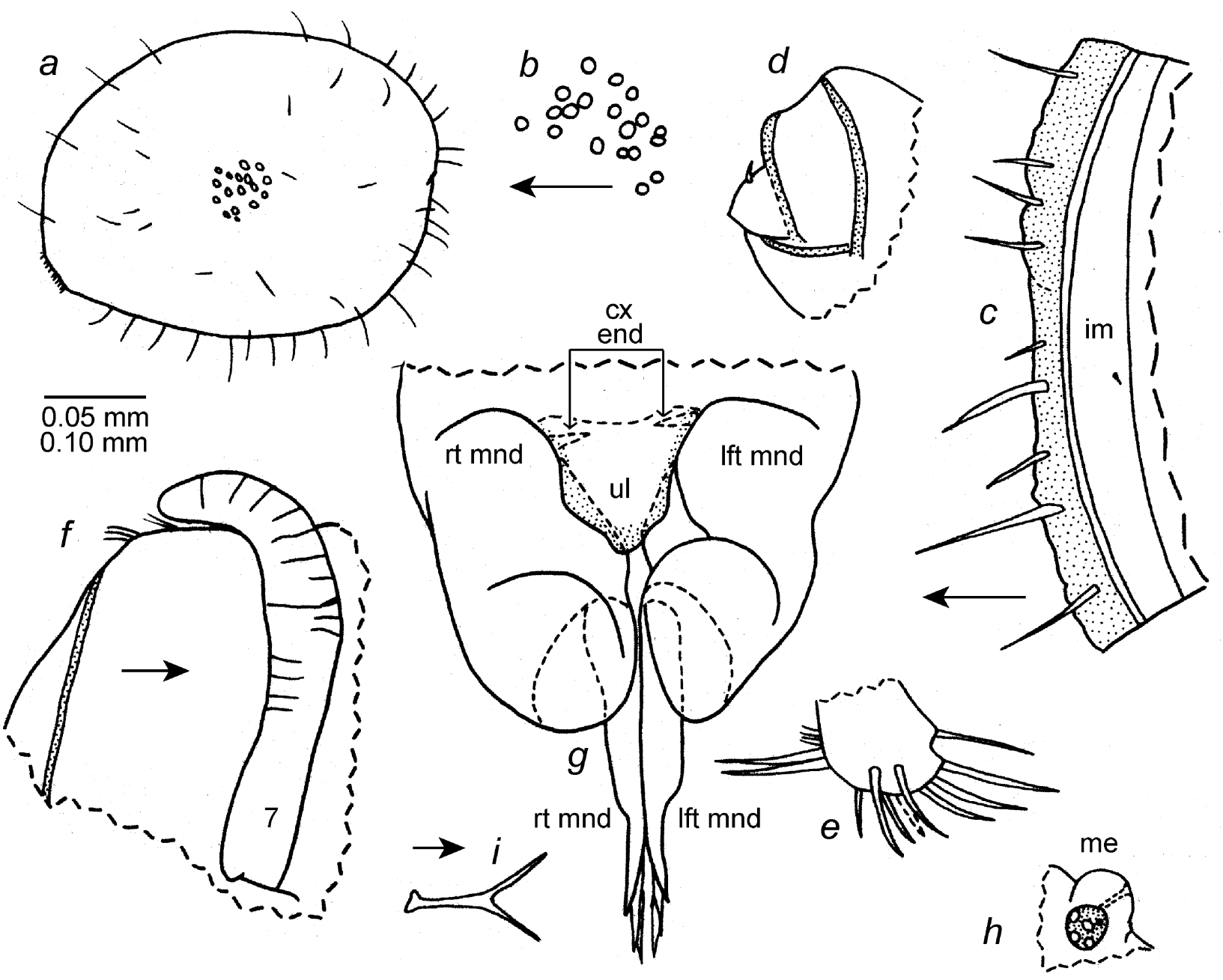

FIGURE 75. Eurypylus hapax Kornicker \& Iliffe 2000, USNM 1021485, instar III female: $a$, complete specimen from right side, length $0.75 \mathrm{~mm} ; b$, central adductor muscles left valve, ov; $c$, anterior right valve, iv; $d$, endopod right second antenna, mv; $e$, left sixth limb, mv; $f$, posterior of body from right side showing seventh limb and part of girdle; $g$, ventral view of anterior of body showing furca, upper lip (stippled) and outlines of mandibles ( 2 dashed triangles at dorsal end of upper lip represent coxa endites of mandibles); $h$, medial and right lateral eyes; $i$, right Y-sclerite. Scale equals $0.10 \mathrm{~mm}$ $(b, c, h)$ and $0.05 \mathrm{~mm}(d-g)$.

Y-Sclerite (Fig. 75i): Similar to that of instar II female except posterior end with small flare.

Gut content: Unidentified amber-colored particulate matter.

Supplementary description of instar IV female. Carapace size (length, height in $\mathrm{mm}$ ): USNM 1021487, 0.90, 0.71.

Comparisons. E. hapax and E. concentricostatus (Hartmann 1974) are the only species known in the genus with a furca without secondary claws and with five claws on each lamella (Kornicker \& Iliffe 2000). The carapace of E. hapax is without the concentric rib present on E. concentricostatus.

Discussion. The instar IV male and female of this species have been described (Kornicker \& Iliffe 2000:45; Kornicker et al. 2002:64). Instars II (female) and III (female) are described herein, and the carapace size is given for an instar IV female. All specimens are identified as females, mainly because the seventh limbs of all are fairly well developed, and also the endopods of the second antennae consist of single segments. Adults of the species are unknown. 


\section{Junctichela Kornicker \& Caraion 1978}

Type species. Junctichela margalefi Kornicker \& Caraion 1978.

Composition and distribution. Crab Cay Cravasse, Crab Cay, Great Bahama Bank. Also known from shelf off Mauritania, and questionably from Madagascar and Sri Lanka (Kornicker et al. 2002: 67).

\section{Junctichela pax Kornicker et al. 2002}

Junctichela pax Kornicker et al. 2002: 67, figs. 48-58.

Holotype. USNM 194587, adult female on slide and in alcohol.

Type locality. Crab Cay Crevasse, Crab Cay, Great Bahama Bank.

Material. USNM 1021488, 1 instar II, sex unknown (specimen partly crushed) in alcohol, from Crab Cay Crevasse, depth $41 \mathrm{~m}$.

Distribution. The species is known from only Crab Cay Crevasse, depth 35-41 m.

Supplementary description of instar II (sex unknown). Carapace size (length, height in mm): USNM 1021488 , left valve, $0.62,0.48$.

Remarks. The species was collected in Crab Cay Crevasse in 1995 (Kornicker et al. 2002: 67). It continued to be present in the crevasse in 2000 showing that environmental stresses during that period have not decimated the species.

\section{Subfamily Dantyinae Kornicker \& Cohen 1978}

\section{Dantya Kornicker \& Cohen 1978}

Type species. Dantya magnifica Kornicker \& Cohen 1978.

Composition and distribution. The genus includes eight species: one species from Carrie Bow Cay, Belize (D. magnifica Kornicker \& Cohen 1978), four species from the western Indian Ocean (D. fossula Kornicker 1983, D. benthedi Kornicker 1983, D. piercei Kornicker 1983, D. dux Kornicker 1998 in Kornicker \& Thomassin 1998), one species from the Southwest Florida shelf (D. heardi Kornicker 1986), D. ferox Kornicker \& Iliffe 1989d from a sea cave on the island of Niue, central South Pacific, and D. tryx Kornicker 1994 from off Southeast Australia. A key to species of the genus is presented in Kornicker and Thomassin 1998. A juvenile collected herein on the Great Bahama Bank is left in open nomenclature as Dantya sp. A.

\section{Dantya sp. A}

Figs. 76, 77

Material. Great Bahama Bank, South Andros (Four Shark Blue Hole), Sta 99-050: USNM 1021489, 1 early instar.

Distribution. South Andros (Four Shark Blue Hole).

Description of early instar (Figs. 76, 77). Carapace elongate with ventral edge of rostrum forming rightangle with anterior margin of valve ventral to rostrum; projecting caudal process with flat tip; straight hinge line visible through valve (dashed in Fig. 77a). 
Ornamentation (Fig. 76, 77a,c): Surface with scallop-like reticulations with digitate margins; numerous minute pustules present within reticulations; surface with indistinct horizontal ribs; posterior dorsal corner of valve with prominent node; valve surface and margins with single bristles.

Central adductor muscle attachments (Figs. 76, 77a,b): With about 30 small round attachments.

Carapace size (length, height in mm): USNM 1021489: 0.76, 0.43.

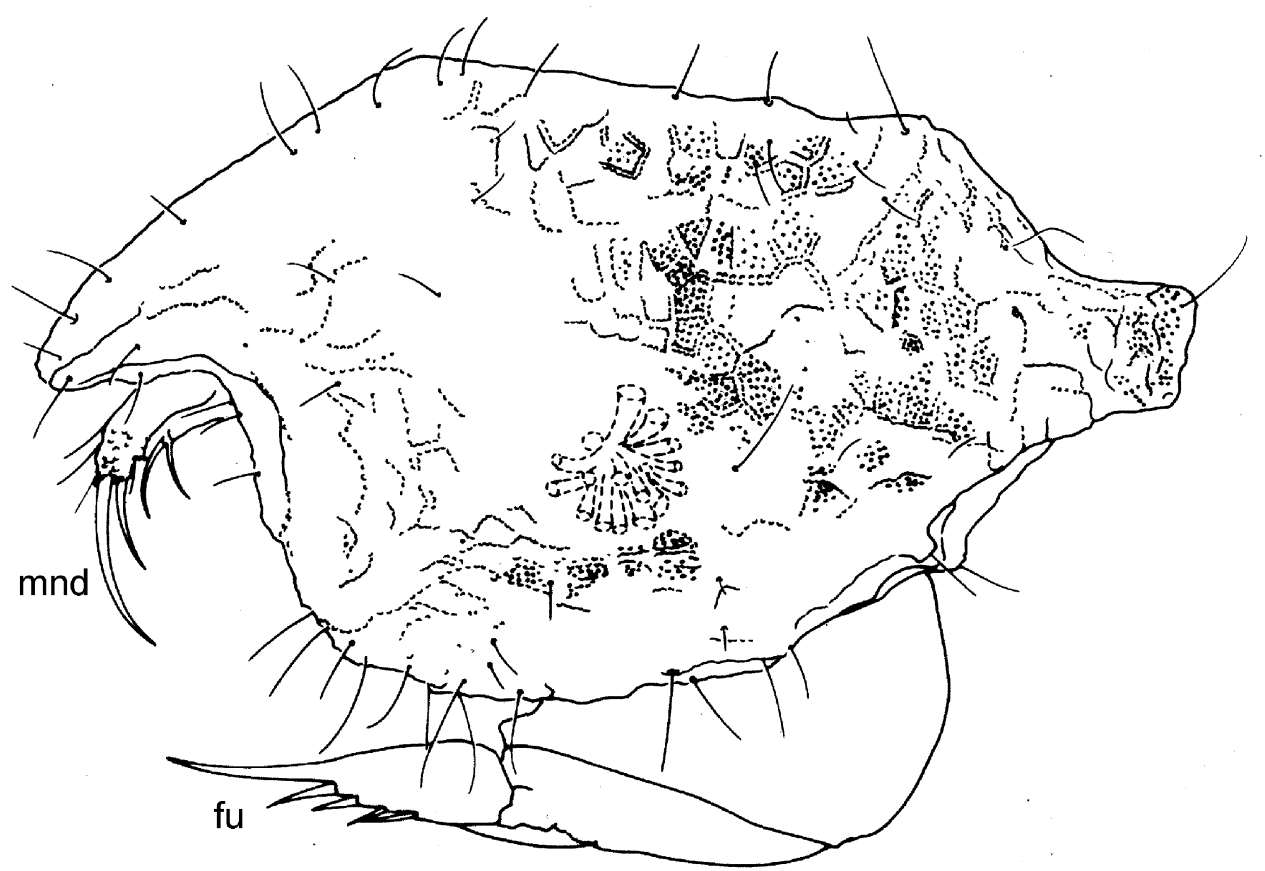

FIGURE 76. Dantya sp. A, USNM 1021489, early instar, complete specimen from left side, length $0.76 \mathrm{~mm}$.
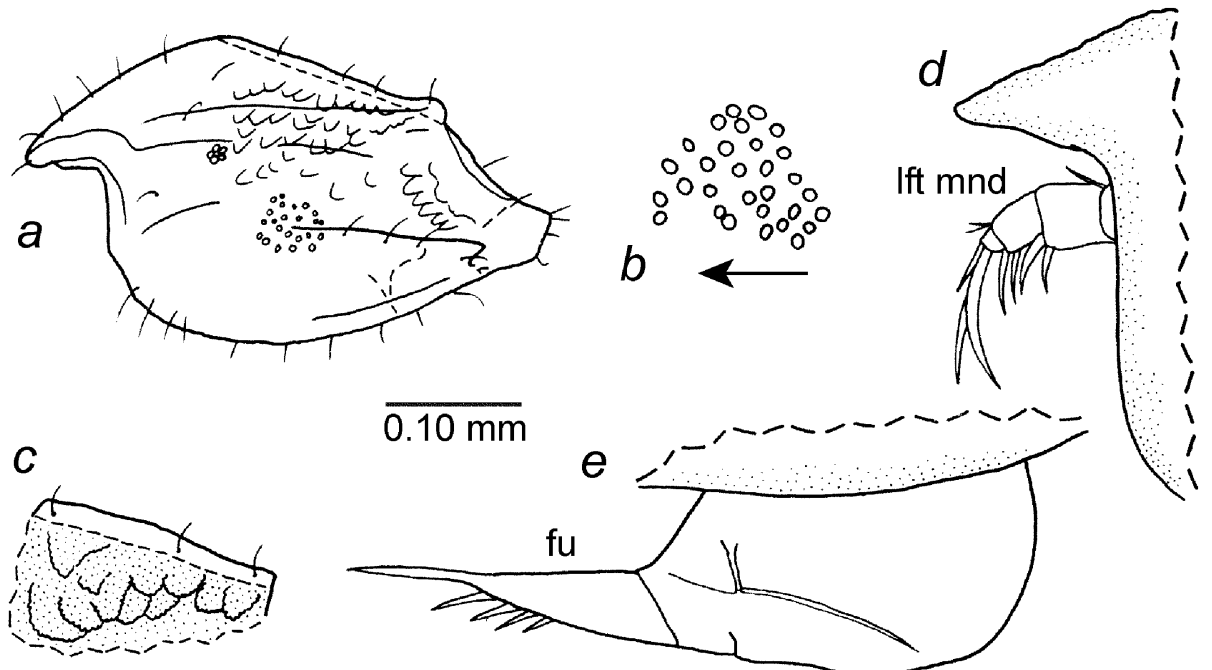

FIGURE 77. Dantya sp. A, USNM 1021489, early instar: $a$, complete specimen from left side, showing lateral eye, length $0.76 \mathrm{~mm}$, height, $0.43 \mathrm{~mm} ; b$, detail of central adductor muscle scars from " $a$ "; $c$, detail of upper edge of left valve from " $a$ "; $d$, anterior of shell showing projecting left mandible; $e$, left lamella of furca projecting from shell. Scale equals $0.10 \mathrm{~mm}(b-e)$.

Mandible (Fig. 77d): Not examined in detail, but in general similar to that of holotype of Dantya magnifica Kornicker \& Cohen 1978. 
Furca (Fig. 77e): Each lamella with 5 claws; claw 1 fused to lamella, other claws separated from lamella by suture. Claws decrease in length and width along lamella.

Remarks. This early instar was left intact. The valve of the early instar differs somewhat from the holotype of Dantya magnifica illustrated by Kornicker \& Cohen (1978: Fig.1) in lacking nodes, and the fourth furcal claw is not broader than the third as it is in the holotype (Kornicker \& Cohen 1978: Fig. 4d), but these differences could be attributed to the immaturity of the specimen. The carapace of Dantya heardi Kornicker 1986, does not have the posterodorsal node present on Dantya sp. A, but it is possible that Dantya sp. A could be referred to $D$. heardi when adults are known. This is the first report of a member of the genus Dantya in the Bahamas.

\section{Superfamily Cylindroleberidoidea Müller 1906}

\section{Family Cylindroleberididae Müller 1906}

Subfamily Cylindroleberidinae Müller 1906

\section{Diasterope Kornicker 1975}

Type species. Diasterope pilosa Poulsen 1965; subsequent designation by Kornicker (1975: 388).

Composition and distribution. See Kornicker \& Iliffe (2000: 61).

\section{Diasterope procax Kornicker \& Iliffe 2000}

Holotype. USNM 194460, adult female on slide and in alcohol.

Type locality. Sta 95-006, transect BB, Exuma Sound, Great Bahama Bank, depth 88 m.

Material. Holotype. No specimens were in the present collections.

Remarks. Kornicker \& Iliffe (2000: 61) did not completely describe the maxilla and fifth limb of the adult female holotype. The number of bristles on the various parts of those limbs are given herein. The total number of bristles on other appendages given below are from descriptions by Kornicker \& Iliffe (2000: 6172).

Correction. In Kornicker \& Iliffe (2000: 72: Fig. 44) the legend incorrectly stated Diasterope prolixa instead of Diasterope procax.

Supplementary description of adult female. Maxilla: Baleen comb with 109 bristles. Endites with 7 bristles. Basis with 6 bristles. endopod with 3 bristles. Total bristles 125 .

Fifth limb: Epipod with 64 bristles. Anterior vertical margin of protopod with 31 bristles. Ventral margin of comb with 36-39 bristles. Lateral side of comb with 8 bristles. Total bristles 139-142.

Number of bristles on limbs: 1st antenna 21, 2nd antenna 21, mandible 44, maxilla 125, 5th limb 139-142, sixth limb 25, seventh limb 11, furca 10. Total bristles on each side 396-399.

\section{Synasterope Kornicker 1975}

Type species. Synasterope implumis Poulsen 1965; subsequent designation by Kornicker (1975: 440).

Composition and distribution. See Kornicker \& Iliffe (2000: 72). 
Fig. 78

Synasterope browni Kornicker \& Iliffe 2000: 72-77, figs. 39-44.—Kornicker et al. 2002: 85-95, figs. 61-68.

Holotype. USNM 194469, adult female on slide and in alcohol.

Type locality. Exuma Sound, depth $96 \mathrm{~m}$.

Material. Great Bahama Bank, Bottomly's Blue Hole, Sta 99-065: USNM 1021490, undissected adult male in alcohol. Mystery Cave, Sta 00-019, 2 specimens: USNM 1021491, partly dissected instar III in alcohol; USNM 1021492, undissected instar I in alcohol,

Distribution. Exuma Sound, depth 96 m; Four Shark Cave, South Andros Island, depth 27-33 m. Bottomly's Blue Hole, Stocking Island, Great Exuma, Exuma Cays, depth 27-29 m. Mystery Cave, Stocking Island, depth $52 \mathrm{~m}$.

Supplementary description of adult male (Fig. 78). Carapace size (length, height in mm): USNM $1021490,0.74,0.45$.

Remarks. The species was collected in Mystery Cave in 1997 (Kornicker et al. 2002: 85). Its presence in the cave in 1999 shows that it continues to live there and was not affected by environmental stresses during that period.

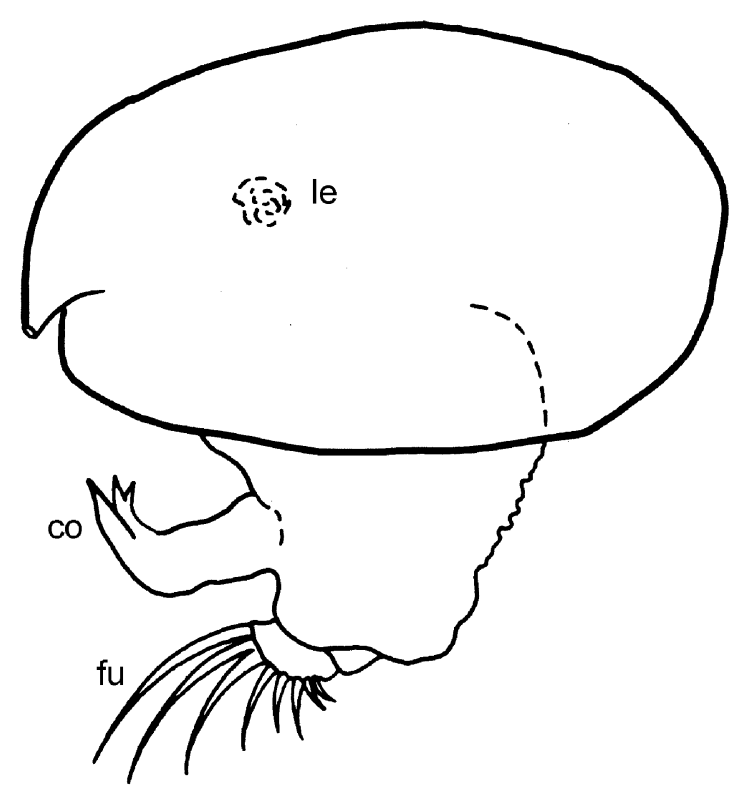

FIGURE 78. Synasterope browni Kornicker \& Iliffe 2000, USNM 1021490, adult male, complete specimen from left side, length $0.74 \mathrm{~mm}$.

\section{Synasterope matrix, new species}

Figs. 79-81

Etymology. From the Latin matrix (mother, womb, source).

Holotype. USNM 1021493, adult male on slide and in alcohol.

Type locality. Sta 99-065, Bottomly's Blue Hole, Stocking Island, Great Exuma, Exuma Cays, Great Bahama Bank, depth 27-29 m.

Paratypes. None.

Distribution. Type locality. 
Description of adult male (Figs. 79-81). Carapace elongate with evenly rounded anterior and posterior margins (Fig. 79a).

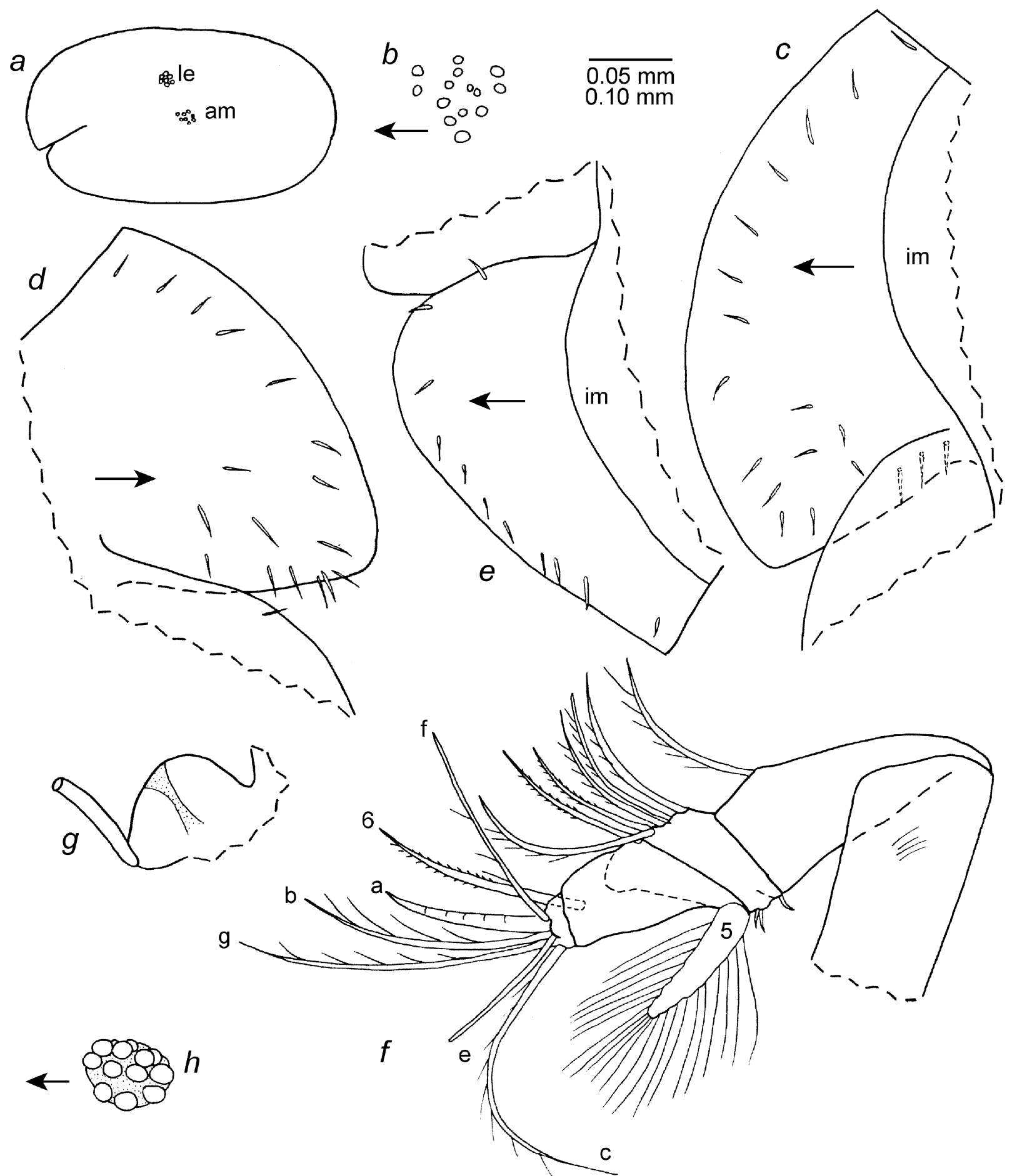

FIGURE 79. Synasterope matrix, new species, holotype1021493, adult male: $a$, complete specimen from left side, length $0.87 \mathrm{~mm} ; b$, central adductor muscle projecting from left side of body with left valve remove; $c, d$, anterior of right and left valves, iv; $e$, anteroventral part right valve, iv; $f$, left first antenna drawn on body, lv; $g$, medial eye and proximal part of Bellonci Organ; $h$, left lateral eye. Scale equals $0.10 \mathrm{~mm}(b)$ and $0.05 \mathrm{~mm}(c-h)$.

Ornamentation: Vertical row of few long hairs near posterior end of valve.

Infold: Obscure on slide, especially posterior end of valves. Infold of rostrum with about 19 bristles (Fig. $79 c, d$ ). Anteroventral infold with about 11 bristles (Fig. 79e). Ventral infold with about 7 bristles. Flap-like 
posterior bristles present but number obscured. Few small bristles present between flap-like bristles and posterior margin of valve. No processes observed between posteroventral list and valve margin.

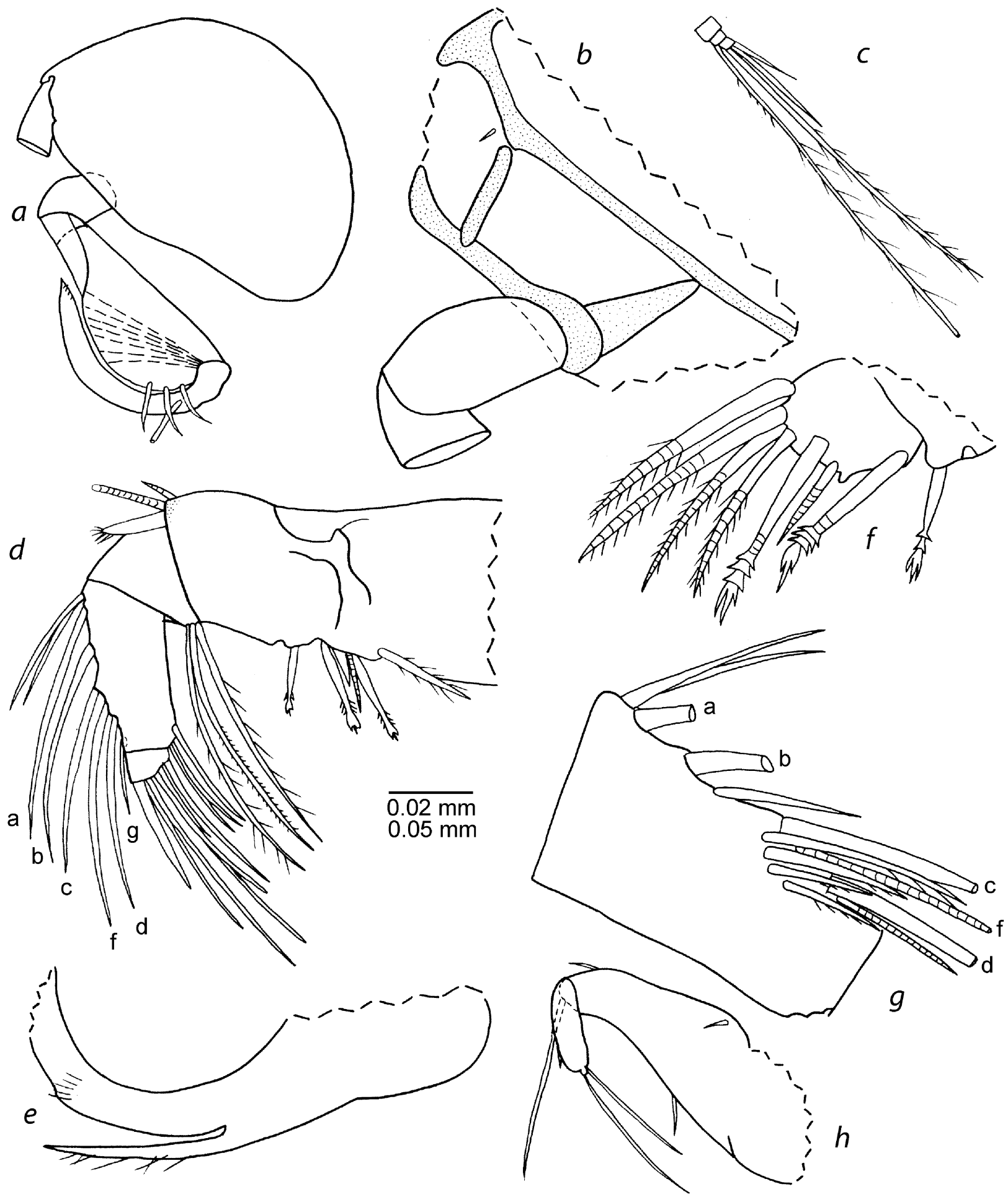

FIGURE 80. Synasterope matrix, new species, holotype USNM 1021493, adult male: $a$, protopod and endopod left second antenna, lv; $b$, distal protopod and endopod left second antenna, mv; $c$, distal articles exopod left second antenna, lv; $d$, left maxilla drawn on body, lv; $e$, coxa endite right maxilla, lv; $f$, basis endite and proximal ventral corner of basis of left mandible, mv; $g$, dorsal bristles of second endopod article of left mandible, mv; $h$, right maxilla, mv (nabs). Scale equals $0.05 \mathrm{~mm}(a, c, d, h)$ and $0.02 \mathrm{~mm}(b, e-g)$. 
Central adductor muscle attachments (Fig. 79a,b): Consisting of about 14 ovoid attachments (Fig. 79b).

Carapace size (length, height in mm): USNM 1021493, 0.87, 0.48.

First antenna (Fig.79f): 1st segment with indistinct lateral hairs. 2nd segment with spinous dorsal bristle. 3rd and 4th segments fused; 3rd segment with small bristle on short ventral margin and 5 spinous dorsal bristles ( 3 single with long spines, 2 paired (lateral with long spines, medial with short spines)) on long dorsal margin. 4th segment with long terminal dorsal bristle and 2 small ventral bristles. 5th segment fused to 6th, with stout ventral bristle with about 40 (not all shown) long filaments (terminal 3 filaments stouter than others; bristle of right limb broken off near base). 6th segment long, with long medial bristle with short spines. 7th segment: a-bristle claw-like, bare; b-bristle with 4 long dorsal filaments; long c-bristle with about 8 filaments. 8th segment: d-bristle absent; bare e-bristle about $1 / 2$ length of c-bristle; f-bristle bent dorsally, with 3 marginal filaments; g-bristle long with about 5 filaments.

Second antenna: Protopod with small distal medial bristle (Fig. 80b). Endopod with 3 segments (Fig. 80a): segment 1 short bare; segment 2 broad distally, with 3 short bare dorsal bristles; segment 3 reflexed on 2nd segment, long and narrow, with bare proximal bristle and serrations at tip. Exopod: 2nd segment only slightly longer than 3rd; bristle of 2nd segment reaching 9th segment, bare; bristles of segments 3-6 with slender ventral spines and distal natatory hairs; bristles of segments 7 and 8 with natatory hairs; 9 th segment with 3 bristles (ventral bristle about $1 / 2$ length of bristle of 8th segment; 2 dorsal bristles short bare) (Fig. 80c). Segments 2-8 with indistinct minute spines along distal dorsal edge; stout basal spines absent.

Mandible (Fig. 80d-g): Details of coxa endite obscured (Fig. 80e). Basis endite with 4 spinous end bristles, glandular peg, 1 fairly long dwarf bristle, and 2 triaenid bristles with 3 pairs of spines proximal to terminal pair (Fig. 80f). Basis: ventral margin with proximal U-shaped boss and trianid bristle (with 2 pairs of marginal spines proximal to terminal pair) proximal to boss; dorsal margin with 2 terminal bristles (1 long, 1 short). Exopod longer than one-half dorsal margin of 1st segment of endopod, with hirsute tip and 2 small subterminal bristles (Fig. 80d). Endopod: 1st segment with 3 long ventral bristles ( 2 with long spines to tip, 1 with short spines). 2nd segment: ventral margin with 3 terminal bristles with short spines; dorsal margin with a-, b, c-, d-, f- and g-bristles (c-bristle only slightly broader than bases of b- and d-bristles), and 2 short bristles proximal to a-bristle; medial surface of segment with 1 short bare bristle between $\mathrm{b}$ - and c-bristles (bristle very close to ventral margin), and 4 spinous cleaning bristles near base of c-bristle. 3rd segment with straight claw and 6 bristles.

Maxilla (Fig. 80h): Epipod and endites fragmented during dissection. Basis: medial surface with 1 proximal bristle near dorsal margin; dorsal margin with short distal bristle; ventral margin with 1 backward-pointing bristle near midlength; ventral margin with long terminal bristle. Endopod: 1st segment with short alphabristle and long beta-bristle. 2nd segment with terminal bristle reaching past beta-bristle.

Fifth limb (Fig. 81a): Comb: lateral side with stout spinous exopodial bristle; 1 short slender spine just ventral to base of exopodial bristle and 3 short bristles closer to ventral margin.

Sixth limb (Fig. 81b,c): Small medial bristle near proximal anterior corner. Anterior margin with slender spinous bristle at upper and lower endites. Skirt: narrow lateral flap with slender hirsute anterior bristle; anterior end with 3 or 4 ventral bristles; ventral margin with 5 or 6 spinous bristles near midlength; posteroventral corner with short spinous bristle; margin of skirt hirsute.

Seventh limb (Fig. 81d): Proximal group with 6 bristles (3 on each side), each with 2 to 4 bells; distal group with 5 or 6 bristles ( 2 or 3 on each side), each with 3 or 4 bells. Terminus misshapen, with opposing combs. Illustrated left limb with 3 short proximal bristles; these bristles long on right limb.

Furca (Fig. 81e): Each lamella with 9 claws; posterior 4 claws bristle-like with rings (3 bent backward) Claws 1-5 with teeth along posterior edge, some longer than others; claw 1 with distal anterior spines; right lamella anterior to left by width of base of claw 1 . 

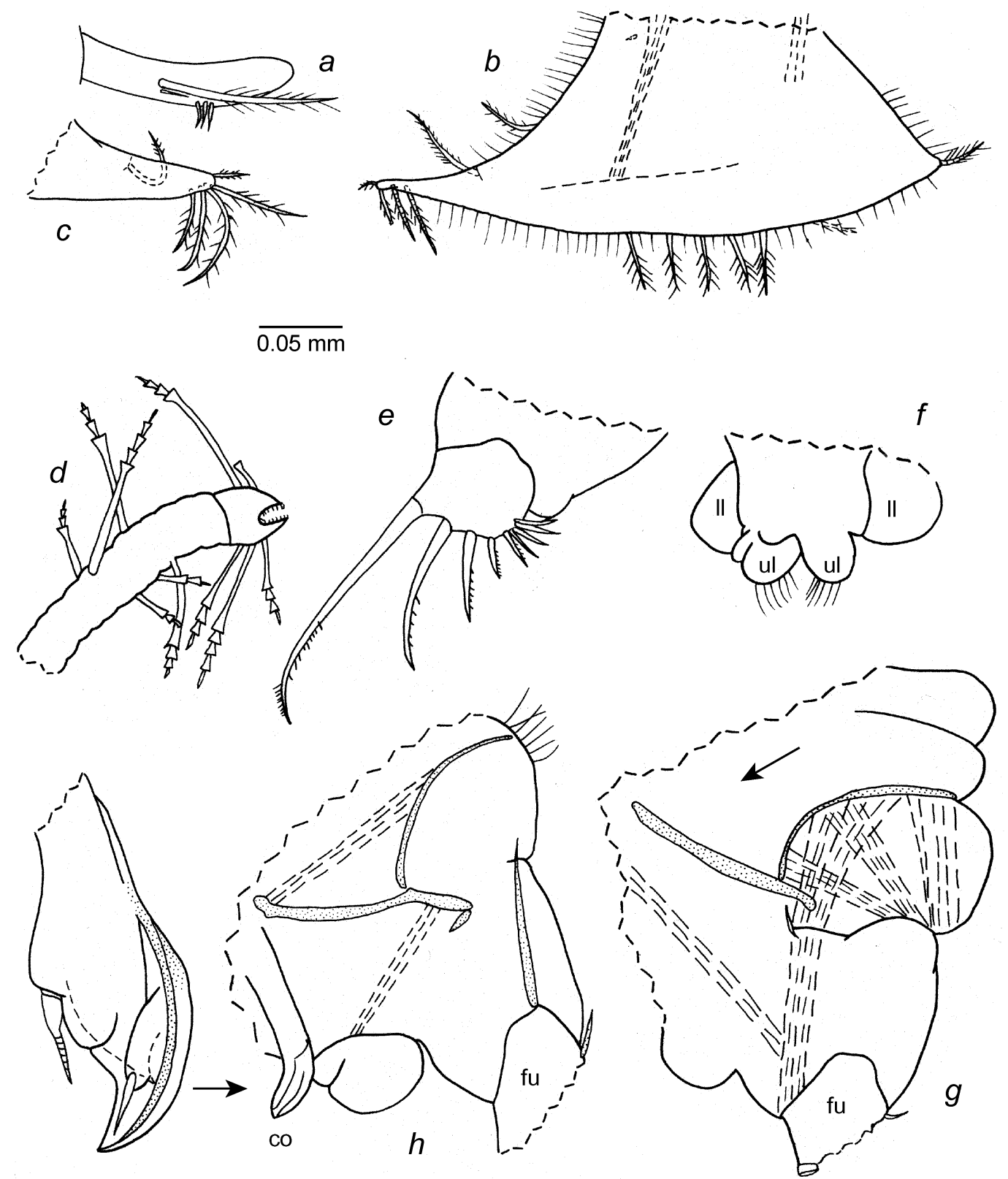

FIGURE 81. Synasterope matrix, new species, holotype USNM 1021493, adult male: $a$, comb of right fifth limb, lv; $b$, left sixth limb, lv; $c$, anterior tip right sixth limb, lv; $d$, left seventh limb drawn on body, lv; $e$, left lamella of furca; $f$, anterior view of upper and lower lips drawn on body; $g, h$, posterior of body from left side. Scale equals $0.05 \mathrm{~mm}(a-h)$.

Bellonci Organ: Elongate (Fig. 79g) (tip missing on illustrated organ).

Eyes: Lateral eye with 12 ommatidia and light brown pigment between them (Fig. 79a,h). Medial eye slightly larger than lateral eye (Fig. 79g).

Lips: Lower and upper lips hirsute, oval in anterior view (Fig. 81f).

Genitalia (Fig. 81h): Copulatory organ drawn back on body, with sclerotized hook-like process and 2 bristles.

Posterior of body (Fig. 81h): Posterodorsal corner with hair-like spines.

Gills (Fig. $81 \mathrm{~g}$ ): With 7 or 8 gills on each side (2 shown).

Y-Sclerite (Fig. $81 g, h$ ): Without ventral branch.

Gut content: Unrecognized particulate matter.

Comparisons. The new species S. matrix was collected in the same sample as Synasterope browni. The 
sensory bristle of the first antenna of the adult male of $S$. matrix bears about 40 filaments compared to over 100 for S. browni. The dorsal margin of the basis of the mandible of the adult male of $S$. matrix bears one long and one short terminal bristles, compared to two long bristles on $S$. browni. The sixth limb of $S$. matrix has more bristles along the ventral margin than on S. setisparsa (Kornicker 1958) and fewer bristles than the eight species in the "Key to Selected Species of Synasterope" from the Gulf of Mexico and west Atlantic presented in Kornicker $(1986: 68,69)$.

\section{Synasterope species indeterminate}

Material. Sta 99-055, Double Drop Blue Hole, South Andros: USNM 1021494, undissected instar III female in alcohol, length $0.60 \mathrm{~mm}$, height $0.38 \mathrm{~mm}$. Sta 99-065, Bottomly's Blue Hole, Stocking Island: USNM 1021495, 1 dissected ovigerous female on slide and in alcohol, length $0.91 \mathrm{~mm}$, height $0.57 \mathrm{~mm}$; USNM 1021508, undissected instar III (sex unknown) in alcohol, length $0.54 \mathrm{~mm}$, height $0.41 \mathrm{~mm}$. The specimens were unsuitable for identifying at the species level.

\section{Results}

In this paper, 33 cave dwelling species from 15 genera within the ostracode Subclass Myodocopa are discussed or described. A total of 15 stygobitic species, including two new, from Danielopolina, Spelaeoecia and Deeveya in the Suborder Halocypridina inhabit inland, anchialine caves. Of these three genera, Danielopolina, with 11 anchialine species, is the most widely distributed, inhabiting caves, mostly on islands, on opposite sides of the Atlantic and Pacific Oceans. Spelaeoecia, with 11 species, is intermediate in distribution, being found in Bermuda and the Caribbean, while Deeveya, with eight species, has the most limited distribution, occurring only in the Bahamian archipelago.

The Bahamas appears to be the center of biodiversity for anchialine halocyprids, being inhabited by four species of Danielopolina, six species of Spelaeoecia and all eight species of Deeveya. A comparable situation exists pertaining to the known biogeography of the crustacean Class Remipedia, which occurs in many of the same caves and geographic locations as Danielopolina, e.g., the Bahamas, Yucatan Peninsula, Cuba, Canary Islands and Western Australia, and has the majority of its described species, 13 out of a total of 17, inhabiting caves in the Bahamas (Koenemann et al. 2007).

Uncertainty exists as to whether the present day distribution of relict anchialine taxa such as Danielopolina results from vicariance (earth history) or dispersal (biological) events (Humphreys \& Danielopol 2005). Kornicker and Iliffe (1989) and others have argued for a Tethyan origin of Danielopolina in the Mesozoic with subsequent dispersal by plate tectonics. The recent discovery of Danielopolina on Christmas Island, a limestone-capped, volcanic seamount in the Indian Ocean, has fueled debate concerning the potential for oceanic dispersal of anchialine taxa to such otherwise isolated locations (Humphreys \& Danielopol 2005).

The relative breadth of the distributions of three anchialine genera suggests a possible order in the evolution and dispersal of these three genera. Danielopolina, which occurs on opposite sides of the Earth, would seem to have the earliest origins. Spelaeoecia, which occurs only in the Western Atlantic, would be intermediate in age, while Deeveya, which is restricted to just the Bahamas, would have the most recent origins of the three.

The Bahamas archipelago consists of two very large shallow-water platforms, the Great Bahama Bank with the islands of Andros, New Providence, Eleuthera, the Exumas, Cat and Long, and the Little Bahama Bank containing the islands of Grand Bahama and Abaco, separated by deep-water channels. Other islands occur on separate but smaller platforms, including the Turks and Caicos Islands, which are geographically and 
geologically an extension of the archipelago. Within the Bahamas, Danielopolina has so far been found only on the Great Bahama Bank (Andros, Eleuthera and the Exumas). Spelaeoecia occurs on both the Little Bahama Bank (Grand Bahama) and the Great Bahama Bank (Andros, Exumas and Long Island), in addition to San Salvador. Deeveya extends from the Little Bahama Bank (Grand Bahama and Abaco) through the Great Bahama Bank (Andros, Exumas and Eleuthera) to the Caicos Bank (Providenciales). We can compare these halocyprid distributions to the three families that make up Remipedia (Koenemann et al. 2007). The Family Godzilliidae is found only in the Bahamas and occurs on the Little Bahama Bank (Grand Bahama and Abaco), the Great Bahama Bank (Exumas) and the Caicos Bank (North Caicos). The Micropacteridae with one species is found exclusively on the Caicos Bank (Providenciales). The Speleonectidae, which has the largest worldwide distribution (Cuba, Yucatan, the Dominican Republic, the Canary Islands and Western Australia), inhabits the Little Bahama Bank (Grand Bahama and Abaco), the Great Bahama Bank (Exumas and Cat), San Salvador, and the Caicos Bank (Providenciales and North Caicos). While both the Speleonectidae and Danielopolina have an extremely wide distribution on a global scale, it is unclear why the former occurs in a number of locations on separate banks throughout the Bahamas, while the latter inhabits just two islands in the Bahamas from the same platform.

Another interesting parallel between halocyprid ostracods and remipedes is the presence of multiple genera and species within a single cave. For example, Sanctuary Blue Hole on South Andros contains species from all three genera of halocyprids, i.e., Danielopolina palmeri, Deeveya bransoni and Spelaeoecia styx. Sagittarius and Virgo Blue Holes on Sweeting's Cay both contain species from two genera: Spelaeoecia sagax and Deeveya medix. Basil Minn's Blue Hole on Great Exuma Island is likewise inhabited by Danielopolina exuma and Deeveya medix. Mermaid's Lair on Grand Bahama is inhabited by two species from the same genus: Spelaeoecia hox and Spelaeoecia parkeri. From the Remipedia, Dan's Cave on Abaco includes four genera: Godzilliognomus frondosus Yager 1989, Pleomothra apletocheles Yager 1989, Cryptocorynetes haptodiscus Yager 1987 and Speleonectes benjamini Yager 1987, while three new species of Speleonectes, S. minnsi, S. parabenjamini and S. tanumekes, were described from Basil Minn's Blue Hole by Koenemann et al. (2003).

With the exception of one species of Danielopolina from deep waters of the South Atlantic, all other species of Danielopolina, Spelaeoecia and Deeveya have been so far exclusively found in inland, anchialine caves. The discovery of Deeveya inhabiting deeper, hydrologically isolated waters in ocean blue holes, which are otherwise comparable to classical anchialine environments, has raised questions concerning the geographic limits to the anchialine habitat and its supposed reliance on terrestrial inputs. The use of helium-containing breathing mixtures for deep diving and closed circuit rebreathers permitting much longer dive times should significantly expand the depth and distance limits of cave divers and thus enable cave diving scientists to investigate more effectively the biodiversity and ecology of both marine and anchialine caves.

\section{Disposition of specimens}

All specimens have been deposited in the collections of the former United States National Museum (USNM), now the National Museum of Natural History, Smithsonian Institution, and have been assigned USNM numbers.

\section{Acknowledgements}

Biological collections from caves on Andros and Grand Bahama Islands were carried out during a filming trip sponsored by NDR Northern German Public TV and the Rob Palmer Blue Holes Foundation. We thank 
Stephanie Schwabe, Dan Malone, and Rob Parker for assistance with cave diving collections. Logistical assistance was provided by the crew of the Ocean Explorer and the film crew led by Gerhard Stueting. Specimens were obtained under the terms of Marine Resource Collection Permits issued by the Bahamas Department of Fisheries to Brian Kakuk and Thomas Iliffe. This paper is a contribution of the Exploration and Conservation of Anchialine Faunas Project of the International Biodiversity Observation Year (IBOY) 2001-2002. Penciled camera lucida taxonomic illustrations drawn by Kornicker were inked by Mary Ellen Didion-Carsley. Graphs and rendered shaded drawings of carapaces were prepared by Molly K. Ryan, Smithsonian Institution. This research was supported by grants from the Caribbean Marine Research Center (CMRC) of the National Oceanic and Atmospheric Administration (NOAA) and from the National Science Foundation (NSF \#9870219). We thank Jill Yager for some of the specimens collected in caves in the Bahamas. We thank Ivana Karanovic, ShinIchi Hiruta, and Andrew R. Parker for reviewing the manuscript. Editor Rosalie F. Maddocks made many suggestions that greatly improved the paper.

\section{Literature cited}

Alvarez, F., Iliffe, T.M. \& Villalobos, J.L. (2006) Macromaxillocarididae, a new family of stenopodidean shrimp from an anchialine cave in the Bahamas, with the description of Macromaxillocaris bahamaensis, n. gen., n. sp. Journal of Crustacean Biology, 26(3), 366-378.

Angel, M.V. (1993) Marine Planktonic Ostracods. Synopses of the British Fauna (New Series), Linnean Society of London/Estuarine \& Brackish Water Society, 48: 240 pages.

Angel, M. \& Iliffe, T. (1987) Spelaeocia bermudensis new genus, new species, a halocyprid ostracod from marine caves in Bermuda. Journal of Crustacean Biology, 7, 541-553.

Baird, W. (1850) The Natural History of the British Entomostraca. Printed for the Ray Society, London, 364 pp.

Botosaneanu, L. \& Iliffe, T.M. (2003) A new genus of stygobitic/troglomorphic cirolanid (Isopoda: Cirolanidae) from a "blue hole" cave in the Bahamas. Bulletin de L'Institut Royal des Sciences Naturelles de Belgique, Biologie, 73, 8190.

Bowen, C. (1999) In search of new life. Advanced Diver Magazine, 4, 25-28.

Bowman, T.E. \& Iliffe, T.M. (1983) Bermudalana aruboides, a new genus and species of troglobitic Isopoda (Cirolanidae) from marine caves on Bermuda. Proceedings of the Biological Society of Washington, 96, 291-300.

Boxshall, G.A. \& Iliffe, T.M. (1986) New cave-dwelling misophrioids (Crustacea: Copepoda) from Bermuda. Sarsia, 71, 55-64.

Boxshall, G.A. \& Iliffe, T.M. (1987) Three new genera and five new species of misophrioid copepods (Crustacea) from anchialine caves on Indo-West Pacific and North Atlantic Islands. Zoological Journal of the Linnean Society, 91, 223-252.

Bozanic, J.E. (2002) Mastering Rebreathers. Best Publishing Co., Flagstaff, AZ, 548 pp.

Brady, G. (1869) Entomostracés. In: de Folin, A. and Périer, L. (Eds.), Les Fonds de la Mer, 1 (supplement), pp. 138141.

Brady, G. \& Norman, A. (1896) A monograph of the marine and fresh water Ostracoda of the north Atlantic and of northwestern Europe. The Scientific Transactions of the Royal Dublin Society, 2(5), 621-784.

Chavtur, V.G. (1979) [New Data on Ostracodes of the Polycopidae Family (Ostracoda-Cladocopa) for Eastern Seas.] In: Investigations of Pelagic and Bottom Organisms from the Far-Eastern Seas. Transactions of the Institute of Marine Biology, Far East Science Center, Academy of Sciences of the U.S.S.R. (Vladivostok), pp. 91-105. [In Russian; translated by Dr. Ervin G. Otvos.]

Chavtur, V.G. (1981) [On the Systematic Position of the Modern Ostracoda in the Family Polycopidae (Ostracoda, Cladocopinae).] Trudy Institute Okeanologiia, 115, 53-60. [In Russian; translated by Dr. Ervin G. Otvos.]

Chavtur, V.G. (1983) Ostracodes (Myodocopina, Cladocopina) of Temperate and Cold Waters of the Northern Hemisphere. Academy of Sciences of the USSR, Far-Eastern Science Center, Institute of Marine Biology, Vladivostok, $132 \mathrm{pp}$.

Chavtur, V.G. (1984) Cypridinidae of the Continental Shelves of Southeastern North America, the Northern Gulf of Mexico, and the West Indies (Ostracoda: Myodocopina), Smithsonian Contributions to Zoology, 401, $37 \mathrm{pp}$.

Chavtur, V.G. (1985) [The Composition and Some Features of the Distribution of the Benthic Ostracods (Myodocopida) at Moneron Island. In: The Shelf Benthos of Moneron Island. Academy of Sciences of the USSR, Far-East Science Center, Institute of Marine Biology, Vladivostok, pp. 55-63.] [In Russian]

Cohen, A. (1983) Rearing and postembryonic development of the myodocopid ostracode Skogsbergia lerneri from coral 
reefs of Belize and the Bahamas. Journal of Crustacean Biology, 3(2), 235-256.

Cohen, A. \& Kornicker, L.S. (1975) Taxonomic indexes to Ostracoda (suborder Myodocopina) in Skogsberg (1920) and Poulsen (1962, 1965). Smithsonian Contributions to Zoology, 204, 29 pp.

Cohen, A. \& Kornicker, L.S. (1987) Catalog of the Rutidermatidae (Crustacea: Ostracoda). Smithsonian Contributions to Zoology, 449, 11 pp.

Cohen, D. \& Robins, C. (1970) A new ophidioid fish (genus Lucifuga) from a limestone sink, New Providence Island, Bahamas. Proceedings of the Biological Society of Washington, 88(11), 133-144.

Dana, J. (1853) Tribe III: Cyproidea = Ostracoda. In: Crustacea of United States Exploring Expedition during the Years 1838, 1839, 1840, 1841, 1842, under the Command of Charles Wilkes, U.S.N., with Atlas of 96 plates, 13(2), 12771304. Philadelphia: C. Sherman.

Danielopol, D. (1972) Sur la presence de Thaumatocypris orghidani n. sp. (Ostracoda, Myodocopida) dans une grotte de Cuba. Comptes Rendus Academie des Sciences, series D, 247, 1390-1393.

Danielopol, D, Baltanás A. \& Humphreys, W. (2000) Danielopolina kornickeri sp. n. (Ostracoda, Thaumatocypridoidea) from a western Australian anchialine cave: morphology and evolution. Zoologica Scripta, 29, 1-16.

Darby, D. (1965) Ecology and Taxonomy of Ostracoda in the Vicinity of Sapelo Island, Georgia. In: Kesling, R. (Ed.) Four Reports of Ostracod Investigations, Ann Arbor, University of Michigan, pp. 1-77.

De Filippi, F. (1853) Nouvelles espèces de poissons. Revue et Magasin de Zoologie pure et appliqué, Paris (Serie 2), 164-171.

Exley, S. (1994) Caverns Measureless to Man. Cave Books, St. Louis, 326 pp.

Fosshagen, A, Boxshall, G. \& Iliffe, T. (2001) The Epacteriscidae, a cave-living family of calanoid copepods. Sarsia, 86, $245-318$.

Fosshagen, A. \& Iliffe, T.M. (1985) Two new genera of Calanoida and a new order of Copepoda, Platycopioida, from marine caves on Bermuda. Sarsia, 70, 345-358.

Fosshagen, A. \& Iliffe, T.M. (2003) Three new genera of the Ridgewayiidae (Copepoda, Calanoida) from anchialine caves in the Bahamas. Sarsia, 88(1), 16-35.

Fosshagen, A, \& Iliffe, T. (2004) New epacteriscids (Copepoda, Calanoida) from anchialine caves in the Bahamas. Sarsia, 88, 16-35.

Hartmann, G. (1974) Zur Kenntnis des Eulitorals der afrikanischen Westküste zwischen Angola und Kap der Guten Hoffnung und der afrikanischen Ostküste von Südafrika und Moçambique unter besonderer Berücksichtigung der Polychaeten und Ostracoden. Die Ostracoden des Untersuchungsgebiets. Part 3. Mitteilungen aus dem Hamburgischen Zoologischen Museum und Institut, 69 (Ergaenzungsband), 229-520.

Hartmann, G. (1985) Danielopolina wilkensi n. sp. (Halocyprida, Thaumatocyprididae), ein neuer Ostracode aus einem marinen Lava-Tunnel auf Lanzarote (Kanarische Inseln). Mitteilungen aus dem Hamburgischen Zoologischen Museum und Institut, 82, 255-261.

Hiruta, S. (1983) Post-Embryonic Development of Myodocopid Ostracoda. In: Maddocks, R. (Ed.) Applications of Ostracoda, University of Houston, Houston, pp. 667-677.

Holthuis, L. (1973) Caridean shrimp found in land locked saltwater pools at Four Indo-West Pacific Localities (Sinai Peninsula, Funafuti Atoll, Maui and Hawaii Islands), with the description of one new genus and four new species. Zoologische Verhandelingen, 128, 1-48.

Humphreys, W. (2001) Westralian Superbasin: Is the Tethyan Connection Supported by the Extant Anchialine Community? In: Humphreys, W. \& Harvey, M. (Eds.) Records of the Western Australian Museum (Supplement), Subterranean Biology, Australia, 64, 234-235.

Humphreys, W.F. (2004) Diversity patterns in Australia. In: Culver, D.C. \& White, W.B. (Eds.), Encyclopedia of Caves. Elsevier Academic Press, Burlington, MA 64, 183-196

Humphreys, W.F. \& Danielopol, D.L. (2005) Danielopolina (Ostracoda, Thaumatocyprididae) on Christmas Island, Indian Ocean, a sea mount island. Crustaceana, 78, 1339-1352.

Humphreys, W.F., Poole, A., Eberhard, S.M. \& Warren, D. (1999) Effects of research diving on the physico-chemical profile of Bundera Sinkhole, an anchialine remipede habitat at Cape Range, Western Australia. Journal of the Royal Society of Western Australia, 82, 99-108

Iliffe, T.M. (1979) Bermuda's caves: A non-renewable resource. Environmental Conservation, 6, 181-186.

Iliffe, T.M. (2000) Anchialine Cave Ecology. In: Wilkens, H., Culver, D. \& Humphreys, W. (Eds.), Ecosystems of the World. 30. Subterranean Ecosystems xiv, Elsevier Science, Amsterdam, pp. 59-76.

Iliffe, T.M (2007) Anchialine Caves and Cave Fauna of the World, Texas A\&M University at Galveston. Available from: http://www.cavebiology.com/ (26 March 2007).

Iliffe, T.M., Jickells, T.D. \& Brewer, M.S. (1984) Organic pollution of an inland marine cave from Bermuda. Marine Environmental Research, 12, 173-189.

Iliffe, T.M., Parzefall J. \& Wilkens, H. (2000). Ecology and species distribution of the Monte Corona lava tunnel on Lanzarote, Canary Islands. In: Wilkens, H., Culver, D.C. \& Humphreys, W.F. (Eds.), Ecosystems of the World. 30. Subterranean Ecosystems. Elsevier Science, Amsterdam, pp. 633-644. 
IUCN (2006) The 2006 IUCN Red List of Threatened Species. IUCN Species Survival Commission, Cambridge, UK. Available from http://www.iucnredlist.org/ (accessed 3 July 2006)

Jaume, D. \& Boxshall, G.A. (1996) A new genus and two new species of cave-dwelling misophrioid copepods from the Balearic Islands (Mediterranean). Journal of Natural History, 30, 989-1006.

Joy, J.A. \& Clark, D.L. (1977) The distribution, ecology and systematics of the benthic Ostracoda of the central Arctic Ocean, Micropaleontology, 23(2) 129-154.

Koelbel, K. (1892) Beitrage zur Kenntniss der Krustaceen der Kanarischen Inseln. Annalen des Kaiserlich-Köngliches Naturhistorischen Hofmuseums (Vienna, Austria), 7, 105 pp.

Koenemann, S., Iliffe, T.M. \& van der Ham, J. (2003) Three new sympatric species of Remipedia (Crustacea) from Great Exuma Island, Bahamas Islands. Contributions to Zoology, 72, 227-252.

Koenemann, S., Schram, F.R., Hoenemann, M. \& Iliffe, T.M. (2007) Phylogenetic analysis of Remipedia (Crustacea). Organisms, Diversity \& Evolution, 7, 33-51.

Kornicker, L.S. (1958) Ecology and taxonomy of recent marine ostracodes in the Bimini area, Great Bahama Bank. Publications of the Institute of Marine Science (The University of Texas), 5, 194-300.

Kornicker, L.S. (1959) Distribution of the ostracode suborder Cladocopa and a new species from the Bahamas. Micropaleontology, 5(1), 69-75.

Kornicker, L.S. (1967) The myodocopid ostracod families Philomedidae and Pseudophilomedidae (New Family). Proceedings of the United States National Museum,_120(3580), 1-35.

Kornicker, L.S. (1969) Relationship between the free and attached margins of the myodocopid ostracod shell. In: Neale, J. (Ed.) The Taxonomy, Morphology and Ecology of Recent Ostracoda, Oliver and Boyd, Edinburgh, pp.109-135.

Kornicker, L.S. (1974) Revision of the Cypridinacea of the Gulf of Naples (Ostracoda). Smithsonian Contributions to Zoology, 178, 64 pp.

Kornicker, L.S. (1975) Antarctic Ostracoda (Myodocopina) Parts 1 and 2. Smithsonian Contributions to Zoology, 163, $720 \mathrm{pp}$.

Kornicker, L.S. (1977) Myodocopid Ostracoda of the Indian River Complex, Florida. Proceedings of the Biological Society of Washington, 90(4), 788-797.

Kornicker, L.S. (1978) Harbansus, a New Genus of Marine Ostracoda, and a Revision of the Philomedidae (Myodocopina). Smithsonian Contributions to Zoology, 260, 75pp.

Kornicker, L.S. (1981) Benthic Marine Cypridinoidea from Bermuda (Ostracoda). Smithsonian Contributions to Zoology, 331, $15 \mathrm{pp}$.

Kornicker, L.S. (1983) Rutidermatidae of the Continental Shelf of Southeastern North America and the Gulf of Mexico (Ostracoda: Myodocopina). Smithsonian Contributions to Zoology, 371, 89 pp.

Kornicker, L.S. (1984) Philomedidae of the Continental Shelf of Eastern North America and the Northern Gulf of Mexico (Ostracoda: Myodocopina). Smithsonian Contributions to Zoology, 393, 78 pp.

Kornicker, L.S. (1986) Sarsiellidae of the Western Atlantic and Northern Gulf of Mexico, and Revision of the Sarsiellinae (Ostracoda: Myodocopina). Smithsonian Contributions to Zoology, 415, 217 pp.

Kornicker, L.S. (1989) The adult male of the troglobitic ostracode Spelaeocia bermudensis Angel and Iliffe, 1989, from an anchialine cave in Bermuda (Crustacea: Ostracoda: Halocypridoidea). Proceedings of the Biological Society of Washington, 102(2), 313-323.

Kornicker, L.S. (1994) Ostracoda (Myodocopina) of the SE Australian Continental Slope, Part 1. Smithsonian Contributions to Zoology, 553, $200 \mathrm{pp}$.

Kornicker, L.S. (2003) Morphology and Musculature of the Fifth and Sixth Limbs of Halocyprida (Ostracoda: Myodocopa). Journal of Crustacean Biology, 23(4), 765-776.

Kornicker, L.S. \& Barr, D. (1997)Anchialine Ostracoda (Halocyprididae) from San Salvador, Bahamas. Smithsonian Contributions to Zoology, 588, $20 \mathrm{pp}$.

Kornicker, L.S. \& Caraion, F. (1978) West African Myodocopid Ostracoda (Sarsiellidae, Rutidermatidae). Smithsonian Contributions to Zoology, 250, $110 \mathrm{pp}$.

Kornicker, L.S. \& Cohen, A. (1978) Dantyinae, a new subfamily of Ostracoda (Myodocopina: Sarsiellidae). Proceedings of the Biological Society of Washington, 91(2), 490-508.

Kornicker, L.S, Danielopol D. \& Humphreys W. (2006) Description of the anchialine ostracode, Danielopolina sp. cf. kornickeri from Christmas Island, Indian Ocean. Crustaceana, 79(1), 77-88.

Kornicker, L.S. \& Iliffe, T.M.(1985) Deeveyinae, a new subfamily of Ostracoda (Halocyprididae) from a marine cave on the Turks and Caicos Islands. Proceedings of the Biological Society of Washington, 98(2), 476-493.

Kornicker, L.S. \& Iliffe, T.M. (1989a.) New Ostracoda (Halocyprida: Thaumatocyprididae and Halocyprididae) from Anchialine Caves in the Bahamas, Palau, and Mexico. Smithsonian Contributions to Zoology, $470,47 \mathrm{pp}$.

Kornicker, L.S. \& Iliffe, T.M. (1989b.) Ostracoda (Myodocopina, Cladocopina, Halocypridina) from Anchialine Caves in Bermuda. Smithsonian Contributions to Zoology, 475, 88 pp.

Kornicker, L.S. \& Iliffe, T.M. (1989c.) Troglobitic Ostracoda (Myodocopa: Cypridinidae, Thaumatocyprididae) from Anchialine Pools on Santa Cruz Island, Galapagos Islands. Smithsonian Contributions to Zoology, 483, 38 pp. 
Kornicker, L.S. \& Iliffe, T.M. (1989d) Dantya ferox, a new species of myodocopid ostracode from Niue, Central South Pacific (Crustacea: Ostracoda: Sarsiellidae). Proceedings of the Biological Society of Washington, 102(4), 901-911.

Kornicker, L.S. \& Iliffe, T.M. (1992) Ostracoda (Halocypridina, Cladocopina) from Anchialine Caves in Jamaica, West Indies. Smithsonian Contributions to Zoology, 530, 22 pp.

Kornicker, L.S. \& Iliffe, T.M. (1995) Ostracoda (Halocypridina, Cladocopina) from an Anchialine Lava Tube in Lanzarote, Canary Islands. Smithsonian Contributions to Zoology, 568, 32 pp.

Kornicker, L.S. \& Iliffe, T.M. (1998) Myodocopid Ostracoda (Halocypridina, Cladocopina) from Anchialine Caves in the Bahamas, Canary Islands, and Mexico. Smithsonian Contributions to Zoology, 599, 93 pp.

Kornicker, L.S. \& Iliffe, T.M. (2000) Myodocopid Ostracoda from Exuma Sound, Bahamas, and from Marine Caves and Blue Holes in the Bahamas, Bermuda, and Mexico. Smithsonian Contributions to Zoology, 606, 98 pp.

Kornicker, L.S, Iliffe, T.M. \& Harrison-Nelson, E. (2002) Ostracoda (Myodocopa) from Bahamian Blue Holes. Smithsonian Contributions to Zoology, 616, 99 pp.

Kornicker, L.S. \& Palmer, R. (1987) Deeveya bransoni, a new species of troglobitic halocyprid ostracode from anchialine caves on South Andros Island, Bahamas (Crustacea: Ostracoda). Proceedings of the Biological Society of Washington, 100(3), 610-623.

Kornicker, L.S. \& Sohn, I. (1976) Phylogeny, Ontogeny, and Morphology of Living and Fossil Thaumatocypridacea (Myodocopa: Ostracoda). Smithsonian Contributions to Zoology, 219, $129 \mathrm{pp}$.

Kornicker, L. S. \& Thomassin, B.A. (1998) Ostracoda (Myodocopina) of the Tuléar Reef Complex, SW Madagascar. Smithsonian Contributions to Zoology, 595, $134 \mathrm{pp}$.

Kornicker, L.S. \& Yager, J. (1996) The Troglobitic Halocyprid Ostracoda of Anchialine Caves in Cuba. Smithsonian Contributions to Zoology, 580, 16 pp.

Kornicker, L.S. \& Yager, J. (2002) Description of Spelaeoecia saturno, a new species from an anchialine cave in Cuba, (Crustacea: Ostracoda: Myodocopa: Halocyprididae). Proceedings of the Biological Society of Washington, 112(1), 153-170.

Kornicker, L.S, Yager, J. \& Williams, D. (1990) Ostracoda (Halocyprididae) from Anchialine Caves in the Bahamas. Smithsonian Contributions to Zoology, 495, $51 \mathrm{pp}$.

Kozur, H. (1974) Eine Neue Gattung der Familie Polycopidae (Cladocopida, Ostracoda). Zeitschrift für Geologische Wissenschaften, 2(7), 853-855.

Latreille, P.A. (1802) Histoire Naturelle, Générale et Particulière des Crustacès et des Insectes. Tome III. Paris, F. Dufart. xii +467 pp.

Martin, J.W. \& Davis, G.E. (2001) An Updated Classification of the Recent Crustacea. Natural History Museum of Los Angeles County, Science Series 39. Natural History Museum of Los Angeles County, Los Angeles, 124 pp.

Mejía, L., Yañez, G. \& López-Mejía, M. (2006) Fauna of five anchialine caves in Cozumel Island, Mexico. Available from: http://www.yucatech.net/cavefauna.htm (19 September 2006).

Müller, G. (1890) Neue Cypridiniden. Zoologische Jahrbücher, 5(2), 211-252.

Müller, G. (1893) Ueber Lebensweise und Entwicklungsgeschichte der Ostracoden. Sitzungsberichte der Königlich Preussischen Akademie der Wissenschaften zu Berlin, 23, 355-381.

Müller, G. (1894) Die Ostracoden des Golfes von Neapel und der angrenzenden Meeres-Abschnitte. In Fauna und Flora des Golfes von Neapel, 21, 404 pp.

Müller, G. (1906) Die Ostracoden der Siboga-Expedition. In: Max Weber (Ed.) Siboga-Expeditie, Uitkomsten op Zoologisch, Botanisch, Oceanographisch. . . en H. M. Siboga..., Monographien, 30, E. J. Brill, Leiden, pp.40

Norman, A. (1869) Shetland final dredging report - part 2: on the Crustacea, Tunicata, Polyzoa, Echinodermata, Actinozoa, Hydrozoa, and Porifera. Reports of the Meetings of the British Association for the Advancement of Science, 38, 247-336.

Palmer, R. (1985) The Blue Holes of the Bahamas. Cape, London, 192 pp.

Palmer, R. (1997) Deep into Blue Holes. Media Publishing, Ltd, Nassau, Bahamas, 188 pp.

Pohlman, J.W., Iliffe, T.M. and Cifuentes, L.A. (1997) A stable isotope study of organic cycling and the ecology of an anchialine cave ecosystem. Marine Ecology Progress Series, 155, 17-27.

Pohlman, J.W., Cifuentes, L. \& Iliffe, T.M. (2000) Food web dynamics and biochemistry of anchialine caves: a stable isotope approach. In: Wilkens, H., Culver, D.C. \& Humphreys, W.F. (Eds.), Ecosystems of the World. 30. Subterranean Ecosystems, Elsevier Science, Amsterdam, 345-357.

Poulsen, E. (1962) Ostracoda-Myodocopa, 1: Cypridiniformes-Cypridinidae. Dana Report, 57, 414 pp.

Poulsen, E. (1965) Ostracoda-Myodocopa, 2: Cypridiniformes-Rutidermatidae, Sarsiellidae and Asteropidae. Dana Report, 65, 484 pp.

Prosser, J. \& Gray, H.V. (1998) NSS Cave Diving Manual: An Overview. National Speleological Society Cave Diving Section, Lake City, FL, 377 pp.

Sars, G. (1866) [1865] Oversigt af Norges marine Ostracoder. Forhandlinger i Videnskabs-Selskabet I Christiania, 8, 1130. Preprint, 1865.

Sket, B. (2004) Anchialine habitats. In: Gunn, J., Encyclopedia of Caves and Karst Science, Fitzroy Dearborn, New 
York, pp. 64-66.

Skogsberg, T. (1920) Studies on Marine Ostracods, I: Cypridinids, Halocyprids, and Polycopids. Zoologiska Bidrag från Uppsala, supplement 1, $784 \mathrm{pp}$.

Stock, J.H. (1976) A new genus and two new species of the crustacean order Thermosbaenacea from the West Indies. Bijdragen tot de Dierkunde, 46, 47-70.

Stock, J, Iliffe, T. \& Williams, D. (1986) The concept "anchialine" reconsidered. Stygologia, 2, 90-92.

Trott, R. \& Warner, G. (1986) The biota in the marine blue holes of Andros Island. Cave Science, 13(1), 13-19.

Warner, G. \& Moore, C.A.M. (1984) Ecological studies in the marine blue holes of Andros Island, Bahamas. Cave Science, 11(1), 30-44.

Wienke, B. (2002) Technical Diving in Depth. Best Publishing Co., Flagstaff, AZ, 428 pp.

Yager, J. (1987) Cryptocorynetes haptodiscus, new genus, new species, and Speleonectes benjamini, new species, of remipede crustaceans from anchialine caves in the Bahamas, with remarks on distribution and ecology. Proceedings of the Biological Society of Washington, 100(2), 302-320.

Yager, J. (1989) Pleomothra apletocheles and Godzilliognomus frondosus, two new genera and species of remipede crustaceans (Godzilliidae) from anchialine caves of the Bahamas. Bulletin of Marine Science, 44(3), 1195-1206.

Yager, J. \& Humphreys, W. (1996) Lasionectes exleyi, sp. nov., the first remipede crustacean recorded from Australia and the Indian Ocean, with a key to the world species. Invertebrate Taxonomy, 10, 171-187.

Yager, J. \& Schram, F. 1986. Lasionectes entrichoma, new genus, new species, (Crustacea: Remipedia) from anchialine caves in the Turks and Caicos, British West Indies. Proceedings of the Biological Society of Washington, 99(1), 6570 .

\section{Appendix-Station data with specimens collected (in chronological order by location)}

Bahamas: Anchialine Caves (Inland Blue Holes)

Coll: 29 May 1989, Sagittarius Blue Hole, Sweeting's Cay, Grand Bahama Island, Little Bahama Bank; collected by Jill Yager; received 31 Mar 2000.

Spelaeoecia sagax: 2 specimens.

Deeveya medix: 1 specimen.

Coll: 29 Mar 1989, Sagittarius Blue Hole, Sweeting's Cay, Grand Bahama Island, Little Bahama Bank; collected by Jill Yager and Dennis Williams; received from Yager 31 Mar 2000.

Spelaeoecia sagax: 10 specimens.

Deeveya medix: 2 specimens.

Coll: XI 1996, Nov, 1996, Dan’s Cave, Abaco Island, Little Bahama Bank; collected by J. Oromoroid, received from Jill Yager, 2001.

Deeveya medix: 1 specimen.

Sta 98-010, 4 Jan 1998, Oven Rock Cave, Great Guana Cay, Exuma Cays, Great Bahama Bank; collected with suction bottle from 0-22 m depths by Brian Kakuk.

Spelaeoecia capax: 7 specimens.

Sta 98-012, 4 Jan 1998, Oven Rock Cave, Great Guana Cay, Exuma Cays, Great Bahama Bank; collected with suction bottle from 0-22 m depths by Brian Kakuk.

Spelaeoecia capax: 3 specimens.

Sta 98-014, 31 Mar 1998, Oven Rock Cave, Great Guana Cay, Exuma Cays, Great Bahama Bank; collected with suction bottle from 0-22 m depths by Brian Kakuk.

Spelaeoecia capax: 1 specimen.

Sta 98-038, 14 Aug 1998, Mermaid's Lair, Grand Bahama Island, Little Bahama Bank; collected with plankton net from halocline region at bottom of cavern in 17-19 $\mathrm{m}$ depths.

Spelaeoecia hox: 2 specimens.

Spelaeoecia parkeri: 2 specimens.

Sta 98-039, 14 Aug 1998, Mermaid's Lair, Grand Bahama Island, Little Bahama Bank; same collection data as Sta 98038.

Spelaeoecia hox: 2 specimens.

Spelaeoecia parkeri: 1 specimen.

Sta 99-061, 6 Oct 1999, Sanctuary Blue Hole, South Andros Island, Great Bahama Bank; collected with plankton net from water column in 35-50 m depths.

Danielopolina palmeri: 4 specimens.

Deeveya bransoni: 9 specimens. 
Spelaeoecia styx: 19 specimens.

Sta 99-066, 15 Apr 1999, Oven Rock Cave, Great Guana Cay, Exuma Cays, Great Bahama Bank; collected with a suction bottle in 0-22 m water depth by Brian Kakuk, maximum depth in cave $22 \mathrm{~m}$.

Spelaeoecia capax: 3 specimens.

Sta 00-001, 18 Mar 2000, Basil Minn's Blue Hole, Great Exuma Island, Great Bahama Bank; collected with suction bottle in 10-50 $\mathrm{m}$ depths in dome room.

Danielopolina exuma: 1 specimen.

Deeveya medix: 6 specimens.

Sta 00-002, 19 Mar 2000, Norman's Pond Cave, Lee Stocking Island, Norman's Pond Cay, Exuma Cays, Great Bahama Bank; collected with plankton net and suction bottle from 10-60 m depths in 1st and 2nd rooms.

Deeveya exleyi: 1 specimen.

Sta 00-004, 20 Mar 2000, Basil Minn’s Blue Hole, Great Exuma Island, Great Bahama Bank; collected with vial from $10-50 \mathrm{~m}$ depths in dome room.

Danielopolina exuma: 1 specimen.

Sta 00-005, 21 Mar 2000, Oven Rock Cave, Great Guana Cay, Exuma Cays, Great Bahama Bank; collected with suction bottle from 10-20 m depths.

Spelaeoecia capax: 6 specimens.

Sta 01-001, Apr 2001, Guardian Blue Hole, Andros Island, Great Bahama Bank; collected by Brian Kakuk with suction bottle near second drop at $240 \mathrm{~m}$ penetration and $52 \mathrm{~m}$ depth.

Deeveya sp. indent: 1 fragmented carapace without soft parts.

Sta 01-002, 2001, Sagittarius Blue Hole, Sweeting's Cay, Grand Bahama Island, Little Bahama Bank; collected by Brian Kakuk with suction bottle from back of cave below hydrogen sulfide layer in 13-24 m depths..

Spelaeoecia sagax: 5 specimens.

Deeveya medix: 1 specimen.

Sta 01-013, 25 Jul 2001, Oven Rock Cave, Great Guana Cay, Exuma Cays, Great Bahama Bank; collected with suction bottle from main passage just past old bat roost at $15 \mathrm{~m}$ depth.

Spelaeoecia capax: 8 specimens.

Sta 01-015, 2 Dec 2001, Virgo Blue Hole, Sweeting's Cay, Grand Bahama Island, Little Bahama Bank; collected with suction bottle, vials, and plankton net from 15-21 m depths of large room.

Spelaeoecia sagax: 3 specimens.

Deeveya medix: 3 specimens.

Sta 01-016, 3 Dec 2001, Sagittarius Blue Hole, Sweeting's Cay, Grand Bahama Island, Little Bahama Bank; collected with suction bottle and plankton net from 18-25 m depths.

Spelaeoecia sagax: 31 specimens.

Deeveya medix: 8 specimens

Sta 01-017, 4 Dec 2001, Lucy's Cave, Sweeting's Cay, Grand Bahama Island, Little Bahama Bank; collected with suction bottle and plankton net from 18-25 m depths.

Spelaeoecia parkeri: 2 specimens.

Sta 01-018, 7 Dec 2001, Mermaid's Lair, Grand Bahama Island, Little Bahama Bank; collected with vial from just below halocline in $16 \mathrm{~m}$ depth.

Spelaeoecia parkeri: 1 specimen.

Yucatan: Anchialine Caves (cenotes)

Sta 00-007, 13 July 2000, Temple of Doom Cenote, Tulum, Quintana Roo, Mexico.; collected with vial from 15-18 m depths just below halocline.

Danielopolina mexicana: 1 specimen.

Sta 01-011, 9 Nov 2001, Cenote Aerolita, Isla Cozumel, Quintana Roo, Mexico; collected with plankton net from $18 \mathrm{~m}$ depth in fully marine waters below halocline about 200 to $300 \mathrm{~m}$ inside the cave.

Pseudopolycope helix n. sp.: 1 specimen.

Bermuda: Anchialine Caves

Sta 00-033, 27 Nov 2000, Wonderland Cave, Hamilton Parish, Bermuda; collected with plankton net from water column in $10-15 \mathrm{~m}$ depths of main pool.

Spelaeoecia bermudensis: 18 specimens.

Sta 02-001, 11 Jan 2002, Bermuda Aquarium saltwater well, Flatts, Bermuda; collected from pump filter of drilled saltwater well, about $15 \mathrm{~cm}$ in diameter, that is open between 26 and $30 \mathrm{~m}$ depths.

Spelaeoecia bermudensis: 2 specimens. 
Bahamas: Oceanic Blue Holes

Sta 98-048, 18 Jul 1998, Angelfish Blue Hole, Stocking Island, Exuma Cays, Great Bahama Bank; collected 360 m inside the cave at $29 \mathrm{~m}$ depth.

Skogsbergia lerneri: 1 specimen.

Sta 99-050, 1 Oct 1999, Four Shark Cave, South Andros Island, Great Bahama Bank; collected with plankton net from water column in 60-70 $\mathrm{m}$ depth past restriction.

Eusarsiella sp. indet.: 1 specimen.

Dantya sp. A: 1 specimen.

Pontopolycope storthynx: 1 specimen.

Sta 99-053, 4 Oct 1999, South Bight \#2 Blue Hole, South Andros Island, Great Bahama Bank; collected with plankton net and suction bottle from surface of silty sediment in $40 \mathrm{~m}$ depth.

Eusarsiella sp. indet.: 3 specimens.

Sta 99-054, 5 Oct 1999, Exley’s Boiling Blue Hole, South Andros Island, Great Bahama Bank; collected with plankton net and suction bottle from water column and surface of silty sediment in 60-70 m depths.

Pontopolycope storthynx: 1 specimen.

Sta 99-055, 6 Oct 1999, Double Drop Blue Hole, South Andros Island, Great Bahama Bank; collected with plankton net from water column in 60-70 $\mathrm{m}$ depth at about $200 \mathrm{~m}$ inside cave.

Deeveya bransoni: 2 specimens.

Synasterope sp. indet.:1 juvenile.

Pseudopolycope helix n. sp.: 1 specimen.

Sta 99-056, 6 Oct 1999, Double Drop Blue Hole, South Andros Island, Great Bahama Bank; same collection data as Sta 99-055.

Deeveya bransoni: 4 specimens.

Skogsbergia lerneri: 5 specimens.

Sta 99-059, 13 Oct 1999, Vortex Blue Hole, Middle Bight, Andros Island, Great Bahama Bank; collected with suction bottle and plankton net in 40-45 m depths.

Skogsbergia lerneri: 1 specimen.

Sta 99-065, 27 Mar 1999, Bottomly’s Blue Hole, Stocking Island, Great Exuma, Exuma Cays, Great Bahama Bank; collected with plankton net and suction bottle in crossover passages, and Mystery Cave in 27-29 m depths.

Harbansus paucichelatus: 3 specimens.

Pseudophilomedes ferulanus: 1 specimen.

Synasterope browni: 1 specimen.

Synasterope matrix: 1 specimen

Synasterope sp. indet.: 2 specimens.

Sta 00-006, 22 Mar 2000, The Subway, Great Exuma, Great Bahama Bank; collected with suction bottle from 10-20 m depths of strongly tidal blue hole.

Harbansus paucichelatus: 1 specimen.

Eusarsiella sp. indet.: 1 specimen.

Sta 00-019, 8 Aug 2000, Mystery Cave, Stocking Island, Exuma Cays, Great Bahama Bank; collected with plankton net from surface of coarse sand in $52 \mathrm{~m}$ depth about $150 \mathrm{~m}$ inside cave.

Eusarsiella syrinx: 8 specimens.

Eusarsiella sp. indet.: 3 specimens.

Eurypylus hapax: 5 specimens.

Synasterope browni: 2 specimens.

Sta 00-020, 9 Aug 2000, Crab Cay Crevasse, Crab Cay, Exuma Cays, Great Bahama Bank; collected with plankton net from surface of coarse sand or bottom at $41 \mathrm{~m}$ depth about $200 \mathrm{~m}$ inside cave.

Junctichela pax: 1 specimen.

Sta 00-023, 13 Aug 2000, Conch Sound Blue Hole, Andros Island, Great Bahama Bank; collected with plankton net from sediment at about $30 \mathrm{~m}$ depth at about $1200 \mathrm{~m}$ inside cave.

Deeveya bransoni: 3 specimens.

Sta 00-024, 17 Aug 2000, Conch Sound Blue Hole, Andros Island, Great Bahama Bank; collected with plankton net from sediment at about $30 \mathrm{~m}$ depth at about $1200 \mathrm{~m}$ inside cave.

Deeveya bransoni: 1 specimen.

Sta 00-025, 17 Aug 2000, Conch Sound Blue Hole, Andros Island, Great Bahama Bank; collected with plankton net from sediment at $25 \mathrm{~m}$ depth about $365 \mathrm{~m}$ inside cave.

Eusarsiella fax: 1 specimen.

Eusarsiella paniculata: 3 specimens.

Eusarsiella sp. indet.: 1 juvenile.

Rutiderma flex: 1 specimen. 
Sta 00-027, 20 Aug 2000, Four Shark Cave, Andros Island, Great Bahama Bank; collected with plankton net from surface sediment at $60 \mathrm{~m}$ depth about $100 \mathrm{~m}$ inside cave.

Eusarsiella sp. indet.: 1 specimen.

Podocopa: 1 specimen

Sta 01-003, 7 Jul 2001, Conch Sound Blue Hole, Andros Island, Great Bahama Bank; collected by Brian Kakuk from new room at one mile penetration into underwater cave.

Deeveya bransoni: 29 specimens.

Sta 01-004, 27 Jan 2001, Conch Sound Blue Hole, Andros Island, Great Bahama Bank; same collection data as Sta 01003.

Deeveya bransoni: 7 specimens.

Sta 01-012, 7 Jul 2001, Conch Sound Blue Hole, Andros Island, Great Bahama Bank; collected with suction bottle from new Room (about 1 mile in from entrance) at $15 \mathrm{~m}$ depth.

Deeveya bransoni: 8 specimens. 